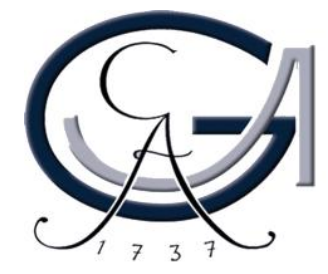

\title{
Conformational state of monomeric kinesin UNC-104 in vivo
}

\author{
Dissertation of the award of degree \\ "Doctor rerum naturalium" \\ Division of Mathematics and Natural Sciences \\ of the Georg-August-University Göttingen \\ submitted by \\ Volker Christoph Henschel \\ born in Munich \\ Göttingen 2012
}


Member of the Thesis Committee (First Reviewer):

\section{Prof. Dr. Nils Brose}

Max Planck Institut für Experimentelle Medizin

Georg-August University, Goettingen

Member of the Thesis Committee (Second Reviewer):

Prof. Dr. Andreas Wodarz

Göttingen Center of Molecular Biosciences (GZMB)

Department of Anatomy and Cell Biology

Georg-August University, Goettingen 


Dedicated to my father, who awoke my interest in science in my early childhood and encouraged and supported it for decades. 
Applause, applause, applause!

Kermit the frog, since the 70 s 


\section{LIST OF ABBREVIATIONS}

code for amino acids

$\begin{array}{llllll}\text { A } & \text { Ala } & \text { alanine } & \text { Q } & \text { Gln } & \text { glutamine } \\ \text { C } & \text { Cys } & \text { cysteine } & \text { R } & \text { Arg } & \text { arginine } \\ \text { D } & \text { Asp } & \text { aspartate } & \text { S } & \text { Ser } & \text { serine } \\ \text { E } & \text { Glu } & \text { glutamate } & \text { T } & \text { Thr threonine } \\ \text { F } & \text { Phe } & \text { phenylalanine } & \text { V } & \text { Val } & \text { valine } \\ \text { G } & \text { Gly } & \text { glycine } & \text { W } & \text { Trp tryptophane } \\ \text { H } & \text { His } & \text { histidine } & \text { Y } & \text { Tyr tyrosine } \\ \text { I } & \text { Iso } & \text { isoleucine } & & & \\ \text { K } & \text { Lys } & \text { lysine } & & & \\ \text { L } & \text { Leu } & \text { leucine } & & & \\ \text { M } & \text { Met } & \text { methionine } & & & \\ \text { N } & \text { Asn } & \text { asparagine } & & & \\ \text { P } & \text { Pro } & \text { proline } & & & \end{array}$

General abbreviations

$\begin{array}{ll}\text { A } & \text { adenine (DNA and RNA) } \\ \text { aa } & \text { amino acid(s) } \\ \text { AB } & \text { antibody } \\ \text { ACh } & \text { acetylcholine } \\ \text { AMP-PNP } & 5^{\prime} \text {-adenylyl-beta, gamma-imidodiphosphate } \\ \text { APP } & \text { amyloid precursor protein } \\ \text { ATP } & \text { adenosine-5-triphosphate } \\ \text { bp } & \text { basepair(s) } \\ \text { BRB } & \text { Britton-Robinson buffer } \\ \text { BSA } & \text { bovine serum albumine } \\ \text { CCD } & \text { charge-coupled device } \\ \text { CD } & \text { circular dichroism } \\ \text { CDNA } & \text { complementary DNA } \\ \text { C. elegans } & \text { Caenorhabditis elegans } \\ \text { CGC } & \text { Caenorhabditis Genetics Center } \\ \text { C-terminus } & \text { carboxy terminus } \\ \text { D } & \text { dalton } \\ \text { DETA } & \text { diethylentriamin } \\ \text { DIC } & \text { differential interference contrast } \\ \text { DMSO } & \text { dimethyl sulfoxide } \\ \text { DNA } & \text { desoxyribonucleic acid }\end{array}$


dNTP

DTT

ECL

E. coli

EDC

EDTA

EGF

EGTA

eq.

ER

FIONA

FITC

$\mathrm{FL}$

FRET

GABA

GDI

GEF

GFP

GTP

$\mathrm{HC}$

HEPES

HIV

HRP

IPTG

KIF

$\mathrm{KHC}$

LB

MDF

MT

MTOC

M6PR

$\mathrm{NHS}$

NGM

$\mathrm{N}$-terminus

p.a.

PAGE

PCR

PAGE 2'-desoxynucleoside-5'-triphosphate

dithiothreitol

enhanced chemical luminescence

Escherichia coli

1-ethyl-3- (3-dimethylaminopropyl)-carbodiimide

ethylenediaminetetraacetic acid

epidermal growth factor

ethylene glycol tetraacetic acid

equation

endoplasmatic reticulum

fluorescence imaging with one-nanometer accuracy

fluoresceinisothiocyanate

full length

Förster resonance energy transfer

gamma-aminobutyric acid

guanidine dissociation inhibitor

guanine nucleotide exchange factor

green fluorescent protein

guanosine-5'-triphosphate

heavy chain

4-(2-hydroxyethyl)-1-piperazineethanesulfonic acid

human immunodeficiency virus

horseradish peroxidase

isopropyl- $\beta$-D-thiogalactopyranoside

kinesin superfamily

kinesin heavy chain

Luria-Bertani

main distribution frame

microtubule(s)

microtubule organizing center

mannose-6phosphate receptor

$N$-hydroxysulfosuccinimide

nematode growth medium

amino terminus

pro analysi, analysis grade

polyacrylamide gel electrophoresis

polymerase chain reaction

polyacrylamide gel electrophoresis 


$\begin{array}{ll}\text { PBS } & \text { phosphate buffered saline } \\ \text { pH } & \text { negative common logarithm of the proton } \\ \text { PH } & \text { plextrin homology } \\ \text { PMSF } & \text { phenylmethylsulphonyl fluoride } \\ \text { PIPES } & \text { piperazine-1,4-bis-(2-ethansulfonic acid) } \\ \text { Ptdlns(3,4,5)P } & \text { phosphatidyl inositol }(3,4,5) \text {-trisphosphate } \\ \text { Ptdlns(4,5)P } 2 & \text { phosphatidyl inositol (4,5)-diphosphate } \\ \text { RNA } & \text { ribonucleic acid } \\ \text { RNAi } & \text { RNA interference } \\ \text { RT } & \text { room temperature } \\ \text { rpm } & \text { rotations per minute } \\ \text { SDS } & \text { sodium dodecyl sulfate } \\ \text { SDS-PAGE } & \text { SDS-polyacrylamid gelelectrophoresis } \\ \text { siRNA } & \text { small interfering RNA } \\ \text { SOB } & \text { Super Optimal Broth } \\ \text { TAE } & \text { TRIS/Acetate/EDTA } \\ \text { techn. } & \text { technical grade } \\ \text { TEMED } & \text { N,N,N',N'-tetramethylethan-1,2-diamine } \\ \text { TIRF } & \text { total internal reflection fluorescence } \\ \text { TMR } & \text { tetramethylrhodamine } \\ \text { Triton X-100 } & \text { 4-octylphenol polyethoxylate } \\ \text { Tween20 } & \text { polyoxyethylene (20) sorbitan monolaurate } \\ \text { unc } & \text { uncoordinated } \\ \text { UV } & \text { ultraviolet } \\ \text { v/v } & \text { volume per volume } \\ \text { WB } & \text { Western blot } \\ \text { WT } & \text { wild type } \\ \text { w/v } & \text { weight per volume } \\ & \end{array}$

SI units and general prefixes are applying but additionally can be found in the appendix. 


\section{LIST OF ABBREVIATIONS}

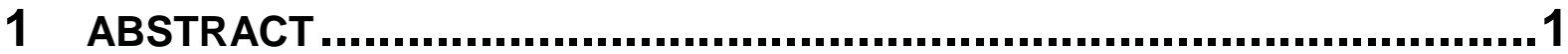

2 INTRODUCTION

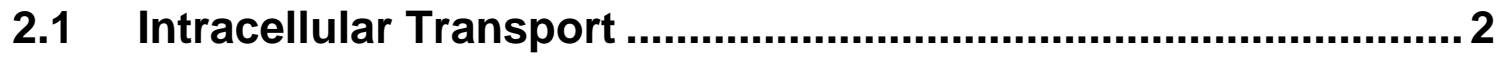

2.2 Molecular motor proteins ...........................................................

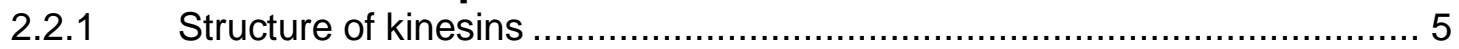

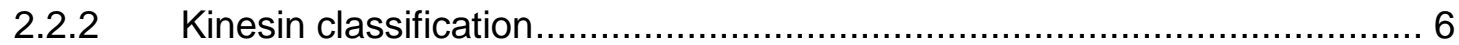

2.2.3 Walking of kinesins - models .......................................................... 8

2.2.4 Motor-Cargo interactions ................................................................. 9

2.2.5 Kinesins in neuronal transport...........................................................

2.2.6 Diseases based on kinesin motors defects .........................................13

2.3 The kinesin-3 member UNC-104 ..............................................14

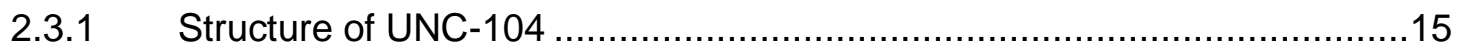

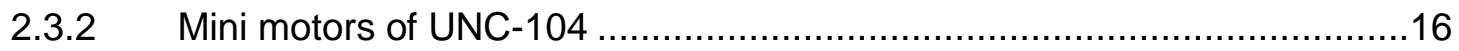

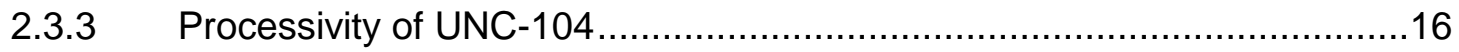

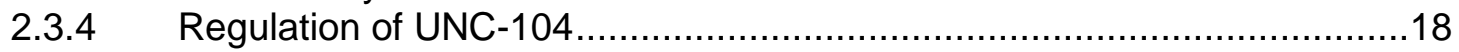

2.4 C. elegans as a model organism ................................................19

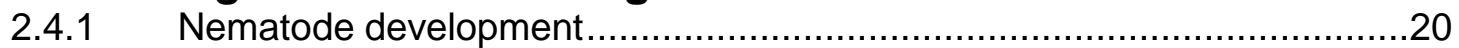

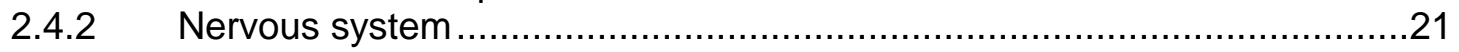

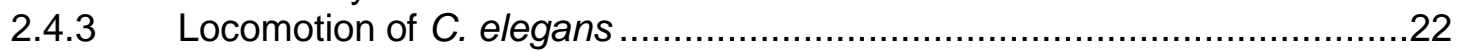

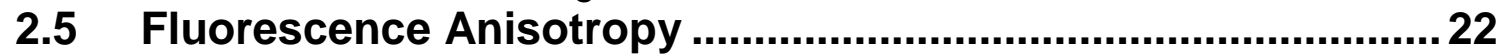

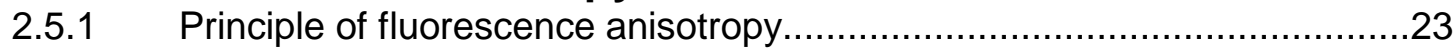

2.5.2 Biological applications of fluorescence anisotropy ................................23

3 AIMS OF THIS THESIS..............................................................25

4 Materials UNd MethodS..........................................................26

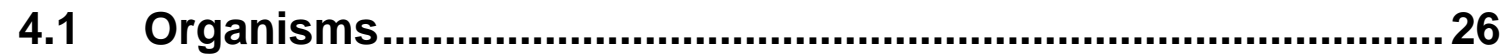

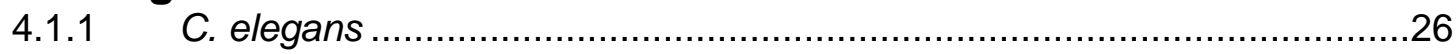

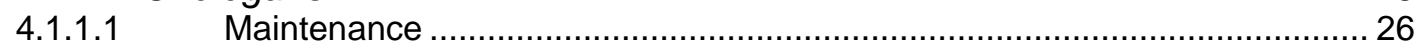

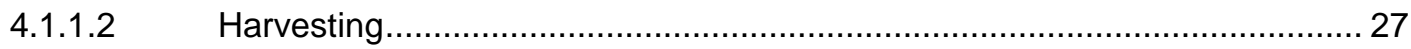

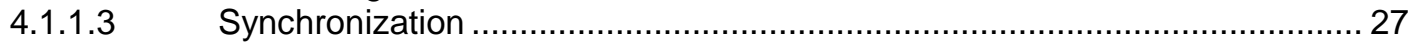

4.1.1.4 Worm preparation for Western blotting................................................... 28

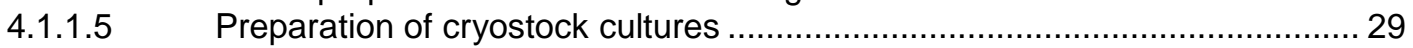

4.1.1.6 Worm manipulation........................................................................ 30

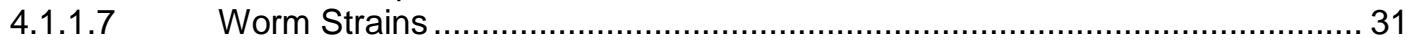

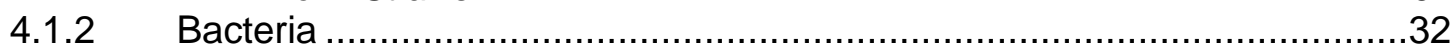

4.1.2.1 Strains

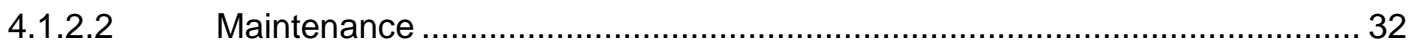

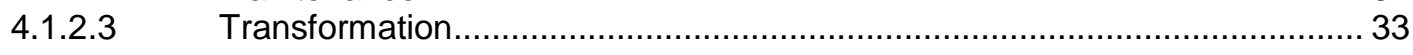

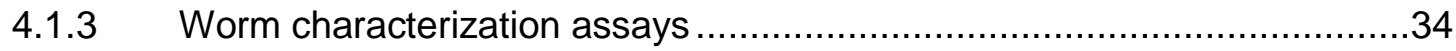

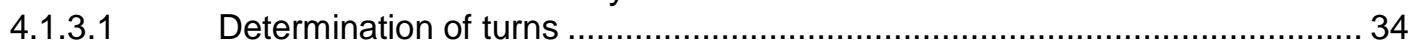

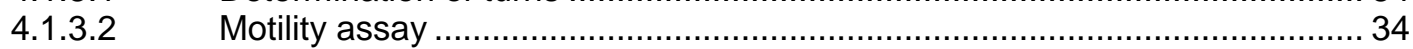

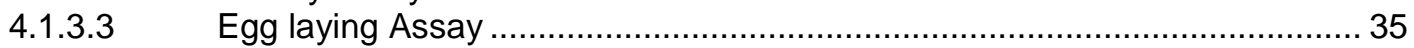

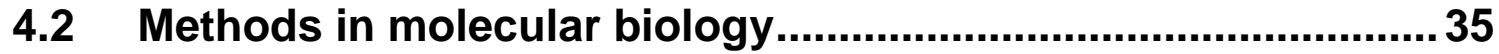

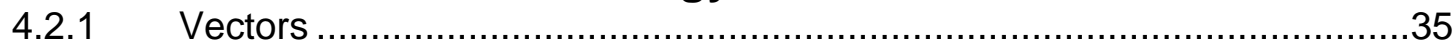

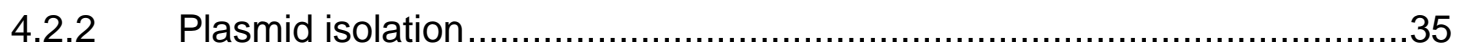

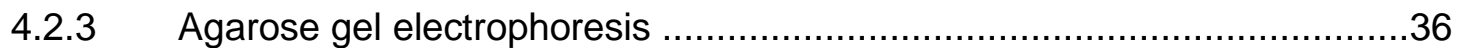

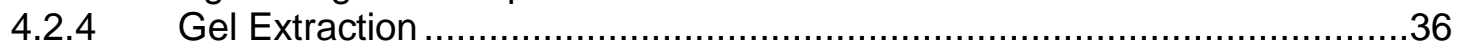




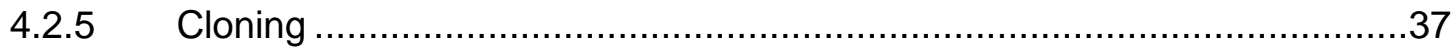

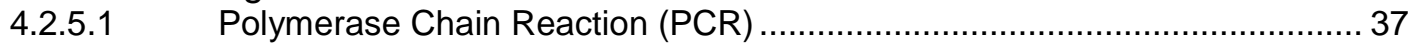

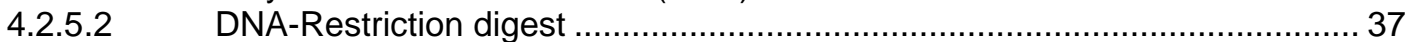

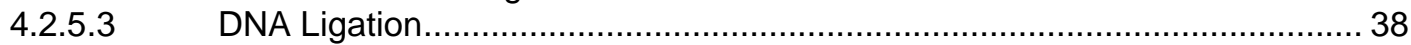

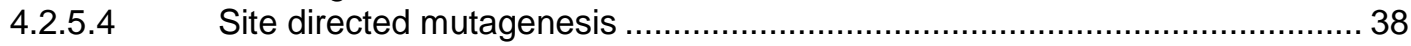

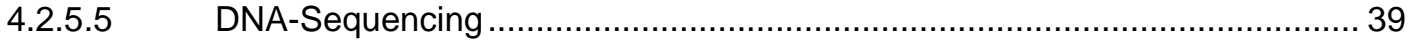

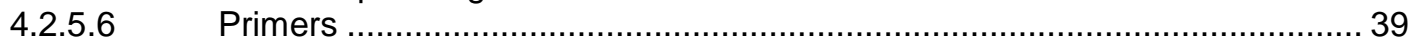

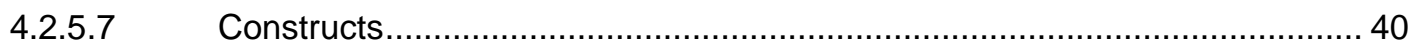

4.3 Biochemical Methods ................................................................. 42

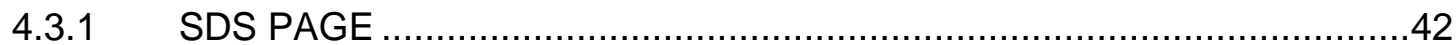

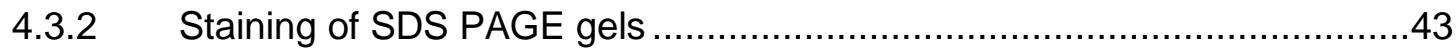

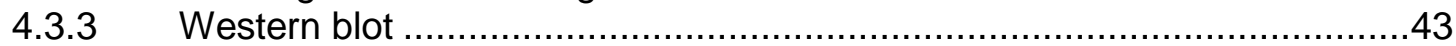

4.3.4 Staining of Western blot membranes ...................................................4

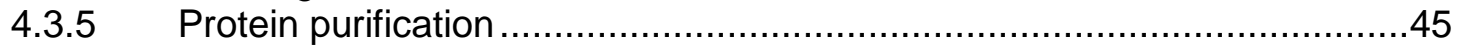

4.3.5.1 Expression of proteins in E. coli ......................................................... 45

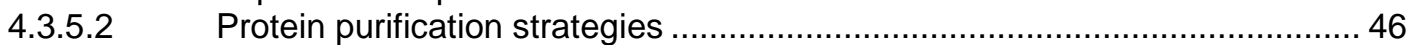

4.3.5.3 Microtubule affinity purification of kinesin-3 Mini Motors ............................. 47

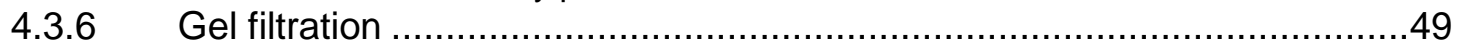

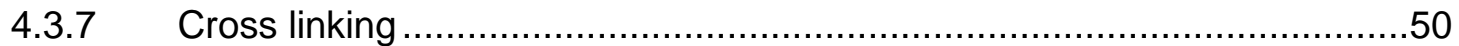

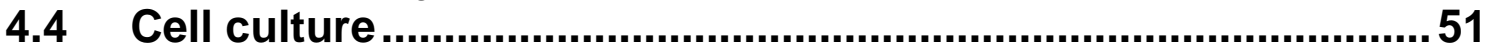

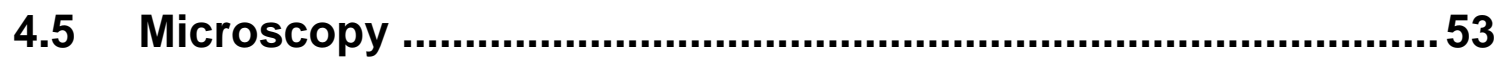

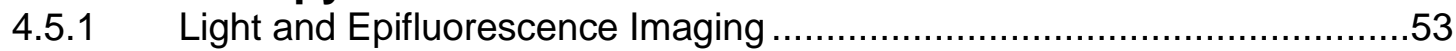

4.5.2 Spinning Disc Confocal Laser Microscopy .........................................54

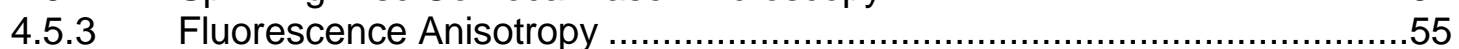

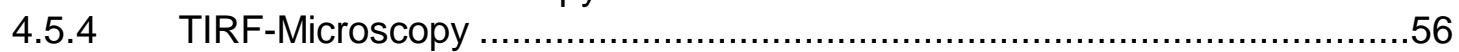

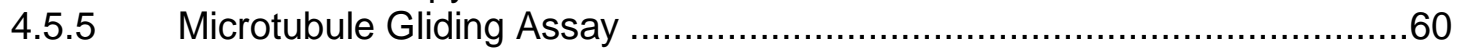

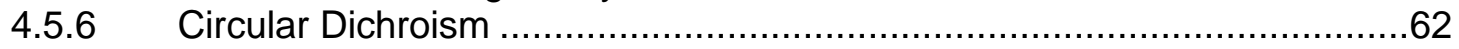

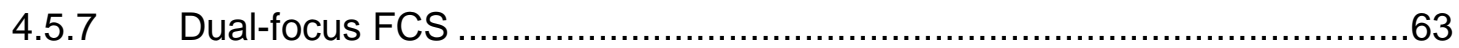

4.6 In silico calculation ......................................................................64

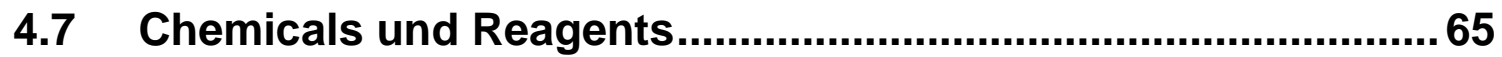

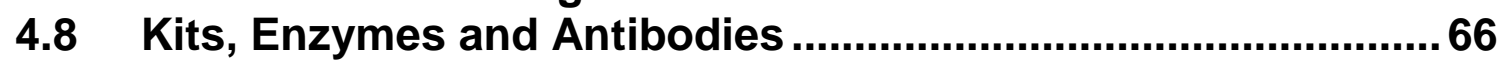

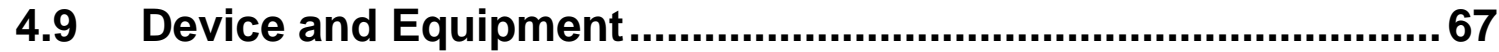

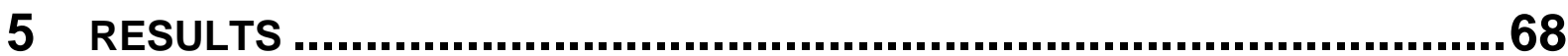

$5.1 \quad$ Prediction of coiled-coils.........................................................68

5.2 Testing alpha helical contents by circular dichroism ...............71

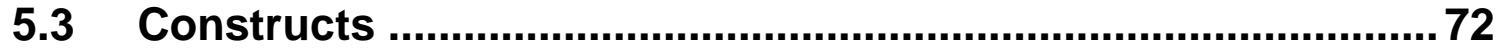

5.4 Testing coiled-coil point mutations in vivo ...............................73

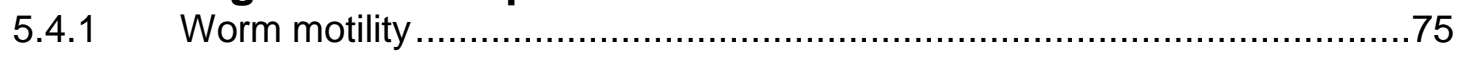

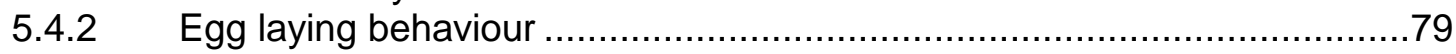

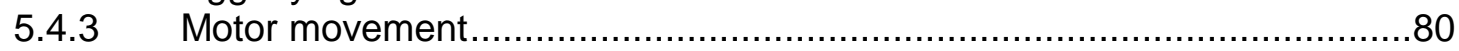

5.4.4 Determination of conformational states in vivo....................................... 84

5.4.4.1 Development of a new setup to detect conformational states of proteins in C. elegans in vivo by fluorescence anisotropy …….................................. 85

5.4.4.2 Conformational states of UNC-104 and UNC-104-mutants determined via

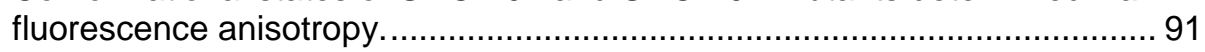

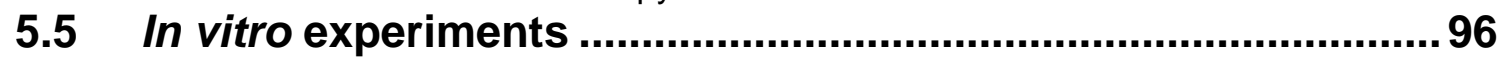

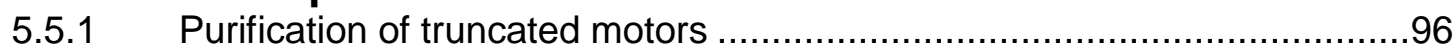

5.5.2 Mutations in the neck coiled-coil do not affect activity and properties of

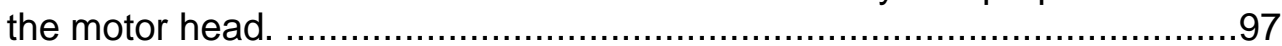

5.5.3 Ability of UNC-104 to form complexes in vitro .....................................103

5.5.4 Microtubule affinity purification.........................................................105

5.5.5 Direct interaction of UNC-104 visualized by chemical cross-linking ........106 
6 Discussion

6.1 UNC-104 is in dimeric conformation in living neurons in C. elegans 110

6.2 Fluorescence anisotropy is a suitable method to analyze conformational states of proteins

6.3 The neck coiled-coil of UNC-104 is an essential part in the homodimerization process.

6.4 Direct link between vesicle velocities and the potential to form a homodimer in vivo

6.5 Consequences of an active dimeric kinesin-3 for the neuron

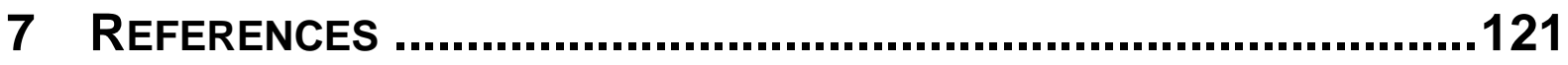

8 ACKNOWLEDGEMENTS ........................................................132

9 APPENDIX .........................................................................133 


\section{ABSTRACT}

The fast anterograde monomeric kinesin-3 motor UNC-104 is crucial for synaptic vesicle transport in neurons. In vitro, UNC-104 is a non-processive motor with biased-diffusional motion behaviour on a single molecule level. In contrast kinesin UNC-104 appears to be a fast motor in vivo. This leads to the hypothesis that in vivo the monomeric kinesin-3 may not act as single, monomeric motor but may dimerize when bound to cargo membranes. So the conformational state of UNC-104 during active (+)-directed motion in living organisms is still under debate.

In vivo and in vitro studies in this thesis lead to the conclusion, that, in fact, UNC104 can act as a dimeric motor in the neurons of living organisms. Previous in vitro studies suggest the neck coiled-coil region as the putative dimerization region (Tomishige et al., 2002, Klopfenstein et al., 2002). To investigate the role of the endogenous coiledcoils, point mutations in the neck coiled-coil are introduced, promoting either coiled-coil formation of kinesin-3 or reducing the likelihood of generating coiled-coils. Full length proteins are expressed in $C$. elegans neurons, and their truncated forms tested in in vitro assays. Only motors with high probability for coiled-coil formation in the neck coiled-coil region reach high transport velocities in vivo. Coiled-coil impairing mutants affect the control of muscle contraction in $C$. elegans and do not achieve velocities necessary for fast axonal transport in vivo. Dimer formation itself is tested in vivo by a newly developed system combining fluorescence anisotropy with spinning disc laser confocal microscopy, showing that coiled-coil promoting motors are more dimeric than WT motors in vivo. On the other hand coiled-coil impaired motors are more monomeric than WT motors in vivo and lead to decreased vesicle transport velocities. In vivo studies are supported by singlemolecule measurements in vitro, indicating the same correlation of coiled-coil formation and velocity as given in the in vivo experiments, although Michalelis-Menten kinetics are indistinguishable in in vitro multi-motor gliding assays. Direct dimerization of WT and the coiled-coil promoting strains in vitro is evidenced by cross linking.

The data show that kinesin-3 can act as a dimer in vivo and suggest a direct link between dimerization status and transport velocities. 


\section{INTRODUCTION}

Molecular motors play a crucial part in intracellular transport of membranous organelles, protein complexes and mRNAs along cytoskeletal tracks and therefore enable vital functions like morphogenesis, differentiation, polarity and motility of the cell, down to the basis of definition of life, autopoiesis (Varela et al., 1974) - cell division. Directed intracellular motion driven by, at that time unknown, motor proteins was first reported in alga Chara by Bonaventura Corti in the late 18th century (Corti, 1774). Over 200 years later a classification based on speed had been introduced. Studies on axonal transport in laboratory animals with radio isotopic pulse labelling have shown that there are hundreds of axonally transported proteins, but that these proteins basically move at two discrete transport rates, which can be categorized as either "fast cellular transport" or "slow cellular transport" (Lasek et al., 1984). Fast transport processes are in particular crucial in nerve cells as those have tremendous spatial dimensions compared to a non-neuronal cell. For example it would take almost 27 years for neurofilament proteins to pass through a $1 \mathrm{~m}$ long human sciatic nerve, using only slow transport processes. (Campenot and Eng, 2000). Thus fast axonal transport is essential for functionality and maintenance of nerve cells. This thesis gives insight in the conformation of one protein involved in fast axonal transport.

\subsection{Intracellular Transport}

In many prokaryotes rapid diffusion of molecules is the main transport mechanism. With further evolution of the species, cell shape determination, polarity of the cells, formation of macromolecular structures (e.g. flagella) and cell differentiation became increasingly dominant. These evolutionary very important mechanisms require delivery and localization of molecules in a directed way. A concurrent step was the development of tracks within the cells where a toolbox of molecular motors performing site directed transport of distinct cargo are able to locomote (Laferrière et al., 1997). In eukaryotes the main tracks are the microtubules. From these tracks a fine actin filamentous network is faning out to allow molecules to reach almost every site within the cell (Fig 11) (Goode et al., 2000, Kapitein and Hoogenraad, 2011). Microtubules are filamentous protein bundles emanating at the so called microtubule organizing center (MTOC) and directing to the periphery of the cell. The microtubules themselves are oriented with their (-)-end at the MTOC and their (+)end directed to the periphery. These large and stable tracks function as "highways" of 
transport processes in the cell. The distribution from the (+)-end of the microtubules to the target position for example at the plasma membrane is mediated by the actin filamentous network. In general it can be said, that transport processes on microtubules are utilized for long-range transport and actin filaments are utilized for short-range transport (Goode et al., 2000), although there are exceptions to this rule. As one motor protein family is restricted to one kind of track the cargo has to be transferred to another motor protein family at the intersections (Vale, 2003).

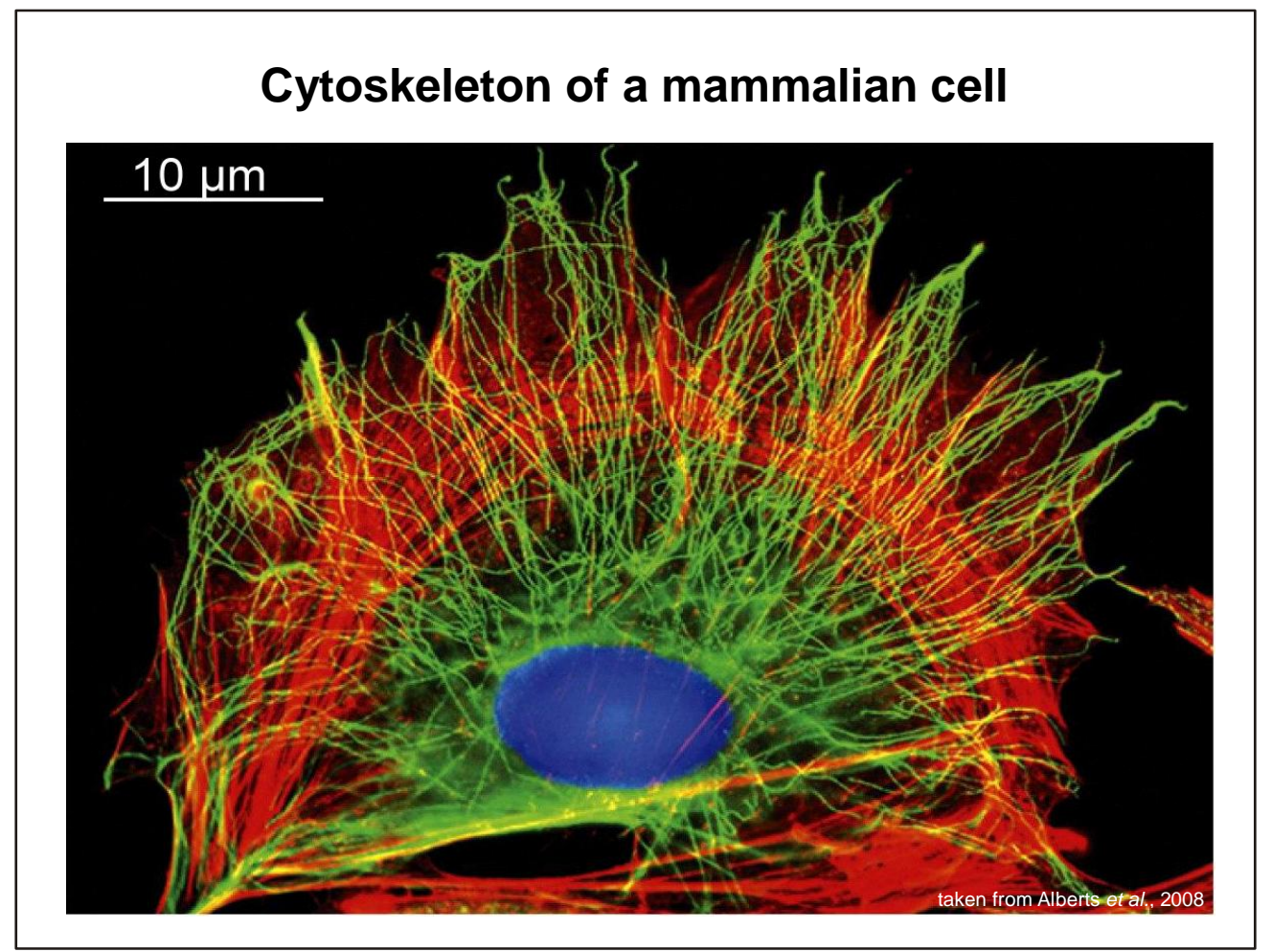

Fig. 11: Cytoskeleton of a mammalian cell

Cytoskeleton of a mammalian cell. Microtubules are stained in green, actin filaments in red and DNA in blue.

There are several important transport processes within the cell soma, mediated by motor proteins travelling along microtubules (Hirokawa et al., 2009). One is between the endoplasmic reticulum (ER) and the Golgi apparatus. At the membrane of the ER the newly synthesized membrane proteins are modified and folded, followed by a packaging to the transport vesicles destined to the Golgi apparatus. Another transport process is from the Golgi to the plasma membrane (as described above). In contrast to the (+)-end directed transport that delivers cargo to the plasma membrane, another important transport processes has its origin in the plasma membrane. Molecules, peptides and proteins can be internalized into the cell by endocytosis. The particles have to be transported from the periphery to special locations within the cell. This needs (-)-end 
directed transport on the microtubules which requires specialized motor proteins (Vale, 2003).

The machinery for directed intracellular transport needs a complex collaboration of proteins. This is most prominent in polarized cells, such as neurons and is fundamental for neuronal function and survival. Proteins are required in the axon and nerve terminals and need to be transported from the cell body and survival signals and cellular sensors have to be transported from the neurite tip to the cell soma (Campenot and Maclnnis, 2004). Because of the multiple directed transport processes, neurons are a good model system for studying the fast cellular transport systems (Hirokawa et al., 2009).

\subsection{Molecular motor proteins}

The directional transport process is performed by molecular motors. Force generation is mediated by hydrolysis of nuclein triphosphate (e.g. adenosine triphosphate (ATP)) to nuclein diphosphate. Three large superfamilies of molecular motors have been identified that are involved in intracellular transport: kinesins, dyneins and myosins (Vale, 2003).

Kinesin motors are mechanochemical enzymes coupling ATP hydrolysis to physical translocation along microtubules in (+)-end direction (anterograde movement in axons). They are specific to a various bunch of cargoes from dense core vesicles (kinesin-3) and organelles (kinesin-4, KIF1Ba) (Miki et. al., 2005, Nangaku et al., 1994), to synaptic vesicle precursors (kinesin-1) (Byrd et. al. 2001). In axons the main function of kinesins is the maintenance of the synapses by providing synaptic proteins, which are expressed in the cell soma and transported in a ATP-dependent manner to their target area.

Dyneins transport cargo along microtubules in (-)-end direction (retrograde movement in axons) (Gibbons and Rove, 1965) in all higher organisms and are responsible for the motility of cilia and flagella (Paschal et al., 1987). Cytoplasmic dynein is present in all organisms performing different kinds of transport processes from movement of nuclei in fungi to migration of neurons in the mammalian brain (Bloom, 2001, Vallee et al., 2001). The bulk of cytoplasmic dynein consists of two identical heavy chains which contain the ATPase activity and therefore are responsible for generating the power stroke during processive movement along the microtubule. The exact mechanisms during the power stroke have recently been discovered by $6 \AA$ resolution crystal structure analysis. It was found, that the stalk domain is connected with a stiff amino acid chain (so called buttress) to the motor head (Reck-Petersen et al., 2006). The structure of this very 
stiff component assures the correct twist of the two stalk chains, who are responsible for the step size and direction (Cho and Vale, 2011, Carter et al., 2011).

Myosins are the driving force of muscle contraction and take part in short transport processes near the plasma membrane such as movement of endoplasmic reticulum in squid axoplasm (Tabb et al., 1998). The most prominent member of this family is the Myosin II (conventional myosin) which is responsible for producing muscle contraction in muscle cells by directed movement along actin filaments. Myosin II consists of two heavy chains each containing an $\mathrm{N}$-terminal head domain and a C-terminal tail with coiled-coil morphology connecting the two heavy chains (Sweeney and Houdusse, 2010). In muscle cells, the long coiled-coil tails of the individual myosin molecules join together, forming the thick filaments of the sarcomere.

From now on I will concentrate on kinesin motors, although keeping in mind that detailed insight in the dynein or myosin superfamily won't be less interesting.

\subsubsection{Structure of kinesins}

All proteins of the kinesin superfamily (KIF) consist of a filamentous polypeptide chain and a motor domain. In kinesin-1 both domains together are called heavy chain ( $\mathrm{HC})$. The well conserved motor domain is a 360 -residue globular domain with $30-40 \%$ identity within the KIFs and is sometimes referred as the "catalytic core" and contains both a catalytic pocket, for hydrolyzation of ATP and an area with microtubule binding sites (Aizawa et al., 1992, Hirokawa et al., 1989). Electron microscopy reveals that most kinesins form filamentous, extended structures with the conserved globular motor domain at one end and a protein interaction area at the opposite end (Hirokawa et al., 1989). The catalytic core domain is from now on referred to as the head domain of kinesin-1 and followed by the stalk region and the tail domain at the opposite end of the protein. The head domain with its catalytic domain is responsible for creating the power stroke the stalk and the tail domain is responsible for interaction with cargo-binding proteins or direct cargo interaction (Diefenbach et al., 1998).

The family specific differences and further properties are described at the model of conventional kinesin (kinesin-1).

Kinesin-1 (Fig. 12) is a hetero-tetrameric protein consisting of one homodimer of kinesin heavy chain (KHC) containing the motor domain (blue) the coiled-coil neck region followed by the stalk region and the binding region to kinesin light chain (white) and ending with the tail domain (purple). The part adjacent to the motor domain that is connecting the catalytic core to the neck region is called the neck linker. The length of this region differs in many kinesin motors. 


\section{Structure of kinesin-1}

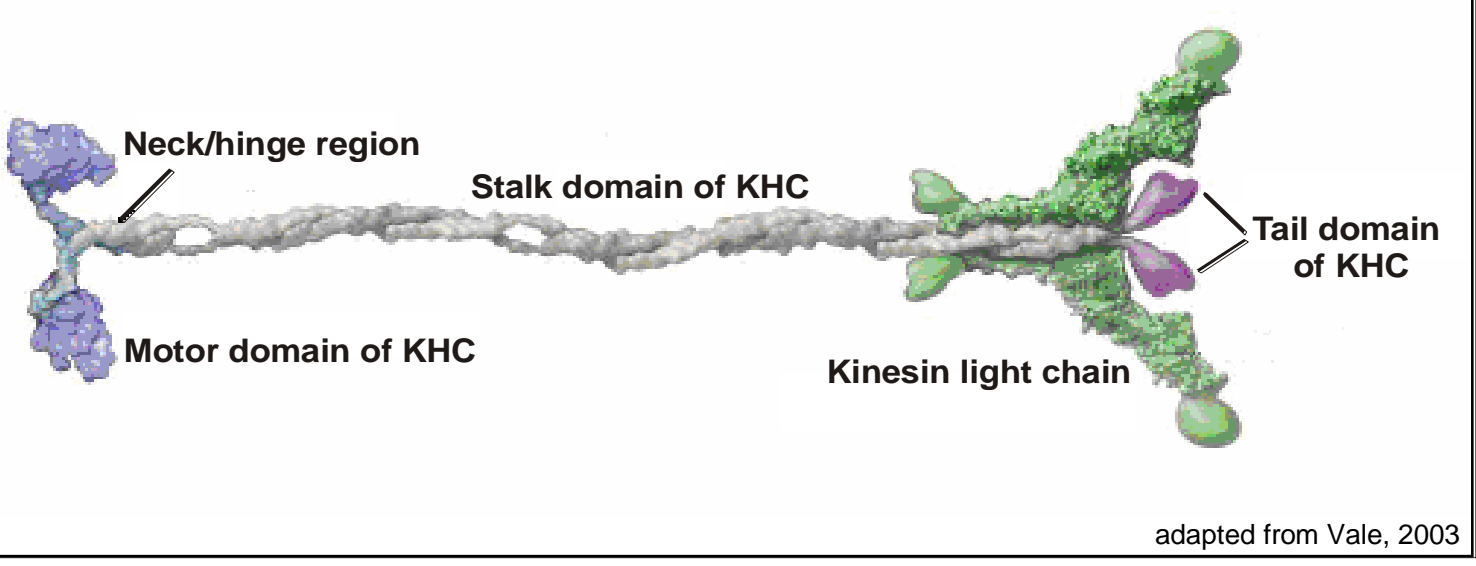

Fig. 12: Structure of kinesin-1

It is widely discussed if speed or processivity is indeed dependent on the length of the neck linker (Turner et al., 2001, Tomishige, 2006, Shastry and Hancock, 2010, Kutys, 2010). The neck region or neck colied-coil region is also a family specific region. It is an influencing parameter for processivity such as direction or regulation of activity of the motor protein (Endow and Waligora, 1998).

\subsubsection{Kinesin classification}

The classification of the different members of KIF was constructed by amino acid sequences in relationship with structure and function. 15 families of kinesins have been identified (Miki et al., 2005, Hirokawa et al., 2009). The four most prominent ones are presented here.

\section{Kinesin-1 - the founding member}

Kinesin-1 or conventional kinesin is the most prominent member of the kinesin superfamily. It was not only the first described kinesin (Vale et al., 1985) but is also the best characterized and structure-resolved kinesin of the family (Hirokawa et al., 2009). It contains two kinesin heavy chains $(\mathrm{KHC})$ that strictly form a stable homodimer. This property can be found in all organisms from fungi to mammals. The stalk domain is a highly conserved coiled-coil motif. Animal KHCs are able to bind kinesin light chains and bear, in addition, a cargo binding domain at the tail for (Palacios and Johnston, 2002). Kinesin-1 motors are reported to transport organelles like lysosomes and mitochondria (Brady et al., 1990, Nakata and Hirokawa, 1995, Tanaka et al., 1998), are involved in nuclear movement (Holzinger et al., 2002) and additionally play an important role in 
microtubule dynamics and stability (Daire et al., 2009, Terada et al., 2000). A lack of kinesin-1 in neurons can not be compensated by other kinesins and causes neuronal transport defects (Saxton et al., 1991, Patel et al., 1993). In Drosophila, kinesin-1 mutants show neuronal dysfunction and resulting in progressive distal paralysis and lethality in late larval stages. Axons of these mutants show focal swellings with accumulations of transport vesicles containing presynaptic proteins. Additionally an accumulation of mitochondria and prelysosomal organelles could be detected at the same place (Hurd and Saxton, 1996). In mammals mutations in the kinesin-1 light chain lead to axonopathies, cytoskeletal disorganization and abnormal cargo accumulation (Falzone et al., 2009).

\section{Kinesin-2 - the heterotrimeric motor}

Members of kinesin-2 family are prominent because of their diversity due to their ability to form heterodimer/trimers. Kinesin-2 motors show downstream of the motor head a region of several clusters of positively and negatively charged amino aids. As other members if this family shows clusters of oppositely charged residues, this region enables these motors to form heterodimers or heterotrimers (Henson et al., 1997). Members of this family are involved in organelle transport (Setou et al., 2000), intraflagellar transport processes (Henson et al., 1997), fodrin associated transport of vesicles in axons (Takeda et al., 2000) and anterograde transport between endoplasmic reticulum to the Golgi complex (Stauber et al., 2006). Kinesin-2 motors are additionally important for left right determination during development of node cells (Takeda et al., 1999). The importance of the kinesin-2 family in the nervous system becomes obvious, when knock-out mice are generated or motor down regulation by RNA interference (RNAi) in cell culture is performed, as this leads to impaired neuronal development by misorientation of microtubules in dendrites (Mattie et al., 2010), and fragmentation of the Golgi apparatus in mammalian cells (Stauber et al., 2006).

\section{Kinesin-3 - the monomeric motor}

Kinesin-3 motors, the so called monomeric kinesins, show characteristic a-helical structures in the neck region, followed by a fork-head domain (Westerholm-Parvinnen et al., 2000). Cargo binding domains for interaction with phosphoproteins or phospholipids are very prominent in this family. Kinesin-3 motors are known to be monomeric, but there is evidence for one dimeric kinesin-3 (Dorner et al., 1999). Kinesin-3 is responsible for transport processes of organelles (Nangaku et al., 1994), vesicle and vesicle precursors (Hall, et al., 1991, Okada et al., 1995). As UNC-104 is a member of the kinesin-3 family emphasis and insight detail will be presented in the following chapter 2.3. 


\section{Kinesin-5 - the tetrameric motor}

Members of the kinesin-5 family are the most conserved proteins within the kinesin superfamily (Miki et al., 2005). This is due to their force generating purposes during spindle formation and their crucial role in cell division (Blangy et al., 1995, Hemerly et al. 1993). These motors are known to form homo-tetramers to pull the two centrosomes towards each other and therefore provide correct spindle formation (Cole et al., 1994). Some members of the kinesin- 5 family are additionally involved in migration of neurons (Falnikar et al., 2011). When kinesins as Eg5 are down regulated by RNAi no spindle formation and cell division is possible which is lethal in further cell cycles (Peters and Kropf, 2006, Ferenz et al., 2010).

\subsubsection{Walking of kinesins - models}

Since the first publications with single molecule measurements in 1989 (Howard et al., 1989) a potential model how kinesins move along microtubules has been controversial discussed. Kinesin-1 was the most prominent kinesin motor so first models were designed

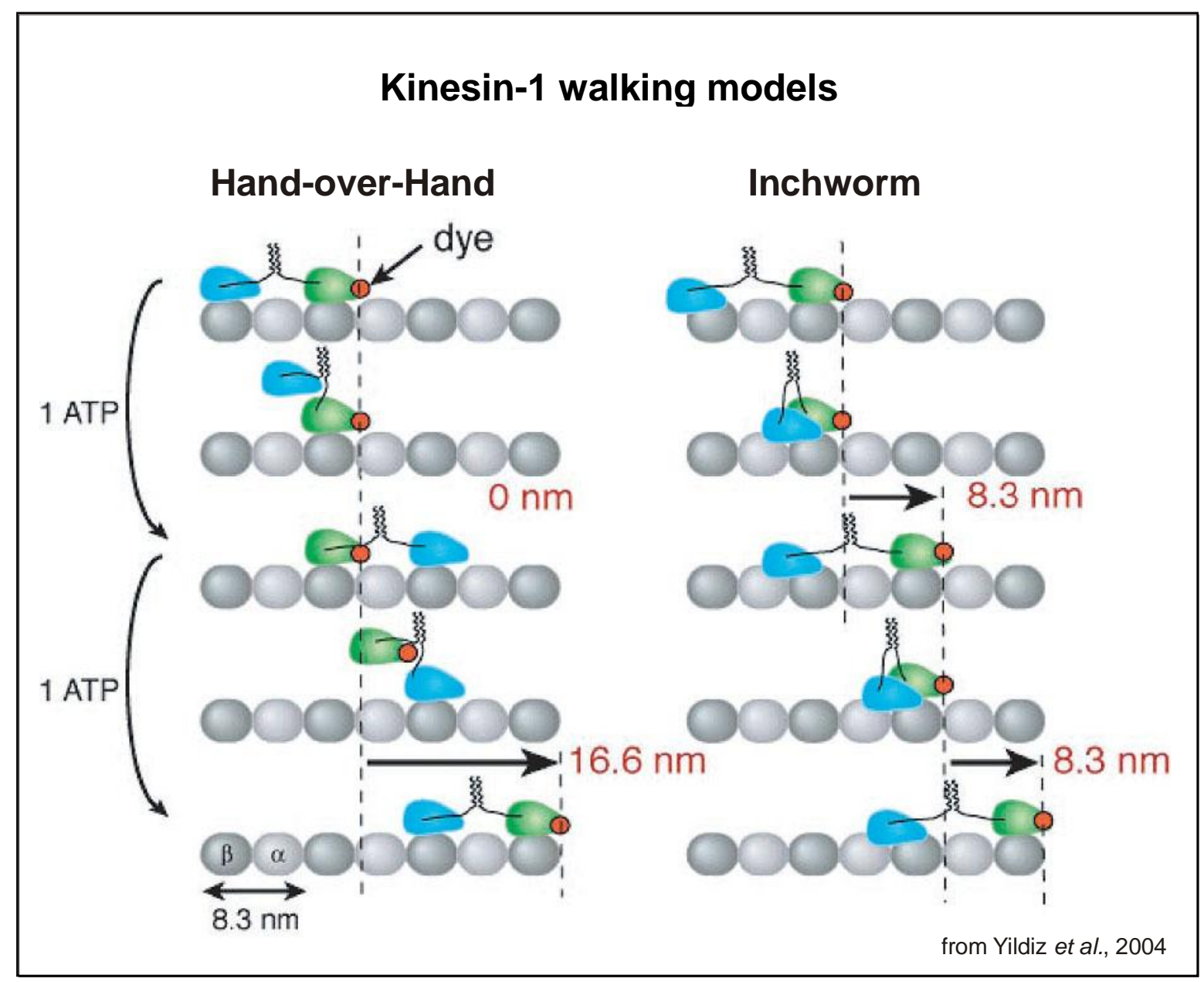

Fig. I3: Kinesin-1 walking models: "Hand-over-Hand" and "Inchworm". 
containing motors or motor protein complexes consistent of two ATP-hydrolyzing motor heads. On the other hand the model has to assure that the motors can perform several consecutive steps without dissociating, as the motors are able to take multiple $8.3 \mathrm{~nm}$ long steps along microtubules (Svoboda et al., 1993) and can therefore walk over a large distance (compared to their molecule size). In order to take many consecutive steps along the microtubule without dissociating, the two heads must operate in a coordinated manner and at least one oft the two heads must be bound to the microtubule track at any time.

Two models have been postulated: the "hand-over-hand" model in which the two heads alternate in the lead (Rice et al., 1999), and an "inchworm" model in which one head always leads (Hua et al., 2002).

The hand-over-hand model predicts that with each hydrolyzed ATP, the rear head moves twice the center of mass, whereas the front head does not translate (Fig. I3 left). In contrast, the inchworm model predicts a uniform translocation of $8.3 \mathrm{~nm}$ for all parts of the motor, which is equal to the center-of-mass translation (Fig. I3 right). In addition, each model makes predictions about rotation of the stalk. The inchworm model predicts that the stalk does not rotate during a step. A symmetric version of the hand over-hand model predicts that the stalk rotates 180 degrees, whereas an asymmetric hand-over-hand model does not require stalk rotation (Yildiz et al., 2004). With the development of novel analytical methods such as FIONA (fluorescence imaging with one-nanometer accuracy, Yildiz et al., 2003, Fehr et al., 2008) for kinesin-1, the "hand-over-hand model" was proved to be the most probable one.

\subsubsection{Motor-Cargo interactions}

The kinesin family consists of a large variety and number of different motor proteins reflecting very specific functions with respect to their cargo binding molecules. This ensures delivery of the right cargo to the right destination area and the possibilities of regulative influences by the cell.

In unpolarized cells microtubules usually emanate from the microtubule organizing centre (MTOC) to the periphery of the cell near the plasma membrane. Kinesins are the driving force in the most important (+)-end directing transport mechanisms within the cell. This chapter will give an overview of important cellular transport processes driven by kinesins and their specific binding partners ensuring the transport of the correct load. A schematic overview of the pathways is shown in Fig. 14.

Transport vesicles containing surface proteins e.g. receptor proteins, ion channels, etc. are transported from the trans Golgi network to the plasma membrane by kinesin-1 
(KIF5) through a binding site for p75 (Jaulin et al., 2007), kinesin-3 (KIF13a) via docking at the M6PR (mannose-6-phosphate receptor) and usage of adaptin complexes as adaptor proteins (Munier-Lehmann et al., 1996, Nakagawa, et al., 2000) and one member of the kinesin-14 family (KIFC3) with annexin as cargo molecule (Noda et al., 2001). The transport of vesicles between the Golgi apparatus and the ER is another important transport process. Newly synthesized proteins in the ER are translocated to the "distribution and sorting center" Golgi apparatus and vesicles for recycling are transported from Golgi to the ER (Klumpermann, 2000). The retrograde transport from ER to Golgi is mainly performed by cytoplasmic dynein, but there is a hint, that a member of the kinesin-2 family is also involved in this process (Stauber et al., 2006). The transport from Golgi to ER is mainly performed by conventional kinesin (KIF5) via binding at kinectin (Santama et al., 2004) or at p115 (Wozniak and Allan 2006). Kinesin-2 (KIF3) is also a part of the transport machinery between Golgi and ER docking at the KDEL receptors at vesicle membranes (Stauber et al., 2006). Another important transport mechanism for translocation of endosomes is derived at the plasma membrane. Particles from outside the cell are internalized either in an unspecific or specific and directed way, initialized via dockage at receptors and mediated by e.g. clathrin or flotillin (Doherty and McMahon,

\section{Vesicle traffic in eucaryotic cells}

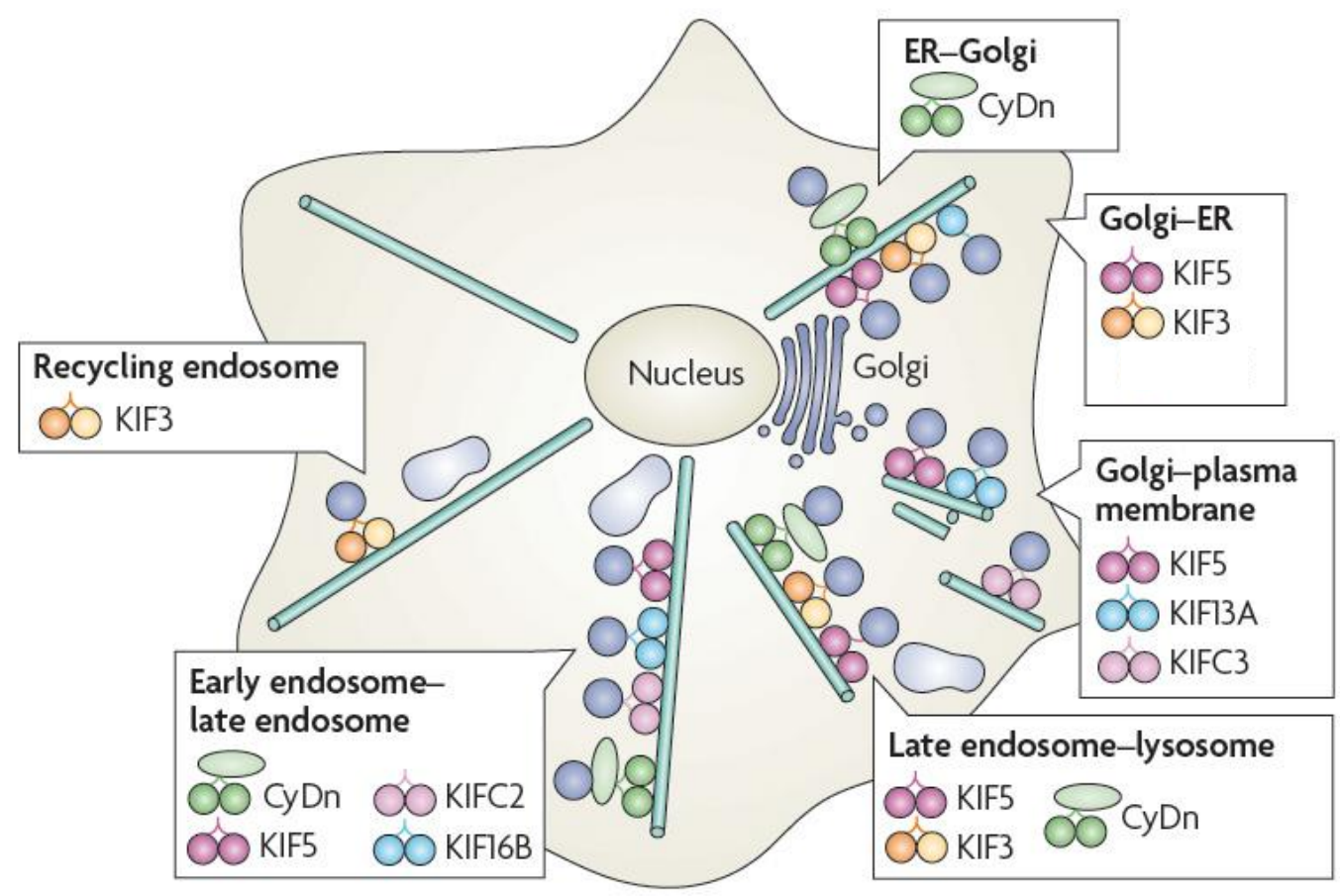

from Hirokawa et al., 2009

Fig. 14: Vesicle traffic in eucaryotic cells 
2009, Anderson, 2011). All pathways lead to vesicular organelles called endosomes, that is transported from the plasma membrane to cell compartments within the center of the cell and back to the plasma membrane (Doherty and McMahon, 2009).

As there is a vast functional variety of endosomes (maturation, sorting, recycling), small GTPases of the Rab family are regulating the sorting of these membranes by recruiting different motors. Small GTPases are regulatory proteins can act as a molecular switch by a mechanism depending on the nucleotide-bound state. Two conformational states exist: the on-switch in the GTP bound state and the off-switch with GDP-bound Rab state. The switch between conformations is catalyzed by guanidine exchange factors (GEF) while the on-switch is preserved by guanidine dissociation inhibitor (GDI) (Goud and McCaffrey, 1991). Thus the regulation of these transport processes can be controlled by both expression levels and localization of the different Rab proteins and the expression of the GEFs (Novick and Brennwald, 1993). Besides cytoplasmic dynein, several kinesins are involved in this process and the motors drive cargos in opposite directions and this determines the localization of endosomes. The transport from early to late endosomes is additionally mediated by kinesin-1 (KIF5) and kinesin-14b (KIFC2) via binding at RAB4 (Bananis et al., 2004) and a member of the kinesin-3 family (KIF16b) by binding at phosphatidyl-inositol(3,4,5)trisphosphate, Rab5 and the epidermal growth factor (EGF) or its receptor (Hoepfner et al., 2005). The transport processes form late endosome to the lysosome is performed by kinesin-1 (KIF5), with Rab4 as binding partner (Bananis et al., 2004) and a member of the kinesin-2 family (KIF3) via binding of RAB4 and RAB7 (Imamura et al., 2003, Brown et al., 2005). KIF3 is additionally responsible for transport processes to the recycling endosomes, witch is mediated by binding to RAB11 (Schonteich et al., 2008).

\subsubsection{Kinesins in neuronal transport}

Neurons are highly polarized and have large expansions from nucleus to the most distant cell membranes. Thus a well balanced transport system is indispensable for cell survival and function. Additionally neurons have other cellular mechanisms than non-neuronal cells. For example they have an increased demand on ATP compared to non-neuronal cells (except for muscular cells) (Bindokas et al., 1998, Morris and Hollenbeck, 1993, Fabricius et al., 1993, Verburg and Hollenbeck, 2008). Thus neurons have their own set of motor proteins exclusively expressed in the nervous system where they power the long range transport of membrane vesicles in neurite processes (Fig. I5). 
Kinesin-1 with its homologues KIF5A and KIF5C, exclusively expressed in neurons, is responsible for transport of mitochondria via the so called scaffolding proteins miro, milton (Glater et al., 2006), syntabulin (Cai et al., 2005) and RanBP2 (Cho et al., 2007). Additionally, kinesin-1 transports tubulin dimers and therefore influences microtubule dynamics and microtubule stability. Kinesin-1 is also involved in vesicle transport, when the vesicles do contain amyloid precursor protein (APP) or apolipoprotein $\mathrm{E}$ receptor2 at its surface (Kamal et al., 2000, Verhey et al., 2001).

\section{Motor proteins involved in neuronal transport processes}

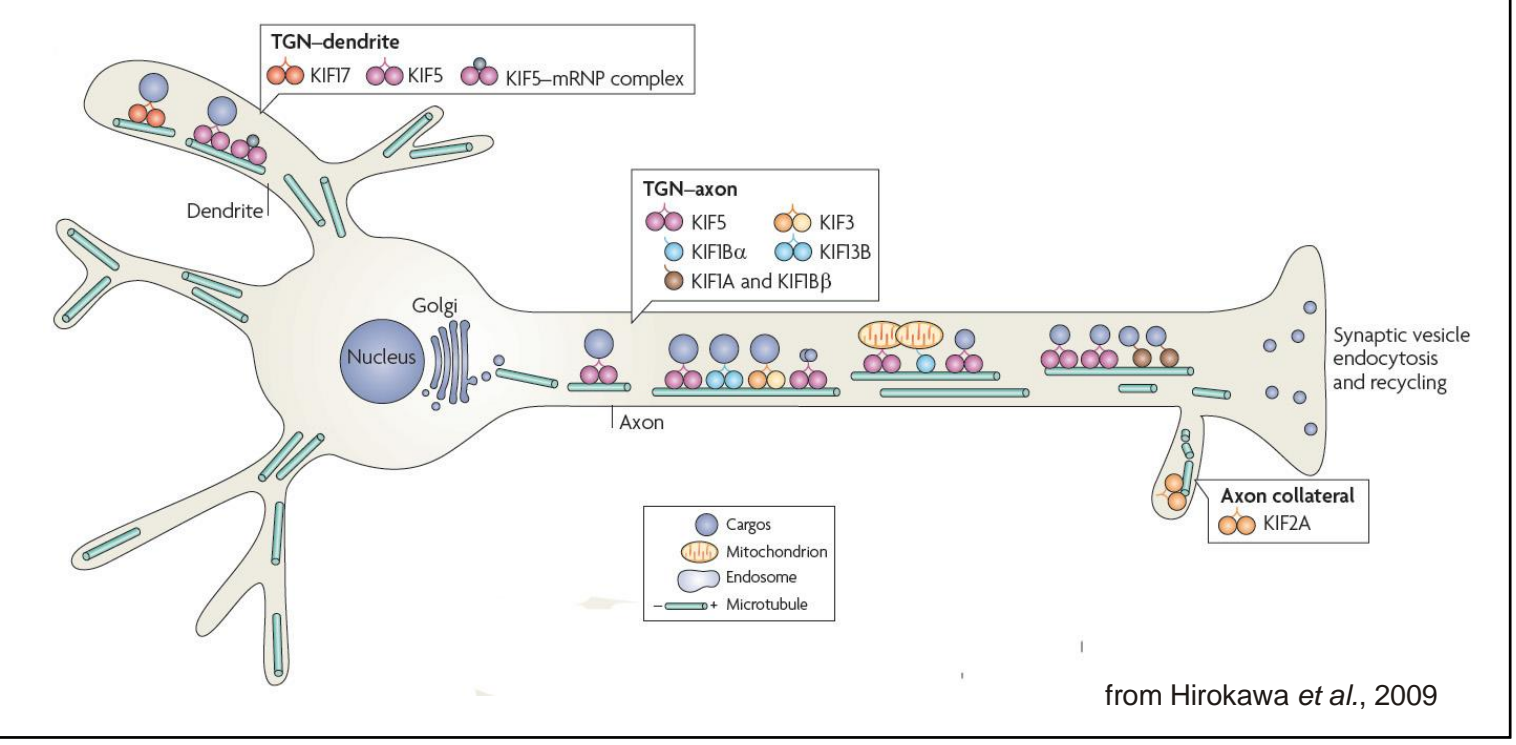

Fig. 15: Motor proteins involved in neuronal transport processes

Kinesin-3 family members are responsible for the transport of synaptic vesicles and synaptic vesicle precursors. KIF1A, one member of this family is responsible for the transport of synaptic vesicles and dense core vesicles from the cell soma to the axon tips. UNC-104, the KIF1A orthologue from $C$. elegans, directly binds to $P \operatorname{td} \ln s(4,5) \mathrm{P}_{2}$ (also called $\operatorname{PIP}(4,5)_{2}$, phosphatidyl-inositol(4,5)bisphosphate) (Klopfenstein et al. 2002, Klopfenstein and Vale, 2004). An influence of the adapter protein SYD-2 in this process is under debate (Wagner et al., 2009). KIF1A and KIF1B $\beta$ (a splicing variant of KIF1B) are responsible for the transport of synaptic vesicle precursors containing synaptotagmin, synaptophysin in mice (Okada et al., 1995, Zhao et al., 2001). Both KIF1A and KIF1B $\beta$ bind to Rab3 proteins through the adapter protein DENN/MADD. The importance of kinesin-3 in neurons becomes visible in KIF1A knock-out mice, as this knock-out is lethal (Niwa et. al., 2008). More details to KIF1A can be found in the next chapter. Another kinesin-3, KIF1B $\beta$, is responsible for transport of mitochondria with KIF1 binding protein 
(KBP) as scaffolding protein (Wozniak et al., 2005). The guanylate kinase-associated kinesin (GAKIN), a kinesin-like motor protein, is involved in vesicle transport mechanisms in mice and plays a role transport of vesicles containing Ptdlns $(3,4,5) \mathrm{P}_{3}$ mediated by binding of centaurin-a1 (Horiguchi et al., 2006).

In a neuronal network not only the correct distribution of proteins in the axon is essential for functionality, but also the postsynaptic membrane located at the dendrites has to be provided with the right proteins and cell sensors in their right composition. The role of kinesins in transport processes in dendrites is less well described than in axons, in part owing to the fact that microtubule polarity is mixed in proximal dendrites, unlike the uniform distal polarity of plus ends in axons (Hirokawa et al., 2009). Nevertheless, the two most important kinesins here are kinesin-1 and kinesin-2 member Osm3 (KIF17). Kinesin-1 is responsible for transport of RNA-transporting granulae containing a bulk of mRNA important for dendrite maintenance (Kanai et al., 2004) while Osm3 is driving vesicles containing membrane compounds of the postsynaptic membrane to their target area. Osm3 mediated transport is performed in associative manner with scaffold proteins of the LIN family and NR2B as cargo binding protein (Kayadjanian et al., 2007, Setou et al., 2000, Jo et al.,1999). Other possible binding proteins are the glutamate receptor and the $\mathrm{K}^{+}$channel Kv4.2 (Kayadjanian et al., 2007).

The diversity of kinesins in neurons is considerable. From 45 known mammalian KIF genes leading to purposed twice as much isofoms (alternative mRNA-splicing) proteins (Miki et al., 2001), but only a handful are not restricted to neuronal expression. Surprisingly a kinesin was characterized in murine neurons that even plays an active role in retrograde transport. This kinesin is the founding member of a novel kinesin family, called c-kinesins (Hanlon et al., 1997).

\subsubsection{Diseases based on kinesin motors defects}

The anterograde trafficking of proteins is a tightly regulated process. Defects in trafficking are known to be a major cause of many diseases. Protein aggregates in neurodegenerative disease like Alzheimer's Disease has been linked to defects in kinesin-1 transport of amyloid precursor protein (APP) (Kamal et al., 2000 \& 2001) and genetic reduction of kinesin light chain 1 (KLC1) expression enhances axonal accumulations of APP (Stokin et al., 2005). In addition Tau misbehaviour can be induced by transport defects of kinesin-1 (Falzone et al., $2009 \&$ 2010). There is also a direct connection from mutations in kinesin-1 heavy chain to hereditary spastic paraplegia (SPG10) in humans (Reid et al., 2002). As kinesin-1 is responsible for distribution of 
mitochondria within the neurons there is a link between dysfunction of kinesin-1 transport processes and amyotrophic lateral sclerosis (ALS) (Manfredi and Xu, 2005). But not only defects in kinesin-1 are affecting neurons. Defects in kinesin-2 can lead to neuronal degeneration (Marszalek et al., 2000), skeletal development defects (Koyama et al., 2007, Haycraft et al., 2007) obesity and cystic kidney disease (Davenport et al., 2007). As members of the kinesin- 3 family are prominent in neurons and are involved in fast axonal transport, transport of synaptic vesicles and transport of synaptic vesicle precursors, the effects of impaired proteins lead to severe effects. Impaired motors show severe effects in viability of cells or even organisms (abortion in mammals) (Yonekawa et al., 1998). The maintenance and function of neurons is severely imparted. Knock out of kinesin-3s in mice are either lethal or cause neuronal degeneration and synaptic dysfunction (Yonekawa et al., 1998). Mutations in KIF1B $\beta$ cause the neurodegenerative disease Charcot-Marie-Tooth Disease Type 2A (Zhao et al., 2001). Recent studies also show, that there is a correlation between kinesin-3 motility and Tau-expression (Tien et al., 2011), probably giving new insights in Alzheimer's disease in future.

\subsection{The kinesin-3 member UNC-104}

The kinesin-3 member UNC-104 has described 1991 by Hall and Hedgecock for the first time. The gene was discovered at a screen of UNC-104 mutants in C. elegans where an analysis of the phenotypes connected with a comparison of the genomic information lead to the conclusion, that these kinds of proteins are neuron-specific motors used for anterograde translocation of synaptic vesicles along axonal microtubules (Hall and Hedgecock, 1991). A few years later, 1995, UNC-104 and its murine homologue KIF1A (Aizawa et al., 1992) was characterized as a monomeric kinesin and therefore the founding member of the new family of kinesins, later defined as kinesin-3 family (Okada et al., 1995). As this thesis addresses mainly UNC-104 from the nematode C. elegans, from now it is focused on UNC-104 and its mammalian orthologue KIF1A.

UNC-104 is exclusively expressed in neuronal cells of $C$. elegans, as well as $\mathrm{KIF} 1 \mathrm{~A}$ expression is restricted to neurons in mammals. It is responsible for the retrograde axonal transport of vesicles (Hall and Hedgecock, 1991, Klopfenstein et al., 2002) by binding on $\mathrm{PI}(4,5) \mathrm{P}_{2}$ on their surface and transport of synaptic vesicle precursors via binding at synaptophysin, synaptotagmin and RAB3A (Niwa et al., 2008, Zhao et al., 2001). Recent studies also showed that an UNC-104 orthologue contributes to an organelle specific dynein-driven retrograde transport mechanism (Barkus et al., 2008). 


\subsubsection{Structure of UNC-104}

UNC-104, a member of the kinesin-3 family, is a so called monomeric kinesin. Analysis of kinesins by electron microscopy show, that this is the case in diluted solution. Whereas kinesin-1 as a constitutive dimer shows two motor heads and binding at the stalk peptide chain, UNC-104 shows globular structure and occurs as a single molecule (Fig. 16A, also Hirokawa et al., 2009).

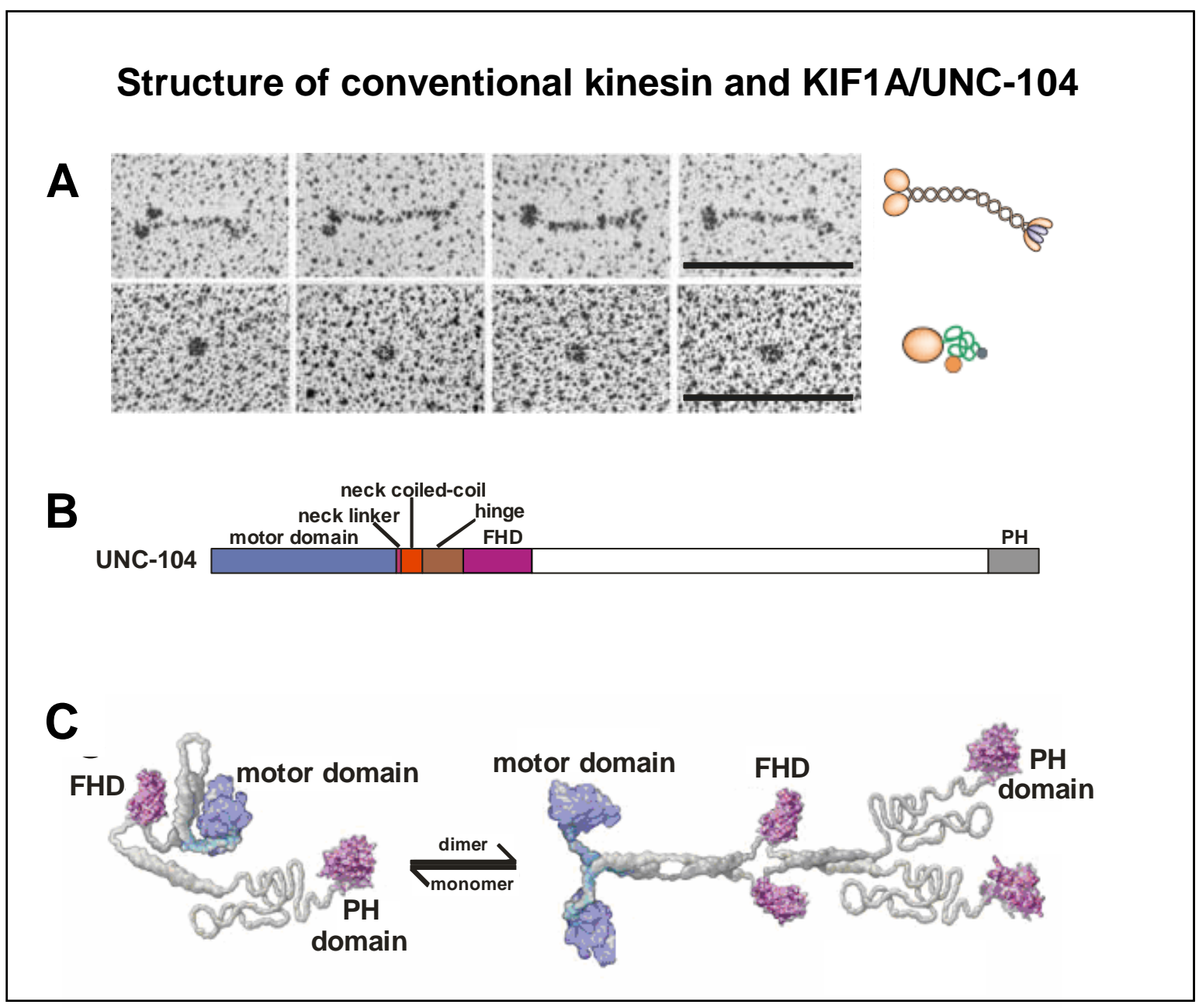

Fig 16: Structure of conventional kinesin and KIF1A/UNC-104

A) Structure of conventional kinesin (top) and Kif1A (bottom), observed by low angle rotary shadowing. Diagrams constructed on the basis of electron microscopy or predicted from the analysis of their primary structures, are shown on the right. Bar, $100 \mathrm{~nm}$ (from Hirokawa et al., 2009). B) UNC-104 domain organization, a schematic representation drawn to scale. C) UNC-104 and its proposed dimer confirmation (from Vale, 2003).

UNC-104 consists of an amino-terminal motor domain (aa 1-348) as the ATP hydrolyzing and force generating unit, a flexible neck linker (aa 349-357), followed by a neck coiledcoil (aa 358-389) region. After the hinge region (aa 390-462) a fork-head-homology (FHA) domain (aa 463-592) is located. There is evidence in other proteins, that this domain can bind phosphotreonine, so this could be a possible area for regulation (Vale, 2003). An 
elongated stalk region of unknown structure and a C-terminal pleckstrin homology $(\mathrm{PH})$ domain (aa 1460-1566) responsible for membrane attachment and cargo binding are the following structures of UNC-104 (Fig 16B). The PH domain has been identified to bind Ptdlns (4,5) $\mathrm{P}_{2}$ (Klopfenstein et al., 2002). Ptdlns $(4,5) \mathrm{P}_{2}$ is the lipid target of several $\mathrm{PH}$-domains and is also known to be implicated in membrane traffic events (Martin, 2001). It is also reported, that Ptdlns $(4,5) \mathrm{P}_{2}$ is enriched in lipid rafts (Simons and Ikonen, 1997, Caroni et al., 2001) thus a lipid raft can provide multiple binding sites for UNC-104 within a small area of the transport vesicle.

\subsubsection{Mini motors of UNC-104}

An in vitro investigation of properties of a protein is important for its characterization. As members of the kinesin-3 family are not easy to purify from their original organism and also can not recombinantly produced and purified in bacteria as full length (FL) protein, there are two strategies used for molecule studies. The first one is the expression in insect cells (using baculo viruses as transfection medium) this method is expensive and potential post translational modifications can differ the proteins from its origin. A suitable and well established strategy is the generation of truncated forms of the protein, the so called mini motors (Klopfenstein et al., 2002). With this system it is focused on the areas of interest and those constructs are more easy to amplify recombinantly in bacteria and the following purification of the bacterial lysate is a common biochemical procedure. For this reason mini motors of UNC-104 are used in this thesis for in vitro experiments.

\subsubsection{Processivity of UNC-104}

The processivity of UNC-104 in vivo was described by Zhou, when he was able to visualize vesicles driven by UNC-104 by time lapse microscopy in living $C$. elegans. The velocity of $1.2 \mu \mathrm{m} / \mathrm{sec}$ identified UNC-104/KIF1A as one of the fastest anterograde motor proteins in axonal transport (Zhou et al., 2001, Lee et al., 2002) and therefore the main candidate for fast axonal transport processes.

How does a monomeric motor is able reach these high velocities? Several theories of walking mechanism are currently under debate. How is monomeric motor able to move processively? If UNC-104 is really a monomeric motor, it can not perform the walking model of conventional kinesin, in which one motor head anchors the molecule to the microtubule whereas the other moves to the next binding site. 


\section{Moving as a monomeric motor:}

A single-headed molecule is not expected to move processively, as the motor is not anchored at the microtubule while it moves to the next binding site. (Okada and Hirokawa, 1999). For a closer look to one of these mechanisms a closer look at the structure of the catalytic core is necessary. X-ray structure analysis shows, that kinesin-3 has several surface loops that differ from the corresponding loops in conventional kinesin (Sack et al., 1997). In case of UNC-104/KIF1A this is loop L2, L3, L10 and L12 whereupon only monomeric kinesins have a highly conserved insertion in loop L3. L3 forms a part of the nucleotide-binding pocket and might modulate nucleotide binding and release during the enzymatic cycle of monomeric kinesins (Kikkawa et al., 2001). Another interesting loop is L12 containing of 12 residues of which 6 are lysins, arranged in tandem and giving this loop the name K-loop. This loop is also uniquely conserved among monomeric kinesins and essential for their processivity in vitro experiments (Okada and Hirokawa, 1999). The K-loop, positively charged by its lysins, is interacting with a negatively charged C-terminal region of tubulin, the so called E-hook (Okada and Hirokawa, 2000). With this interaction the binding-constant between the motor head and the microtubule is increased at the weak binding state (Okada and Hirokawa, 2000) and an about $20^{\circ}$ rotation of the catalytic core is performed. The authors suppose that this dislocation might provide a mechanism of single motor head movement along microtubules allowing a processive motion. All these experiments have been performed with the pure catalytic core of KIF1A continued by the neck linker and a short peptide sequence, both of kinesin-1 origin. The kinesin-1 parts are known to be not taking part in kinesin-1 dimerization. The velocities of these constructs do not reach in vivo velocities but even stay in areas close to slow cellular transport processes (defined by Lasek et al., 1984 and Brown, 2000) of less than $0.15 \mu \mathrm{m} / \mathrm{s}$ (Okada and Hirokawa, 1999 and 2000), so another mechanism is postulated.

\section{Moving as a dimeric motor:}

The basics for this mechanism is adapted from the fact that UNC-104 can cluster in Ptdlns $(4,5) \mathrm{P}_{2}$ containing rafts and is able to achieve high velocities necessary for fast axonal transport (Klopfenstein et al., 2002). This was proven in an in vitro liposome transport assay and leads to the postulation, that accumulation can lead to dimerization of the motor and therefore it could proceed in a hand-over-hand mechanism. The same year it was shown, that artificial dimers of UNC-104, in fact, can act as processive motor in vitro (Tomishige et al., 2002). To further understand the mechanism of putative dimerization of UNC-104, again a closer look at the structure has to be taken. Sequence analysis of UNC-104/KIF1A revealed potential coiled-coil regions adjacent to the motor domain. This region has similarity with a kinesin-1 aa-chain that was first believed to play a role in head- 
head coordination (Vale and Milligan, 2000). It was shown, that this area has a lower coiled-coil probability compared to the long kinesin-1 coiled-coil (Tomishige et al., 2002), and therefore may require high motor concentrations for dimerization. Later, on this region was defined as the neck coiled-coil (aa 358-389). Together with the fact, that UNC-104 can accumulate at the vesicle surface via accumulation of its binding site Ptdlns $(4,5) \mathrm{P}_{2}$ in lipid rafts, a two headed hand-over-hand movement of UNC-104 is plausible. This hypothesis was strengthened as it was shown, that artificial dimers (created by a leucine zipper) of truncated forms of UNC-104 can move processively in an in vitro single molecule assay and these constructs can reach velocities over $1.5 \mu \mathrm{m} / \mathrm{s}$. This is in the range of wild type UNC-104 velocities. On the other hand, mutations of the neck coiledcoil domain, affecting its coiled-coil probability, show no movement in single molecule assays in vitro (Tomishige et al., 2002). Based on these experiments a putative structure of an UNC-104 dimer was presented (Fig I6C) (Vale, 2003). The mechanism of homodimer formation was also supported by immunogold electron-microscopy. Pictures of gold labelled kinesin-3 transporting organelles in axoplasmic spreads mostly shows a pair of gold particles lying within $25 \mathrm{~nm}$ distance, indicating a paired clustering of UNC-104 (DeGiorgis et al,. 2008). A first putative structure of an UNC-104 dimer was presented (Fig. I6 C, Vale, 2003). Overexpression of UNC-104 in non-neuronal cells shows a tendency of forming dimers in a living cell (Hammond et al., 2009). Unfortunately the authors used a system where the motor is not actively transporting vesicles though the direct proof of an UNC-104 dimer actively transporting cargo in a living neuronal cell is still missing.

\subsubsection{Regulation of UNC-104}

Expression of kinesin-3 is crucial for development and neuronal outgrowth (Yonekawa et al., 1998). Overexpression of UNC-104 in C. elegans leads to neuronal defects visualized in an uncoordinated phenotype (Zhou et al., 2001). A controlled level of UNC-104 and a controlled activation of UNC-104 transport processes are essential for survival and functionality of neurons. One way to control UNC-104 is based on the motor protein itself and is independent from regulatory proteins. Early after the identification of the kinesin family there had been hints of an inactive state of the motor when they are not bound to their cargo (Hollenbeck, 1989). From the biological and energetical side of view this mechanism of the inactivation of the catalytic core in a non-bound cargo state is very efficient. Futile ATP hydrolysis and walking along microtubules is prevented and UNC-104 is readily available for transport processes at the same time. The first evidence of a 
probable tail-head inhibition of kinesins was shown within a short period of time (Friedman and Vale, 1999, Coy et al., 1999). Shortly afterwards this phenomenon could be detected at UNC-104 proteins. A coiled-coil domain in the stalk of KIF1A was shown to negatively regulate the motor activity upon binding to the FHA domain. The interacting proteins were proposed to relieve this inhibition upon binding to the motor (Lee et al., 2002). Another possible regulatory strategy could be the already mentioned clustering of the UNC-104 motors on the lipid rafts (Klopfenstein et al., 2002) resulting in high transport velocities. In this case, an increase in the Ptdlns $(4,5) \mathrm{P}_{2}$ level both on the surface of cargo molecules and additionally in lipid rafts can have a regulatory effect on UNC-104 transport processes. In $C$. elegans this could be performed by the PPK1 (phosphatidylinositol phosphate kinase type I, Kumar et al., 2010). Another putative regulation mechanism is the interaction between UNC-104 and the active zone scaffolding protein SYD-2, that is able to cluster and activate UNC-104 in C. elegans (Wagner et al., 2009). The last two effects will even become more important, if homo-dimerization of UNC-104 is responsible for generating high velocities in axonal transport. Recent studies with DNC-1 as binding partner show that DNC-1 is responsible for UNC-104 distribution in the neuron and influences velocity and net transport (Hsu et al., 2011).

\subsection{C. elegans as a model organism}

Since the 1970s, the nematode Caenorhabditis elegans (Maupas, 1900, Brenner, 1973) became a more and more popular model organism to address questions of basic research ranging from molecular cell biology to developmental genetics. C. elegans is an about $1 \mathrm{~mm}$ long, free living nematode and can be found all over the world. Under optimal conditions it has a life cycle of about 3 days. There are 2 sexes, hermaphrodites and males whereas hermaphrodites can reproduce by self fertilization and can lay about 300 eggs during its reproductive life span (10-15 days) (Fig 17). Adult hermaphrodites have 959 cells and developmental fate of every single somatic cell has been mapped out (Sulston and Horvitz, 1977). Mostly every cell type identified in higher animals, e.g. mammals, can be found in the nematode. Additionally in most cases, complex protein families in mammalia which are encoded by many different genes and splicing variants are represented by only one or very few genes in the nematode.

The main food source of $C$. elegans are soil-inhabiting bacteria, making it easy to cultivate. As the nematode is transparent from embryonic to adult stage, giving the opportunity of using various microscopy techniques that are easy to perform. 


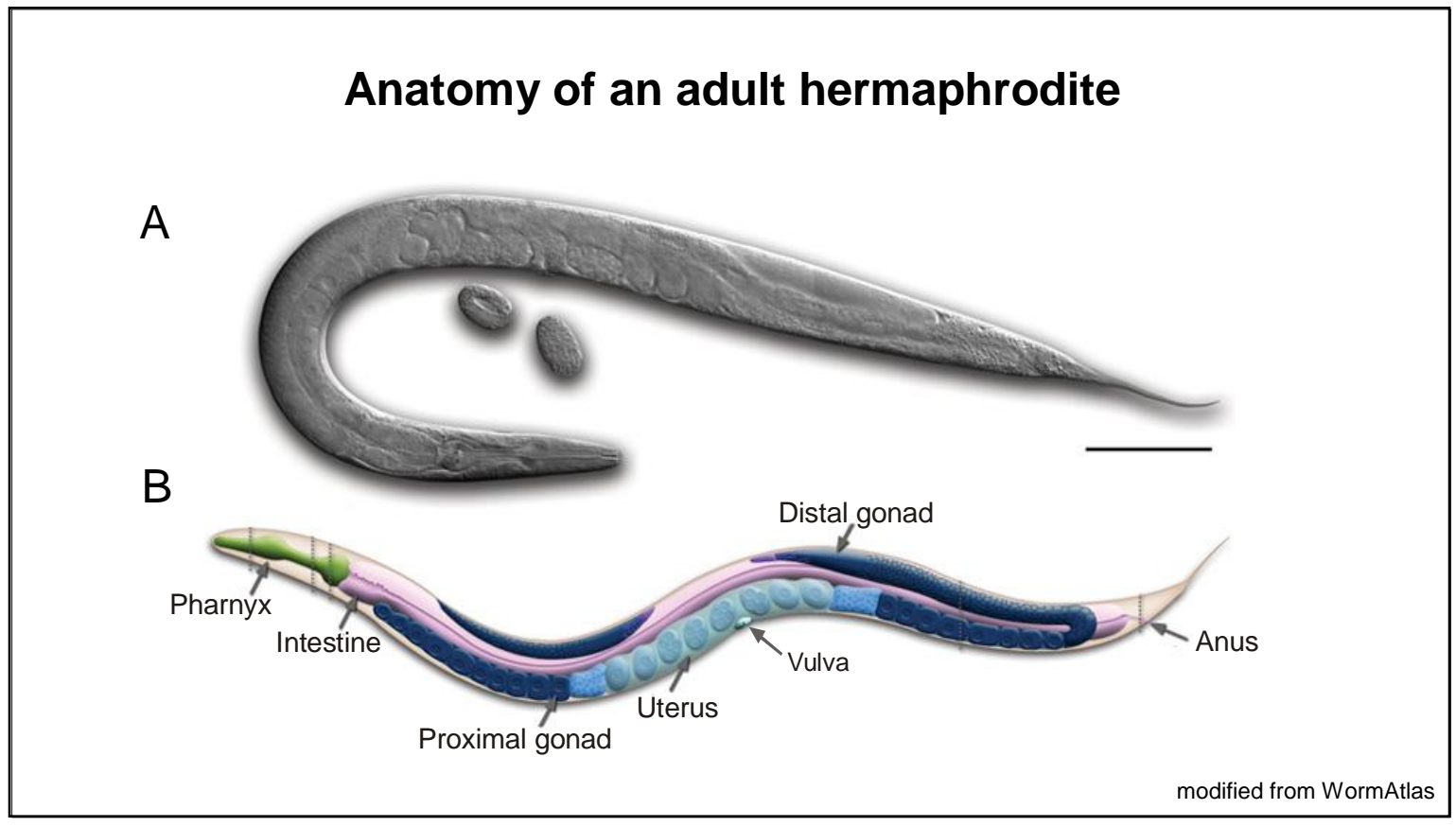

Fig. 17: Anatomy of an adult hermaphrodite

A) Differential interference contrast (DIC) image of an adult hermaphrodite, left lateral side. Scale bar $0.1 \mathrm{~mm}$. B) Schematic drawing of anatomical structures, left lateral side. (taken from: http://www.wormatlas.org/hermaphrodite/introduction//ntroframeset.html)

The nematode is a small, transparent and genetically tractable organism well suited for analysis of axonal transport by fluorescence microscopy. With its well-defined body movement and behaviour, innervation anomalies of motoneurons can be screened visually as many defects ranging from axon guidance to vesicle transport and synaptic vesicle recycling result in uncoordinated (unc) movement. Phenotypic rescue experiments by generation of transgenic animals allow to investigate the structure/function relationships of domains necessary for fast motor and cargo motility. As the cell lineage of all hermaphrodite's 959 cells (302 are neurons) is invariable and the neuronal connectivity has been mapped, individual subsets of neurons can be compared between animals for motor expression and transport activity. The combination of these parameters makes C. elegans a suitable model for addressing questions regarding axonal transport.

\subsubsection{Nematode development}

C. elegans has a very short life cycle. It takes $14 \mathrm{~h}$ from fertilization to hatching of the larva and then the nematode undergoes several larva states with period of high division frequency and those of lower ones until it reaches the young adult stage. The reproduction cycle is in total about 64 hours. The identification of the entire cell lineage was made possible with the invention of the differencial interfere contrast microscopy 
enabling high magnification and non invasive observations of organisms over a large period of time. This allowed the determination of the fate of every single cell of the nematode. Combined with its small cell number its additionally conserved cell lineage (Sulston and Horvitz, 1977), C. elegans became a very popular model organism beginning in the 1970 s.

\subsubsection{Nervous system}

Exactly 302 (37\%) of the 959 cells of the adult hermaphrodite are neurons. Their positions and wiring is completely determined and conserved in every single WT animal (Durbin, 1987). Most of the neurons have a very simple morphology, they are monopolar and have single unbranched processes. Where branches occur, they are usually very stereotyped and occur in very stereotype occasions (Wood, 1988). The main neurotransmitters in the nervous system are acetylcholine (ACh), representing the activating neuromuscular

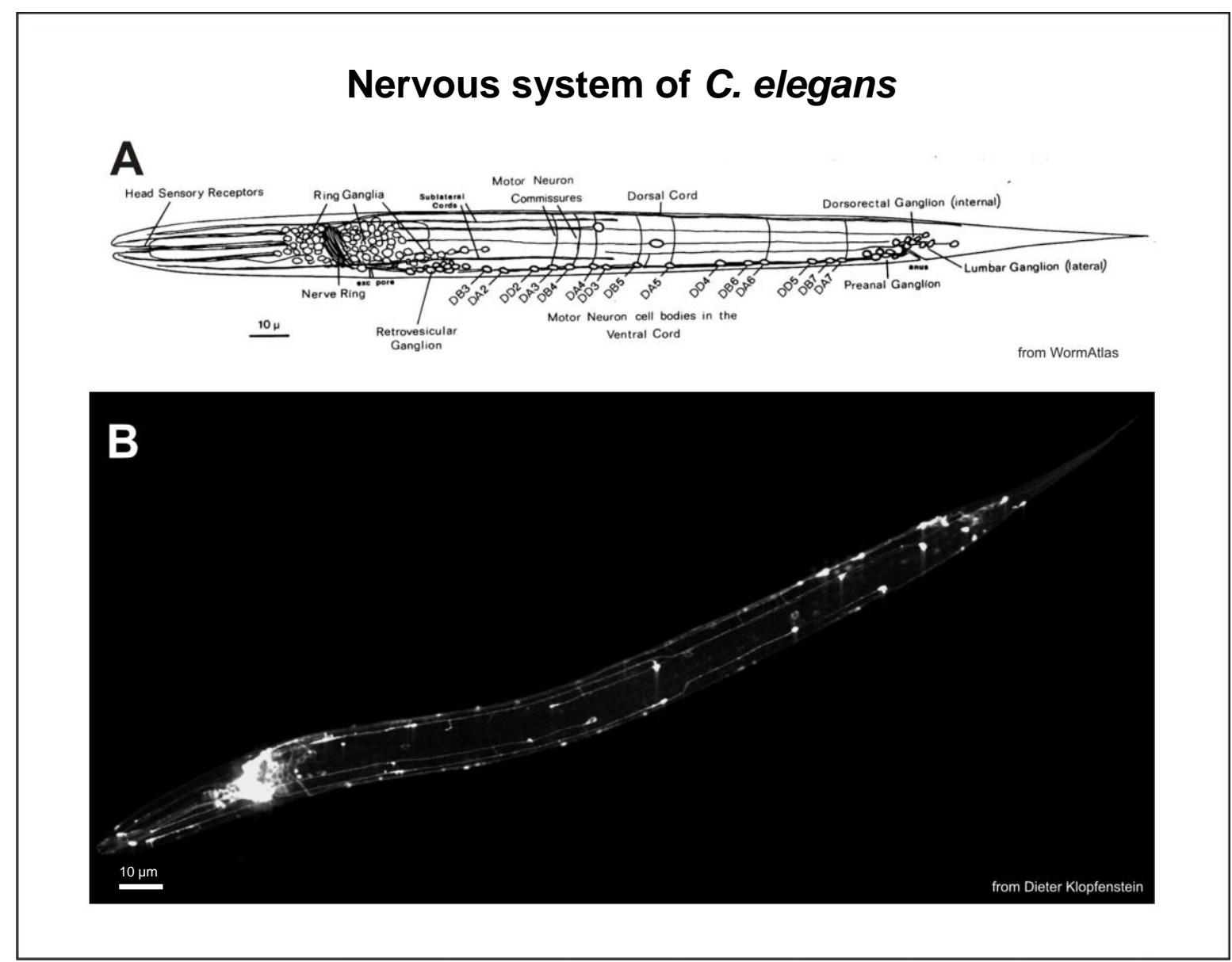

Fig. 18: Nervous system of $C$. elegans

A) Schematic illustration of the nervous system of C. elegans, taken from WormAtlas B) C. elegans expressing a GFP-tagged protein under a pan-neuronal promotor. 
transmitter, and gamma-aminobutyric acid (GABA) representing the inhibitory neuromuscular transmitter. Overall, the nervous system shows a high similarity to mammalian systems. Taking a closer look to the worm nervous system 3 prominent structures can be detected (Fig 18). The first one is the nerve ring near the head of the nematode. Here are located the cell somata of the sensory neurons (whose dendrite tips reach the tips of the pharynx) and many different other somata from neurons which axons are directed towards the tail of the worm. The second and third are the dorsal and ventral nerve cord mainly consisting of the motoneurons enerving the body wall muscles on both sides of the nematode.

\subsubsection{Locomotion of C. elegans}

C. elegans moves forward and backward by wiggling movement within its body. On a bacterial lawn the trace gives a perfect sinusoidal shape that induced the discoverers to manifest this into the nematods name "the elegant". This very special form of movement is induced by alternating stimuli or repression of nerve signals to the motoneurons enervating the body wall muscles (Wood et al., 1988). Sidney Brenner, who established C. elegans as a model organism described many mutants of the nematode who phenotypically differ from the WT. Any mutant that does not follow the normal pattern of strong sinusoidal movement and shows various detectable defects of motility behaviour is called "uncoordinated" (Brenner, 1974). This term was then continuously used to mark mutants with abnormal moving behaviour, manifesting in the term "unc" in the mutants name. Unc mutants can be caused by various kinds of defects like defects in enervation, defects in pre- and post-synaptic proteins, in neurotransmitter uptake and release, in motor proteins, in receptors and so on. Another prominent phenotype of impaired enervation is the so called "bag of eggs" or "bag of worms" phenotype. This phenotype is caused by impaired muscle contraction of the vulva muscles, avoiding or impairing the laying of eggs. Eggs accumulate in the hermaphrodites body, impairing movement and cause a swelling and shortening of the nematode ("bag of eggs"). If the worms hatch inside the adult worm and are filling the adults body it is called "bag of worms".

\subsection{Fluorescence Anisotropy}

Upon excitation with polarized light the emission from the excited fluorophore is also polarized, due to the transition moments of absorption and emission, which lie along spacial directions. The orientation of fluorophores in homogeneous solution is completely random (Lakowitcz, 1999). 


\subsubsection{Principle of fluorescence anisotropy}

Polarized light most likely excites fluorophores with a transition moment of absorption parallel to the angle of polarization. Therefore, it selects these molecules within a homogenous distribution of fluorophores. If the excited fluorophores can not change their orientation before emitting their fluorescence photon, the emitted light will also be polarized. Any reorientation of the excited molecules (due to rotation) will decrease the amount of polarization.

A common measure of the degree of polarization of fluorescence is the anisotropy. It is determined by the difference between the fluorescence intensity with polarization parallel and orthogonal to the polarization of the excitation light relative to the total amount of fluorescence. It is therefore necessary to split the beam and to measure the parallel and the orthogonal intensity of the emitted light.

$$
\begin{gathered}
r=\frac{I_{\|}-g I_{\perp}}{I_{\|}+2 g I_{\perp}} \quad \text { eq. } 1 \\
\begin{array}{l}
I_{\|}=\text {intensity parallel orientation } \quad g=\lambda \text {-based factor } \\
I_{\perp}=\text { intensity orthogonal orientation } \quad \mathrm{r}=\text { anisotropy }
\end{array}
\end{gathered}
$$

In order to understand the effects on fluorescence anisotropy used in this thesis, another physical effect has to be described. Förster resonance energy transfer (FRET) is known as the resonance (meaning non-radiative) transfer of energy from an excited molecule to a nearby acceptor (Lidke et al., 2003). FRET is only efficient if the both fluorophores are separated not more than 8 nanometer (Lakowitcz, 1999). The energy transfer can also occur between identical fluorophores (Weber, 1953), then called homo-FRET. Since the transferred energy is then emitted by the acceptor fluorophore the polarization of the photon is determined only by the acceptors orientation. Generally, the orientation of donor and accepter are not parallel. So, FRET provides an additional channel to reduce the anisotropy of the observed fluorescence. By implication, if one observes reduced fluorescence anisotropy in a solution of the same fluorophore, one can reason to observe FRET.

\subsubsection{Biological applications of fluorescence anisotropy}

The primary studies using fluorescence anisotropy in biological systems have been performed to study lipid domain formation in 1974 ending in detailed analysis of the lipid rafts in 2001 (Fung and Stryer, 1978, Gidwani et al., 2001). Anisotropy was also used to 
identify binding sites of DNA binding proteins (Bauman and Fayer, 1986, Li et al., 2008) and to study protein-protein interaction. In recent times fluorescence anisotropy was used as a non invasive method to find binding partners in living cells (Tramier et al., 2008). In this thesis, I use fluorescence anisotropy similarly to detect conformational states of a protein. The anisotropy of fluorophores that undergo homo-FRET is significantly lower than the emission of those not affecting homo-FRET. Exciting a fluorophore tagged to a protein we can distinguish between monomeric states of the protein compared to homodimeric and oligomeric states of the protein. As fluorescence anisotropy is a noninvasive method it can be performed for detection in living animals. 


\section{AIMS OF THIS THESIS}

The fast anterograde monomeric kinesin-3 motor UNC-104 is crucial for synaptic vesicle transport in neurons. In the past decade, the processivity and velocity of UNC-104 have been well documented mainly in reconstituted transport assays in vitro. However, a puzzling discrepancy between in vivo and in vitro results emerged: in vivo kinesin UNC104 appears to be a fast motor, in vitro the motor appears non-processive with biaseddiffusional motion behaviour on a single molecule level. This lead to hypothesize that in vivo kinesin-3 motors may not act as single, monomeric motors but rather engage in an ensemble activity or achieve transport competence by a facilitated dimerization when bound to cargo membranes. In addition, the conformational state of UNC-104 during active (+)-directed motion in living organisms is still under debate. Aim of this thesis is to analyze the biophysical properties of UNC-104 in vivo with respect to its conformational states. Specifically I will investigate whether an accumulation of monomeric UNC-104 motors in the cleft between microtubule and transport vesicle is sufficient to generate fast transport velocities (Fig A1 A) or whether it is necessary for UNC-104 to form homodimers (Fig A1 B)?

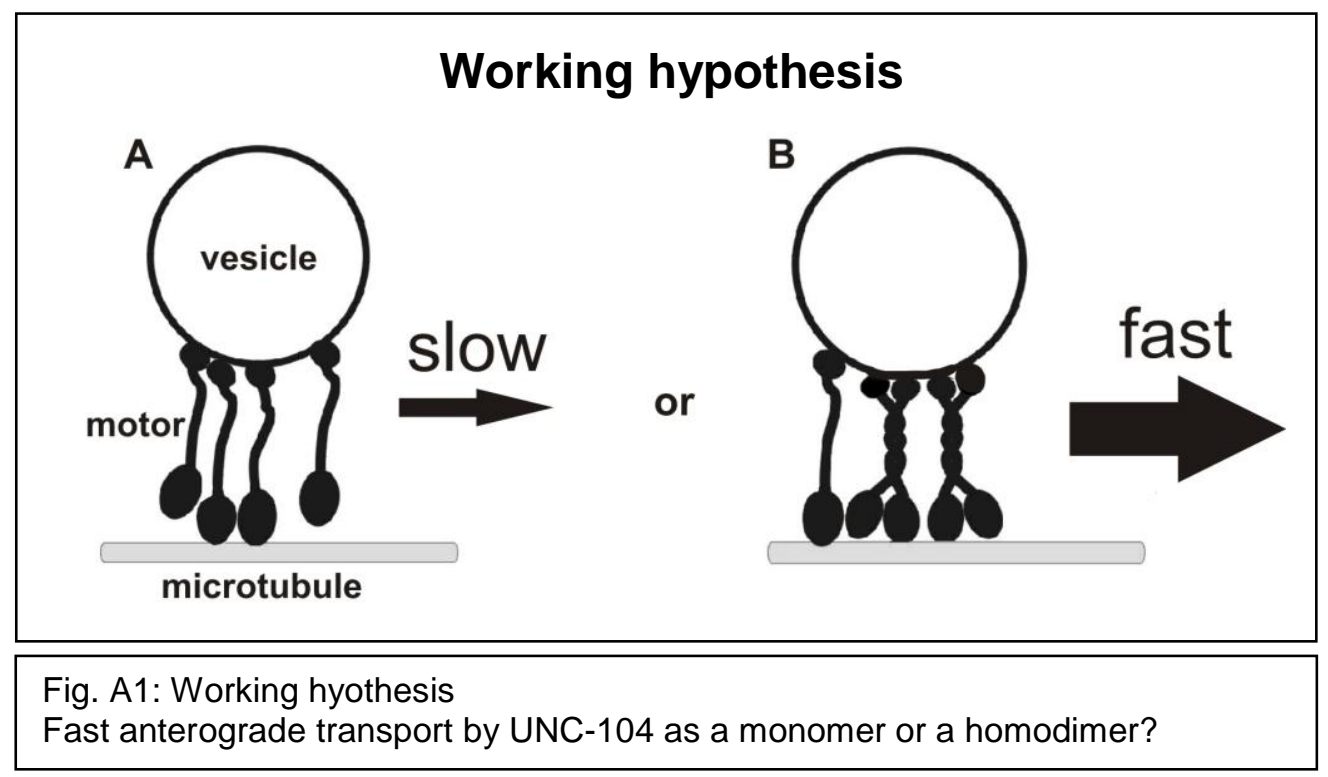

To address this question, I develop and test a novel combination of fluorescence anisotropy and spinning disc confocal microscopy to detect conformational states in vivo. Furthermore, I investigate the relationship between motor conformations and transport properties, analyzing the rescue potential of mutant motors in vivo in the model organism C. elegans. For an appropriate comprehensive comparison, in vivo findings are validated using single and multiple motor transport assays and chemical cross linking in vitro. The results of this thesis aim for a better understanding of kinesin-3 motor properties and mechanism under physiological conditions. 


\section{Materials Und Methods}

\subsection{Organisms}

\subsubsection{C. elegans}

The nematode is a small, transparent and genetically tractable worm well suited for analysis of neurological questions by fluorescence microscopy. With its well defined body movement and behaviour, innervation anomalies of motoneurons can be screened visually as many neuronal defects such as axon guidance defects, vesicle transport aberrancies and impaired synaptic vesicle recycling result in uncoordinated movement. Phenotypic rescue experiments by generation of transgenic animals allow to investigate the structure/function relationships of domains necessary for fast motor and cargo motility. As the cell lineage of all hermaphrodite's 959 cells (302 are neurons) is invariable and the neuronal connectivity has been mapped, individual subsets of neurons can be compared between animals for motor expression and transport activity. The combination of these parameters makes $C$. elegans an extremely suitable model for addressing questions regarding axonal transport.

\subsubsection{Maintenance}

Nematodes are grown on nematode growth medium (NGM) plates seeded with streptomycin resistant E. coli OP50-1 at RT (Brenner, 1974). Before worms are transferred, agar plates need to be dried for $24 \mathrm{~h}$ at RT. After inoculation plates are incubated at least $24 \mathrm{~h}$ at RT before any transfer of the worms is performed, to ensure a proper bacterial lawn and therefore a long term food source for the nematodes. The nematodes are grown on these plates at $15^{\circ} \mathrm{C}$ in an incubator. When food resource is consumed 5-20 worms at different stages are transferred (chunked) to a new plate with food supply.

$\begin{array}{ll}\mathrm{NGM} \text { (1 I volume for plates) } & \\ \mathrm{NaCl} & 3.0 \mathrm{~g} \\ \text { agar agar } & 17.0 \mathrm{~g} \\ \text { peptone } & 2.5 \mathrm{~g} \\ \mathrm{dH}_{2} \mathrm{O} & \text { ad. } 975 \mathrm{~m} \\ \text { autoclaving procedure } & \\ \mathrm{cool} \text { flask to } 55^{\circ} \mathrm{C} \text { in a water bath } & \\ \mathrm{CaCl}_{2} 1 \mathrm{M} \mathrm{(sol)} & 1.0 \mathrm{ml} \\ \text { cholesterol } 5 \mathrm{mg} / \mathrm{ml} \text { in ethanol (sol) } & 1.0 \mathrm{ml} \\ \mathrm{MgSO}_{4} 1 \mathrm{M}(\mathrm{sol}) & 1.0 \mathrm{ml}\end{array}$

$\begin{array}{ll}\text { nystatin } 50 \mathrm{mg} / \mathrm{ml}(\mathrm{sol}) & 1.0 \mathrm{ml} \\ \text { streptomycin } 25 \mathrm{mg} / \mathrm{ml}(\mathrm{sol}) & 1.0 \mathrm{ml} \\ \mathrm{KH}_{2} \mathrm{PO}_{4} \text { buffer. } 1 \mathrm{M}(\mathrm{sol}) & 25.0 \mathrm{ml}\end{array}$

$\mathrm{CaCl}_{2} 1 \mathrm{M}$

$\mathrm{CaCl}_{2} \cdot 2 \times \mathrm{H}_{2} \mathrm{O} \quad 147.0 \mathrm{~g}$

$\mathrm{dH}_{2} \mathrm{O}$ ad 1.0 I

sterile filtering procedure $(0.22 \mu \mathrm{m})$ 


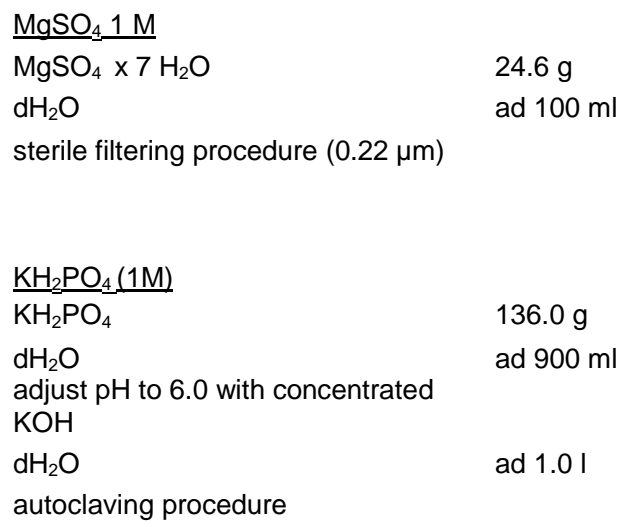

cholesterol $5 \mathrm{mg} / \mathrm{ml}$ (12.9 mM)

cholesterol

$0.5 \mathrm{~g}$

ethanol

ad $100 \mathrm{ml}$

nystatin $(50 \mathrm{mg} / \mathrm{ml})$

nystatin

$2.5 \mathrm{~g}$

DMSO

streptomycin $(25 \mathrm{mg} / \mathrm{ml})$

streptomycin $\quad 1.25 \mathrm{~g}$

$\mathrm{dH}_{2} \mathrm{O}$

\subsubsection{Harvesting}

Nematodes are grown on a $\varnothing=9 \mathrm{~cm}$ plate until the plates are crowded or show a suitable amount of adult and egg bearing worms. The nematodes are washed down with $10 \mathrm{ml}$ M9. This washing step is repeated with $5 \mathrm{ml} \mathrm{M9}$ to increase the yield. The worm suspension is spun down at $800 \mathrm{rpm}$ and worms are washed with the same volume of M9. This procedure is repeated 3-4 times until the supernatant appears clear, indicating a minimum contamination with bacteria and bacterial debris.

\begin{tabular}{|c|c|c|c|c|c|}
\hline M9 $\left(-\mathrm{MgSO}_{4}\right) 10 \mathrm{x}$ & & & M9 1x & & \\
\hline $\mathrm{Na}_{2} \mathrm{HPO}_{4}$ & $60.0 \mathrm{~g}$ & $422.6 \mathrm{mM}$ & $\mathrm{M} 9\left(-\mathrm{MgSO}_{4}\right) 10 x(\mathrm{sol})$ & $100 \mathrm{ml}$ & \\
\hline $\mathrm{KH}_{2} \mathrm{PO}_{4}$ & $30.0 \mathrm{~g}$ & $402.4 \mathrm{mM}$ & $\mathrm{dH}_{2} \mathrm{O}$ & ad $1.0 \mathrm{I}$ & \\
\hline $\mathrm{NaCl}$ & $50.0 \mathrm{~g}$ & $918.4 \mathrm{mM}$ & autoclaving procedure & & \\
\hline $\mathrm{dH}_{2} \mathrm{O}$ & ad $1.0 \mathrm{I}$ & & $\mathrm{MgSO}_{4} 1 \mathrm{M}(\mathrm{sol})$ & $1.0 \mathrm{ml}$ & $1.0 \mathrm{mM}$ \\
\hline $\mathrm{MgSO}_{4} 1 \mathrm{M}$ & & & & & \\
\hline $\begin{array}{l}\mathrm{MgSO}_{4} \cdot \times 7 \mathrm{H}_{2} \mathrm{O} \\
\mathrm{dH}_{2} \mathrm{O} \\
\text { sterile filtering procedure }(0.22 \mu \mathrm{m})\end{array}$ & $\begin{array}{l}24.6 \mathrm{~g} \\
\text { ad } 100 \mathrm{ml}\end{array}$ & $1.0 \mathrm{M}$ & & & \\
\hline
\end{tabular}

\subsubsection{Synchronization}

Synchronization is necessary if experimental procedure requires a defined age of the worms. During this procedure, adult and larval worms die and only the eggs survive, as their chitinic shells resist the chemicals. Eggs are purified and hatched worms have almost the same state of development (+/- 4 hours). Synchronization can also be performed to clean worm strains from bacterial contaminations.

Worms are harvested and an equivalent volume of Worm Bleaching Solution is added to the pellet and the mixture is harshly shaken until adult worms start to dissolve (check under binocular). The tube is spun in a table top centrifuge for 30 seconds at 
$1300 \times \mathrm{g}$ to pellet released eggs. The supernatant is discarded and the very small pellet is washed 3 times with M9. It is suitable to replace the tubes with sterile ones at every step. The pellet is solved in $8 \mathrm{ml} \mathrm{M9}$ plus an antibiotic (ampicilin, $100 \mathrm{ng} / \mathrm{ml}$ ) and transferred into a new $15 \mathrm{ml}$ tube. After incubation over night at RT while gently shaking the now hatched larvae are spun down for $2 \mathrm{~min}$ at $1300 \times \mathrm{g}$ and the pellet is distributed to several freshly prepared bacteria plates.

\begin{tabular}{|c|c|c|c|c|c|}
\hline Worm Bleaching Solution & & & M9 1x & & \\
\hline $\mathrm{NaOH} 5.0 \mathrm{M}$ & $1.0 \mathrm{ml}$ & & $\overline{\mathrm{M} 9}\left(-\mathrm{MgSO}_{4}\right) 10 \times(\mathrm{sol})$ & $100 \mathrm{ml}$ & \\
\hline sodium hypochloride solution $12 \%$ & $3.0 \mathrm{ml}$ & & $\mathrm{dH}_{2} \mathrm{O}$ & ad $1.0 \mathrm{I}$ & \\
\hline $\mathrm{dH}_{2} \mathrm{O}$ & $2.0 \mathrm{ml}$ & & autoclaving procedure & & \\
\hline & & & $\mathrm{MgSO}_{4} 1 \mathrm{M}(\mathrm{sol})$ & $1.0 \mathrm{ml}$ & \\
\hline $\mathrm{M} 9\left(-\mathrm{MgSO}_{4}\right) 10 \mathrm{x}$ & & & ampicillin $(100 \mathrm{mM} / \mathrm{ml}$, & $00 x)$ & \\
\hline $\mathrm{Na}_{2} \mathrm{HPO}_{4}$ & $60.0 \mathrm{~g}$ & $422.6 \mathrm{mM}$ & ampicillin (Na-salt) & $\overrightarrow{5.0 \mathrm{~g}}$ & $269 \mathrm{mM}$ \\
\hline $\mathrm{KH}_{2} \mathrm{PO}_{4}$ & $30.0 \mathrm{~g}$ & $402.4 \mathrm{mM}$ & $\mathrm{dH}_{2} \mathrm{O}$ & ad $50 \mathrm{ml}$ & \\
\hline $\mathrm{NaCl}$ & $50.0 \mathrm{~g}$ & $918.4 \mathrm{mM}$ & & & \\
\hline $\mathrm{dH}_{2} \mathrm{O}$ & ad $1.0 \mathrm{I}$ & & & & \\
\hline $\mathrm{MgSO}_{4} 1.0 \mathrm{M}$ & & & & & \\
\hline $\mathrm{MgSO}_{4}\left(\times 7 \mathrm{H}_{2} \mathrm{O}\right)$ & $24.6 \mathrm{~g}$ & $1.0 \mathrm{M}$ & & & \\
\hline $\mathrm{dH}_{2} \mathrm{O}$ & ad $100 \mathrm{ml}$ & & & & \\
\hline sterile filtering procedure $(0.22 \mu \mathrm{m})$ & & & & & \\
\hline
\end{tabular}

\subsubsection{Worm preparation for Western blotting}

50 or 80 gravid adult worms are transferred to a tube containing $15 \mu \mathrm{l}$ of Nematode Solubilization buffer. Directly after transfer the worm containing solution is mixed 100 times with a pipette using a yellow tip (with the set volume of $10 \mu \mathrm{l}$ ) and the tube is instantly frozen in liquid nitrogen. The solution now can be stored at $-80{ }^{\circ} \mathrm{C}$ for later procedures or used instantly. The frozen solution is thawed in a PCR machine $1 \mathrm{~min}$ at $95^{\circ} \mathrm{C}$ and the solution is spun for $1 \mathrm{~min}$ in a table centrifuge at highest speed. After this procedure it is mixed 100 times a pipette using a yellow tip continued with an additional mixture 100 times with a pipette using a white tip (both with the set volume of $10 \mu \mathrm{l}$ ). After this procedure $10 \mu \mathrm{l}$ of $2 x$ Lämmli buffer is added. The mixture is again boiled in a PCR machine for 2 minutes at $95^{\circ} \mathrm{C}$ and the solution is spun for $1 \mathrm{~min}$ in a table centrifuge at highest speed. Next, solution is mixed 100 times with a pipette using a white tip with a set volume of $10 \mu \mathrm{l}$ and spun down for $1 \mathrm{~min}$ in a table centrifuge at highest speed. The solution is now ready for SDS-PAGE. 


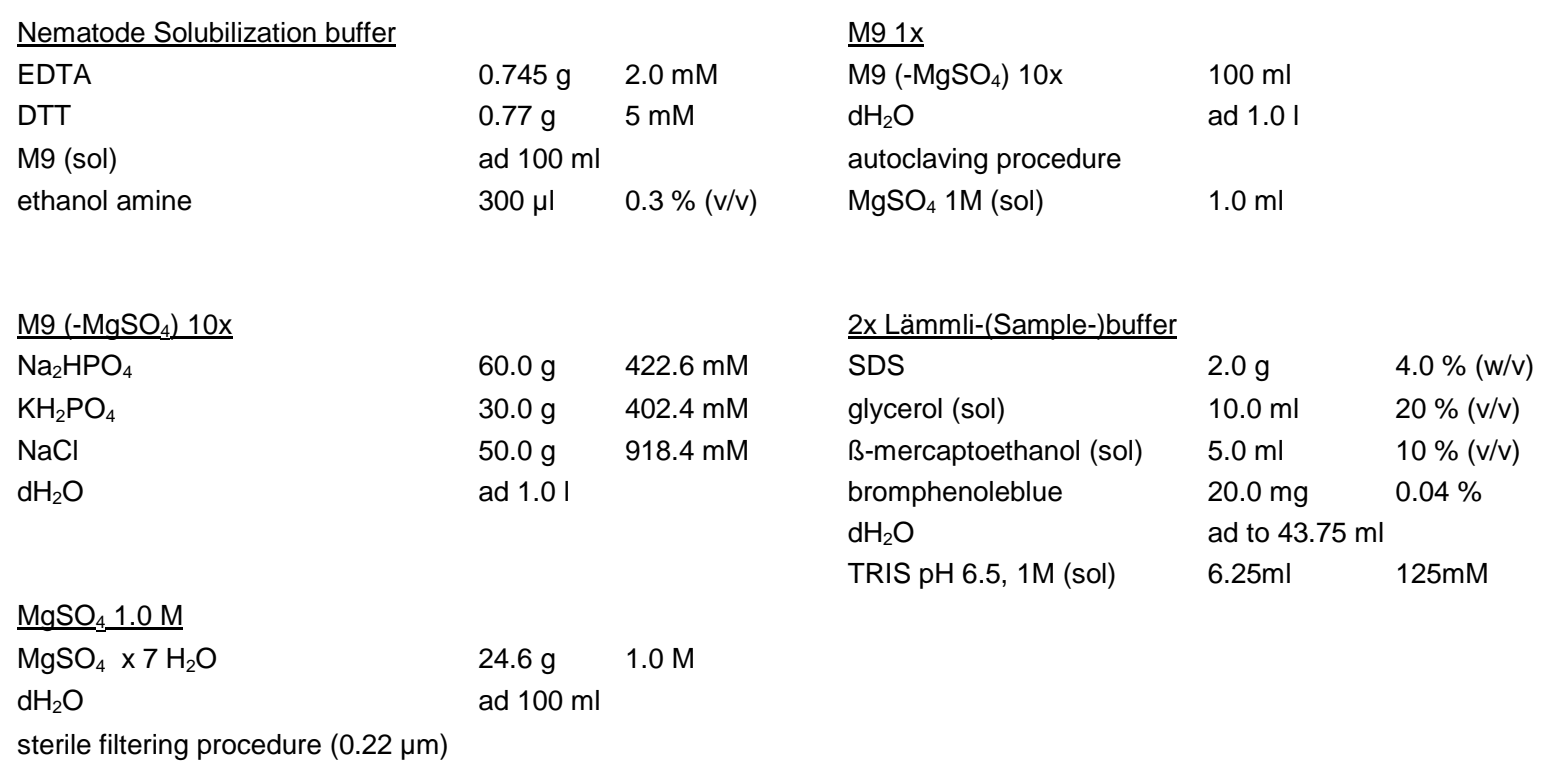

\subsubsection{Preparation of cryostock cultures}

For long time storage, nematodes are grown until there are both lot of egg bearing worms and additionally worms in dauer stage are represented on the plate. Worms are harvested, the pellet is mixed with an equivalent volume of Worm Freezing Medium and gently frozen to $-80^{\circ} \mathrm{C}$ in a freezing container containing isopropanol.

Worm Freezing Medium

$\mathrm{NaCl} 1.0 \mathrm{M}$ (sol)

$\mathrm{KH}_{2} \mathrm{PO}_{4} 1.0 \mathrm{M} \mathrm{pH} 6.0$ (sol)

glycerol $100 \%$ (sol)

$\mathrm{dH}_{2} \mathrm{O}$

autoclaving procedure

$\mathrm{MgSO}_{4} 1.0 \mathrm{M}$ (sol)

$\underline{\mathrm{MgSO}}_{4}(1.0 \mathrm{M})$

$\mathrm{MgSO}_{4} \times 7 \mathrm{H}_{2} \mathrm{O}$

$\mathrm{dH}_{2} \mathrm{O}$

$20 \mathrm{ml}$
$10 \mathrm{ml}$
$60 \mathrm{ml}$
ad $200 \mathrm{ml}$
$60 \mu \mathrm{l}$

$24.6 \mathrm{~g}$

ad $100 \mathrm{ml}$
$\mathrm{KH}_{2} \underline{P O}_{4}(1.0 \mathrm{M})$

$\mathrm{KH}_{2} \mathrm{PO}_{4} \quad 136.0 \mathrm{~g}$

$\mathrm{dH}_{2} \mathrm{O} \quad$ ad $900 \mathrm{ml}$

adjust $\mathrm{pH}$ to 6.0 with concentrated $\mathrm{KOH}$

$\mathrm{dH}_{2} \mathrm{O} \quad$ ad $1.0 \mathrm{~L}$

autoclaving procedure

$\underline{\mathrm{NaCl}(1.0 \mathrm{M})}$

$\mathrm{NaCl}$

$58,44 \mathrm{~g} \quad 1.0 \mathrm{M}$

$\mathrm{dH}_{2} \mathrm{O}$

ad $1.0 \mathrm{~L}$ 


\subsubsection{Worm manipulation}

To create transgenic nematodes, expression vectors are microinjected in the gonad of young adults as described (Mello et al., 1991). Foreign DNA is randomly taken up in oocytes and accumulates as an extra chromosomal array in the nucleus. This extra chromosomal array is replicated like the original genomic DNA and can be passed to every cell of the developing animal and to the progenies. This effect ensures a stable expression of target proteins within the whole strain and also ensures reproducible conditions for scientific experiments. Using appropriate promoters, the fusion protein of choice can be specifically expressed in a special tissue or a subset of cells. In some cases a coinjection marker is needed for easy identification of transgenic animals. The UNC-104 constructs in this thesis do not need any coinjection marker as the UNC-104 transgenic worms express a GFP fusion protein making transgenic animals easy to identify by excitation of the GFP with $\lambda=491 \mathrm{~nm}$.

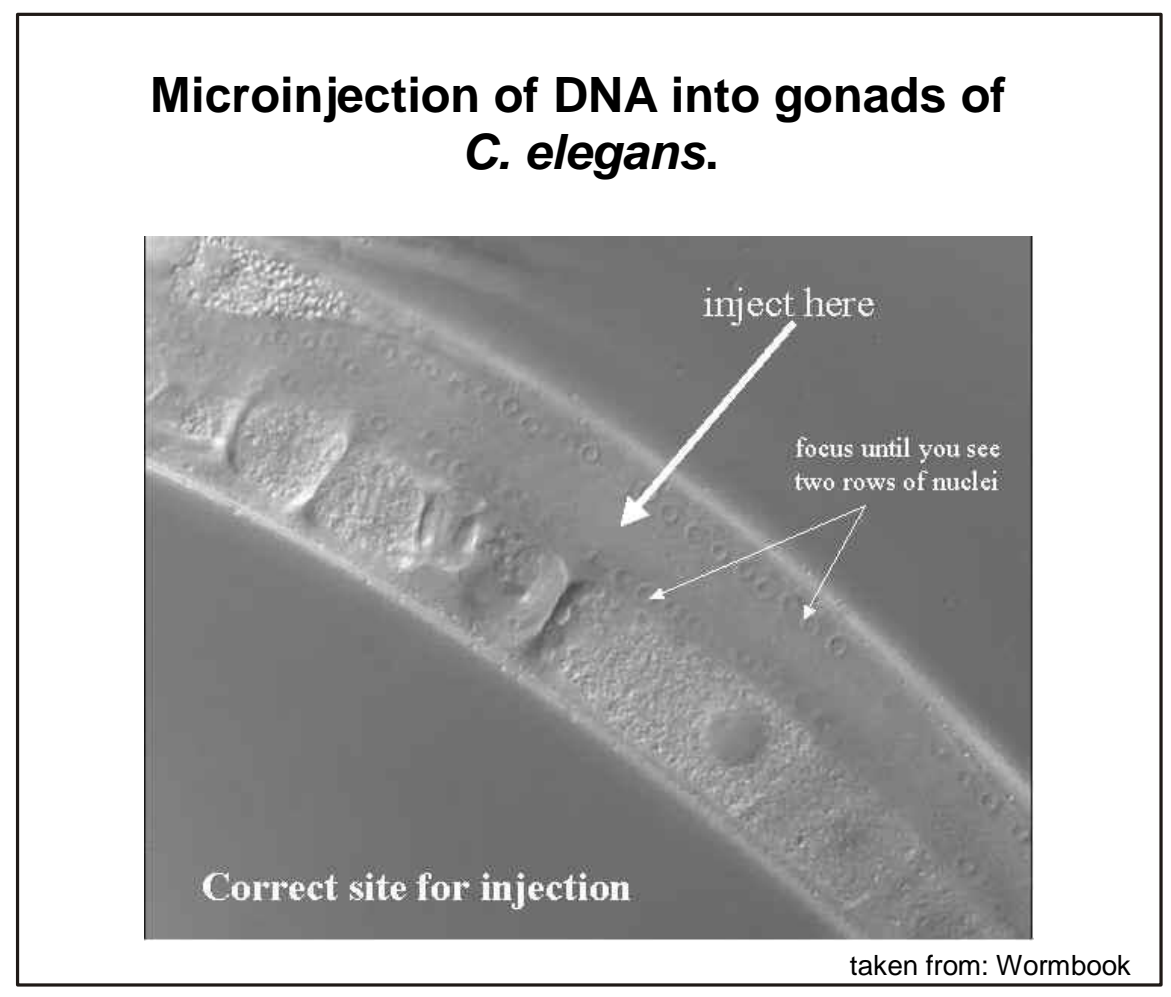

Fig.M1: Microinjection of DNA into gonads of $C$. elegans

\section{Preparation of the injection slides}

$80 \mu \mathrm{l}$ of a $4 \%(\mathrm{v} / \mathrm{w})$ agarose solution in water is heated to $80^{\circ} \mathrm{C}$ and placed in the middle of a glass slide. During cool-down a cover slip is pressed with low pressure on the agarose drop forming a thin layer of about $1.5 \mathrm{~cm}$ in diameter. After $20 \mathrm{~min}$ at RT the cover slip is removed and the agarose pad is dried over night at RT. 


\section{Preparation of the DNA}

DNA for microinjection is diluted to the designated concentration with M9 to an end volume of $10 \mu \mathrm{l}$. To purify the DNA from any precipitations the solution is spun at highest speed for $30 \mathrm{~min}$ at $4{ }^{\circ} \mathrm{C}$. After a transfer to a new tube this procedure is repeated for another $10 \mathrm{~min}$.

\section{Preparation of the worms}

A drop of hydrocarbon oil is placed on a prepared agarose pad and single young adult worm is transferred into this drop. From now on the injection procedure has to be finished within 6-10 minutes unless the worm will die because of exsiccation.

\section{Injection and recovery}

The microinjection is done with a conventional microscope with a 40x objective (Olympus IX70), a transjector (Transjector 5246, Eppendorf) and a mechanic arm driven by Transferman NK2 (Eppendorf). As injection capillaries Femtotips ${ }^{\oplus}$ II (Eppendorf) with $0.5 \mu \mathrm{m}$ inner and $0.7 \mu \mathrm{m}$ outer diameter are used. $1-2 \mu \mathrm{l}$ of the DNA solution is injected into the gonads (Fig. M1). The injection is performed in unc-104(e1265) worm strain that has slightly deformed gonads. Therefore the visualization of the gonads and the correct injection site is not as easy as seen in the figure. The capillary tip is removed carefully and the worm is renaturated by a $20 \mu \mathrm{l}$ drop of M9 and transferred to a fresh NGM plate with bacteria with a platinum scoop.

\begin{tabular}{|c|c|c|c|c|}
\hline \multicolumn{3}{|l|}{$\underline{\mathrm{M} 9\left(-\mathrm{MgSO}_{4}\right) 10 \mathrm{x}}$} & \multicolumn{2}{|l|}{ M9 1x } \\
\hline $\mathrm{Na}_{2} \mathrm{HPO}_{4}$ & $60.0 \mathrm{~g}$ & $422.6 \mathrm{mM}$ & M9 (-MgSO $)_{4}{ }_{1} 10 x$ (sol) & $100 \mathrm{ml}$ \\
\hline $\mathrm{KH}_{2} \mathrm{PO}_{4}$ & $30.0 \mathrm{~g}$ & $402.4 \mathrm{mM}$ & $\mathrm{dH}_{2} \mathrm{O}$ & ad $1.0 \mathrm{I}$ \\
\hline $\mathrm{NaCl}$ & $50.0 \mathrm{~g}$ & $918.4 \mathrm{mM}$ & autoclaving procedure & \\
\hline $\mathrm{dH}_{2} \mathrm{O}$ & ad $1.0 \mathrm{I}$ & & $\mathrm{MgSO}_{4} 1 \mathrm{M}$ (sol) & $1.0 \mathrm{ml}$ \\
\hline
\end{tabular}

\subsubsection{Worm Strains}

The worm strains in this thesis are based on.

pPD 95.77, unc-104::UNC-104::GFP, extra chromosomal array, Scholey Lab, UC Davis pPD 105.62, rab3::unc-116::GFP, extra chromosomal array, Klopfenstein Lab gateway, rab3::GFP::unc-64, extra chromosomal array, Klopfenstein Lab gateway, rab3::GFP::TBA-1, extra chromosomal array, Klopfenstein Lab pPD 95.77, unc-104::UNC-104::GFP, extra chromosomal array, Klopfenstein Lab pPD 95.77, unc-104::UNC-104::1-1369 ( $\Delta \mathrm{PH})::$ GFP, extra chromosomal array,

Klopfenstein Lab

pPD 95.77, unc-104:: $\Delta 633-1368-U N C-104:: G F P$, extra chromosomal array, Klopfenstein Lab pPD 95.77, DP132, integrated array, Kang Shen Lab, Stanford, CA 


\subsubsection{Bacteria}

\subsubsection{Strains}

\section{E. coli DH5a}

This strain is optimized for amplification of plasmid DNA.

Genotype: F- p80lacZ $\Delta$ M15 $\Delta$ (lacZYA-argF)U169 deoR recA1 endA1 hsdR17(rk-, mk+) phoA supE44 thi-1 gyrA96 relA1 $\lambda$ (Invitrogen).

\section{E. coli Top10}

This strain is optimized for amplification of plasmid DNA and transformation of more critical and low yield constructs like mutagenesis products.

Genotype: F- mcrA $\Delta$ (mrr-hsdRMA-mcrBC) phi80lacZ $\Delta$ M15 $\Delta$ lacX74 recA1 araD139 $\Delta$ (araleu) 7697 galU galK rpsL (StrR) endA1 nupG, (Invitrogen).

\section{E. coli XL 10 gold}

This strain is optimized for high copy amplification of plasmid DNA with high competence. They are similar to the Top10 and have been replaced by this strain during the thesis.

Genotype: endA1 glnV44 recA1 thi-1 gyrA96 relA1 lac Hte $\Delta$ (mcrA)183 $\Delta$ (mcrCBhsdSMR-mrr) 173 tet $^{R} F^{\prime}\left[\right.$ proAB lacl ${ }^{q} Z \Delta M 15 \operatorname{Tn}^{2} 0\left(\right.$ Tet $^{R}$ Amy $\left.\left.\mathrm{Cm}^{\mathrm{R}}\right)\right]$, (Stratagene).

\section{E. coli OP50-1}

The OP50 strain is a supplier of nutrients for $C$. elegans. All worm strains are fed with this strain during development and maintenance. This strain has a streptomycin resistance.

Genotype: E. coli, B, uracil auxotroph, streptomycin resistant (Caenorhabditis Genetics Center, University of Minnesota, U.S.A. (CGC)).

\section{E. coli BL21 gold (DE3)}

BL21 gold (DE3) cells are optimized for protein expression. The cells are modified to electrical competent cells using standard protocols.

Genotype: E. coli B F- dcm + Hte ompT hsdS $\left(r_{B^{-}}-m_{B^{-}}\right)$gal $\lambda(D E 3)$ endA Tet $^{r}$, (Stratagene)

\subsubsection{Maintenance}

There are two different states of maintenance for bacteria, the culturing on agar plates and the culturing in liquid media, respectively. 


\section{Agar plate culture}

E. coli strains are grown at $37^{\circ} \mathrm{C}$ on lysogeny broth (LB) plates (Bertani, 1951) or super optimal broth (SOB) Plates (Hanahan, 1983), dependent on the strain and the transformed vectors appropriate antibiotics are added.

Liquid culture

Liquid bacteria cultures were grown in SOB medium or LB medium at $37^{\circ} \mathrm{C}$ and $180 \mathrm{rpm}$ with appropriate antibiotics.

For long term storage, $400 \mu \mathrm{l}$ of an overnight liquid culture were mixed with $600 \mu \mathrm{l}$ of a 1:1 $(\mathrm{v} / \mathrm{v})$ solution of LB liquid medium and glycerol and stored at $-80^{\circ} \mathrm{C}$.

\begin{tabular}{|c|c|c|c|c|c|}
\hline \multicolumn{3}{|c|}{ LB Medium (Luria-Bertani Medium) } & \multicolumn{3}{|l|}{$\underline{\text { SOB medium }}$} \\
\hline tryptone & $10.0 \mathrm{~g}$ & $1.0 \%(w / v)$ & tryptone & $20.0 \mathrm{~g}$ & $2.0 \%(w / v)$ \\
\hline yeast extract & $5.0 \mathrm{~g}$ & $0.5 \%(w / v)$ & yeast extract & $5.0 \mathrm{~g}$ & $0.5 \%(w / v)$ \\
\hline \multirow{6}{*}{$\begin{array}{l}\mathrm{NaCl} \\
\mathrm{dH}_{2} \mathrm{O} \\
\text { autoclaving procedure }\end{array}$} & $5.0 \mathrm{~g}$ & $92 \mathrm{mM}$ & $\mathrm{NaCl}$ & $0.54 \mathrm{~g}$ & $10 \mathrm{mM}$ \\
\hline & ad to $1.0 \mathrm{I}$ & & $\mathrm{KCl}$ & $186.0 \mathrm{mg}$ & $2.5 \mathrm{mM}$ \\
\hline & & & $\mathrm{dH}_{2} \mathrm{O}$ & & ad to $1.0 \mathrm{I}$ \\
\hline & & & autoclaving procedure & & \\
\hline & & & $\mathrm{MgCl}_{2}$ (water free) & $1.9 \mathrm{~g}$ & $20 \mathrm{mM}$ \\
\hline & & & glucose & $4.0 \mathrm{~g}$ & $0.4 \%(w / v)$ \\
\hline
\end{tabular}

\subsubsection{Transformation}

Transformation is the internalization of DNA into bacteria e.g. by chemical or electrical transformation. During chemical transformation the DNA attaches to the bacteria cell wall and a following heat shock activates mechanisms leading to the uptake of the DNA. During electrical transformation electrical pulse reversibly perforates the cell wall of the bacteria, permitting the DNA to get into the bacteria`s cytoplasm. Both processes damage the cell membranes requiring a renaturation and dividing phase at proper growing conditions.

\section{Chemically transformation}

$50 \mu$ bacteria suspension E. coli $\mathrm{DH} 5 \alpha$ or $25 \mu$ suspension E. coli Top10, E. coli XL 10 gold, respectively are thawed on ice and gently mixed with $100 \mathrm{ng}$ target DNA. After an incubation of $30 \mathrm{~min}$ on ice the tube is rapidly heated to $42{ }^{\circ} \mathrm{C}$ and incubated for 45 seconds at this temperature. After a 2 min cooling step on ice $300 \mu \mathrm{l}$ SOC medium is added, followed by 60 min incubation at $37^{\circ} \mathrm{C}$ with slight shaking. After this procedure the suspension is dispensed on an LB-agar plate with the suitable antibiotics. For transformation of constructs in pPD 95.77 vector (see below), the renaturation step was increased to $120 \mathrm{~min}$ at $30^{\circ} \mathrm{C}$. 


\section{Transformation by electroporation}

$50 \mu \mathrm{l}$ of the electrical competent E. coli BL21 gold (DE3), kept on ice are mixed with $20 \mu \mathrm{l}$ $\mathrm{dH}_{2} \mathrm{O}\left(4^{\circ} \mathrm{C}\right)$ and $100 \mathrm{ng}$ of ice cold target DNA solution. The mixture is transferred to single packed and sterile electrical cuvettes for electroporation (2 mm, Bio-Rad Gene Pulser $^{\circledR}$ ) and pulsed with the MicroPulser ${ }^{\circledR}$ (Bio-Rad) according manufacturers protocol. The renaturation is performed identical to chemically competent cells.

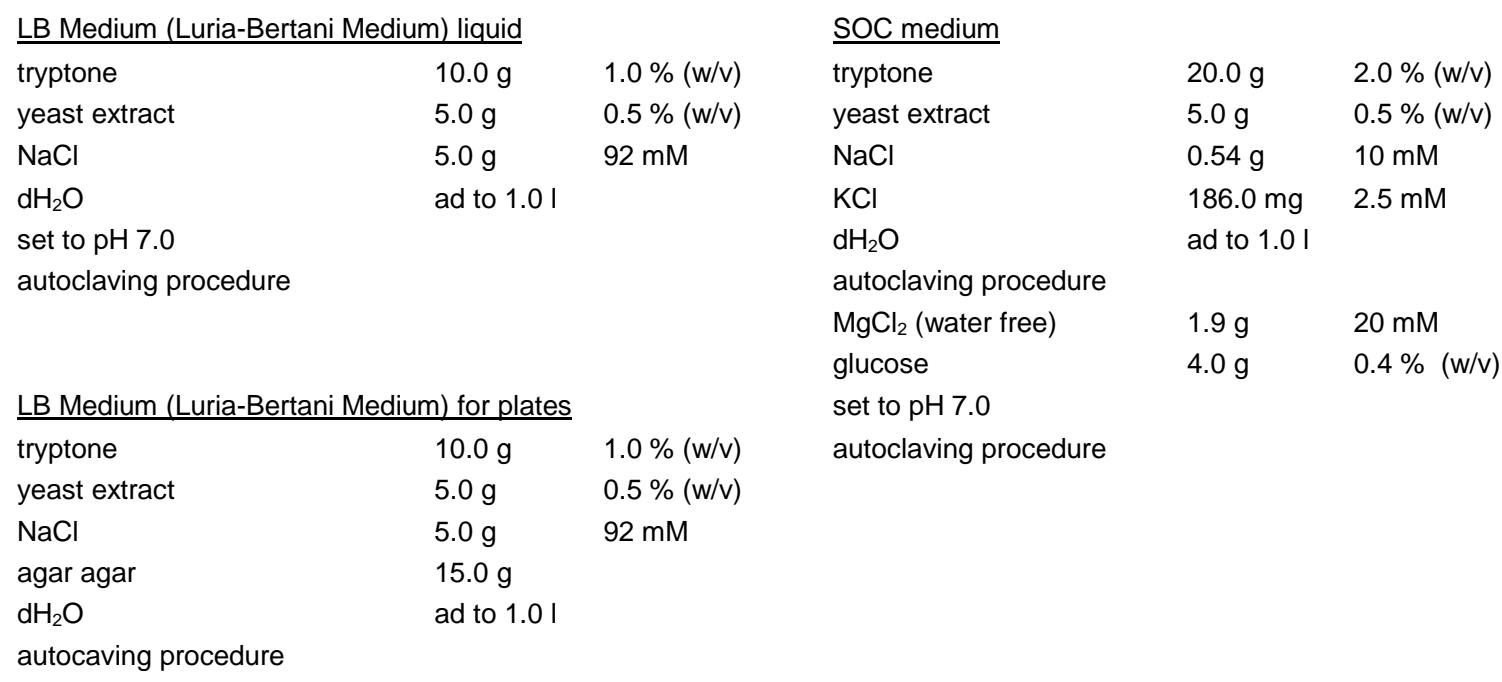

\subsubsection{Worm characterization assays}

\subsubsection{Determination of turns}

The determination of turns is a method to analyze and quantify worm movement behaviour with respect to uncoordinated movement of the worm. 6 adult worms are transferred to 2 inoculated plates incubated at RT for 5 minutes. Traces of the worms are monitored and crawlen distance is determined and changes in directions $>40^{\circ}$ angle are counted. The area of $1 \mathrm{~cm}^{2}$ around the place of transfer is negated in this experiment.

\subsubsection{Motility assay}

The motility assay is another method to quantify the motility of worms for appraising proper innervation of the worm's body wall muscles. 9-15 adult worms are transferred to 3 to 5 inoculated plates and incubated at RT for 5-10 minutes. Because of the low density and the undamaged bacterial lawn the traces can easily be identified and quantified. For each worm the body bends per minute are counted. One body bend is defined as one full sine curve (one wave length). All worms were monitored for 5-7 minutes. 


\subsubsection{Egg laying Assay}

The egg laying assay is a method to draw conclusions about the enervation of the vulva muscles. Impaired enervation result in delays of egg laying behaviour and the accumulation of unlaid eggs in the worm ("bag of eggs"). Worms are synchronized and grown on fresh plates until third larva state. Five times 7-17 worms per strain are transferred to fresh plates and the number of laid eggs is counted every 2 hours for a period of 12 hours, beginning with the first lawn egg.

\subsection{Methods in molecular biology}

\subsubsection{Vectors}

Three different set of vectors are used in this work.

pBluescript (Stratagene) a small and rudimentary vector for intermediate mutagenesis steps and cloning

pPD 95.77 for efficient protein expression in C. elegans (provided from Fire lab) pET17b (Novagen) for high-yield inducible expression of proteins in E. coli The detailed vector maps can be found in the appendix.

\subsubsection{Plasmid isolation}

E. coli DH5a cells carrying the appropriate plasmid are inoculated with 4-8 ml LB medium containing suitable antibiotics, and cultured over night at $37^{\circ} \mathrm{C}$ with agitation at $280 \mathrm{rpm}$. The culture is precipitated by centrifugation at $4000 \mathrm{rpm}$ for $5 \mathrm{~min}$ at $4{ }^{\circ} \mathrm{C}$. For $E$. coli cultures bearing the pPD 95.77 vector the temperature during incubation was set to $30^{\circ} \mathrm{C}$. The purification of the pBluescript and pET17b plasmid-DNA is performed using NucleoSpin ${ }^{\circledR}$ Plasmid Kits (Macherey\&Nagel) according to the manufacturers manual. This system is based on alkaline lysis of bacteria followed by an acidic precipitation of protein components and DNA. Instead of using the manufacturer's elution buffer $10 \mathrm{mM}$ Tris set to $\mathrm{pH} 8.2$ with $\mathrm{HCl}$ is used for the elution of DNA.

Plasmid-DNA of pPD 95.77 is purified using the Wizard ${ }^{\circledR}$ PlusSV Miniprep Kit (Promega) as this kit ensures higher yield for plasmids over $12 \mathrm{kbp}$. The plasmid purification is performed according to the manufacturer's protocol. Instead of using the 
manufacturer's elution buffer $10 \mathrm{mM}$ Tris- $\mathrm{HCl}, \mathrm{pH} 8.2$ is used. The buffer is set to $72{ }^{\circ} \mathrm{C}$ before final incubation of the column.

\begin{tabular}{lll} 
Elution buffer: & \\
\hline TRIS & $0.012 \mathrm{~g}$ & $100 \mathrm{mM}$ \\
$\mathrm{dH}_{2} \mathrm{O}$ & ad $90 \mathrm{ml}$ & \\
adjust pH 8.2 with $\mathrm{HCl}$ & \\
$\mathrm{dH}_{2} \mathrm{O}$ & ad $100 \mathrm{ml}$ &
\end{tabular}

\subsubsection{Agarose gel electrophoresis}

The agarose gel electrophoresis is used for separation and size determination of DNA fragments or circular structures. In an electrical field DNA fragments move in agarose towards the anode according their size creating distinct bands. The bands are detected with ethidium bromide that intercalates in double stranded DNA and can be visualized under UV-light excitation. The intensity of the emitted light is proportional to the DNA present in the band.

The DNA samples are mixed with the according volume of 6x DNA-Loading buffer (Fermentas) and set in gels of $1,0 \%$ agarose dissolved in 1x TAE buffer with $0.001 \%$ ethidium bromide. The gel is run in the chamber system of BioRad, filled with TAE buffer at $125 \mathrm{~V}$ for $25 \mathrm{~min}$ (power supply system: Consort). As standarized size marker $1 \mathrm{~kb}$ ladder from Fermentas is used.

\begin{tabular}{|c|c|c|c|c|}
\hline \multicolumn{3}{|l|}{ TAE buffer $10 x$} & \multicolumn{2}{|l|}{ TAE buffer $1 \mathrm{x}$} \\
\hline TRIS & $48.4 \mathrm{~g}$ & $0.4 \mathrm{M}$ & TAE buffer $10 x$ & $100 \mathrm{ml}$ \\
\hline EDTA & $2.92 \mathrm{~g}$ & $10.0 \mathrm{mM}$ & $\mathrm{dH}_{2} \mathrm{O}$ & ad $1.0 \mathrm{I}$ \\
\hline $\mathrm{dH}_{2} \mathrm{O}$ & ad $900 \mathrm{ml}$ & & & \\
\hline adjust to $\mathrm{pH} 8.0$ with acetic acid & & & & \\
\hline \multirow[t]{2}{*}{$\mathrm{dH}_{2} \mathrm{O}$} & ad $1.0 \mathrm{I}$ & & \multicolumn{2}{|c|}{ ethidium bromide solution $1 \%(1000 x)$} \\
\hline & & & $\begin{array}{l}\text { ethidium bromide } \\
\mathrm{dH}_{2} \mathrm{O}\end{array}$ & $\begin{array}{l}200 \mathrm{mg} \\
\mathrm{ad} 20 \mathrm{~m}\end{array}$ \\
\hline
\end{tabular}

\subsubsection{Gel Extraction}

For further processing, distinct bands of DNA in the agarose gel electrophoresis are extracted from the gel. This is done by cutting out bands of interest by a scalpel, solubilization of the gel piece and purification of the DNA by a silica column.

The DNA is purified using the Wizard ${ }^{\circledR}$ SV Gel and PCR Clean-Up System (Promega) according to the manufacturer's protocol. Instead of using the manufacturer's elution buffer, self-made Elution buffer was used at a temperature of $72^{\circ} \mathrm{C}$. 
Elution buffer:

TRIS

$\mathrm{dH}_{2} \mathrm{O}$

adjust $\mathrm{PH} 8.2$ with $\mathrm{HCl}$
$0.012 \mathrm{~g} \quad 100 \mathrm{mM}$ ad $90 \mathrm{ml}$

\subsubsection{Cloning}

\subsubsection{Polymerase Chain Reaction (PCR)}

PCR is a very efficient method for in vitro amplification of DNA fragments by heat robust DNA polymerases. DNA double strands are revealed by heat purposes $\left(95^{\circ} \mathrm{C}\right)$. Annealing of primers can occur during a following cooling process. Primers are short oligonucleotides, complementary to the flanking areas of the target sequence that is to be amplified. In the following elongation phase the target sequence is copied started at the end of the primers at optimal temperature for polymerase activity. In general 20-30 cycles are used. Vent polymerase (NewEngland Biolabs), a high-fidelity polymerase with integral $3^{\prime} \rightarrow 5^{\prime}$ proofreading activity and the dNTP mix (Invitrogen) was used. The PCR procedure was performed according to the providers manual as long as there is no explicit exception. (See chapter "Constructs" below)

Thermocycler program Lid $-105^{\circ} \mathrm{C}$
1) $\quad 95^{\circ} \mathrm{C}-5 \mathrm{~min}$
2) $\quad 95^{\circ} \mathrm{C}-30 \mathrm{sec}$
3) $53^{\circ} \mathrm{C}-30 \mathrm{sec}$
4) $72^{\circ} \mathrm{C}-1$ min per $1000 \mathrm{bp}$
Repeat steps $2-4$ for 28 cycles
5) $72^{\circ} \mathrm{C}$
6) $\quad 4{ }^{\circ} \mathrm{C}$ - hold

\subsubsection{DNA-Restriction digest}

Restriction digests are performed for linearization of circular DNA. Restriction enzymes (restriction endonucleases) are able to cut double stranded DNA at specific basepair sequences with a length of 6-8 basepairs. Digests are performed at temperature of optimum enzyme activity. All restriction endonucleases in this thesis are provided by (NewEngland Biolabs). The digest itself is performed according the provider's protocols. The buffers for any double digests performed was chosen according suggestions of the Double digest Finder on NewEngland Biolab's Homepage 
(www.NEB.com/nebecomm/DoubleDigestCalculator.asp) All restriction endonucleases used are causing sticky ends, allowing uncomplicated ligation procedure.

\subsubsection{DNA Ligation}

DNA ligases are enzymes that recognize and repair single stranded discontinuities in double stranded DNA molecules. Using this property ligases are used for inserting target DNA into vectors. Both, target DNA and vectors, are cut with the same restriction endonuclease(s) allowing ligation after mixture. The products used in this thesis are the T4-Ligase (Invitrogen) and the DNA Ligation kit long 2.1 (Takara). Ligation reactions are performed according to the manufacturer's protocol unless mentioned below. In addition, pPD 95.77 plasmid constructs, are ligated with the Ligase long Kit with a plasmid/insert ratio of $1: 3$ and $1: 6$ and increased recovery time of $120 \mathrm{~min}$ at $30^{\circ} \mathrm{C}$. Clones are picked from both plates.

\subsubsection{Site directed mutagenesis}

Site directed mutagenesis is a special form of PCR in order to create gene mutations. In this method primers are used which contain defined mismatch(es) causing mutations flanked by complemetary regions. With these primers daughter-strands of circular DNA, bearing the mutation(s) can be amplified. The PCR results in a mixture of the amplified products bearing the mutation and template DNA without the mutation(s). As the template DNA is amplified in bacteria it is methylated. Dpnl, a restriction endonuclease, is recognizing and degrading methylated DNA so only mutated circular DNA remains in the reaction mixture after digest.

In this thesis the QuickChange ${ }^{\circledR}$ Site-Directed Mutagenesis kit (Stratagene) is used. The Pfu-polymerase (and its buffer) is exchanged to Vent polymerase (NewEngland Biolabs) (and its buffer), the Dpnl from Stratagene is exchanged to Dpnl from NewEngland Biolabs and the XL10-Gold from Stratagene are replaced to Top-10 (Invitrogen). Sometimes it is necessary to flank the mutation site in the primer by more than 20 bases (the manual advices maximum 15 bases). This is due to restrictions in GCcontent and therefore the melting temperature, necessary for a successful polymerization. The PCR-program using the Vent Polymerase is modified according the enzymes properties. In all cases Dpnl digest was increased to $90 \mathrm{~min}$ at $37^{\circ} \mathrm{C}$ and $10-15 \mu$ of the mixture was used for transformation. 


\subsubsection{DNA-Sequencing}

The DNA Sequencing is done "in house" or using the service of Invitrogen. When done in house it is performed with the BigDye ${ }^{\circledR}$ Terminator v3.1 Cycle Sequencing kit (ABI) using the following protocol (see below).

The solution is mixed and transferred to an unautoclaved $1.5 \mathrm{ml}$ tube and centrifuged at maximum speed for $30 \mathrm{~min}$ at $4{ }^{\circ} \mathrm{C}$. The supernatant is removed, the precipitate washed with $70 \%$ ethanol (in aqueous solution) and spun at maximum speed for $5 \mathrm{~min}$ at $4{ }^{\circ} \mathrm{C}$. After the supernatant is removed, the pellet is dried in a speed vac for 5 10 minutes and is solved in HiDi Dimethylformamide (ABI).

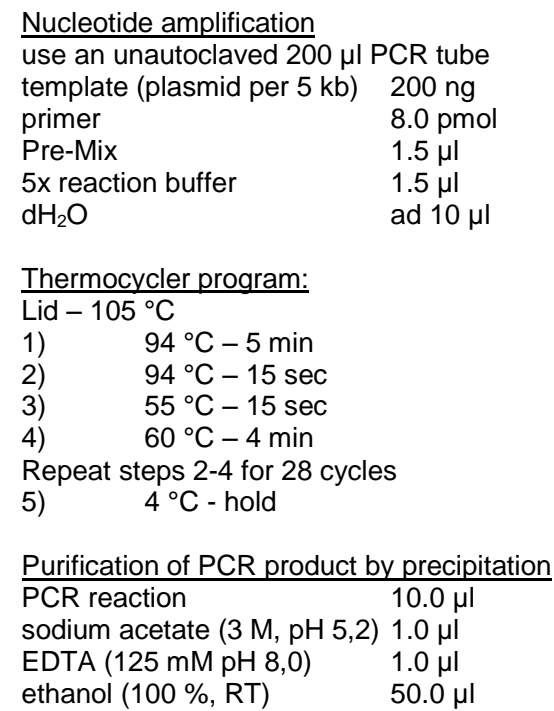

\subsubsection{Primers}

Primers are artificial single strands of deoxyribonucleic acid that serve as a starting point for DNA synthesis. It has to be distinguished between PCR primers, sequencing primers and mutagenesis primers.

PCR primers flank the sequence area that has to be amplified and contain a restricition enzyme site in the beginning.

Sequencing primers are shorter and complementary to a unique sequence 80-200 bp in front of the area of interest without any motifs.

Mutagenesis primers are very long and have designed mismatch area(s) causing point mutations in the expressing protein gene. They have to have a distinct GC-content and melting temperature. C. elegans prefers certain codons and therefore bares different amount of tRNA species (Riddle, 1997). This affects the efficiency of protein expression in 
the worm. For site directed mutagenesis we use the most common codons in $C$. elegans with respect to exchanged amino acid.

The entire list of primers can be found in the appendix 9.5

\subsubsection{Constructs}

\section{p-Bluescript $(\mathrm{K}+)$}

The vector with the insert of the UNC-104::GFP coiled-coil area, cloned with Dralll and Bsgl site, with its origin from cDNA is kindly provided by Mini Zhou, Scholey lab, UC DAVIS. Mutations are inserted by site directed mutagenesis and success is checked by sequence analysis. The mutated coiled-coil area fragments are cloned into the PPD 95.77.

\section{pPD 95.77}

This vector with the FL-UNC-104 under the endogenous promoter is provided by Dieter Klopfenstein. As pPD 95.77 is an expression vector designed for expression in C. elegans, the properties of the inserted DNA of the target protein are different from that of bacterial expression systems. Here, introns of the chromosomal DNA need to remain in the sequence, as expression efficiency is dramatically decreased using cDNA. All UNC-104 constructs bare the first six introns (compared to chromosomal sequence) to ensure efficient expression in the worm. The coiled-coil area is free of introns and can therefore be cloned by restriction and ligation.

As in this case the pPD 95.77 vector backbone (BB) is very large (16 kbp), an extraction of the BB with conventional gel extraction kits results in very low yields and high contamination of the product. Ligation using a high amount of digested BB followed by gel extraction and purification of the DNA by precipitation fails.

Finally, $2 \mu \mathrm{g}$ of the BB vector is digested twice as long with 2-3 fold enzyme units as recommended in the manual. After inactivation of the enzymes for $30 \mathrm{~min}$ at $65^{\circ} \mathrm{C}$, no gel extraction is performed. $2 \mu \mathrm{g}$ of insert bearing vector (pBluescript $(\mathrm{K}+)$ ) is digested, the insert was purified and the concentration is determined. The ligation reaction was performed with the Ligation Kit 2.1. (TaKaRa), according to the manual. Ratios of 1:3 (50 ng BB : 29 ng insert) and 1:6 (50 ng BB : 58 ng insert) are set with a total volume of $5 \mu \mathrm{l}$ plus $5 \mu \mathrm{l}$ ligation reaction mix. The reaction is done over night at $16{ }^{\circ} \mathrm{C}$. The transformation of TOP-10-Cells (Invitrogen) by heat shock is followed by a $2 \mathrm{~h}$ recovery time at $30{ }^{\circ} \mathrm{C}$ before the transfer to agar plates with the suitable antibiotics. 


\section{pET17b}

The vector with the UNC-104 1-446::GFP insert is provided by Dieter Klopfenstein. The constructs in this vector are manufactured identical to those in the pBluescript, using the same primers.

Following constructs of UNC-104 were cloned:

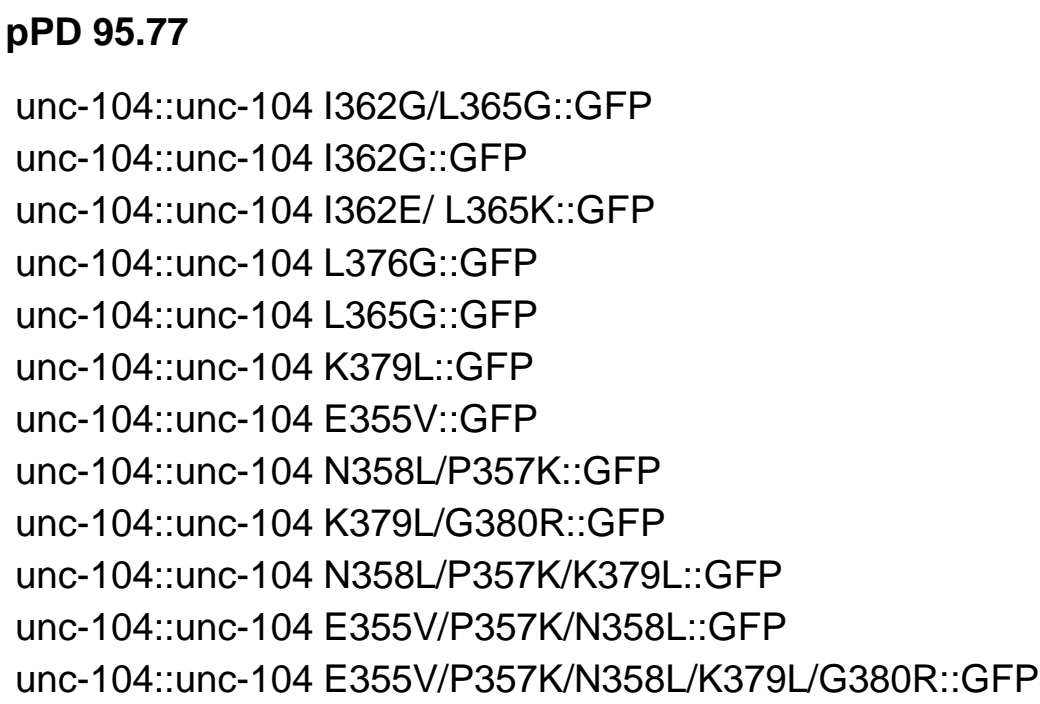

\section{pET17b}

unc-104 1-446 I362G/L365G::GFP

unc-104 1-446 I362G::GFP

unc-104 1-446 I362E/ L365K::GFP

unc-104 1-446 L376G::GFP

unc-104 1-446 L365G::GFP

unc-104 1-446 K379L::GFP

unc-104 1-446 E355V::GFP

unc-104 1-446 N358L/P357K::GFP

unc-104 1-446 K379L/G380R::GFP

unc-104 1-446 N358L/P357K/K379L::GFP

unc-104 1-446 E355V/P357K/N358L::GFP

unc-104 1-446 E355V/P357K/N358L/K379L/G380R::GFP

unc-104 1-446 N145K 


\subsection{Biochemical Methods}

\subsubsection{SDS PAGE}

Denaturating Sodium Dodecyl Sulfate PolyAcrylamide Gel Electrophoresis (SDS PAGE) is a commonly used method to separate proteins in polyacrylamid gels according their size. In this thesis, concentration of $10.0 \%$ for the analytical part of the gel is used. To increase acuity of the protein bands, a $4 \%$ collecting gel (loading gel) is set on top of the analytical gel. Partly prepared gels (10\% Bis-Tris) from Invitrogen are used. As hardware the Mini Trans-Blo ${ }^{\circledR}$ Electrophoretic Transfer system (Bio-Rad) is used.

\begin{tabular}{|c|c|}
\hline$\frac{\text { analytical gel }(10.0 \mathrm{ml}, \text { for two gels })}{\mathrm{H}_{2} \mathrm{O}}$ & $\frac{10 \%}{4.1 \mathrm{ml}}$ \\
\hline $1.5 \mathrm{M}$ Tris- $\mathrm{HCl}, \mathrm{pH} 8.8$ & $2.5 \mathrm{ml}$ \\
\hline $20 \%(w / v)$ SDS & $50.0 \mu \mathrm{l}$ \\
\hline acrylamide/bis-acrylamide $(30 \% / 0.8 \%(\mathrm{w} / \mathrm{v}))$ & $3.5 \mathrm{ml}$ \\
\hline $10 \%(w / v)($ APS) & $100 \mu \mathrm{l}$ \\
\hline TEMED & $4.0 \mu \mathrm{l}$ \\
\hline loading gel ( $3.78 \mathrm{ml}$, for one gel) & $\underline{4 \%}$ \\
\hline $\mathrm{H}_{2} \mathrm{O}$ & $2.3 \mathrm{ml}$ \\
\hline 1.0 M Tris- $\mathrm{HCl}, \mathrm{pH} 6.8$ & $937 \mu \mathrm{l}$ \\
\hline $20 \%(w / v)$ SDS & $18.0 \mu \mathrm{l}$ \\
\hline Acrylamide/Bis-acrylamide $(30 \% / 0.8 \%(w / v))$ & $500 \mu \mathrm{l}$ \\
\hline $10 \%(w / v)($ APS) & $25.0 \mu \mathrm{l}$ \\
\hline TEMED & $3.8 \mu \mathrm{l}$ \\
\hline
\end{tabular}

Samples are mixed with 2x Lämmli buffer, boiled for $3 \mathrm{~min}$ in $95^{\circ} \mathrm{C}$ and placed into the pockets of the gel. As a size reference prestained protein marker Page ruler ${ }^{\mathrm{TM}}$ Prestained Protein Ladder Plus (Fermentas) is used. After inserting the gel into the hardware system filled with electrophoresis buffer, the electrical field is set on $25 \mathrm{~mA}$ per gel and the procedure is stopped at any adequate separation status, defined by the separation of the standard.

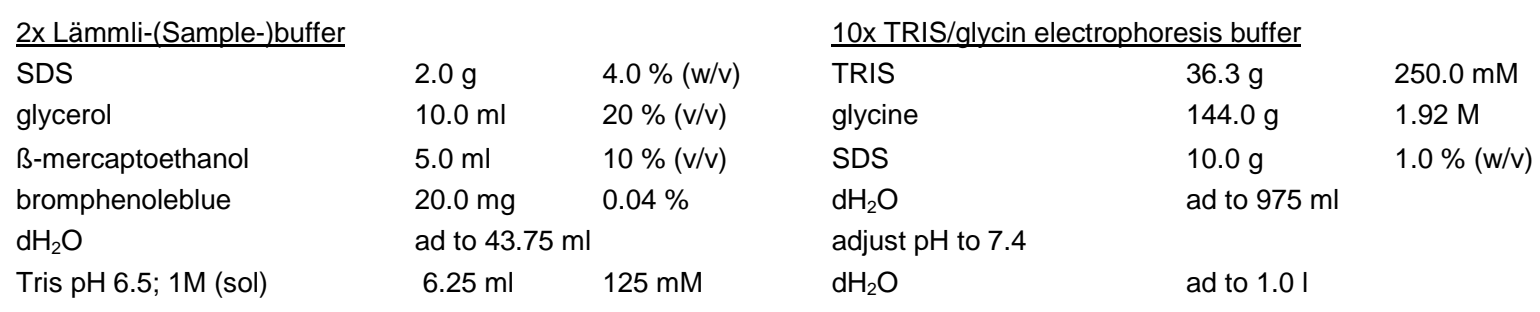




\begin{tabular}{|c|c|c|c|c|}
\hline$\underline{\text { TRIS } 1 \mathrm{M}(\mathrm{pH} 6.5)}$ & & & $\underline{1 x}$ TRIS/glycin electro & sis buffer \\
\hline $\begin{array}{l}\text { TRIS } \\
\mathrm{dH}_{2} \mathrm{O}\end{array}$ & $\begin{array}{l}121.1 \mathrm{~g} \\
\text { ad to } 975 \mathrm{ml}\end{array}$ & $1.0 \mathrm{M}$ & $\begin{array}{l}\text { 10x TRIS/glycin buffer } \\
\mathrm{dH}_{2} \mathrm{O}\end{array}$ & $\begin{array}{l}100 \mathrm{ml} \\
\text { ad to } 1.0 \mathrm{l}\end{array}$ \\
\hline $\begin{array}{l}\text { adjust pH to } 6.5 \text { with } \mathrm{HCl} \\
\mathrm{dH}_{2} \mathrm{O}\end{array}$ & ad to $1.0 \mathrm{I}$ & & & \\
\hline
\end{tabular}

\subsubsection{Staining of SDS PAGE gels}

Gels are stained in a saturated solution of Coomasie Blue for 20 minutes, followed by three washing steps with Destaining solution for each 20 minutes. The staining in the later part of the thesis is performed with PageBlue ${ }^{\mathrm{TM}}$ Protein Staining Solution (Fermentas) according manufacturer's manual.

$\begin{array}{llllll}\text { Coomassie blue } & & & \text { Destaining solution } & \\ \text { Coomassie blue } 250 \mathrm{G} & 0.5 \mathrm{~g} & 0.1 \%(\mathrm{w} / \mathrm{v}) & \text { methanol } & 225 \mathrm{ml} & 45.0 \%(\mathrm{v} / \mathrm{v}) \\ \text { methanol } & 200 \mathrm{ml} & 40.0 \%(\mathrm{v} / \mathrm{v}) & \text { acetic acid } & 50 \mathrm{ml} & 10,0 \%(\mathrm{v} / \mathrm{v}) \\ \text { acetic acid } & 50 \mathrm{ml} & 10,0 \%(\mathrm{v} / \mathrm{v}) & \text { dH2O } & 225 \mathrm{ml} & 45.0 \%(\mathrm{v} / \mathrm{v}) \\ \text { dH2O } & \text { ad } 500 \mathrm{ml} & & & \end{array}$

\subsubsection{Western blot}

Western blotting is a highly sensitive method for identification of proteins processed and separated by SDS PAGE. The unstained proteins are transferred onto a nitrocellulose membrane by an electrical field and detected with specific antibodies. The primary antibody binds directly to the target protein on the nitrocellulose membrane whereas a secondary antibody binds specifically to the Fc-part of the primary antibody. The secondary antibody is coupled to an enzyme catalysing a colorforming reaction.

The Western blotting is performed with the hardware from Bio-Rad using nitrocellulose $\operatorname{Protran}^{\circledR}$ (Whatman) and filter papers (3 MM CHR, Whatman). For transfer, a Fiber pad (Mini Trans-Blot ${ }^{\circledR}$ system, Bio-Rad), two filter papers, the nitrocellulose membrane, the SDS polyacrylamid gel, additional filter papers and another fiber pad are stapled without any air bubbles in between. All components except the gel are soaked in Blotting buffer before using. This sandwich is placed towards the anode in the blotting device filled with transfer buffer and attached to a cooling block. The transfer is performed with a voltage of $100 \mathrm{~V}$ without amperage restriction for $60 \mathrm{~min}$. The proteins are travelling in the electrical field to the cathode and caught and fixed by the nitrocellulose membrane. If no prestained marker is used a reversible staining of the membrane was performed by Ponceau S. For saturation of the free protein binding sites of the nitrocellulose membrane an incubation of $60 \mathrm{~min}$ in blocking solution is necessary. The membrane is incubated with 
primary antibody diluted in blocking solution over night at $4-10{ }^{\circ} \mathrm{C}$. This long procedure ensures condition for the binding process of the primary antibody to achieve best possible sensitivity of the antibody. The membrane is washed three times for 10 minutes with 10 $15 \mathrm{ml}$ washing buffer followed by a $2 \mathrm{~h}$ incubation with the secondary antibody diluted in blocking buffer at room temperature. After this procedure three washing steps with 10-15 $\mathrm{ml}$ wash buffer for each 10 minutes are following. The above incubation steps are accompanied by mild see-saw agitation.

\begin{tabular}{|c|c|c|c|c|c|}
\hline Blotting buffer $10 x$ & & & TBS 10x & & \\
\hline TRIS & $30.3 \mathrm{~g}$ & $250,0 \mathrm{mM}$ & $\mathrm{NaCl}$ & $87.6 \mathrm{~g}$ & $1.61 \mathrm{M}$ \\
\hline glycine & $144.0 \mathrm{~g}$ & $1.92 \mathrm{M}$ & $\begin{array}{l}\text { TRIS } \\
\mathrm{dH}_{2} \mathrm{O}\end{array}$ & $\begin{array}{l}12.1 \mathrm{~g} \\
\text { ad } 990 \mathrm{ml}\end{array}$ & $0.1 \mathrm{M}$ \\
\hline Blotting buffer $1 \mathrm{x}$ & & & $\begin{array}{l}\text { adjust to } \mathrm{pH} 8,0 \text { with } \mathrm{HCl} \text {. } \\
\mathrm{dH}_{2} \mathrm{O}\end{array}$ & ad $1.0 \mathrm{I}$ & \\
\hline Blotting buffer $10 x$ & $100 \mathrm{ml}$ & & & & \\
\hline methanol & $200 \mathrm{ml}$ & & TBS $1 x$ & & \\
\hline $\mathrm{dH}_{2} \mathrm{O}$ & $700 \mathrm{ml}$ & & $\overline{\text { TBS } 10 x}$ & $100 \mathrm{ml}$ & \\
\hline & & & $\begin{array}{l}\mathrm{dH}_{2} \mathrm{O} \quad \mathrm{ad} 1.0 \mathrm{I} \\
\text { adjust } \mathrm{pH} \text { to } \mathrm{pH} 8.0\end{array}$ & & \\
\hline Blocking solution & & & TBST 1x & & \\
\hline $\begin{array}{l}\text { milkpowder } \\
\text { TBST 1x }\end{array}$ & $\begin{array}{l}2.5 \mathrm{~g} \\
\text { ad } 50 \mathrm{ml}\end{array}$ & $5 \%(w / v)$ & $\begin{array}{l}\text { TBS 10x } \\
\mathrm{dH}_{2} \mathrm{O}\end{array}$ & 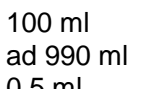 & $005 \%$ \\
\hline & & & $\begin{array}{l}\mathrm{dH}_{2} \mathrm{O} \\
\text { adjust } \mathrm{pH} \text { to } \mathrm{pH} 8.0\end{array}$ & & \\
\hline
\end{tabular}

\subsubsection{Staining of Western blot membranes}

A possibility to visualize proteins on a nitrocellulose reversibly is a staining with Ponceau S. This staining must be done before the blocking procedure. The membrane is incubated for 10 min with Ponceau $S$ solution during mild see-saw agitation. To remove the staining the membrane is washed with PBS buffer 3 times for 15 minutes during gently shaking.

In this thesis two kinds of detection methods based on horse radish peroxidase (HRP) coupled secondary antibody have been performed. $\mathrm{H}_{2} \mathrm{O}_{2}$ and Luminol are reacting catalyzed by the HRP in an oxidative reaction causing a light emission. This chemoluminescence only occurs at the position of the target protein. One kind of detection can be performed by visualization with a photofilm. In this case the $E C L^{\mathrm{TM}}$ WB Detection kit (Amersham) is used combined with the X-ray film Hyperfilm ${ }^{\mathrm{TM}} E C L^{\mathrm{TM}}$, developed and fixed with solutions from Intas and Kodak. The second method is performed with the HRP Color Development Solution (BioRad) according maufacturer's manual including a final wash step with PBS before staining procedure. 


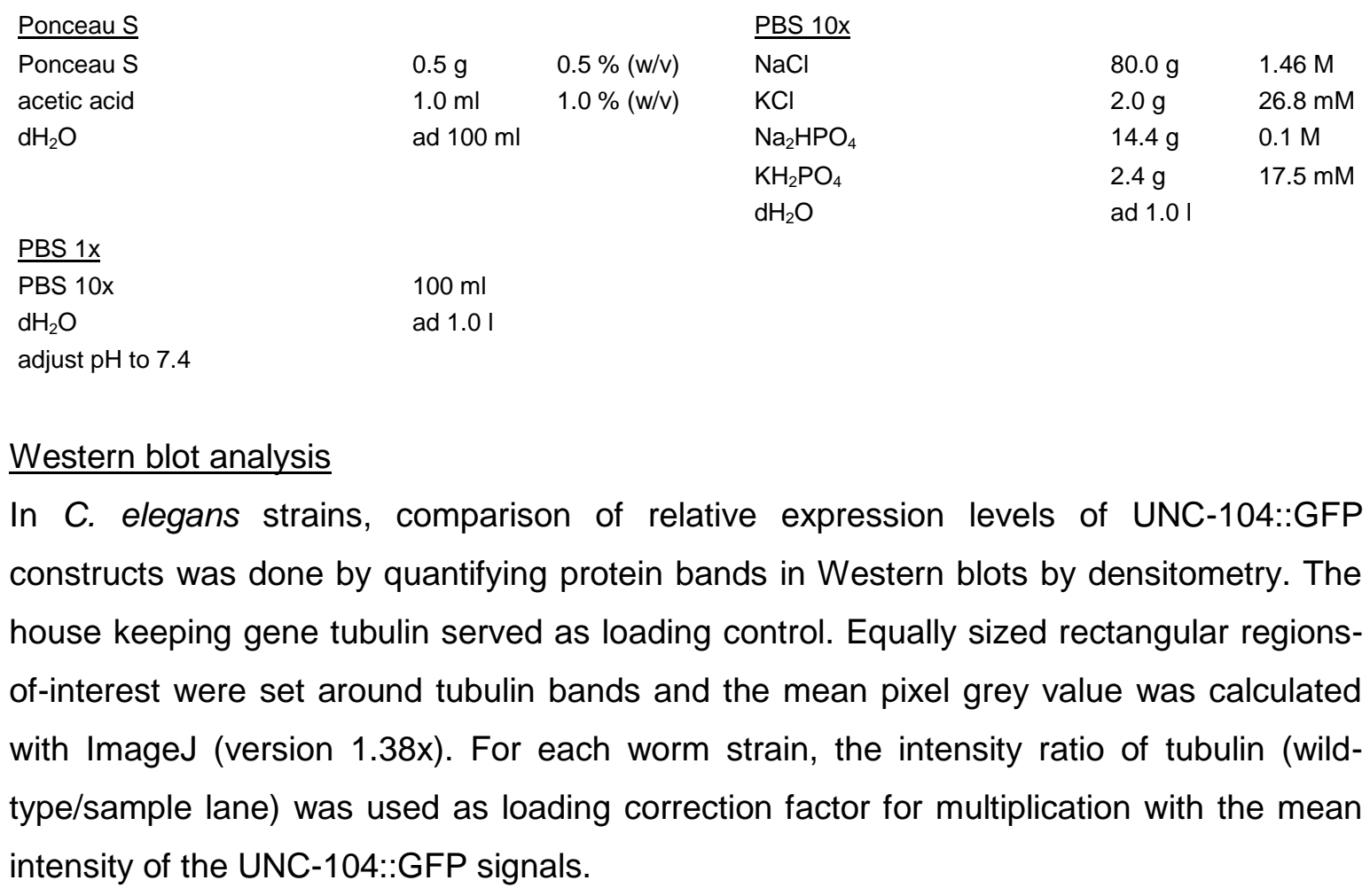

\subsubsection{Protein purification}

\subsubsection{Expression of proteins in E. coli}

To achieve a high yield of protein the expression process is divided into a proliferation part and an expression part. During the proliferation part bacteria are in a phase of unstopped exponential division. This is performed at optimum temperature and nutrition supply. The saturation point is at approx. cell density of $\mathrm{OD}_{600}=0.6-0.8$. At this point proliferation phase is stopped by instant cooling and/or an addition of sucrose. The expression phase starts with lower incubation temperature and addition of IPTG activating the promoter for the target protein.

The constructs of the UNC-104 1-446::GFP are transformed in E. coli BL21 gold (DE3) electroporation-competent cells according to protocol mentioned above. 2.0 I TPM medium culture is initiated with a $5 \mathrm{ml}$ over night pre-culture and cultured at $37^{\circ} \mathrm{C}$ to an $\mathrm{OD}_{600}=0.6-0.8$, cooled down on ice for $10 \mathrm{~min}$, induced with $500 \mathrm{mM}$ IPTG and grown over night (12-16 hours) at $20^{\circ} \mathrm{C}$ for slow induction of the motor proteins. Cells are harvested by centrifuging them in a GSA (Sorvall) rotor at 4000rpm for $15 \mathrm{~min}$ at RT. The pellet is weighed and frozen at $-80^{\circ} \mathrm{C}$. 


$\begin{array}{lllll}\text { TPM medium } & & & & \\ \text { peptone } & 20.0 \mathrm{~g} & 2.0 \%(\mathrm{w} / \mathrm{v}) & \mathrm{dH}_{2} \mathrm{O} & \text { ad to } 950 \mathrm{ml} \\ \text { yeast extract } & 15.0 \mathrm{~g} & 1.5 \%(\mathrm{w} / \mathrm{v}) & \text { adjust } \mathrm{pH} \text { to } 7.0 \text { with } \mathrm{KOH} & \\ \mathrm{NaCl} & 8.0 \mathrm{~g} & 150 \mathrm{mM} & \mathrm{dH}_{2} \mathrm{O} & \text { ad to } 1.0 \mathrm{I} \\ \mathrm{Na}_{2} \mathrm{HPO}_{4} & 2.0 \mathrm{~g} & 14.0 \mathrm{mM} & \text { autoclaving procedure } & \\ \mathrm{KH}_{2} \mathrm{PO}_{4} & 1.0 \mathrm{~g} & & & \end{array}$

\subsubsection{Protein purification strategies}

The purification of fusion proteins can be performed by two principles, by affinity purification, using the His6-tag inserted into the construct (located C-terminal right after GFP), or by the purification via an Ion Exchange Chromatography, where a stationary phase surface displays ionic functional groups that interact with analyte ions of opposite charge and therefore splits protein fractions. Histidine is a basic amino acid. Poly histidine tags bind to nickel or cobalt with micromolar affinity (Hochuli et al., 1988).

\section{Ni-Affinity purification}

$3.0 \mathrm{~g}$ of the pellet is resuspended in $10 \mathrm{ml}$ Lysis buffer and cells lysed by sonication (Branson) $30 \mathrm{sec}$. interval after every 20 seconds (45\% amplitude for $90 \mathrm{sec}$, program 5). The lysate is spun in an SS34 rotor at 12,000 rpm for 45 minutes to remove cell debris. The supernatant is applied to pre-equilibrated Ni NTA beads (Qiagen) and incubated for 1 hour on a rotating wheel $(10-20 \mathrm{rpm} / \mathrm{min})$ at $10^{\circ} \mathrm{C}$. The beads are then applied to $5 \mathrm{ml}$ polypropylene column (Qiagen), washed 3 times with 5 column volume of Ni Wash buffer. The proteins are eluted with an appropriate amount of Ni Elution buffer. The eluted protein is collected in $1 \mathrm{ml}$ fractions and was analyzed by SDS PAGE on a $10 \%$ Bis-Tris gel (Invitrogen, or a home made version) to evaluate the fractions with protein.

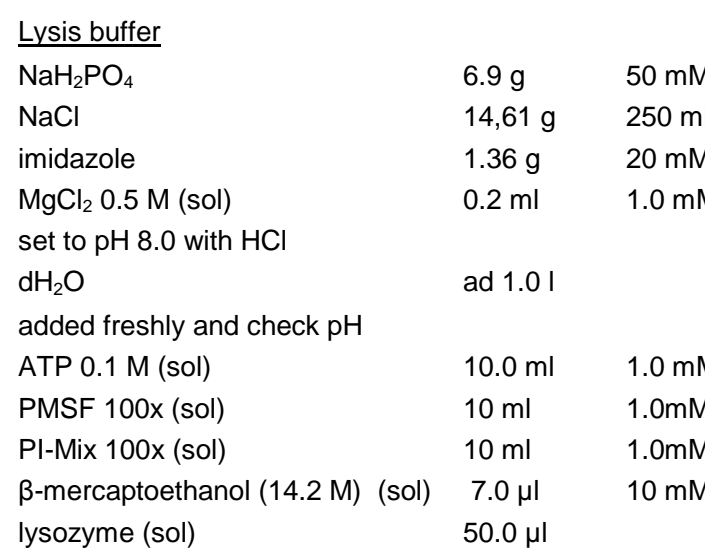

\begin{tabular}{ll}
\multicolumn{2}{l}{ Pl (proteinase inhibitors)- Mix 100x } \\
TAME & $10.0 \mathrm{mg} / \mathrm{ml}$ \\
trypsin inhibitor & $10.0 \mathrm{mg} / \mathrm{ml}$ \\
pepstatin A & $10.0 \mathrm{mg} / \mathrm{ml}$ \\
leupeptin & $1.5 \mathrm{mg} / \mathrm{ml}$ \\
aprotinin & $10.0 \mathrm{mg} / \mathrm{ml}$
\end{tabular}

$\begin{array}{lll}\frac{\mathrm{Ni} \text { Wash buffer }}{\mathrm{NaH}_{2} \mathrm{PO}_{4} \times 1 \mathrm{H}_{2} \mathrm{O}} & 6.9 \mathrm{~g} & 50 \mathrm{mM} \\ \mathrm{NaCl} & 4.61 \mathrm{~g} & 250 \mathrm{mM} \\ \mathrm{MgCl}_{2} 0.5 \mathrm{M} \text { (sol) } & 200 \mu \mathrm{l} & 1.0 \mathrm{mM} \\ \beta \text {-mercaptoethanol }(14.2 \mathrm{M})(\mathrm{sol}) & 7.0 \mu \mathrm{l} & 10 \mathrm{mM} \\ \text { ATP } 0.1 \mathrm{M} \text { (sol) } & 1.0 \mathrm{ml} & 0.1 \mathrm{mM} \\ \text { set pH to } 6.0 & & \\ \mathrm{dH}_{2} \mathrm{O} & \text { ad } 1.0 \mathrm{I} & \end{array}$




$\begin{array}{lll}\text { Ni Elution buffer } & & \\ \mathrm{NaH}_{2} \mathrm{PO}_{4} \mathrm{pH} 7.2 & 3.45 \mathrm{~g} & 50 \mathrm{mM} \\ \mathrm{NaCl} & 7.31 \mathrm{~g} & 250 \mathrm{mM} \\ \text { imidazole } & 17.02 \mathrm{~g} & 500 \mathrm{mM} \\ \mathrm{MgCl}_{2} 0.5 \mathrm{M} \text { (sol) } & 100 \mu \mathrm{l} & 1.0 \mathrm{mM} \\ \beta \text {-mercaptoethanol (14.2 M) } & 7.0 \mu \mathrm{l} & 10 \mathrm{mM} \\ \text { ATP 0.1 M (sol) } & 1.0 \mathrm{ml} & 0.1 \mathrm{mM} \\ \text { set pH to } 7.2 & & \\ \mathrm{dH}_{2} \mathrm{O} & \text { ad } 500 \mathrm{ml} & \end{array}$

\section{lon Exchange Chromatography}

The column the SP Sepharose with $5 \mathrm{ml}$ column volume is used the gradients are set using Unicorn ${ }^{\circledR}$ (Version 5.10). $3.0 \mathrm{~g}$ of the pellet is resuspended in $10 \mathrm{ml}$ Lysis buffer and sonicated as described before. The lysate is spun in an SS34 rotor at 12,000 rpm for 45 minutes to remove cell debris. The column is equilibrated with Buffer $A$ and the supernatant is applied to the column and the column is washed with a mixture of $90 \%$ Buffer $\mathrm{A}$ and $10 \%$ Buffer $\mathrm{B}$. At the same time the collection of the $1.0 \mathrm{ml}$ fractions is started. For elution a gradient is set to $20 \%$ Buffer continued to $30 \%$ Buffer B. After this procedure the column is washed with $100 \%$ Buffer $B$.

\begin{tabular}{|c|c|c|c|c|c|}
\hline Lysis buffer & & & Buffer B: & & \\
\hline Buffer A (see below) & $20 \mathrm{ml}$ & & PIPES & $25.0 \mathrm{mM}$ & \\
\hline $\mathrm{NaCl}$ & $100 \mathrm{mM}$ & & $\mathrm{MgCl}_{2}$ & $2.0 \mathrm{mM}$ & \\
\hline ATP & $100 \mu \mathrm{M}$ & & EGTA & $0.1 \mathrm{mM}$ & \\
\hline DTT & $1.0 \mathrm{mM}$ & & $\mathrm{NaCl}$ & $1.0 \mathrm{M}$ & \\
\hline PMSF & $1.0 \mathrm{mM}$ & & $\mathrm{dH}_{2} \mathrm{O}$ & ad $500 \mathrm{ml}$ & \\
\hline$\beta$-mercaptoethanol & $10.0 \mathrm{mM}$ & & sonication to degas the buffer & & \\
\hline & & & $\operatorname{ATP}(0.1 \mathrm{M})$ & $10.0 \mathrm{ml}$ & $1 \mathrm{mM}$ \\
\hline & & & DTT & $1.0 \mathrm{ml}$ & $1 \mathrm{mM}$ \\
\hline Buffer A: & & & & & \\
\hline PIPES & $25.0 \mathrm{mM}$ & & & & \\
\hline $\mathrm{MgCl}_{2}$ & $2.0 \mathrm{mM}$ & & & & \\
\hline EGTA & $0.1 \mathrm{mM}$ & & & & \\
\hline $\mathrm{dH}_{2} \mathrm{O}$ & ad $500 \mathrm{ml}$ & & & & \\
\hline soncation to degas th & & & & & \\
\hline $\operatorname{ATP}(0.1 \mathrm{M})(\mathrm{sol})$ & $10.0 \mathrm{ml}$ & $1 \mathrm{mM}$ & & & \\
\hline DTT (sol) & $1.0 \mathrm{ml}$ & $1 \mathrm{mM}$ & & & \\
\hline
\end{tabular}

\subsubsection{Microtubule affinity purification of kinesin-3 Mini Motors}

With this method enzymatically active microtubule binding motor proteins can be purified. The protein solution is incubated with a microtubule (MT) solution. All active MT binding proteins are interacting with the MTs. The addition of AMP-PNP - a non hydrolyzable ATP-analogon - locks the motor head in an ATP like state and massively increases the MT-affinity (Vale et al., 1985, Nitta et al., 2004). At the same time, excess ATP in the 
solution is hydrolyzed by apyrase resulting in a stable binding of the motor proteins at the MTs. Ultracentrifugation and wash steps are extracting the non or weak binding proteins in the solution, including the apyrase. By exchanging the AMP-PNP to ATP, active motors are released into solution again and MTs are extracted by centrifugation. The purified protein contains unpolymerized tubulin (signal in SDS-PAGE at $55 \mathrm{kD}$ ). To totally purify the motors an additional purification via Ni-NTA affinity is recommended if following experiments afford tubulin-free samples.

\section{Preparation of taxol stabilized MTs at the same day as the purification}

$1.0 \mathrm{ml}$ Tubulin $[\mathrm{c}]=12 \mathrm{mg} / \mathrm{ml}$

$1.0 \mathrm{mM}$ GTP

$2.0 \mathrm{mM} \mathrm{MgCl} 2$

in BRB 80

are incubated at $37^{\circ} \mathrm{C}$ for $17 \mathrm{~min}$ (solution appears viscous and cloudy).

Taxol is added to a concentration of $20 \mu \mathrm{M}$ and the solution is incubated another 5 minutes at $37^{\circ} \mathrm{C}$.

\section{Purification}

Bacteria expressing mini motors are pelleted by centrifugation and 3-5 $\mathrm{g}$ of the pellet are resuspended in $3 x$ volume of $\mathrm{AP} 100+$ medium plus $10 \mu \mathrm{M}$ ATP and PI-Mix. The resuspended pellet is sonicated (Sonifier 250 Branson) on ice (output 4 ) 4 times for a duration of 30 seconds with 1 second pulse, 1 second pause and 30 seconds cool down between the pulse blocks. The solution is centrifuged at $42000 \mathrm{rpm}$ (rotor Ti70, Beckman/Coulter) at $4{ }^{\circ} \mathrm{C}$ and the supernatant is transferred to a $15 \mathrm{ml}$ conical tube. Taxol is added to a final concentration of $20 \mu \mathrm{M}$ and $0.5 \mathrm{ml}$ of the prepared MT-solution. After addition of $0.5 \mathrm{ml}$ taxol stabilized MTs AMP-PNP is set to a concentration of $200 \mu \mathrm{M}$ and $5 \mathrm{U} / \mathrm{ml}$ apyrase is added. After an incubation of 15 to 60 minutes at RT, the solution is centrifuged at $22{ }^{\circ} \mathrm{C}$ with $42000 \mathrm{rpm}$ (TLA 100.3 rotor) for 30 minutes. The pellet containing MTs and bound motor proteins is resuspended in $1 \mathrm{ml} \mathrm{KCl}$ buffer and set on a $2 \mathrm{ml}, 40 \%$ sucrose cushion. After a centrifugation step of $10 \mathrm{~min}$ and $80000 \mathrm{rpm}$ (TLA 100.3 rotor) at $22{ }^{\circ} \mathrm{C}$ the pellet is resuspended in 200-400 ml Release buffer I and incubated for $15 \mathrm{~min}$ at RT. After another centrifugation step of $10 \mathrm{~min}$ and $80000 \mathrm{rpm}$ (TLA 100.3 rotor) at $22{ }^{\circ} \mathrm{C}$ the supernatant contains the purified motor proteins. Optional a second relieve process can be performed using Release buffer II. The supernatant is set to $20 \%$ glycerine and frozen after aliquoting or used directly to Ni-NTA purification. $5 \mu \mathrm{l}$ is kept for SDS-PAGE analysis. 


\begin{tabular}{|c|c|c|c|c|}
\hline BRB80-buffer & & & AP100 buffer: & \\
\hline PIPES & $24.1 \mathrm{~g}$ & $80.0 \mathrm{mM}$ & PIPES (pH 6,8 with $\mathrm{KOH}$ ) & $100 \mathrm{mM}$ \\
\hline EGTA & $0.38 \mathrm{~g}$ & $1.0 \mathrm{mM}$ & $\mathrm{MgCl}_{2}$ & $2.0 \mathrm{mM}$ \\
\hline $\mathrm{MgCl}_{2}$ (water free) & $95.2 \mathrm{mg}$ & $1.0 \mathrm{mM}$ & EGTA & $1.0 \mathrm{mM}$ \\
\hline $\mathrm{dH}_{2} \mathrm{O}$ & ad $750 \mathrm{ml}$ & & EDTA & $1.0 \mathrm{mM}$ \\
\hline adjust $\mathrm{pH}$ to $\mathrm{pH} 7.0$ & & & & \\
\hline $\mathrm{dH}_{2} \mathrm{O}$ & ad $1.0 \mathrm{I}$ & & & \\
\hline PI (proteinase inhibitors)- Mix 100x & & & $\underline{\text { Release buffer I }}$ & \\
\hline TAME & $10.0 \mathrm{mg} / \mathrm{ml}$ & & ATP & $20 \mathrm{mM}$ \\
\hline trypsin inhibitor & $10.0 \mathrm{mg} / \mathrm{ml}$ & & $\mathrm{MgCl}_{2}$ & $10 \mathrm{mM}$ \\
\hline pepstatin A & $10.0 \mathrm{mg} / \mathrm{ml}$ & & $\mathrm{KCl}$ & $200 \mathrm{mM}$ \\
\hline leupeptin & $1.5 \mathrm{mg} / \mathrm{ml}$ & & Taxol & $10 \mu \mathrm{M}$ \\
\hline aprotinin & $10.0 \mathrm{mg} / \mathrm{ml}$ & & in BRB80-buffer & \\
\hline & & & $\underline{\text { Relieve buffer II }}$ & \\
\hline AP100+ buffer & & & ATP & $50 \mathrm{mM}$ \\
\hline AP100 buffer & & & $\mathrm{MgCl}_{2}$ & $10 \mathrm{mM}$ \\
\hline $1 \mathrm{mM}$ DTT & $1.0 \mathrm{mM}$ & & $\mathrm{KCl}$ & $200 \mathrm{mM}$ \\
\hline $\mathrm{PI}-\mathrm{Mix} 100 \mathrm{x}$ & to $1 x$ & & taxol & $10 \mu \mathrm{M}$ \\
\hline & & & in BRB80-buffer & \\
\hline
\end{tabular}

$\begin{array}{ll}\frac{\mathrm{KCl} \text { buffer }}{\mathrm{KCl}} & 50 \mathrm{mM} \\ \text { taxol } & 10 \mu \mathrm{M} \\ \text { AMP-PNP } & 200 \mu \mathrm{M} \\ \text { in AP100 buffer } & \end{array}$

\subsubsection{Gel filtration}

Gel filtration is a method to separate molecules according to their size. The gel is a heterogenous phase-system with a stationary phase (matrix) and a continuous liquid phase. The gel has pores with a well defined size, is chemically inert and stable to physical forces. As large particles are not able to enter the pores they are not retarded and leave the column earlier than smaller proteins. Those leave according their size.

Superdex $200 \mathrm{gel}$ material is used, with a column volume of $2.6 \mathrm{ml}$. All runs are performed at RT. The volume of the protein fraction is $20 \mu \mathrm{l}$ at a concentration of $400 \mu \mathrm{g} / \mathrm{ml}$. The column is equilibrated over night with $70 \mathrm{ml}$ Equilibration buffer ( $>20$ fold column volume) and low flow rate. The column is washed with one column volume of washing buffer I and a rate of $80 \mu \mathrm{l} / \mathrm{min}$. At this case the conductivity rises. As a check of cleanness of the column the $280 \mathrm{~nm}$ value should not change. One column volume of equilibration buffer with fresh ATP and DDT is added at a rate of $80 \mu \mathrm{l} / \mathrm{min}$. The conductivity drops. After setting the probe at a rate of $40 \mu \mathrm{l} / \mathrm{min} 1.2$ column volumes of elution buffer are set with a rate of $40 \mu \mathrm{l} / \mathrm{min}$. Collection of $50 \mu \mathrm{l}$ fractions starts at the same time. The column is washed with one column volume of washing buffer I at a flow rate of $80 \mu \mathrm{l} / \mathrm{min}$. The 
fraction size is increased to $400 \mu \mathrm{l}$. The procedure is repeated for the other two samples with the exception of the usage of washing buffer II to avoid the drop of absorption due to the lack of ATP regarding to the elution buffer.

$\begin{array}{ll}\text { Equilibration buffer: } & \\ \text { PIPES, pH 6,8 } & 80.0 \mathrm{mM} \\ \mathrm{MgCl}_{2} & 1.0 \mathrm{mM} \\ \text { EGTA } & 1.0 \mathrm{mM} \\ \text { DTT } & 1.0 \mathrm{mM} \\ \text { ATP } & 0.1 \mathrm{mM}\end{array}$

\begin{tabular}{ll} 
Washing buffer II : & \\
\hline PIPES, pH 6,8 & $80.0 \mathrm{mM}$ \\
$\mathrm{MgCl}_{2}$ & $1.0 \mathrm{mM}$ \\
EGTA & $1.0 \mathrm{mM}$ \\
$\mathrm{NaCl}$ & $500 \mathrm{mM}$ \\
DTT (fresh) & $1.0 \mathrm{mM}$ \\
ATP (fresh) & $0.1 \mathrm{mM}$
\end{tabular}

Washing buffer I: PIPES, pH 6,8

$\mathrm{NaCl}$

$500 \mathrm{mM}$

$\begin{array}{ll}\text { Elution buffer } & \\ 80 \mathrm{mM} \mathrm{PIPES}, \mathrm{pH} 6,8 & 80.0 \mathrm{mM} \\ 0.5 \mathrm{MgCl}_{2} & 0.5 \mathrm{mM} \\ \text { EGTA } & 1.0 \mathrm{mM} \\ \text { DTT (fresh) } & 1.0 \mathrm{mM} \\ \text { ATP (fresh) } & 0.1 \mathrm{mM}\end{array}$

\subsubsection{Cross linking}

Cross linking is a common strategy to test protein-protein interaction by covalently binding active side groups of amino acids of two proteins. In this thesis the zero-cross-linker 1-Ethyl-3-(3-dimethylaminopropyl)carbodiimid (EDC) is used that connects a carboxy group of one protein with an amino group of another one building a stable amide bond in presence of $\mathrm{N}$-hydroxysuccinimide (NHS). To compare different mutated 1-446-UNC-104 proteins with respect to their dimerization in vitro we estimated concentrations of MTaffinity purified mini motors by Western blot and used the equivalent amount $(5 \mu \mathrm{g})$ for cross linking procedure. The protein suspension is diluted at least $1: 1$ with $\mathrm{P} 12 \mathrm{pH} 7.0$ to $10 \mu$ l end volume.

\section{1-Ethyl-3-(3-dimethylaminopropyl)carbodiimid}

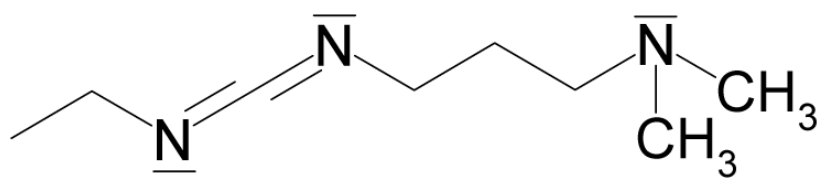

Fig. M2: 1-Ethyl-3-(3-dimethylaminopropyl)carbodiimid (EDC)

$2.5 \mu \mathrm{l} \mathrm{EDC} \mathrm{and} \mathrm{2.0 \mu l} \mathrm{NHS} \mathrm{is} \mathrm{added,} \mathrm{giving} \mathrm{a} \mathrm{final} \mathrm{concentration} \mathrm{of} \mathrm{EDC} \mathrm{and} \mathrm{NHS} \mathrm{of}$ $172 \mu \mathrm{M}(1 / 20$ dilution) or $34 \mu \mathrm{M}$ (1/100 dilution). The reaction is stopped by an addition of 
an equal volume of TRIS containing Lämmli buffer. In this thesis we did time lapse cross linking with time points at $10 \mathrm{~min}, 30 \mathrm{~min}, 60 \mathrm{~min}, 120 \mathrm{~min}$ and $180 \mathrm{~min}$. As control we used a mix of $2.5 \mu \mathrm{l} \mathrm{EDC} \mathrm{and} 2.0 \mu \mathrm{l} \mathrm{NHS}$ with $14 \mu \mathrm{l}$ Lämmli buffer premixed added to the protein solution. In this case the EDC is quenched before adding to the probe. The samples are analyzed via SDS PAGE and Western blotting.

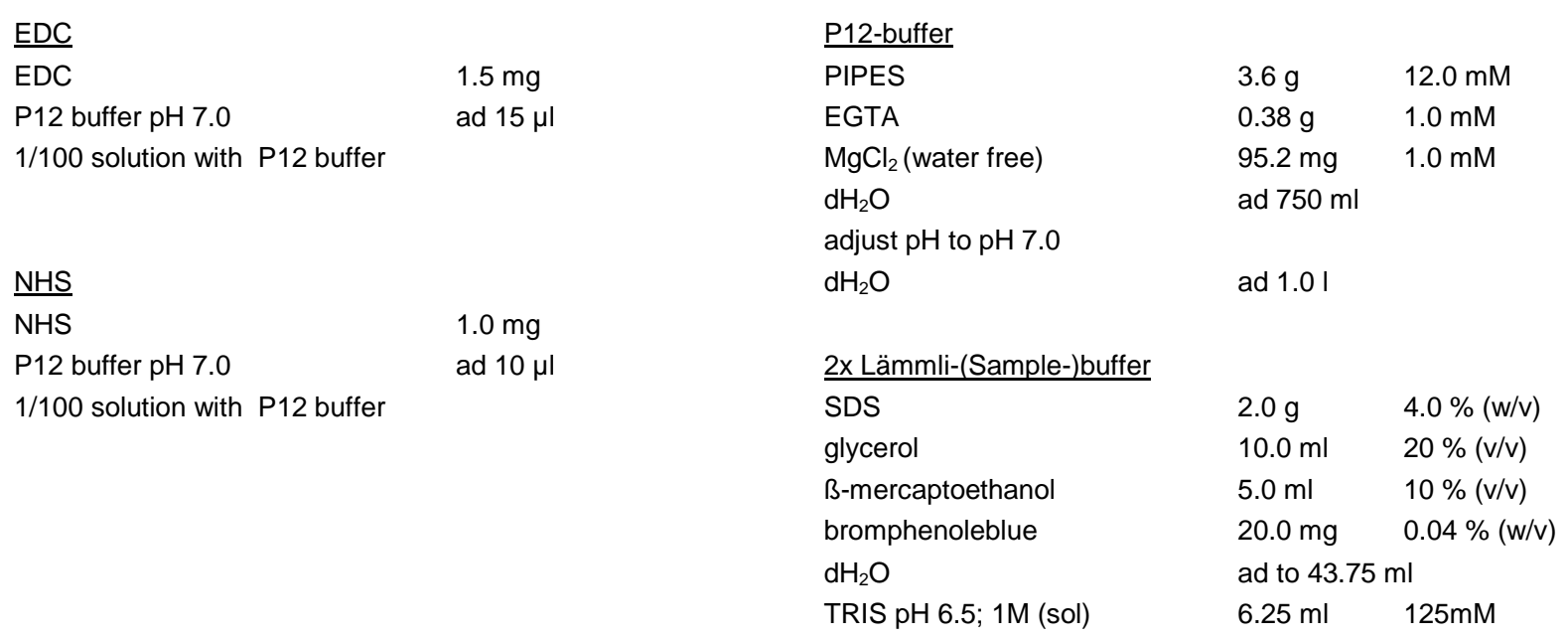

\subsection{Cell culture}

\section{Isolation of $C$. elegans primary neurons}

First challenge is to get a large amount of eggs. To achieve this 5 plates of $9 \mathrm{~cm}$ diameter filled with worms of the strain of interest are synchronized as described above. The eggs are distributed to 10 inoculated MGN plates of $9 \mathrm{~cm}$ diameter. Before worms reach adult age these 10 plates are totally chunked to another 40 inoculated MGN plates of $9 \mathrm{~cm}$ diameter. After all the worms reach adult stage they are cultivated for another 12 to $24 \mathrm{~h}$ so every worm contains a maximum amount of eggs. If the worms are running out of food during this process an additional feeding process has to be performed. $5 \times 50 \mathrm{ml}$ of fresh OP50 liquid is centrifuged with (Megafuge 1.0, rotor 2704, Fisher scientific) at $4000 \mathrm{rpm}$ for $5 \mathrm{~min}$ at RT and the pellet is resuspended with in total $20 \mathrm{ml}$ of fresh OP50 medium. This concentrated bacteria solution is distributed to the 40 plates containing the developing worms.

For harvesting the worms, every plate is washed with $2 \times 5 \mathrm{ml} \mathrm{M9}$ buffer and the liquid containing the worms is collected in $50 \mathrm{ml}$ tubes. The worms are centrifuged at 1300 rpm for 3 min (Megafuge 1.0, rotor 2704, Fisher Scientific). The supernatant is discarded. The worms are washed with $40 \mathrm{ml}$ M9 buffer per tube and the centrifugation step is 
repeated. If there are larger contaminations containing one or several steps with a centrifugation with $600 \mathrm{rpm}$ for 2 minutes can be performed optional. The supernatant is discarded and the worm pellet is solved in $5 \mathrm{ml} \mathrm{M9}$ buffer. $10-15 \mathrm{ml}$ (the content of two 50 $\mathrm{ml}$ tubes) are transferred into one $15 \mathrm{ml}$ tube (resulting in four $15 \mathrm{ml}$ tubes in total). Two washing steps with each $10 \mathrm{ml}$ M9 buffer are following at the same conditions as described above. It is a good strategy to renew the $15 \mathrm{ml}$ tubes at every washing step. After the last washing step the worms are pooled into two $15 \mathrm{ml}$ tubes. The next steps need to be performed at sterile conditions. Worms are treated with hypocloride solution as described in "synchronization of $C$. elegans" before, including washing steps with sterile M9 buffer. It is important to use sterile pipettes to extract the supernatant and pipettes should be exchanged to new ones as often as possible. At the last washing step the pellets of the two falcons are pooled. The end volume of pellet and supernatant should be round $1.0 \mathrm{ml}$.

Now the eggs are extracted by gradient centrifugation. The $1 \mathrm{ml}$ resuspension is diluted with $4 \mathrm{ml}$ sterile $\mathrm{H}_{2} \mathrm{O}$ and $5 \mathrm{ml}$ of a $60 \%$ sucrose solution is added. After mixture (resulting a $10 \mathrm{ml}$ solution of $30 \%$ sucrose), 3 times $1 \mathrm{ml}$ of $5 \%$ sucrose is added carefully on top of the solution building a second phase. A centrifugation step with $1600 \mathrm{rpm}$ for 6 min at RT (Megafuge 1.0, rotor 2704, Fisher scientific) is following. The interphase containing the $C$. elegans eggs is extracted by a $1000 \mu \mathrm{l}$ pipette and transferred to a new $15 \mathrm{ml}$ tube. (Optional: if there is a large amount of eggs the $30 \%$ phase can additionally treated the same as the section described before but both should be kept separately as there will be differences in quality). After a centrifugation step at $1300 \mathrm{rpm}$ for $3 \mathrm{~min}$ at RT a white pellet can be seen. The supernatant is discarded leaving $500 \mu \mathrm{l}$ in the tube. After resuspension and addition of $12 \mathrm{ml}$ Egg-buffer (RT) the solution is centrifuged at 1300 rpm for $3 \mathrm{~min}$ at RT. The supernatant is discarded leaving $250 \mu \mathrm{l}$, the pellet is resuspended and the suspension is transferred to a $1.5 \mathrm{ml}$ tube. After addition of $2 \times 150 \mu \mathrm{l}$ chitinase solution an incubation step of $1 \mathrm{~h}$ at RT and continuous flipping on a rotating wheel (15 rpm) is performed. During this incubation process 12 MatTek petri dishes are incubated with each $50 \mu$ of peanut lectin for $20 \mathrm{~min}$, and 2 washing steps with $100 \mu \mathrm{l}(1 \mathrm{~min}$ incubation time). After the $1 \mathrm{~h}$ incubation of the eggs a check under the microscope has to be performed. The embryos should be raspberry shaped. If this is the case $800 \mu \mathrm{l}$ of L-15 medium (RT) is added followed by a centrifugation step of $3 \mathrm{~min}$ at $300 \mathrm{rpm}$ (RT) (Megafuge 1.0, rotor 2704, Fisher scientific). The supernatant is discarded and $800 \mu \mathrm{l}$ of L-15 medium (Lonza) is added. A $1000 \mu \mathrm{l}$ pipette is set to $600 \mu \mathrm{l}$ and the solution is resuspended gently for over 100 times. It is very important to avoid formation of foam. After a check under the microscope, embryonic cells should be separated. If this is not the case, continue with resuspension. After this process another $500 \mu \mathrm{l}$ of L-15 
medium is added and the cells are pelleted for $5 \mathrm{~min}$ at $300 \mathrm{rpm}$ (RT) and resuspended with $1.0 \mathrm{ml} \mathrm{L}-15$ medium. (On this stage of the purification other protocols (Christiansen, 2002) use another purification step using a sterile filter. We also tested this procedure but did not find any difference in quality leaving this step but lost over $50 \%$ of cells during this process, so we decided not to perform this step.) The density of the cells are evaluated and set to $360000 / \mathrm{ml}$ by adding LB-15. $80 \mu \mathrm{l}$ are set on the pre-coated MatTek dishes. After an incubation time of $1 \mathrm{~h}$, the medium is exchanged to $1.5 \mathrm{ml} \mathrm{L}-15$ medium. Both during the incubation time and the treatments afterwards it is necessary to keep the content of the Petri dishes under humid conditions. This can be managed by a small water soaked packed piece of a kimwipe. Within the next $48 \mathrm{~h}$ the primary neurons will develop and develop neurites. By proper exchange of medium and incubation at $20^{\circ} \mathrm{C}$ the cells can be monitored and analysed the next 3-6 days.

\begin{tabular}{|c|c|c|c|c|}
\hline M9 buffer $\left(-\mathrm{MgSO}_{4}\right) 10 \mathrm{x}$ & & & Egg-buffer & \\
\hline $\mathrm{Na}_{2} \mathrm{HPO}_{4}$ & $60.0 \mathrm{~g}$ & $422.6 \mathrm{mM}$ & $\mathrm{NaCl}$ & $3.45 \mathrm{~g}$ \\
\hline $\mathrm{KH}_{2} \mathrm{PO}_{4}$ & $30.0 \mathrm{~g}$ & $402.4 \mathrm{mM}$ & $\mathrm{KCl}$ & $1.79 \mathrm{~g}$ \\
\hline $\mathrm{NaCl}$ & $50.0 \mathrm{~g}$ & $918.4 \mathrm{mM}$ & $\mathrm{CaCl}_{2} \times 2 \mathrm{H}_{2} \mathrm{O}$ & $0.15 \mathrm{~g}$ \\
\hline $\mathrm{dH}_{2} \mathrm{O}$ & ad 1.01 & & $\mathrm{MgCl}_{2}$ (water free) & $0.20 \mathrm{~g}$ \\
\hline & & & HEPES & $2.98 \mathrm{~g}$ \\
\hline & & & $\mathrm{dH}_{2} \mathrm{O}$ & ad $500 \mathrm{~m}$ \\
\hline $\mathrm{MgSO}_{4} 1.0 \mathrm{M}$ & & & adjust $\mathrm{pH}$ to 7,30 & \\
\hline $\mathrm{MgSO}_{4}\left(\times 7 \mathrm{H}_{2} \mathrm{O}\right)$ & $24.6 \mathrm{~g}$ & $1.0 \mathrm{M}$ & sterile filtration process $(0.22 \mu \mathrm{m})$ & \\
\hline $\mathrm{dH}_{2} \mathrm{O}$ & ad $100 \mathrm{ml}$ & & & \\
\hline sterile filtration process $(0.22 \mu \mathrm{m})$ & & & & \\
\hline & & & $5 \%$ sucrose & \\
\hline & & & $60 \%$ sucrose & $1.0 \mathrm{ml}$ \\
\hline M9 buffer $1 x$ & & & $\mathrm{dH}_{2} \mathrm{O}$ & ad $12 \mathrm{ml}$ \\
\hline M9 Buffer 10x & $100 \mathrm{ml}$ & & & \\
\hline $\mathrm{dH}_{2} \mathrm{O}$ & ad $1.0 \mathrm{I}$ & & & \\
\hline autoclaving procedure & & & chitinase $(1.0 \mathrm{U} / \mathrm{ml})$ & \\
\hline $\mathrm{MgSO}_{4} 1 \mathrm{M}$ (sol) & $1.0 \mathrm{ml}$ & & chitinase & $50 \mathrm{U}$ \\
\hline & & & $\begin{array}{l}\text { Egg-buffer } \\
\text { freeze in } 1.0 \mathrm{ml} \text { aliquots }\end{array}$ & ad $50 \mathrm{ml}$ \\
\hline $60 \%$ sucrose & & & peanut lectin $(0.5 \mathrm{mg} / \mathrm{ml})$ & \\
\hline sucrose & $60.0 \mathrm{~g}$ & & peanut lectin & $25 \mathrm{mg}$ \\
\hline $\mathrm{dH} 2 \mathrm{O}$ & $40.0 \mathrm{~g}$ & & $\mathrm{dH}_{2} \mathrm{O}$ & ad $50 \mathrm{ml}$ \\
\hline & & & freeze in $1.0 \mathrm{ml}$ aliquots & \\
\hline
\end{tabular}

\subsection{Microscopy}

\subsubsection{Light and Epifluorescence Imaging}

As $C$. elegans worms are transparent, they are perfect targets for any kind of microscopy. As the NGM-medium is also fairly transparent there is no need of any modifications for performing light microscopy directly on the agar plates. As binoculars for light microscopy 
of the worms the Leica MZ6 system is used, as binoculars for light microscopy of the worms the M7FLIII system (Leica) is used equipped with a magnification roll from 2.8 to 10 fold and an adapter for a camera. As light sources the EBQ100 (Kübler) and the KL1500 LCD (Leica) is used. The pictures and movies are taken using the SPOT тM imaging software (Diagnostic Instruments, Inc.).

\subsubsection{Spinning Disc Confocal Laser Microscopy}

Performing high magnification microscopy monitoring $C$. elegans worms with oil immersion objectives it is necessary to immobilize the worms. This is done by a combination of immobilizing surface and paralysing reagents.

\section{Preparation of agarose pads}

A $3 \%$ agarose solution in deionized water is melted at $70{ }^{\circ} \mathrm{C} .100 \mu \mathrm{l}$ of this solution is placed in the middle of a glass slides for microscopy. A cover slide (21 x $26 \mathrm{~mm}$, Menzel) is gently pressed on the drop that now is building an agarose pad. After $1 \mathrm{~h}$ of incubation the cover slide is removed gently. After drying over night the slide is ready to use.

\section{Sample preparation}

For microscopy a drop of $5 \mathrm{mM}$ levamisole is pipetted on the agarose pad and up to 10 nematodes are placed in the drop. Drop and paralyzed nematodes are covered with a cover slip. Imaging was performed with an inverted Spinning Disc confocal microscope (Axiovert 200M ZEISS, Nipkow spinning disc unit from VISITRON SYSTEMS, Puchheim, Germany), EM-CCD camera (ANDOR2, iXon DV885LC-VP) with appending software (AndorlQ) using $40 \times$ or $100 \times$ oil immersion objectives. As laser source a $200 \mathrm{~mW}$ solid state laser (Calypso 200, Cobolt) is used with an AOTF and AOTF controller combined by BFI OPTILAS. As immersion oil Immersol 518F (Zeiss) is used.

The acquisition time for time lapse microscopy is depending to the expression level of the GFP in the worm and the autofluorescing background and ranged from $143 \mathrm{~ms}$ to $2000 \mathrm{~ms}$. 


\subsubsection{Fluorescence Anisotropy}

The instrumentation for the fluorescence anisotropy is developed in-house. A Nipkow disk based confocal microscope is adapted and equipped with a dual-view for anisotropy imaging with the addition of a few components.

The dual-view splits the image of the sample into the orthogonal and parallel component to be focussed on the same electron-multiplying charge coupled device. Furthermore, in order to permit the full control of the polarization of the excitation light with the minimal modifications to the system, the scan-head of the Yokogawa CSU2 confocal microscope is adapted, to host polarization optics instead of the filter slider provided by the manufacturer. The in-house developed optomechanics permit the rotation of an achromatic linear polarizer and an achromatic half-wave plate.

\section{$\underline{\text { Calibration }}$}

To obtain maximum contrast between the acquired orthogonal $(\perp)$ and parallel $(\|)$ channel the polarizer is rotated to obtain maximum detected light intensity. Then polarization optics were reinserted in the optical path and the half-wave plate rotated images. To adjust the position of the two channels in our CCD image, 3-8 fluorescent beads (Fluoro Spheres ${ }^{\circledR}$, $1.0 \mu \mathrm{m}$ ) are used. To adjust the anisotropy a solution of $2.0 \mathrm{mM}$ FITC (FITC Isomerl, Calbiochem) in $0.1 \mathrm{M} \mathrm{KHPO}_{4}, \mathrm{pH} 7.1$ is used. Both controls are imaged for 2 seconds with a 100 -fold objective.

\section{In vivo imaging}

To ensure reproducibility of the results, groups of $C$. elegans worms expressing GFPtagged constructs are cultured in identical conditions. 5-8 adult worms are treated for microscopy as described above. As the fusion proteins used in this study were expressed in neuronal cells only, imaging of the dorsal and ventral nerve cord is performed. These regions do not exhibit significant autofluorescence thus permitting robust anisotropy imaging. Depending on the expression levels of the fluorescently tagged proteins, acquisition times ranged between $150 \mathrm{~ms}$ and $2000 \mathrm{~ms}$. Due to autofluorescence restrictions, the number of pictures per worm varied from 6 to 20. As immersion oil Immersol 518F (Zeiss) is used. 


\subsubsection{TIRF-Microscopy}

Total internal reflection fluorescence (TIRF) microscopy is a method to monitor single molecules resp. single fluorophores. This method reduces background fluorescence and also reduces area of fluorescence excitation. The evanescent wave selectively illuminates and excites fluorophores in a very defined region of the specimen immediately adjacent to the glass-water interface. The evanescent electromagnetic field decays exponentially from the interface, and thus penetrates to a depth of only approximately $100 \mathrm{~nm}$ into the sample medium (Fig. M3) (Axelrod, 1989).

\section{Principle of TIRF microscopy}

1 Specimen

2 Evanescent wave range

3 Cover slip

4 Immersion oil

5 Objective

6 Emission beam (signal)

7 Excitation beam

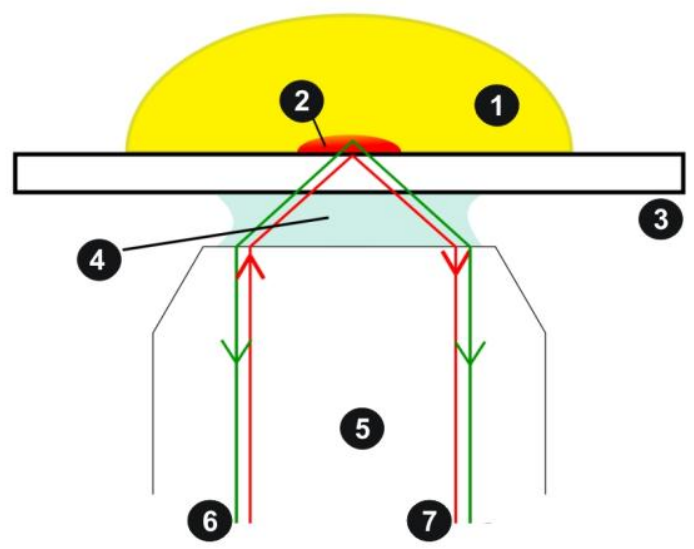

based on http://en.wikipedia.org/wiki/Total_internal_reflection_fluorescence_microscope, as seen 08.01.2012

Fig. M3: Principle of TIRF microscopy

In this lab we use a custom built through the lens (TTL) version of TIRF microscope, built by Christina Thiede. With her microscope settings we are able to monitor both emission of excitated GFP and excitated tetramethyl rodamine (TMR). This allows detection both of TMR-labelled microtubules and GFP-tagged motors in one process (fig. 4).

The aim of using TIRF is the visualization of motor movements on microtubules on a single molecule level. Microtubules are attached to a diethylentriamin (DETA) coated surface. Bacterial expressed and purified GFP-tagged mini motors are added and running and bleaching behaviour is monitored. With this data we can specify both activity and conformational state in vitro of these motors. 


\section{Experimental setting of the TIRF microscope}

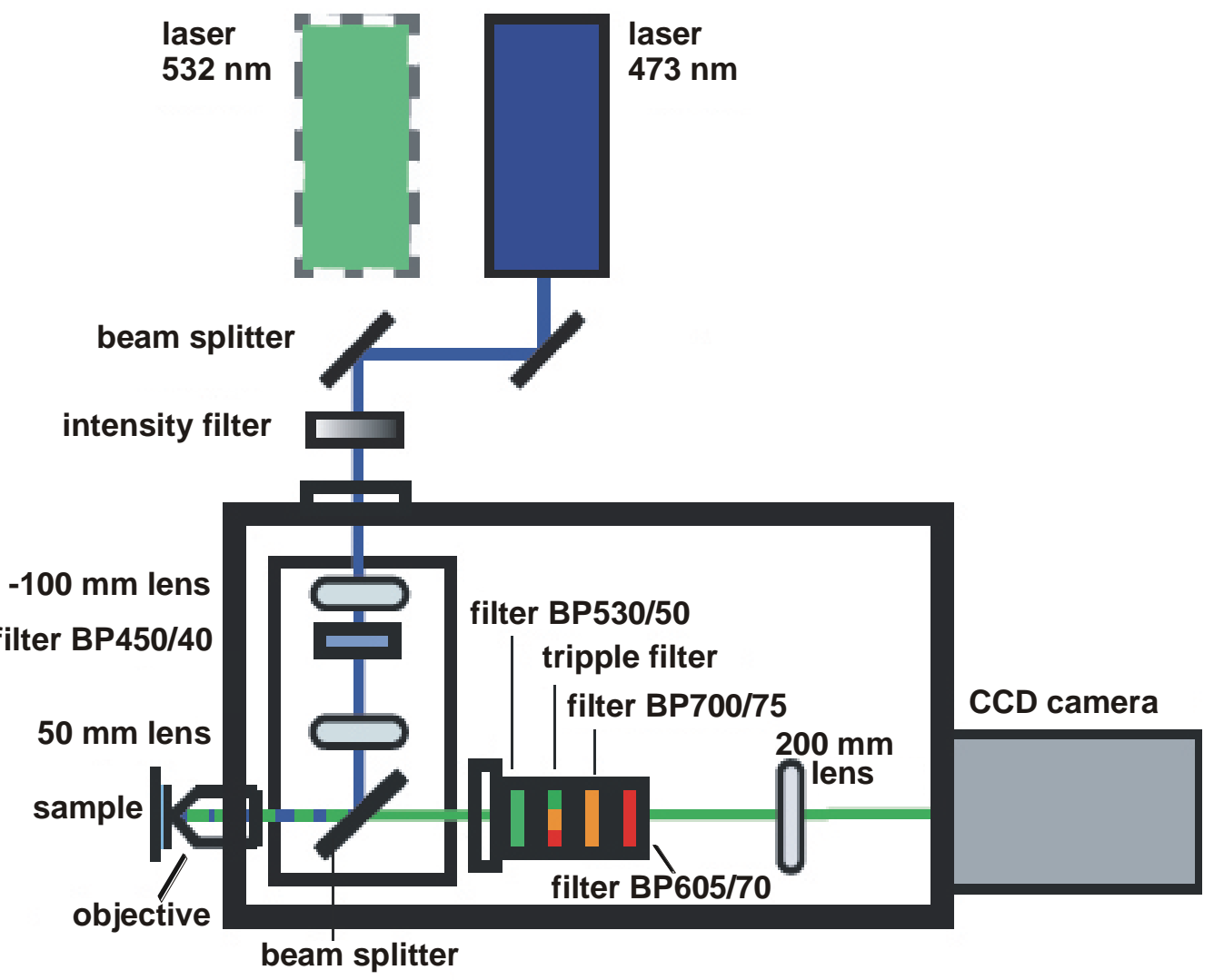

Fig. M4: Experimental setting of the TIRF Microscope

\section{Coverslip coating with DETA}

In an initial step cover slips $(21 \times 26 \mathrm{~mm})$ are placed in a rack without any cover slip touching the other and cleaned in a plasma cleaner for 10 minutes at highest power. The rack is placed in a glass box filled with milipore water and the glass box placed in an ultrasonic bath. After activation of the ultrasonic bath, $200 \mu$ DETA is added dropwise into the water in the glass box far away from the rack. After 5 min of sonication the water/DETA mix is disposed and replaced with milipore water. A 5 min sonication is following. This washing step is repeated twice and the rack is placed in a drying oven for $1 \mathrm{~h}$ at $70^{\circ} \mathrm{C}$. After placement on filter paper in a petri dish the cover slips are ready to use for about one week. 


\section{Microtubule preparation}

Microtubules have been prepared with the following recipe:

As it was dealt with TMR-labelled tubulin it is important to protect the dye from light.

$1 \mu \mathrm{GTP}(25 \mathrm{mM})$

$1 \mu \mathrm{l} \mathrm{MgCl}_{2}(200 \mathrm{mM})$

$1 \mu \mathrm{DMSO}$

$10 \mu \mathrm{g}$ tubulin - TMR-labelled

$30 \mu \mathrm{g}$ tubulin unlabeled

ad to $50 \mu$ with BRB-80

After 15 min incubation at $37^{\circ} \mathrm{C} 100 \mu$ BRB- $80+$ Taxol $\left(1: 100,[\mathrm{c}]_{\text {stock }}=1 \mathrm{mM}\right)$ are added. From now on it is important to store the microtubules at RT.

\section{Preparation of the reaction chamber}

To visualize and monitor moving motor proteins in solution a preparation of a reaction chamber is necessary. Therefore a glass slide is provided with stripes of about $2 \mathrm{~mm}$ width and $35 \mathrm{~mm}$ length of double faced adhesive tape with a gap of about $2 \mathrm{~mm}$ between the stripes. On the stripes a DETA coated cover slip is placed forming several reaction chambers of about $7 \mu \mathrm{l}$ volume. For loading/emptying the chamber on one side a filter paper is placed, soaking the volume out of the paper is placed, soaking the volume out of the chamber, on the other side the new content is placed with a pipette. The suction of the filter paper is filling the chamber, when the drop with the new content that was placed at the other side of the chamber.

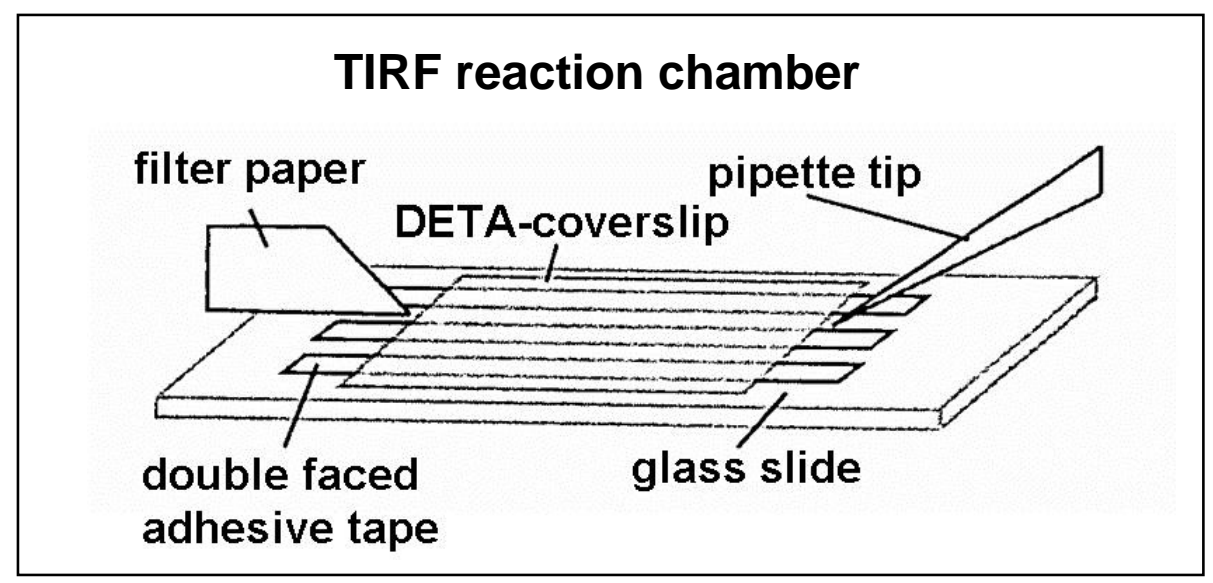

Fig. M5: TIRF reaction chamber

Experimental setup of the reaction chamber for single molecule measurements of the motors.

\section{Step 1) Microtubule fixation}

To prepare the microtubules ready to use a 1:70 dilution BRB-80 + Taxol $(1 \%(\mathrm{v} / \mathrm{v}))$ is set. When the solution is set in the chamber the positively charged microtubules are sticking at the negatively charged DETA coated cover slip. This procedure has to be set at minimal light exposure to save the TMR-fluorophore. The fixation is complete after 5 minutes 
incubation of the slide upside down and enhighted in a humid chamber (petri dish with a water soaked piece of wipe).

\section{Step 2) Blocking}

As the DETA surface is still very sticky for the motors a blocking of the DETA is necessary. Therefore a solution of casein is diluted 1:10 in BRB-80. The Microtubule solution is extracted and the chamber is filled with the blocking solution as described above and incubated 3 min as described above.

\section{Step 3) Motor insertion}

To reduce bleaching the motors are provided in an anti-bleach solution containing:

$40 \mu \mathrm{l} \mathrm{BRB}-80+$ Taxol $(1 \%(\mathrm{v} / \mathrm{v}))$

$1 \mu \mathrm{ATP}(100 \mathrm{mM})$

$1 \mu \mathrm{MgCl}_{2}(200 \mathrm{mM})$

$0.5 \mu \mathrm{IDTT}$

$0.5 \mu$ l glucose oxidase $(5 \mathrm{mg} / \mathrm{ml})$

$0.5 \mu \mathrm{l}$ catalase $40(8 \mathrm{mg} / \mathrm{ml})$

$0.5 \mu \mathrm{l}$ glucose $(1 \mathrm{M})$

$\mathrm{x} \mu \mathrm{l}$ Motor of interest (variable)

ad to $50 \mu \mathrm{l}$ with BRB-80 + taxol $(1 \%(\mathrm{v} / \mathrm{v}))$

The blotting solution is extracted and the chamber is filled with the motor/anti-bleach solution as described above and the sample is placed on the oiled objective. The focus (internal reflection) plane is determined by using the BP605/70. With this filter the microtubules appear as bright and distinct lines because of their TMR labelling. Documentation by a movie of 2 frames per second is started. After 5 seconds the filter is changed to the BP530/50, allowing detection of GFP molecules. The setting stays in this stage until movie frame 300. As the CCD camera is extremely sensitive, all measurements must be done in complete darkness.

\begin{tabular}{|c|c|c|c|c|}
\hline$\underline{\text { P12-buffer }}$ & & & $\underline{\operatorname{ATP}(100 \mathrm{mM})}$ & \\
\hline PIPES & $3.6 \mathrm{~g}$ & $12.0 \mathrm{mM}$ & ATP & $50,7 \mathrm{mg}$ \\
\hline EGTA & $0.38 \mathrm{~g}$ & $1.0 \mathrm{mM}$ & P12-buffer & ad $1.0 \mathrm{ml}$ \\
\hline $\mathrm{MgCl}_{2}$ & $95.2 \mathrm{mg}$ & $1.0 \mathrm{mM}$ & freeze in $10 \mu$ l aliquots & \\
\hline $\mathrm{dH}_{2} \mathrm{O}$ & ad $750 \mathrm{ml}$ & & & \\
\hline adjust $\mathrm{pH}$ to $\mathrm{pH} 7.0$ & & & & \\
\hline $\mathrm{dH}_{2} \mathrm{O}$ & ad 11 & & & \\
\hline$\underline{\mathrm{GTP}}(25 \mathrm{mM})$ & & & DTT $(1 \mathrm{M})$ & \\
\hline GTP & $13.1 \mathrm{mg}$ & & DTT & $154 \mathrm{mg}$ \\
\hline $\begin{array}{l}\text { P12-buffer } \\
\text { freeze in } 10 \mu l \text { aliquots }\end{array}$ & ad $1.0 \mathrm{ml}$ & & $\begin{array}{l}\text { P12-buffer } \\
\text { freeze in } 10 \mu \text { aliquots }\end{array}$ & ad $1.0 \mathrm{ml}$ \\
\hline$\underline{\mathrm{MgCl}_{2}(200 \mathrm{mM})}$ & & & glucose oxidase $(5 \mathrm{mg} / \mathrm{ml})$ & \\
\hline $\mathrm{MgCl}_{2}$ & $19.0 \mathrm{mg}$ & & glucose oxidase & $5.0 \mathrm{mg}$ \\
\hline $\begin{array}{l}\text { P12-buffer } \\
\text { freeze in } 10 \mu \text { aliquots }\end{array}$ & ad $1.0 \mathrm{ml}$ & & $\begin{array}{l}\text { P12-buffer } \\
\text { freeze in } 10 \mu \text { aliquots }\end{array}$ & ad $1.0 \mathrm{ml}$ \\
\hline
\end{tabular}




\begin{tabular}{|c|c|c|c|c|}
\hline \multicolumn{3}{|l|}{ BRB80-buffer } & \multicolumn{2}{|l|}{$\underline{\text { catalase } 40(8 \mathrm{mg} / \mathrm{ml})}$} \\
\hline PIPES & $24.1 \mathrm{~g}$ & $80.0 \mathrm{mM}$ & catalase 40 & $8 \mathrm{mg}$ \\
\hline EGTA & $0.38 \mathrm{~g}$ & $1.0 \mathrm{mM}$ & P12-buffer & ad $1.0 \mathrm{~m}$ \\
\hline $\mathrm{MgCl}_{2}$ (water free) & $95.2 \mathrm{mg}$ & $1.0 \mathrm{mM}$ & freeze in $10 \mu$ l aliquots & \\
\hline $\mathrm{dH}_{2} \mathrm{O}$ & ad $750 \mathrm{ml}$ & & & \\
\hline \multicolumn{5}{|l|}{ adjust $\mathrm{pH}$ to $\mathrm{pH} 7.0$} \\
\hline \multirow[t]{3}{*}{ ad $1.0 \mathrm{I}$} & & & & \\
\hline & & & glucose $(1 \mathrm{M})$ & \\
\hline & & & glucose & $180 \mathrm{mg}$ \\
\hline \multicolumn{3}{|l|}{ casein $(5 \mathrm{mg} / \mathrm{ml})$} & P12-buffer & ad $1.0 \mathrm{~m}$ \\
\hline \multirow{2}{*}{$\begin{array}{l}\text { casein } \\
\text { BRB } 80 \text {-buffer } \\
\text { freeze in } 10 \mu l \text { aliquots }\end{array}$} & $5.0 \mathrm{mg}$ & & freeze in $10 \mu$ l aliquots & \\
\hline & ad $1.0 \mathrm{ml}$ & & & \\
\hline \multirow[t]{4}{*}{ ad 1.01} & & & $\underline{\operatorname{taxol}(1 \mathrm{mM})}$ & \\
\hline & & & taxol & $0.85 \mathrm{mg}$ \\
\hline & & & DMSO & ad $1.0 \mathrm{~m}$ \\
\hline & & & freeze in $10 \mu$ l aliquots & \\
\hline
\end{tabular}

\subsubsection{Microtubule Gliding Assay}

The Microtubule Gliding Assay is a suitable assay to test the activity of molecular motors and to get information about the properties of motor proteins.

Motor proteins are fixed to a cover slip either passively (when it sticks itself on the glass surface) or actively (by fixing suitable antibodies on the glass surface and fixing the motor proteins to the antibody). Using TMR-labelled microtubules motor activity can be monitored as the carpet of motor proteins is moving the labelled microtubules in an active and measurable way.

The reaction chamber is manufactured identically to the chamber for the TIRF-Microscopy apart from using untreated cover slips instead of DETA coated ones.

\section{1) Pre-coating for motor fixation (optional, when motor is sticky enough itself)}

Protein G solution is mixed with BRB-80 in a 1:5 ratio and $10 \mu \mathrm{l}$ of the solution is set into the chamber. For emptying the chamber on one side a filter paper is placed, soaking the volume out of the chamber, on the other side the new content is placed with a pipette. The suction of the filter paper is filling the chamber, when the drop with the new content that is placed at the other side of the chamber. After $10 \mathrm{~min}$ incubation at RT the Protein $\mathrm{G}$ solution is replaced as described by a $1: 1$ mixture of the $A B$-solution (here anti-His $A B$ ) with BRB-80. This solution is incubated in the chamber for 10 minutes at RT. 


\section{2) Motor protein coating}

The motor protein solution is prepared identically to the procedure for the TIRF Microscopy but on this step no anti-bleach solution is needed. It is recommended to start with much higher concentration of the motor proteins, than in the single molecule assay.

\section{3) Mictotubule insertion}

Microtubules are prepared equivalent to those for TIRF Microscopy but with a 1:1 ratio instead a 1:3 ratio of labelled to unlabeled MTs. To reduce bleaching the MTs is provided in an anti-bleach solution containing:

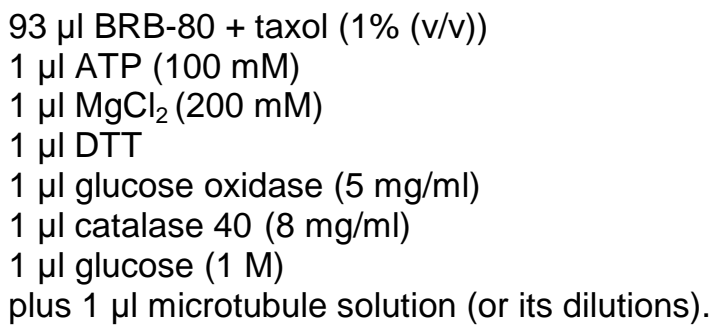

The motor solution is extracted and the chamber filled with the MT/anti-bleach solution as described above. The chamber is set to the oiled objective up side down. The movies are performed with the Coolsnap ${ }^{\mathrm{TM}} \mathrm{EZ}$ (Photometrics) using Winsprec.

\begin{tabular}{|c|c|c|c|c|}
\hline \multicolumn{3}{|l|}{ BRB80-buffer } & \multicolumn{2}{|l|}{ casein $(5.0 \mathrm{mg} / \mathrm{ml})$} \\
\hline PIPES & $24.1 \mathrm{~g}$ & $80.0 \mathrm{mM}$ & casein & $5.0 \mathrm{mg}$ \\
\hline EGTA & $0.38 \mathrm{~g}$ & $1.0 \mathrm{mM}$ & BRB 80-buffer & ad $1.0 \mathrm{~m}$ \\
\hline $\mathrm{MgCl}_{2}$ (water free) & $95.2 \mathrm{mg}$ & $1.0 \mathrm{mM}$ & freeze in $10 \mu \mathrm{l}$ aliquots & \\
\hline $\mathrm{dH}_{2} \mathrm{O}$ & ad $750 \mathrm{ml}$ & & & \\
\hline \multicolumn{5}{|l|}{ adjust $\mathrm{pH}$ to $\mathrm{pH} 7.0$} \\
\hline $\mathrm{dH}_{2} \mathrm{O}$ & ad $1.0 \mathrm{I}$ & & $\underline{\text { ATP }(100 \mathrm{mM})}$ & \\
\hline & & & ATP $\mathrm{Na}_{2}$ & $50.7 \mathrm{mg}$ \\
\hline & & & P12-buffer & ad $1.0 \mathrm{~m}$ \\
\hline Protein G & & & freeze in $10 \mu \mathrm{l}$ aliquots & \\
\hline Protein G & $5 \mathrm{mg}$ & & $\underline{\mathrm{DTT}}(1 \mathrm{M})$ & $154 \mathrm{mg}$ \\
\hline $\mathrm{dH}_{2} \mathrm{O}$ & ad $1.0 \mathrm{ml}$ & & DTT & ad $1.0 \mathrm{~m}$ \\
\hline \multicolumn{3}{|c|}{ aliquot in $20 \mu \mathrm{l}$ fractions and store at $-20^{\circ} \mathrm{C}$} & $\begin{array}{l}\text { P12-buffer } \\
\text { freeze in } 10 \mu \text { l aliquots }\end{array}$ & \\
\hline \multicolumn{5}{|l|}{ anti-His $A B$} \\
\hline anti $\mathrm{His} A B$ & $100 \mu \mathrm{g}$ & & glucose oxidase $(5.0 \mathrm{mg} / \mathrm{ml})$ & \\
\hline \multirow{2}{*}{$\begin{array}{l}\mathrm{dH}_{2} \mathrm{O} \\
\text { aliquot in } 20 \mu \mathrm{l} \text { fractions and store } \\
\text { at }-20^{\circ} \mathrm{C}\end{array}$} & ad $1.0 \mathrm{ml}$ & & glucose oxidase & \\
\hline & & & $\begin{array}{l}\text { P12-buffer } \\
\text { freeze in } 10 \mu \text { aliquots }\end{array}$ & ad $1.0 \mathrm{~m}$ \\
\hline \multicolumn{5}{|l|}{ P12-buffer } \\
\hline PIPES & $3.6 \mathrm{~g}$ & $12.0 \mathrm{mM}$ & catalase $40(8 \mathrm{mg} / \mathrm{ml})$ & \\
\hline EGTA & $0.38 \mathrm{~g}$ & $1.0 \mathrm{mM}$ & catalase 40 & $8 \mathrm{mg}$ \\
\hline $\mathrm{MgCl}_{2}$ (water free) & $95.2 \mathrm{mg}$ & $1.0 \mathrm{mM}$ & P12-buffer & ad $1.0 \mathrm{~m}$ \\
\hline $\mathrm{dH}_{2} \mathrm{O}$ & ad $750 \mathrm{ml}$ & & freeze in $10 \mu \mathrm{l}$ aliquots & \\
\hline
\end{tabular}


GTP $(25 \mathrm{mM})$

GTP $\mathrm{Na}^{+}$salt

P12-buffer

freeze in $10 \mu \mathrm{l}$ aliquots

$\mathrm{MgCl}_{2}(200 \mathrm{mM})$

$\mathrm{MgCl}_{2}$ (water free)

P12-buffer

freeze in $10 \mu \mathrm{l}$ aliquots
$13.1 \mathrm{mg}$

ad $1.0 \mathrm{ml}$

$19.0 \mathrm{mg}$

ad $1.0 \mathrm{ml}$ glucose $(1.0 \mathrm{M})$

glucose

P12-buffer

$180 \mathrm{mg}$

freeze in $10 \mu$ l aliquo

$\underline{\operatorname{taxol}(1 \mathrm{mM})}$

taxol

$0.85 \mathrm{mg}$

DMSO

ad $1.0 \mathrm{ml}$

freeze in $10 \mu$ aliquots

\subsubsection{Circular Dichroism}

Circular Dichroism (CD) is a method used for determination of secondary structures of peptides and proteins since middle of last century (Fasman, 1996). The method is based on the differential absorption of left and right circularly polarized light by optically active chiral molecules.

\section{Characteristic patterns of CD spectra.}

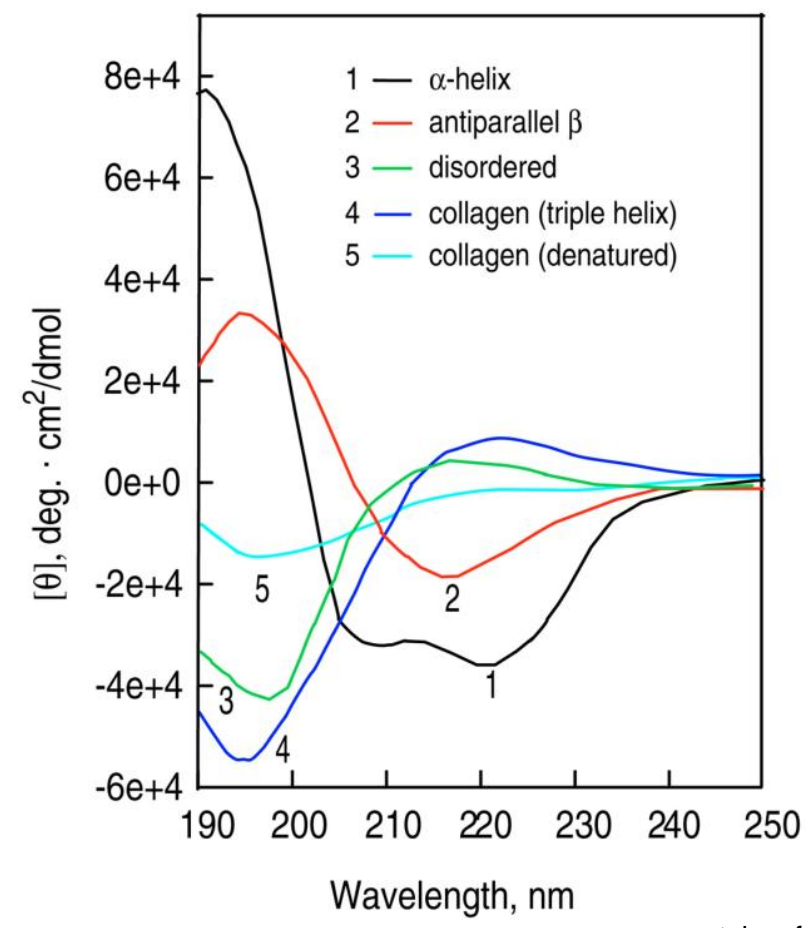

taken from Greenfield, 2006

Fig. M6: Characteristic patterns of CD spectra

For the experiments in this thesis the synthesized peptides have been diluted to a concentration of $1 \mathrm{ng} / \mu \mathrm{l}$ in $0.1 \mathrm{M}$ HEPES buffer with $\mathrm{pH}$ 8.0. 


\subsubsection{Dual-focus FCS}

Dual-focus fluorescence correlation spectroscopy is a method for accurate and absolute diffusion measurements. The setup is described in detail by Dertinger (Dertinger et al., 2007). The light of two identical, linearly polarized pulsed diode lasers is combined by a polarizing beam splitter. Both lasers are pulsed alternately and beams are coupled into a polarization-maintaining single mode fiber. At the fiber output, the light is collimated and reflected by a dichroic mirror towards the microscope's objective and deflected into slightly different directions, so that after focusing one objective obtains two laterally shifted but overlapping excitation foci with $420 \mathrm{~nm}$ distance. Fluorescence is collected by the same objective, passed through the dichroic mirror, focused, split by a 50/50 beam splitter, and focused onto two single-photon avalanche diodes. Single-photon counting electronics records the signals of both detectors independently with an absolute temporal resolution of two picoseconds on a common time frame. Recording photon detection times with picosecond resolution allows associating each fluorescence photon with the laser pulse that has excited it, and thus with the focus it was excited in. With this information, the auto- and cross-correlation curves are calculated. Finally, a global fit of the obtained data is done with a model using three crucial fit parameters: two parameters for the main distribution frame (MDF), and the diffusion coefficient.

With this information we can evaluate the distances between 2 fluorophores passing the field. Using GFP-tagged mini motors of UNC-104 conclusions with respect to the conformational state can be drawn. If the distance is stable and close together, we can conclude a homodimer, if distances vary a solution of monomeric proteins will be suitable. If there is a mixed population a peak in small distanced fluorophores is a hint of dimeric forms of the protein.

The protein was diluted with BRB80 buffer plus DTT and ATP to a concentration of $100 \mathrm{pM}$ and analyzed for $20 \mathrm{~min}$.

$\begin{array}{lll}\text { BRB80-buffer } & & \\ \text { PIPES } & 24.1 \mathrm{~g} & 80.0 \mathrm{mM} \\ \text { EGTA } & 0.38 \mathrm{~g} & 1.0 \mathrm{mM} \\ \mathrm{MgCl}_{2} \text { (water free) } & 95.2 \mathrm{mg} & 1.0 \mathrm{mM} \\ \mathrm{dH}_{2} \mathrm{O} & \text { ad } 750 \mathrm{ml} & \\ \text { adjust pH to } \mathrm{pH} 7.0 & & \\ \mathrm{dH}_{2} \mathrm{O} & \mathrm{ad} 1.0 \mathrm{I} & \\ \text { DTT (fresh) } & 1.0 \mathrm{mM} & \\ \text { ATP (fresh) } & 0.1 \mathrm{mM} & \end{array}$




\subsection{In silico calculation}

\section{Evaluation of coiled coil probability}

To predict the coiled-coil probability of the neck region of UNC-104, "COILS" algorithm available at http://expasy.org/tools is used focussing on a 21 aa frame for heptad motif calculation. The prediction is based on the calculation of the region from amino acid (aa) 331 to aa 401 of UNC-104. 


\subsection{Chemicals und Reagents}

\begin{tabular}{|c|c|}
\hline acetic acid & Carl Roth \\
\hline acrylamid/bis-acrylamid $(30 \% / 0.8 \%(w / v))$ & Carl Roth \\
\hline agar agar & Carl Roth \\
\hline agarose & Carl Roth \\
\hline Amersham Hyperfilm ${ }^{\circledR}$ ECL & Amersham \\
\hline ammonium peroxosulfate (APS) & Carl Roth \\
\hline ampicillin & Carl Roth \\
\hline AMP-PNP & SIGMA-ALDRICH $^{\circledR}$ \\
\hline ATP $\mathrm{Na}_{2}$ (adenosine triphosphate) & SIGMA-ALDRICH $^{\circledR}$ \\
\hline$\beta$-mercaptoethanol & Carl Roth \\
\hline bromphenol blue & SIGMA-ALDRICH $^{\circledR}$ \\
\hline $\mathrm{CaCl}_{2} \times \mathrm{H}_{2} \mathrm{O}$ & Carl Roth \\
\hline cholesterol & SIGMA-ALDRICH ${ }^{\circledR}$ \\
\hline CHR filter papers $3 \mathrm{MM}$ & Whatman \\
\hline Coomassie Brilliant Blue G 250 & Fluka \\
\hline DETA & SIGMA-ALDRICH ${ }^{\circledR}$ \\
\hline Dimethylformamide (HiDi) & $\mathrm{ABI}$ \\
\hline DMSO (dimethyl sulfoxide) & Carl Roth \\
\hline DNA1kb ladder & Fermentas \\
\hline DNA-Loading buffer $(6 \mathrm{x})$ & Fermentas \\
\hline DTT & AppliChem \\
\hline dNTP mix & Invitrogen, New England Biolabs \\
\hline EDC (1-Ethyl-3-[3-dimethylaminopropyl]carbodiimide hydrochloride) & Thermo Scientific Pierce \\
\hline EDTA $\times \mathrm{H}_{2} \mathrm{O}$ & Carl Roth \\
\hline EGTA & Carl Roth \\
\hline ethanol p.a. & Carl Roth \\
\hline ethanol techn. & Carl Roth \\
\hline ethidium bromide & Carl Roth \\
\hline FITC Isomer1 & Calbiochem \\
\hline Fluoro Spheres ${ }^{\circledR}, 1.0 \mu \mathrm{m}$ & Molecular Probes \\
\hline glucose & Fluka \\
\hline Glycerol 99\% & Carl Roth \\
\hline glycine & AppliChem \\
\hline GTP Na salt(guanidine triphosphate) & SIGMA-ALDRICH $^{\circledR}$ \\
\hline $\mathrm{H}_{2} \mathrm{O}_{2}(30 \%)$ & Merck Chemicals \\
\hline $\mathrm{HCl}$ & Carl Roth \\
\hline HEPES (4-(2-hydroxyethyl)-1-piperazineethanesulfonic acid) & Carl Roth \\
\hline imidazole & SIGMA-ALDRICH $^{\circledR}$ \\
\hline Immersol 518F & Zeiss \\
\hline isopropanol & Carl Roth \\
\hline isopropyl $\beta$-D-1-thiogalactopyronoside (IPTG) & Carl Roth \\
\hline $\mathrm{K}_{2} \mathrm{HPO}_{4}$ & Carl Roth \\
\hline $\mathrm{KCl}$ & Carl Roth \\
\hline $\mathrm{KH}_{2} \mathrm{PO}_{4}$ & AppliChem \\
\hline $\mathrm{KOH}$ & Merck Chemicals \\
\hline L-15 medium & Lonza \\
\hline levamisole (tetramisole hydrochloride) & Fluka \\
\hline $\mathrm{MgCl}_{2}$ (water free) & Fluka \\
\hline $\mathrm{MgSO}_{4} \times 7 \mathrm{H}_{2} \mathrm{O}$ & Merck Chemicals \\
\hline milkpowder & Carl Roth \\
\hline $\mathrm{Na}_{2} \mathrm{H} \mathrm{PO}_{4} \times 2 \mathrm{H}_{2} \mathrm{O}$ & Carl Roth \\
\hline $\mathrm{NaCl}$ & Carl Roth \\
\hline $\mathrm{NaOH}$ & Merck Chemicals \\
\hline NHS & Thermo Scientific Pierce \\
\hline Ni-NTA beads & Quiagen \\
\hline nitrocellulose Protran ${ }^{\circledR}$ & Whatman \\
\hline nystatin & SIGMA-ALDRICH $^{\circledast}$ \\
\hline Page ruler ${ }^{\mathrm{TM}}$ Prestained Protein Ladder Plus & Fermentas \\
\hline peanut lectin & SIGMA-ALDRICH ${ }^{\circledR}$ \\
\hline peptone & Carl Roth \\
\hline PIPES (dipotassium salt) & SIGMA-ALDRICH $^{\circledR}$ \\
\hline PMSF & Carl Roth \\
\hline Ponceau S & Carl Roth \\
\hline protease inhibitor coctail & Roche Diagnostics \\
\hline sodium acetate & Carl Roth \\
\hline sodium dodecyl sulfate (SDS) & Carl Roth \\
\hline
\end{tabular}




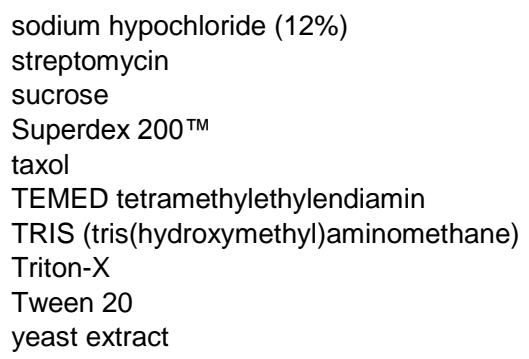

\author{
Carl Roth \\ SIGMA-ALDRICH ${ }^{\circledR}$ \\ SIGMA-ALDRICH ${ }^{\circledR}$ \\ GE-Healthcare \\ SIGMA-ALDRICH \\ Carl Roth \\ Carl Roth \\ Fluka \\ Carl Roth \\ Carl Roth
}

General laboratory equipment and consumables are provided by following companies:

Becton Dickinson, Braun, Corning, Eppendorf, Falcon, Kimberley Clark, Life Science Products, Menzel, Milipore, Omnilab, Qualilab, Sarstedt, Schott and Terumo.

For experiments including $C$. elegans is is impotrant to use tubes from Corning as those increase yield because the worms do less attach and stick at the synthetic material.

\subsection{Kits, Enzymes and Antibodies}

\author{
$\underline{\text { Kits }}$ \\ BigDye ${ }^{\circledR}$ Terminator v3.1 Cycle Sequencing kit \\ ECL ${ }^{\mathrm{TM}}$ WB Detection kit \\ Ligation Kit 2.1 \\ NucleoBond ${ }^{\circledR}$ AX \\ NucleoSpin ${ }^{\circledR}$ Plasmid Kits \\ QuikChange ${ }^{\circledR}$ Site-Directed Mutagenesis Kit \\ Wizard $^{\circledR}$ SV Gel and PCR Clean-Up system \\ Wizard $^{\circledR}$ PlusSV Miniprep Kit
}

\section{enzymes and antibodies (AB)}

all restriction endonucleases

anti -tubulin-1 $A B$

anti-GFP $A B$

catalase 40

chitinase

glucose oxidase

T4-ligase

Vent polymease high-fidelity PCR

\section{organisms}

C.elegans (WT, Bristol strain)

E. coli BL21 gold (DE3)

E. coli DH5a Competent Cells

E. coli OP50-1

E. coli TOP-10

E. coli XL10-Gold
$\mathrm{ABI}$

Amersham

TaKaRa

Machery-Nagel

Machery-Nagel

Stratagene

Promega

Promega

New England Biolabs
invitrogen
Roche diagostics
SIGMA-ALDRICH
SIGMA-ALDRICH
SIGMA-ALDRICH
Invitrogen
New England Biolabs

Caenorhabditis Genetics Center

Stratagene

ilvitrogen

Caenorhabditis Genetics Center

Invitrogen

Stratagene 


\title{
4.9 Device and Equipment
}

\author{
Allegra X-15R Centrifuge \\ ANDOR2, iXon DV885LC-VP EM-CCD camera \\ Arium $^{\circledR} 611$ \\ Avanti $^{\mathrm{TM}} \mathrm{J}-26 \mathrm{XP}$ Centrifuge \\ Axiovert 200M \\ BioPhotometer \\ BioRad Micro Pulser ${ }^{\mathrm{TM}}$ \\ Calypso 200 laser \\ Centrifuge 5415 D \\ Centrifuge $5415 \mathrm{R}$ \\ Centrifunge 5417R \\ Concentrator plus \\ CP224 S (balance) \\ CP3202 P (balance) \\ Dual view ${ }^{\circledR}$ \\ EBQ100 \\ Eppendorf Research Pipettes \\ EV231 power supply \\ Femtotips ${ }^{\oplus}$ II \\ gel electrophoreisis system \\ GFL 1083 water bath \\ Glass Bottom Culture Dishes 1.0 \\ Incubator MIR-136 \\ Incubator MIR-235 \\ Leica KL 1500 LCD \\ Leica M7FLIII \\ Leica MZ6 \\ Mastercycler epgradient-S \\ Mastercycler personal \\ Megafuge 1.0 \\ Micro centrifuge 2 \\ Mini Trans-Blot ${ }^{\circledR}$ Electrophoretic Transfer system \\ MR 3001 (magnetic stirrer) \\ Optima $^{\text {TM }}$ L-90K Utracentrifuge \\ Optima $^{\mathrm{TM}}$ Max Utracentrifuge \\ Pipet aid \\ Plasma Cleaner \\ Sartorius PB-11 (pH-meter) \\ Scotsman AF 100 (ice machine) \\ Sonifier 250 \\ Systec D-150 Autoclave \\ Thermomixer comfort \\ Thermomixer compact \\ Trans-Blot $\AA$ Electrophoretic Transfer system \\ Ultra Low Temperature Freezer \\ Vacuum pump STV \\ Vortex genie 2.1 \\ Vacuum pump STV
}

Beckmann \& Coulter
Andor
Millipore
Beckmann \& Coulter
Zeiss
Eppendorf
BioRad
Cobalt
Eppendorf
Eppendorf
Eppendorf
Eppendorf
Sartorius
Sartorius
Insight Electronics
Kübler
Eppendorf
Consort
Eppendorf
BioRad
GFL
MatTek Corp.
Sanyo
Sanyo
Leica
Leica
Leica
Eppendorf
Eppendorf
Heraeus
LabTech
Bio Rad
Heidolph
Beckmann \& Coulter
Beckmann \& Coulter
Drummond
Harrick
Sartorius
Scotsman
Branson
Systec
Eppendorf
Eppendorf
Bio Rad
New Bruswick Scientiffic
ATB
VWR international
ATB

Beckmann \& Coulter

Beckmann \& Coulter

Cobalt

endor

Eppendorf

Sartorius

Insight Electronics

Kübler

BioRad

Sanyo

Leica

Leica

Eppendor

Heraeus

LabTech

Beckmann \& Coulter

Sartorius

Scotsman

Eysec

Eppendorf

New Bruswick Scientiffic

VWR international

ATB 


\section{RESULTS}

The initial aim of the thesis is to find and evaluate suitable mutations in the neck linker region that influence coiled-coil formation and therefore influence hypothesized dimer formation. Coiled-coil promoting and coiled-coil impairing mutations in the UNC-104 proteins have to be expressed and analyzed in $C$. elegans to test if these mutated proteins are functional in vivo. With this information, conclusions with respect to the importance of coiled-coil probability and putative dimer formation can be drawn.

\subsection{Prediction of coiled-coils}

To predict the coiled-coil probability of the neck region of UNC-104, COILS algorithm available at http://expasy.org/tools is used. The prediction is based on the calculation of the region from amino acid (aa) 331 to aa 401 of UNC-104, a domain, c-terminally adjacent to the motor domain and constitutes the neck linker and the neck coiled-coil domain.

Conventional kinesin (kinesin-1) is a constitutive homodimer with its dimerization region in the coiled-coil neck region. Fig. $\mathrm{R} 1$ shows a continuous repetition of heptad motifs given by positions $a$ and $d$ within this region. Focussing on the UNC-104 WT sequence the first heptad motif begins 5 aa after the start of the neck coiled-coil region at aa 362 . This is one of the reasons why UNC-104 has only a $70 \%$ probability of coiled-coil formation in predictions. In order to test the stability of the coiled-coil structure, point mutants are introduced to effectively raise or abolish coiled-coil probability and therefore coiled-coil formation. In detail, in construct E355V/P357K/N358L/K379L/G380R and construct E355V/P357K/N358L, the heptad area is enlarged by one heptad motif. In the constructs E355V/P357K/N358L/K379L/G380R and K379L/G380R the coiled-coil formation is stabilized in the back of the neck coiled-coil (Fig. R1 and Fig. R2 A). The I362G and L365G constructs show a weakened first heptad motif due to an exchange of the hydrophobic amino acids (aa) leucine and isoleucine by glycine. The double mutant construct I362G/L365G shows a loss of the first heptad motif due to exchange of both hydrophobic aa by glycine. The I362E/L365K construct misses the first two heptad motifs (in prediction) by the exchange of two hydrophobic aa by ionic ones. Construct E355V/P357K/N358L/K379L/G380R has a 31 aa area motif with a predicted coiled-coil probability of more than 95\%. K379L/G380R shows a 27 aa area with a coiled-coil 


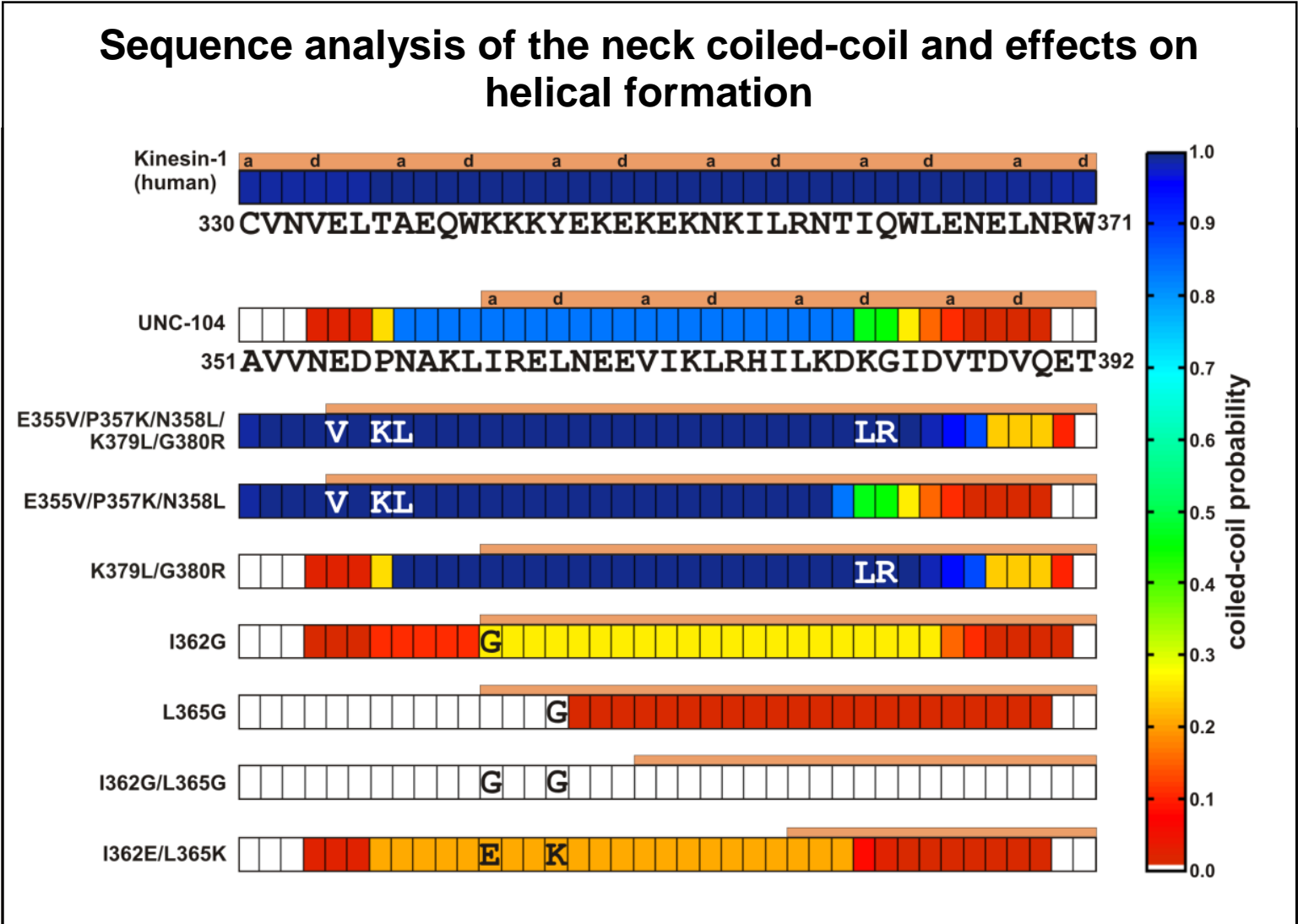

Fig. R1: Sequence analysis of the neck coiled-coil an effects on helical formation

Sequence analysis of the neck coiled-coil of kinesin-1, UNC-104 and UNC-104 point mutants and their effects on helical formation. The numbers near the sequence are representing the first and last number of the aa in the area of interest. The heat map is representing the coiled-coil probability in aa resolution, given by COILS. The bar above the heatmap shows the heptad motif recognition by COILS, marked with the important a and d positions. As heptad progression is defined for WT-UNC-104, a and d positions are omitted in the mutant UNC-104 constructs.

probability of more than $80 \%$ including a 23 aa section with a more than $95 \%$ probability. Construct E355V/P357K/N358L shows a 26 aa area with a predicted coiled-coil probability of more than $80 \%$ including a 22 aa section with an more than $95 \%$ coiled-coil probability. Construct E355V/P357K/N358L/K379L/G380R, construct E355V/P357K/N358L and construct K379L/G380R are from now on classified as coiled-coil promoting constructs. The WT-sequence shows a 21 aa window with more than $70 \%$ coiled-coil probability. L365G has a 21 aa area with a coiled-coil probability of more than $4 \%$. I362G and I362G/L365G do not show any probability of coiled-coil formation greater than $0.1 \%$. The I362E/L365K mutant has an exposed position with two impaired heptad motifs. I act on the assumption that a predicted coiled-coil region with a length smaller than 22 aa and an average probability below $33 \%$ behaves as a bona fide monomer in vivo. The four last mentioned mutants, construct I362G, construct L365G, construct I362G/L365G and construct I362E/L365K are from now on classified as coiled-coil impaired constructs. 
Coiled-coil probability of the neck linker / neck coiled-coil region

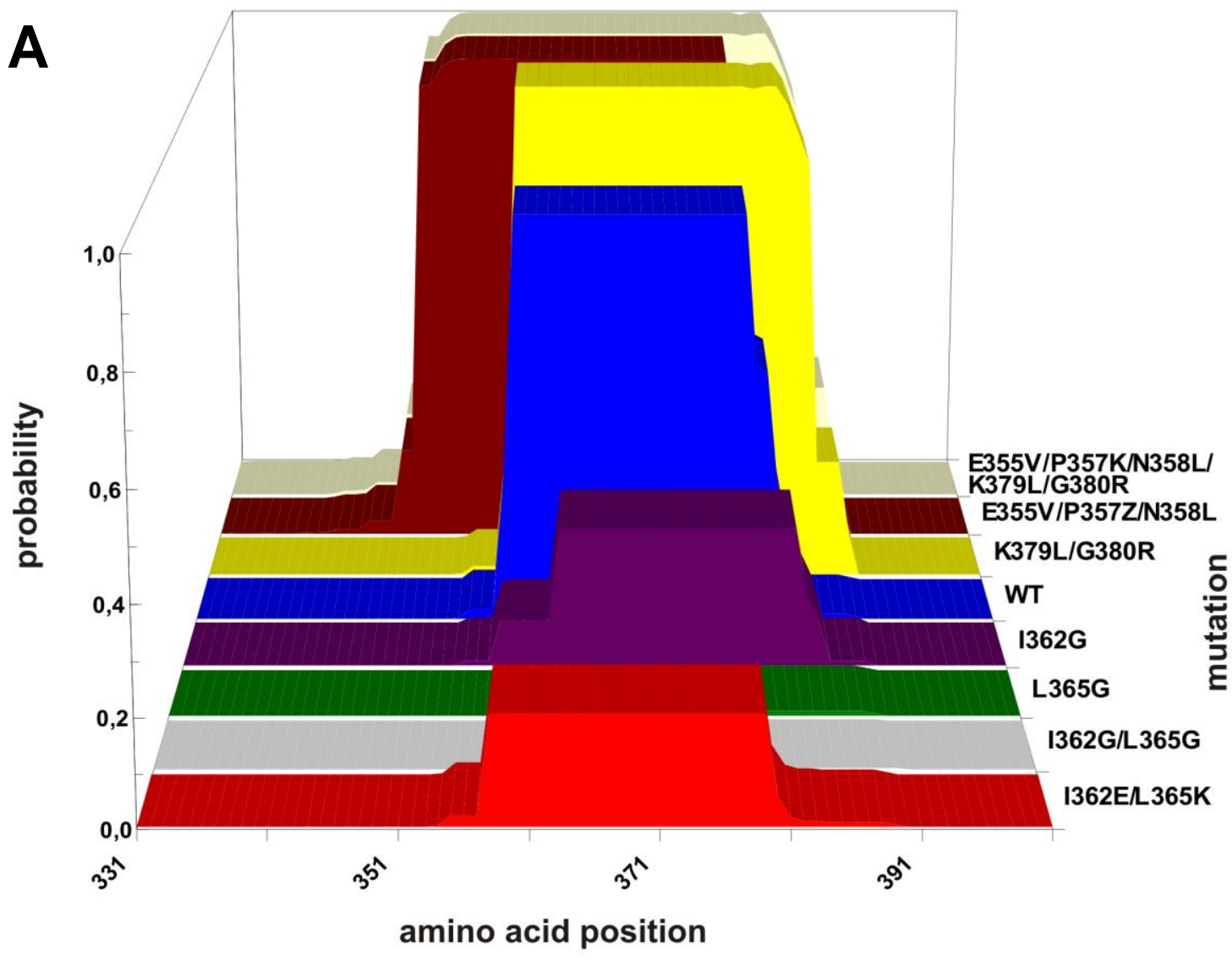

B

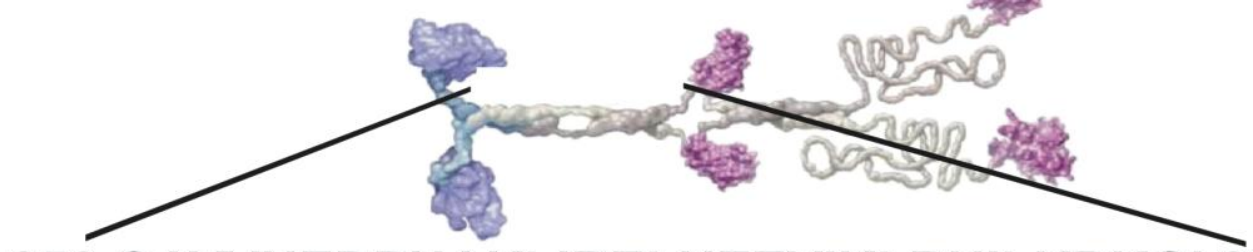

350 QAVVNEDPNAKLIRELNEEVIKLRHILKDKGI 382

E355V/P357K/N358L/ K379L/G380R

\section{E355V/P357K/N358L}

K379L/G380R

WT

I362G

L365G

I362G/L365G

I362E/L365K

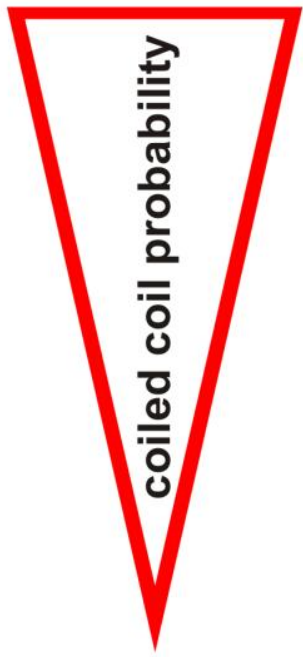


Fig. R2: Coiled-coil probability of the neck linker / neck coiled-coil region

A) Coiled-coil probability of UNC-104 constructs in 3-dimensional arrangement, including neck linker and the $\mathrm{N}$-terminal part of the hinge region of the motor protein. It shows the general predicted probability and the length of the inception responsible for the coiled-coil formation. The $y$-axis shows the coiled-coil probability with 0.0 for $0 \%$ and 1.0 for $100 \%$ probability. The $x$-axis gives the position of the responsible aa while the z-axis shows the responsible mutation. B) Schematic classification of the mutant constructs with respect to WT.

With three putative coiled-coil promoting and four coiled-coil impairing constructs (in reference to WT) a promising set of constructs to address our questions is created.

To additionally distinguish the mutants and mutant strains a color code is given in Fig. R2 B. The mutants on top of the WT are the coiled-coil promoting constructs, those constructs below WT are the coiled-coil impaired constructs. The ranking regarding coiledcoil probability was chosen based on putative heptad motif formation.

\subsection{Testing alpha helical contents by circular dichroism}

The "COILS" prediction program by http://expasy.org/tools is commonly used for coiledcoil predictions, but additionally the $\alpha$-helical content of two mutants examined by circular dichroism (CD) spectra in collaboration with Kathrin Wiederhold and Dr. Jürgen Klingauf at the Max Planck Institute for Biophysical Chemistry.

\section{Circular dichroism spectra of modified peptideds of UNC-104}

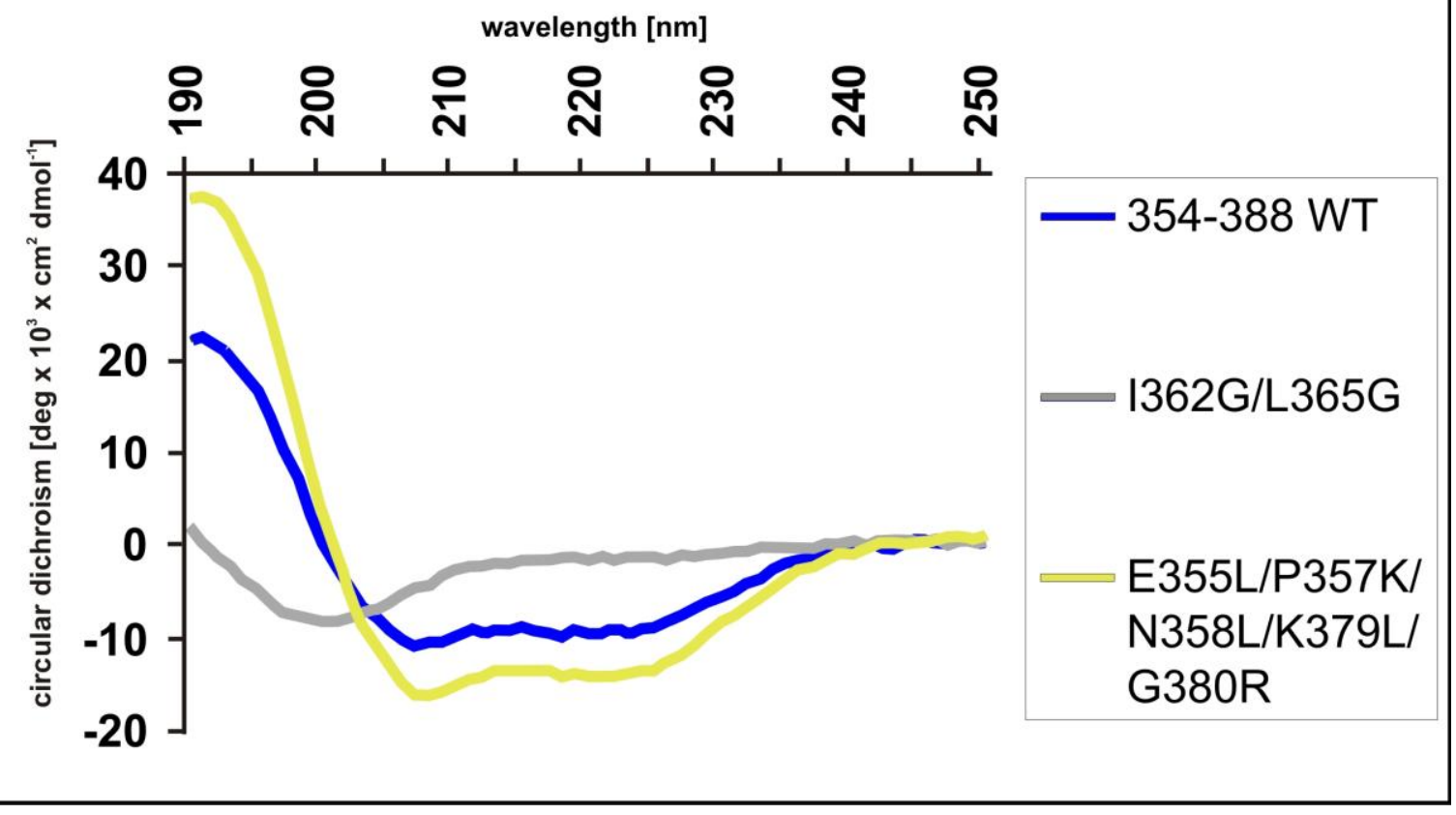

Fig. R3: Circular dichroism spectra of modified peptides of UNC-104 CD spectra of modified peptides of UNC-104 neck region 
The I362G/L365G double mutation in the WT aa-sequence shows a baseline between $210 \mathrm{~nm}$ and $235 \mathrm{~nm}$ that lies near to $0 \mathrm{deg} \times \mathrm{cm}^{2} \mathrm{dmol}^{-1}$ rotation. This indicates that this peptide does not exist in a helical structure during measurement. The E355V/P357K/N358L/K379L/G380R quintruple mutation reaches -10 to $-15 \times 10^{3}$ deg $x$ $\mathrm{cm}^{2} \mathrm{dmol}^{-1}$ rotation in this wavelength area that indicates a stable $\alpha$-helical formation. The values of the WT sequence range between those of the mutated peptides. As $\alpha$-helix formation is necessary for building a coiled-coil structures, this data are affirmative results for the in silico prediction by "COILS".

\subsection{Constructs}

In this thesis the determination of the conformational state will be addressed using in vivo and in vitro assays. Therefore it is necessary to design constructs suitable for in vivo expression of the modified UNC-104 motor and constructs suitable for several in vitro assays.

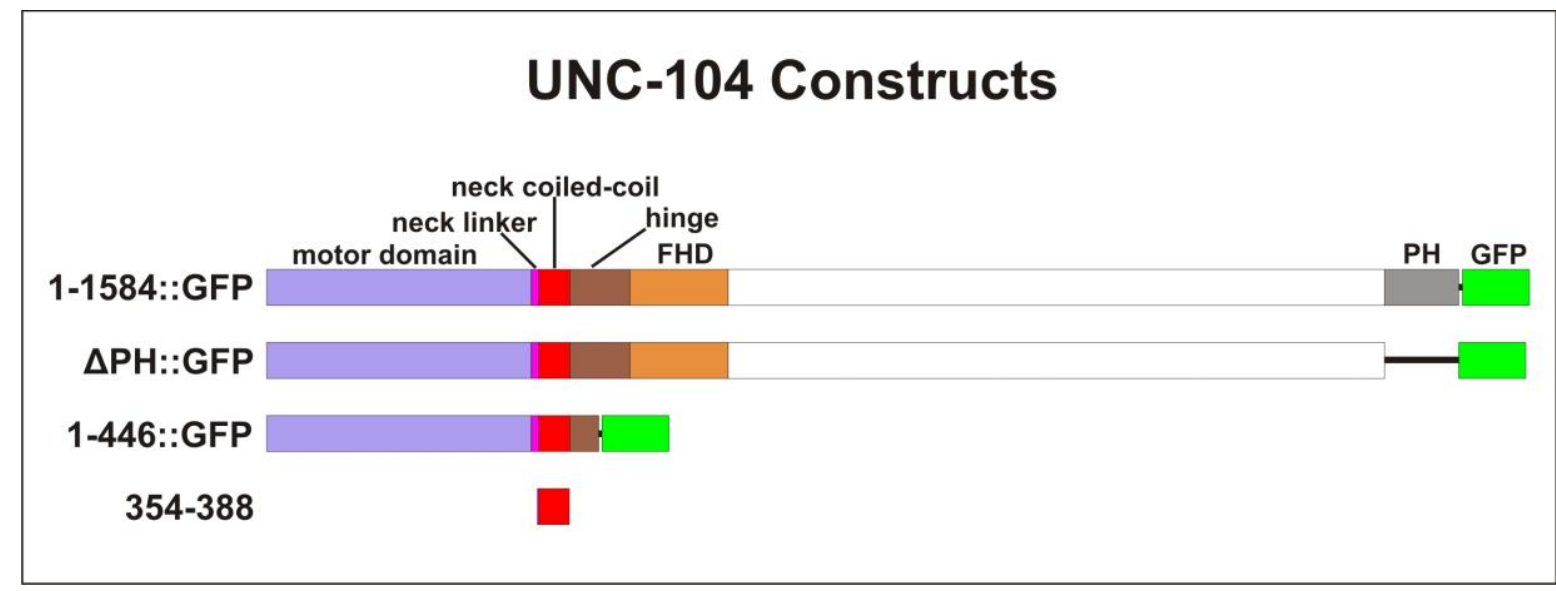

Fig. R4: UNC-104 constructs

UNC-104 domain organization, deletion mutation and peptide. A schematic representation drawn to scale of UNC-104's structure is shown on top (from left to right): an amino-terminal motor domain (aa 1-348), neck linker (aa 349-357), neck coiled-coil (aa 358-389), hinge region (aa 390-462) fork-head-homology (FHA) domain (aa 463-592), elongated stalk region of unknown structure and a C-terminal pleckstrin homology $(\mathrm{PH})$ domain (aa 1460-1584). Construct 1-1584::GFP (and its modified forms) is representing the full-length UNC-104. The green fluorescence protein was added at the carboxy-terminus. Constructs $\triangle P H:: G F P$ and $1-446:: G F P$ are created by either deletions of the $\mathrm{PH}$ domain or truncation within the hinge region. The neck-region peptide 354-388 and its modified forms are synthesized.

To get access to information of the conformational state of UNC-104 during axonal transport in vivo two kinds of constructs (Fig. R4) are used. The WT full length (1-1556, $\mathrm{FL}$ ) constructs, including all its modified forms as describes above, and the $\Delta \mathrm{PH}$ construct are expressed in $C$. elegans. Two other kinds of constructs are designed to get accessory 
information in vitro. The truncated form UNC-104-1-446::GFP from now on called "mini motor" is used in in vivo assays to examine the biophysical properties and the neck-region peptide (354-388) of UNC-104 and for CD spectra as described above.

\subsection{Testing coiled-coil point mutations in vivo}

To examine the motor properties of UNC-104 under physiological conditions an investigation of motor behaviour in a suitable model organism is required. I decided to respond to my questions in the model organism $C$. elegans. One big advantage compared to an in vitro system (e.g. cell culture) is an expression under the endogenous UNC-104 promoter and therefore an perfect expression restriction control for the motor. Another advantage of the observations in living $C$. elegans is the direct detection of motor behaviour in fully differentiated neurons under their native conditions. Cell culture even of primary neurons can not provide any information and effects for surrounding cells, probably induced by effects of the expressed constructs.

As knock out of UNC-104 is lethal, another genetical background for the constructs has to be chosen. The background worm strain has to be vivid and reproductive and has to express as little UNC-104 as possible. The hypomorph $C$. elegans strain unc104(e1265) wears these properties and is therefore a suitable background for answering the questions in this thesis. In this strain the endogenous UNC-104 motor has a severe point mutation (D1497N) in the cargo binding domain impairing Ptdlns $(4,5) \mathrm{P}_{2}$ binding and the total amount of endogenic protein is reduced (Kumar et al., 2010). Another advantage of unc-104(e1265) is, that this stain shows an uncoordinated (unc) movement. This means, that its motility is impaired, in this case because of impaired innervation of the body wall muscles (Zhou et al., 2001). The expression of functional UNC-104 motors in unc-104(e1265) will compensate the negative effects of the mutation and therefore rescues the unc phenotype.

For the expression of point mutated motors the FL-unc-104::GFP constructs PPD 95.77 are injected into the gonads of young adult unc-104(e1265) worms. Transgene progenies are separated, cultivated and characterized and the expression levels of the different constructs are visualized by Western blot. As control strains, the non-transgenic background (unc-104(e1265)) and the unmodified origin WT worm strain (C. elegans Bristol N2) are used. 


\section{Expression levels of the UNC-104 constructs in C. elegans}

A

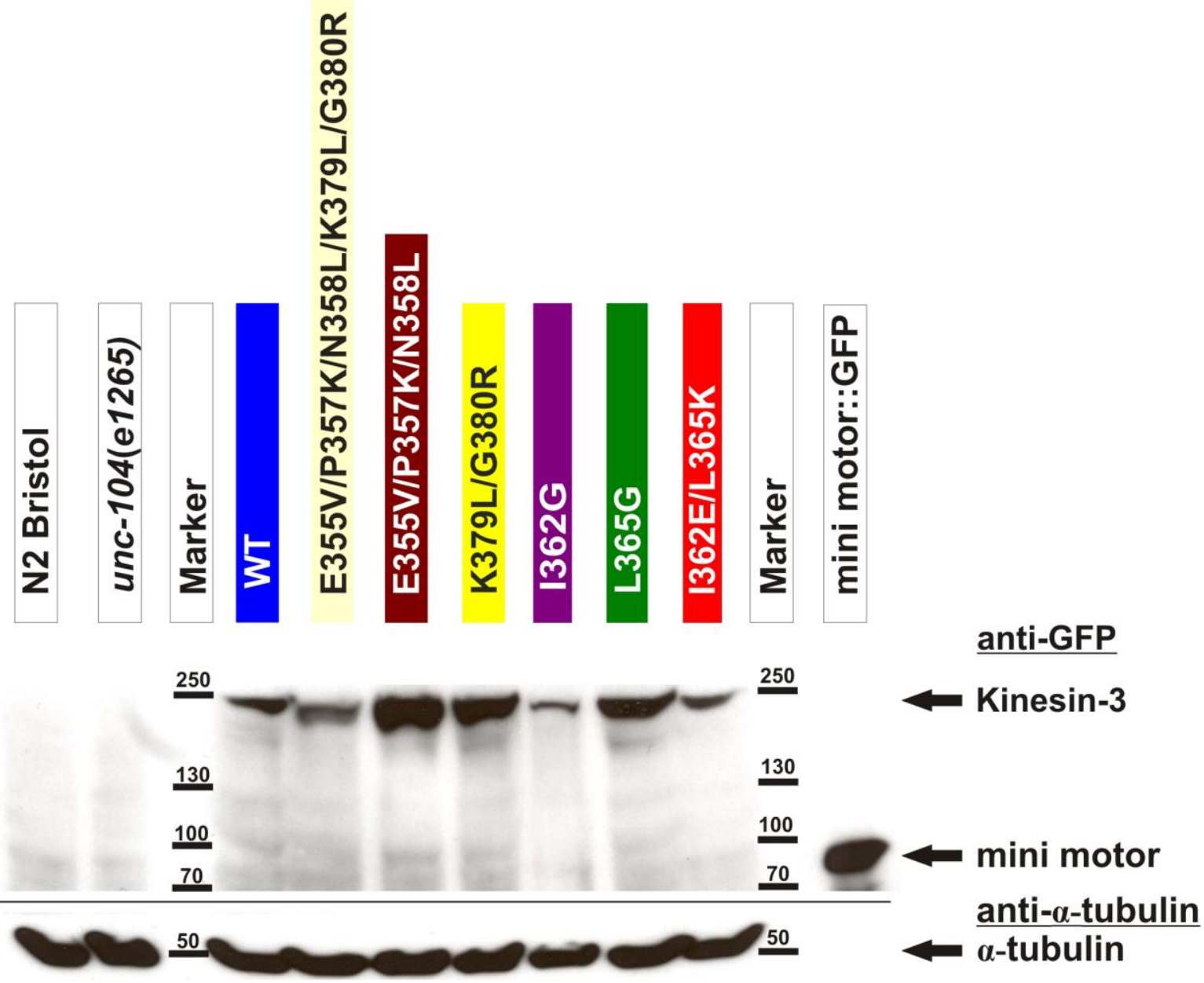

B

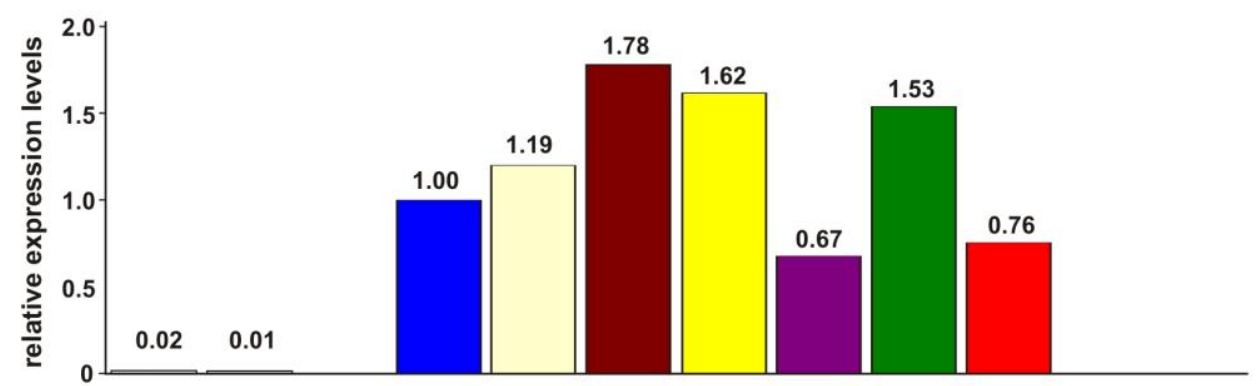

Fig. R5: Expression levels of the UNC-104 constructs in C. elegans

A) Expression levels of the injected constructs in the used UNC-104 worm strains detected by Western blot with antibodies vs. GFP. As negative controls unmodified worm strain $C$. elegans Bristol N2 and the genetical background strain unc-104(e1265) are used. As GFP-positive control one of the bacterial expressed mini motors is used. The house keeping marker for loading control is $\alpha$-tubulin detected by anti $\alpha$-tubulin AB. B) Relative expression levels normalized to the house keeping gene. 
Expression levels of the injected constructs are analyzed by anti GFP antibodies, whereas $\alpha$-tubulin is used for loading control. The house keeping protein $\alpha$-tubulin shows an equivalent amount of material used for SDS-PAGE (Fig. R5 bottom). In Bristol N2 worms and hypomorph unc-104(e1265) no GFP can be detected (Fig. R5 top). The expression level of coiled-coil promoting worm strain E355V/P357K/N358L/K379L/G380R is with less than $20 \%$ difference similar to the expression level of the WT-UNC-104::GFP strain. The other two coiled-coil promoting strains E355V/P357K/N358L and K379L/G380R shows $78 \%$ and $62 \%$ higher expression level compared to WT-UNC-104::GFP strain. Coiled-coil impaired strain I362G shows a 33\% reduced expression compared to WT-UNC-104. This is the reason why some of the following experiments could not be performed with this worm strain as they afford higher GFP-expression levels. The expression level of L365G is $62 \%$ higher compared to the WT-UNC-104::GFP strain. Although expression in mutant strain I362E/L365K is $24 \%$ lower compared to the WT-UNC-104 strain, this strain could be used for the in vivo experiments. As a positive control, bacterial expressed and purified mini motor (described in fig. R4) is used.

All expression levels of coiled-coil promoting, WT and coiled-coil impaired strains are within a similar range. Analytic studies from another kinesin show, that a 2 -fold difference of the motors expression level does not influence cargo velocities (Shubeita et al., 2008). So the analized transgene worm strains are suitable to answer the questions of this thesis.

\subsubsection{Worm motility}

Its is our working hypothesis, that modifications of the coiled-coil probability of UNC-104's neck region will lead to decreased/increased formation of homodimers and therefore affects transport of vesicles in neurons. This effect could lead to an impaired stimulation of body wall muscles in $C$. elegans and therefore uncoordinated movement. One of the advantages of the $C$. elegans system is its well-defined body movement and behaviour. Innervation anomalies of motoneurons can be screened visually as many defects in axon guidance, vesicle transport and synaptic vesicle recycling result in uncoordinated movement. To validate movement behaviour in $C$. elegans, trace analysis and body bend counting is a common and suitable strategy. 

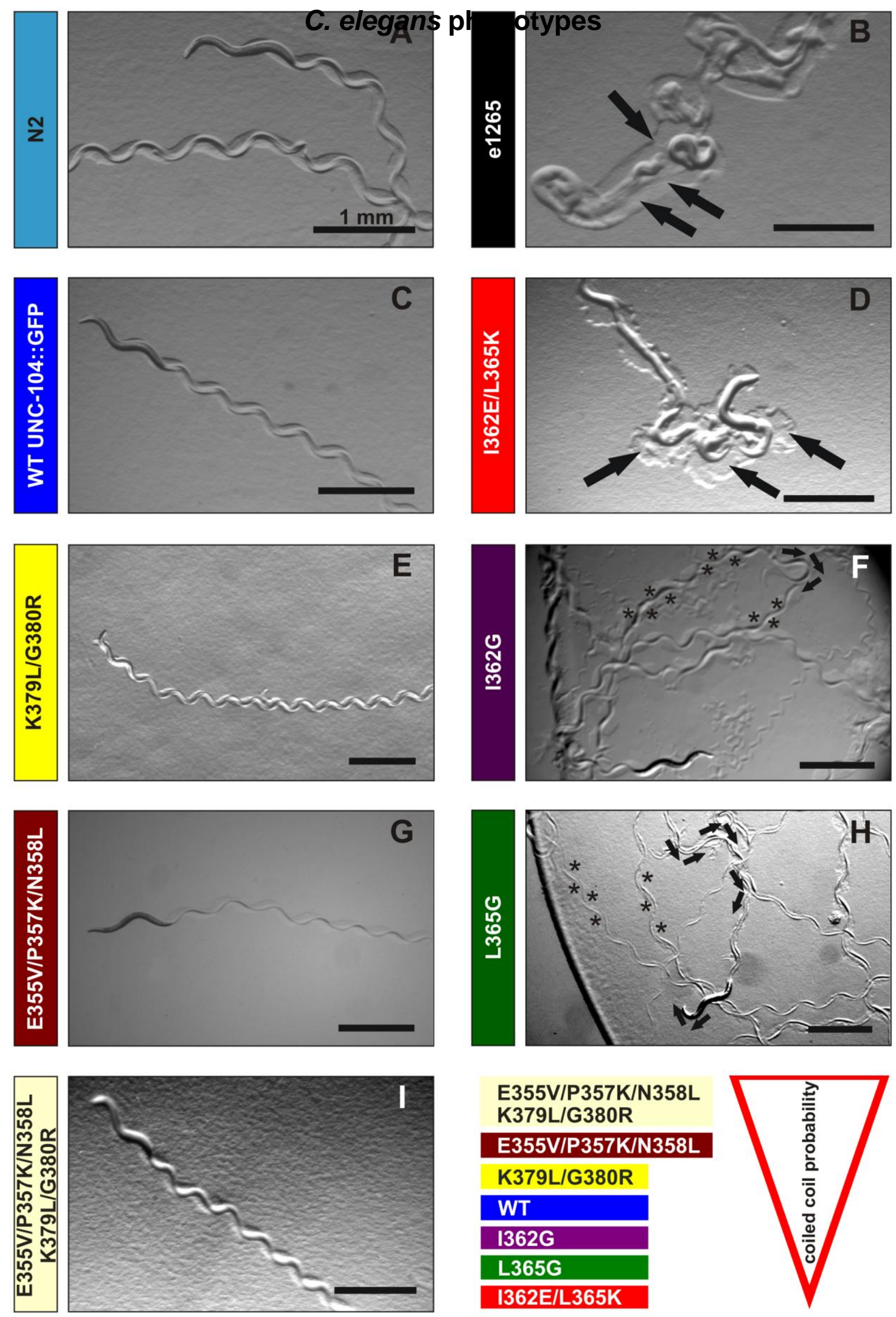
Fig. R6: C. elegans phenotypes

Tracks of N2, unc-104(e1265), UNC-104::GFP WT form and the mutant UNC-104::GFP strains on a fresh bacterial lawn for characterization of phenotypes. All scale bars: $1 \mathrm{~mm}$.

The N2 worm strain is a broadly characterized, unmodified strain and considered as "wild type". They form characteristic straight regular sinus-wave forming traces (Fig. R6 A). These traces are not only results of pure motion but also of feeding behaviour as worms internalize bacteria during motion. The worm strain unc-104(e1265) has a point mutation in the vesicle binding domain of kinesin- 3 and shows an impaired excitation of body wall muscles. Therefore the worms are impaired in their motility (Fig. R6).

These worms move in a very slow manner and the sinusoidal form of the traces can not be identified, their movement is not directed and additional broad feeding marks next to the trace (arrows) are visible. These feeding marks are also characteristics of impaired motility as worms can not get enough nutrition by quick sliding through the bacterial lawn, as they have to turn the head separately to reach enough bacteria to get necessary nutrients. With the injection of the WT-UNC-104::GFP into the unc-104(e1265) strain (Fig. R6) the UNC-phenotype of the unc-104(e1265) can be rescued. The traces become straight and sinusoidal and no additional feeding marks can be detected. With this rescue we additionally show that the attached GFP does not significantly influence the phenotype. Quintruple mutant E355V/P357K/N358L/K379L/G380R (Fig. R6 E), triple mutant E355V/P357K/N358L (Fig. R6 G) and double mutant K379L/G380R (Fig. R6 I) are mutants with increased coiled-coil probability. They all show straight and sinusoidal tracks, move fast and directed and do not show additional feeding marks. All these mutants fully rescue the UNC-phenotype of the (unc-104)e1265. The mutant strain I362E/L365K with two destroyed heptad motifs (Fig. R6 D) can not rescue the phenotype of unc-104(e1265). An uncoordinated movement occurs, no sinusoidal traces can be identified and additional feeding traces can be monitored (arrows). The mutant L365G (Fig. R6 F) is also not able to rescue the WT phenotype in a full extent. Sinusoidal appearance of the tracks is partially present but they show a lower amplitude (flatter curve, asterisk) and the worm

\begin{tabular}{|c|c|c|}
\hline Mutant & $\begin{array}{c}\text { average distance before change } \\
\text { of direction [arbitrary units] }\end{array}$ & difference to WT \\
\hline E355V/P357K/N358L & 717,1 & $2.8 \%$ \\
\hline K379L/G380R & 662,7 & $-4.9 \%$ \\
\hline WT & 697,1 & $0.0 \%$ \\
\hline L365G & 504,0 & $-27.7 \%$ \\
\hline I362G & 366,4 & $-47.4 \%$ \\
\hline
\end{tabular}

Table R1: Determination of turns

All turns $>40^{\circ}$ angle are counted and compared to the running distance of the worm. 
changes frequently its direction (arrows, see Table 1). The mutant I362G with a similar low coiled-coil probability as the L365G (Fig. R6 H) does also show frequent turnovers but, more significantly, they show very low sinusoidal amplitudes or even the disappearance of the sinusoidal shape of the track.

The best test for evaluation of worm motility is a body bend assay where the frequency of body bends per minute is determined.

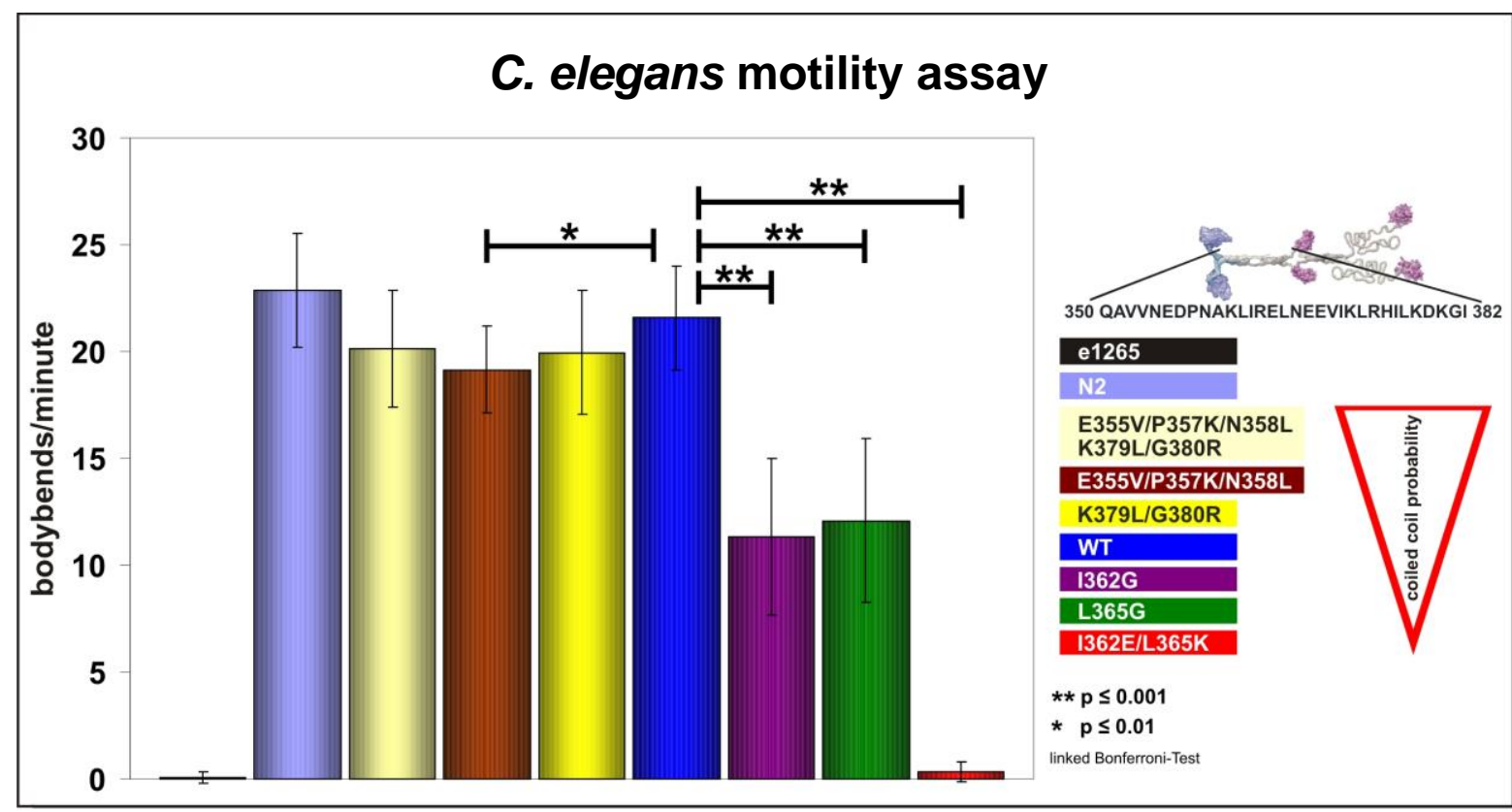

Fig. R7: C. elegans motility assay

Motility assay of reference strains unc-104(e1265), N2 and the WT-UNC-104::GFP compared to the mutant strains.

The results of the body bend assay (Fig. R7) show no significant difference between N2 and the UNC-104::GFP rescue in unc-104(e1265) confirming the analysis of the traces. Coiled-coil promoting quintruple mutant E355V/P357K/N358L/K379L/G380R and double mutant K379/G380R do reach, and triple mutant E355V/P357K/N358L does almost reach WT motility. Colied-coil impaired mutants I362G and L365G show a significant reduction in motility compared to WT with an aprox. $50 \%$ reduction of body bends per minute. The mutant I362E/L365K, bearing the destroyed heptad motif, shows body bend rates that resembles to those of the hypomorph mutant unc-104(e1265).

The hypomorph mutant unc-104(e1265) has an impaired innervation system resulting in an uncoordinated movement. As the colied-coil impaired mutants also show unc-movement there is a hint that a functional coiled-coil motif in the neck region is probably responsible for dimerization and necessary for proper excitation of body wall muscles. 


\subsubsection{Egg laying behaviour}

The mutant $1362 \mathrm{E} / \mathrm{L} 365 \mathrm{~K}$ has an additional phenotype with respect to the egg laying behaviour with a $50 \%$ reduction of identified heptad motifs in the neck coiled coil area

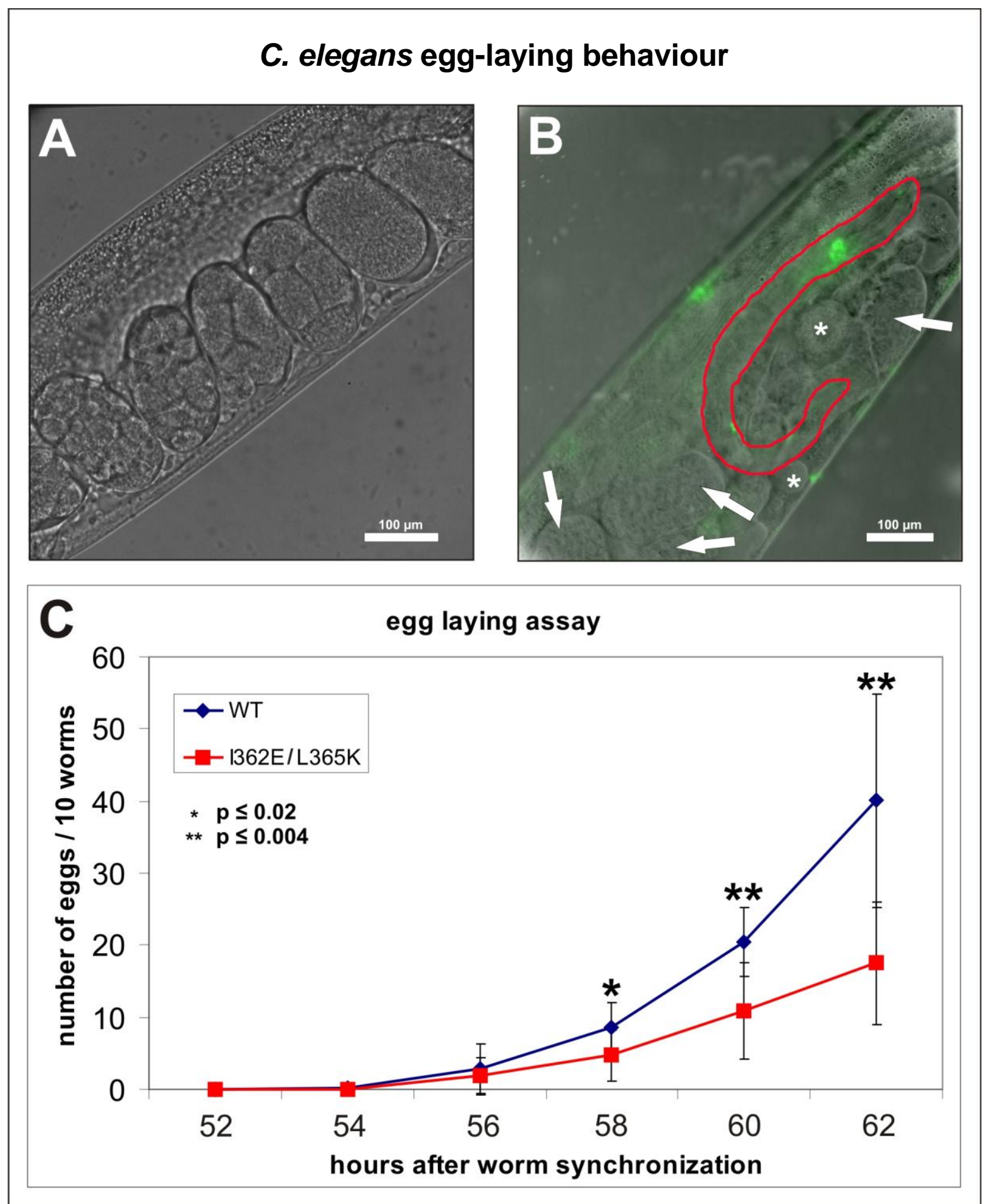

Fig. R8: C. elegans egg-laying behaviour

A) WT phenotype and B) I362E/L365K mutant picture of ventral part of the gonads of an adult hermaphrodite, pictured with DIC and fluorescent light simultaneously. Arrows show eggs, asterisks mark egg-shell debris C) Quantification of the egg laying anomaly of I362E/L365K worm strain compared to WT. 
(Fig. R1). Mutant worms show a common phenotype "bag of eggs" which is characteristic for worms with impaired innervation of the vulva muscles. This leads to a retention of eggs in succession of improper vulva activity. Eggs accumulate in the gonads and the worm breadth increases forming the "bag of eggs". In harsh forms the eggs are retained that long, that the embryos hatch in the adult worm leading to death of the hermaphrodite after a short period of time. This phenomenon is detectable in the I362E, L365K strain (Fig. R8 B). Compared to WT (Fig. R8 A), several eggs (arrows) and egg shell debris (asterisk) can be seen in the adult gonad next to at least one hatched larvae (rounded red).

The egg laying anomaly can be quantified by an egg laying assay (Fig. R8 C). To compare the 1362E/L365K worm strain with the WT-UNC-104::GFP worm, both strains are synchronized with respect to their fertility stage. Both strains start the egg laying simultaneously indicating that there is no developmental delay in the I362E/L365K mutants. Nevertheless, 8 hours after the first eggs are lawn there is a $45 \%$ reduction in the amount of eggs of the I362E/L365K worms compared to WT strain.

In total, worms expressing coiled-coil promoting constructs are able to rescue the uncoordinated phenotype of the unc-104(e1265) strain with respect to their phenotype, motility and egg laying behaviour. The shape of the traces are identical to WT and the motility of the worms are equal, or slightly reduced, compared to WT (Fig. R7). C. elegans expressing coiled-coil impaired constructs can neither rescue uncoordinated nonsinusoidal trace appearance nor motility of the background strain unc-104(e1265). This leads to the conclusion, that enhancement of coiled-coil probability of the neck region of UNC-104 has no negative influence in innervation of the body wall muscles. On the other hand, reduction of the coiled-coil probability of the neck region of UNC-104 leads to a significant reduction of worm`s motility compared to WT. The uncoordinated movement of all coiled-coil impaired strains and the detectable egg laying defect of strain I362E/L365K leads to the conclusion that coiled-coil formation in the neck region of UNC-104 is important for proper innervation of body wall muscles.

Motility and behaviour experiments are consistent with in silico calculation. The next step is the characterization of the motor itself during the transport of the vesicles from cell soma to the synapse.

\subsubsection{Motor movement}

Analysis of the worm phenotypes gives an indirect indication of innervation and vesicle transport. One of my aims is the characterization of relationships between motor 
conformation and transport properties in living $C$. elegans. To answer this task it is necessary to take a closer look into the motor behaviour in the living worm.

The quantification of motor velocities in vivo was done by time lapse confocal fluorescence microscopy. Expression of UNC-104 in C. elegans is restricted to neuronal cells. As motors are fused to GFP and the constructs are driven by the unc-104 promoter, the neuronal system of the worm is green fluorescing during excitation with a $491 \mathrm{~nm}$ laser (Fig. R9 A). During acquisition of a picture series of the dorsal or ventral nerve cord, transport vesicles are moving along the microtubules of the axons. As the motor is actively transporting these vesicles, moving fluorescing particles can be detected. The aim is to calculate the velocities of these vesicles by kymography (Fig. R9 B) and compare the coiled-coil promoting and the coiled-coil impaired mutants with the wild type. In the example kymograph a fast moving particle (arrow) and a slow moving particle (asterisk) can be detected. However, in a biological system side effects can influence the motor velocities. To exclude diffusive or decelerating effects and slow axonal transport, velocities less than $0.1 \mu \mathrm{m} / \mathrm{s}$ are excluded from analysis.

\section{Expression in C. elegans nervous system and kymography}
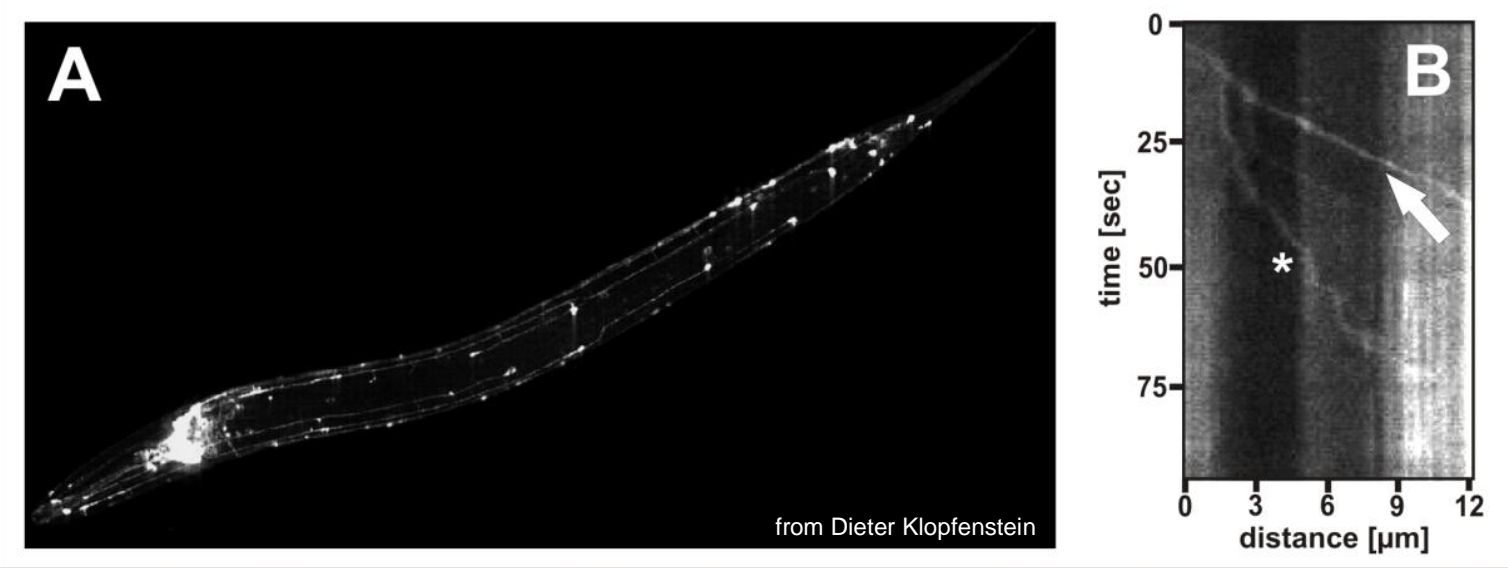

Fig. R9: Expression in C. elegans nervous system and kymography

A) C. elegans worm expressing GFP under a neuronal promotor, acquired with a spinning disc confocal laser microscope. B) Example of a kymograph. The arrow marks an example of a fast moving particle (round $0.8 \mu \mathrm{m} / \mathrm{sec}$ ), the asterisk shows a period where the motor slows down during its way along the microtubule track (under $0.05 \mu \mathrm{m} / \mathrm{sec}$ ).

For better comprehension, coiled-coil promoting and the coiled-coil impaired (as defined above) mutants are compared separately with WT. Fig. R10 shows the data of the coiledcoil promoting strains.

The WT UNC-104 shows the maximum amount of events between of $0.25 \mu \mathrm{m} / \mathrm{s}$ and $0.29 \mu \mathrm{m} / \mathrm{s}$ (Fig. R10). The arrow marks the arithmetic mean of $0.29 \mu \mathrm{m} / \mathrm{s}$. A large amount of events over $0.35 \mu \mathrm{m} / \mathrm{s}$ is conspicuous. 


\section{Motor movement of coiled-coil promoting constructs}
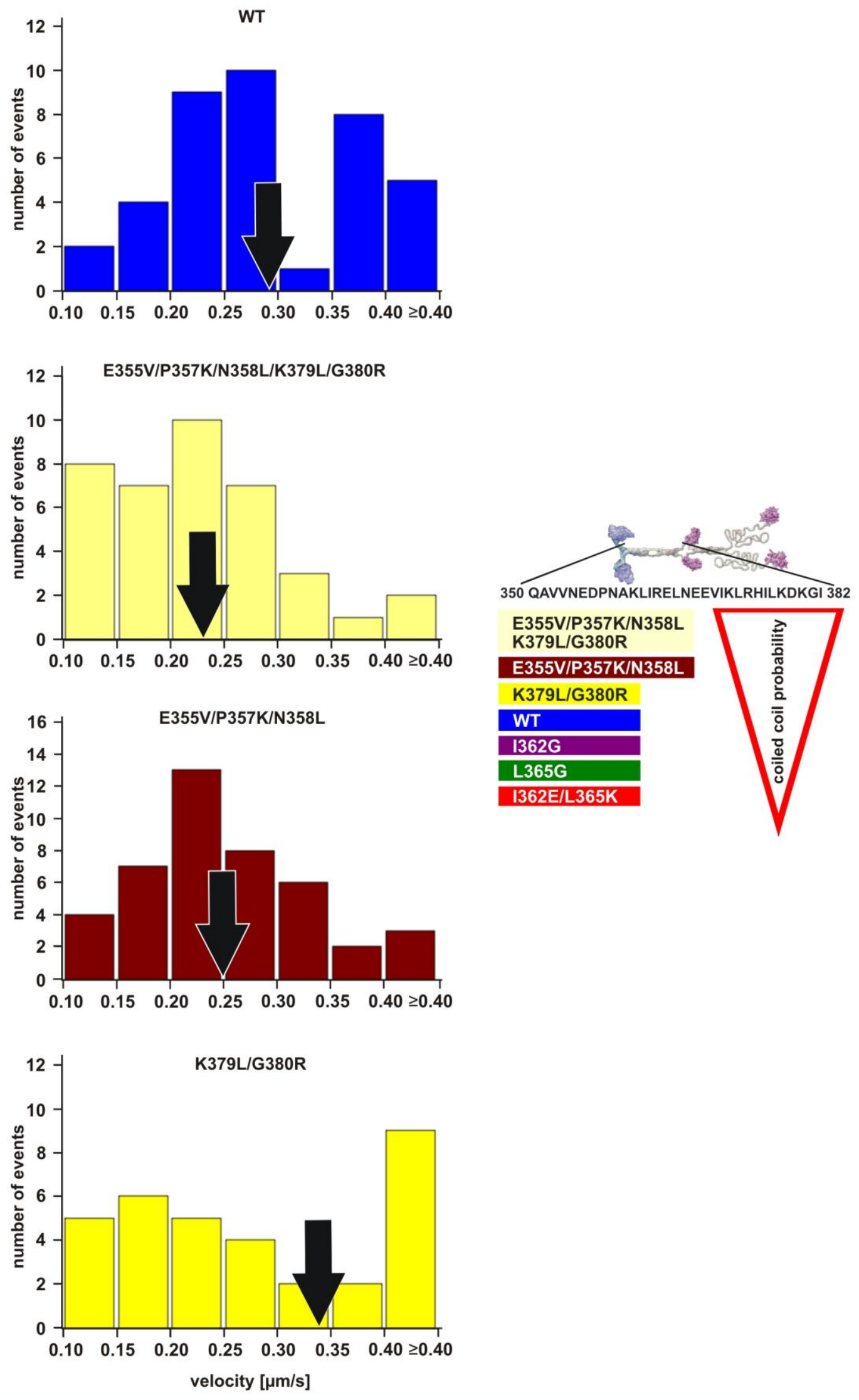

Fig. R10: Motor movement of coiled-coil promoting constructs.

Histograms of motor velocities of coiled-coil promoting mutants compared to WT-UNC-104. The black arrow marks the mean velocity. 
The mutant strains E355V/P357K/N358L/K379L/G380R and E355V/P357K/N358L have the maximum amount of events in between $0.20 \mu \mathrm{m} / \mathrm{s}$ to $0.24 \mu \mathrm{m} / \mathrm{s}$. The arithmetic means of $0.23 \mu \mathrm{m} / \mathrm{s}$ and $0.25 \mu \mathrm{m} / \mathrm{s}$ are comparable to the WT. Mutant K379L/G380R shows a higher average velocity. All putative coiled-coil promoting worm strains, E355V/P357K/N358L/K379L/G380R, N358L/K379L and E355V/P357K/N358L show velocities over $0.35 \mu \mathrm{m} / \mathrm{s}$.

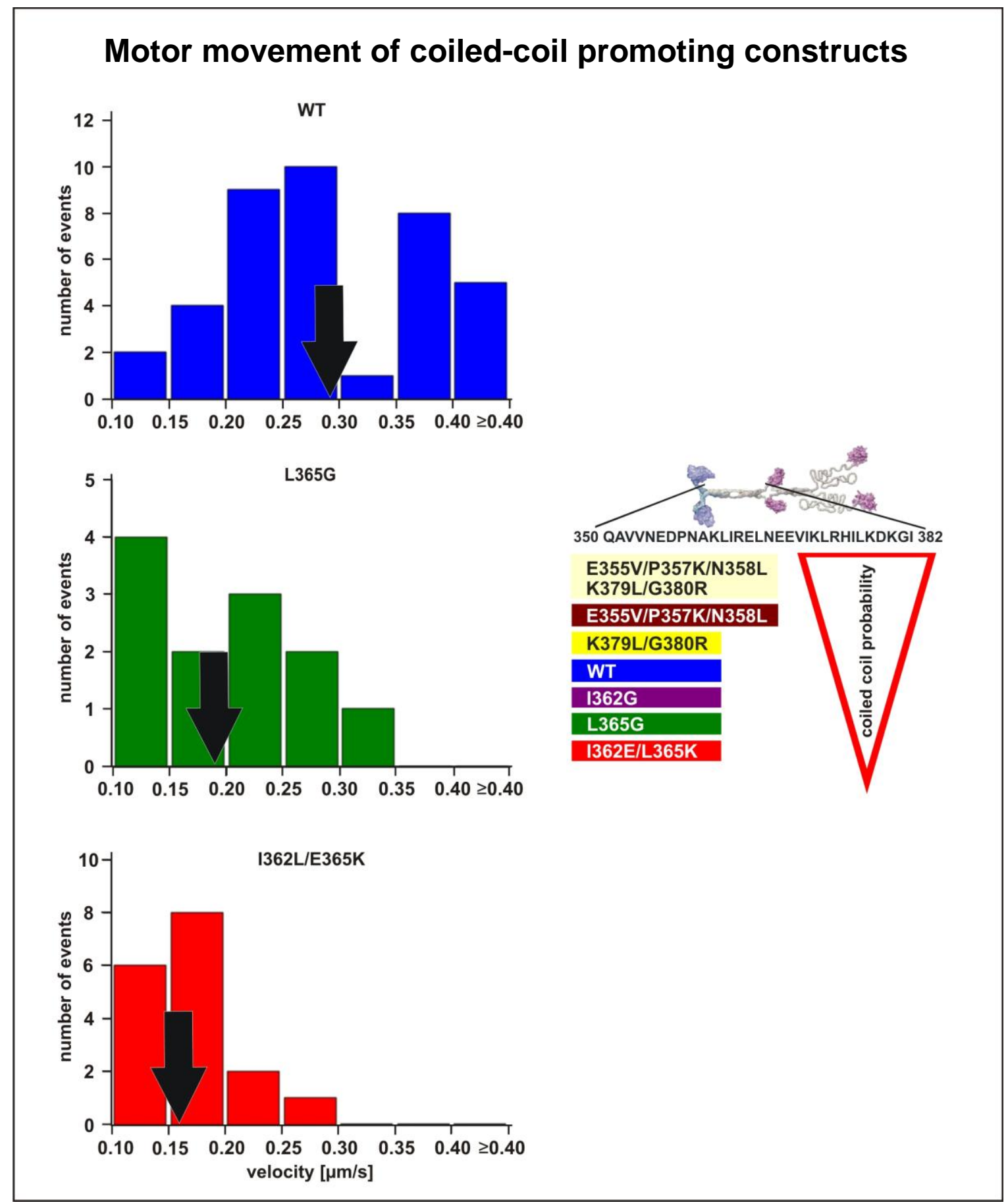

Fig. R11: Motor movement of coiled-coil impaired constructs

Histograms of motor velocities of coiled-coil promoting mutants compared to WT-UNC-104. The black arrow marks the mean velocity. 
The putative coiled-coil impaired mutant L365G has its maximum amount of events between $0.10 \mu \mathrm{m} / \mathrm{s}$ and $0.14 \mu \mathrm{m} / \mathrm{s}$, with an arithmetic mean of $0.19 \mu \mathrm{m} / \mathrm{s}$ also significantly reduced compared to WT (Fig. R11). Velocities over $0.35 \mu \mathrm{m} / \mathrm{s}$ are completely lacking. The heptad motif impaired mutant I362L/E365K has with its main peak between $0.15 \mu \mathrm{m} / \mathrm{s}$ to 0.19 a slightly higher $\mathrm{dim}$, but the arithmetic mean $(0.16 \mu \mathrm{m} / \mathrm{s})$ is reduced compared to L365G and as well as 50\% reduced compared to WT UNC-104.

In conclusion, coiled-coil promoting mutants can reach velocities similar to WT or even higher. Velocities greater $0.35 \mu \mathrm{m} / \mathrm{s}$ can not be monitored in worm strains with less ordered $\alpha$-helical structure. Coiled-coil impaired mutants show up to $50 \%$ reduction of vesicle velocities. These results are consistent to previous predictions and results in phenotype characterization. Impairing coiled-coil formation leads to the reduction of vesicle velocities during transport in $C$. elegans neurons.

The next aim is to test the correlation of coiled-coil- and dimer formation in vivo. The hypothesis is: A higher coiled-coil probability increases the dimer formation in vivo whereas impairing the coiled-coil probability impairs the dimer formation of the motor.

To link coiled-coil formation to dimer formation in vivo, we developed a system capable to detect conformational states of proteins in vivo.

\subsubsection{Determination of conformational states in vivo}

Fluorescence anisotropy is mainly used for analysis of receptor-ligand interaction (Sawyer and Winzor, 2001) or screenings for putative new ligands via fluorescence polarization immunoassays (Smith and Eremin, 2008). In combination with FRET it is also used for protein/peptide interaction analysis assays (Kadkhodayan et al., 2007) Most of the methods are in vitro assays or require artificial models (overexpression in cell culture).

I developed a cost effective setting, able to analyse protein-protein interactions in vivo (in living organisms) with acquisition times $<1 \mathrm{sec}$ with technical support of my collaborators Prof. Fred Wouters, Dr. Alessandro Esposito, Dr. Ingo Gregor and Dr. Matthias Gralle. The optimization of calibration procedures, and all measurements, both to determine capability of the system and to determine the conformational state of the motor protein had been performed by me. 
5.4.4.1 Development of a new setup to detect conformational states of proteins in $C$. elegans in vivo by fluorescence anisotropy

\section{Experimental setup}

As we address our questions in vivo in the $C$. elegans model system, the setup has to be compatible to our worm imaging system. It is based on a conventional confocal spinning disc microscope (Nipkov-disk confocal microscope). To split-up and detect the parallel and orthogonal direction relative to the polarization of the excitation, a beam-splitter was placed between the spinning disc and an electron-multiplying charge coupled device (EMCCD). This beam splitter (Dual-View ${ }^{\oplus}$, Optical Insights) was supplied with analysers forming a so called polarized beam splitter (Fig. R13 bottom).

Furthermore, to permit the full control of the polarization of the excitation light with minimal modifications to the system, we adapted the scan-head of the Yokogawa CSU confocal microscope to host polarization optics instead of the filter slider provided by the manufacturer. In-house developed optomechanics permit the rotation of an achromatic linear polarizer and an achromatic half-wave plate (Fig. R12, Fig. R13 top).

\section{Experimental setup, polarization}

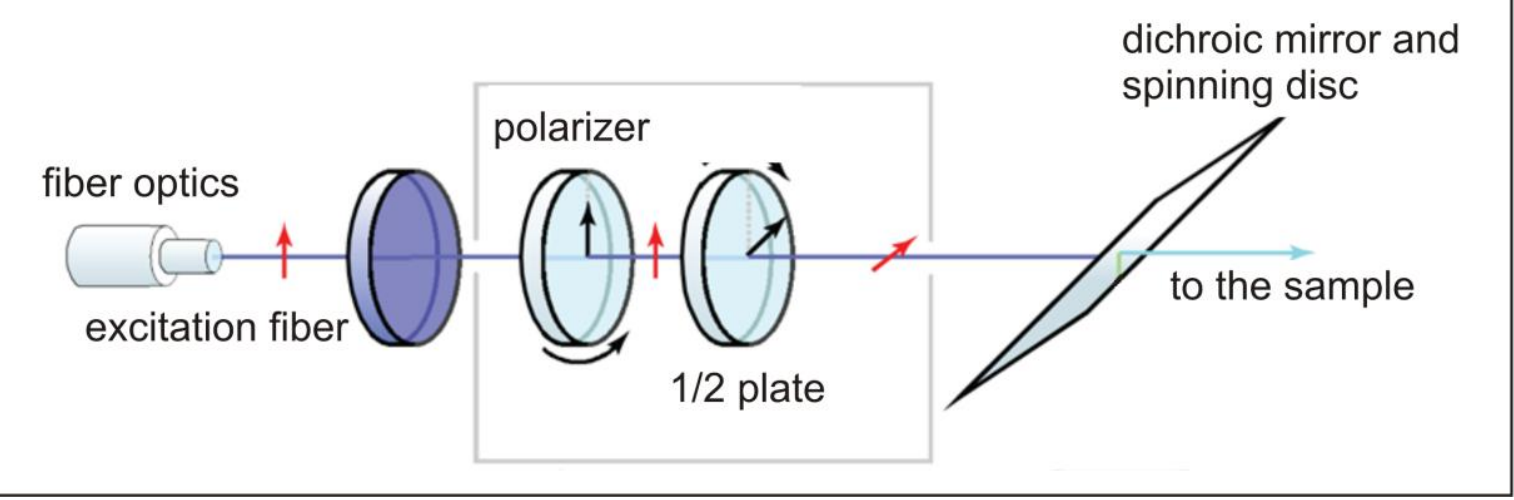

Fig. R12: Experimental setup, polarization

Schematic view of the setting before the sample, including new optomechanics.

\section{Calibration}

The calibration of the Dual-View ${ }^{\circledR}$ was performed according manufacturer`s advices. The polarizer is calibrated to obtain maximum detected light intensity, and the half-wave plate rotated to obtain maximum contrast between the acquired orthogonal $\left(I_{\perp}\right)$ and parallel (III) images by rotation of the achromatic linear polarizer and an achromatic half-wave plate. 


\section{Experimental setup, fluorescence anisotropy}

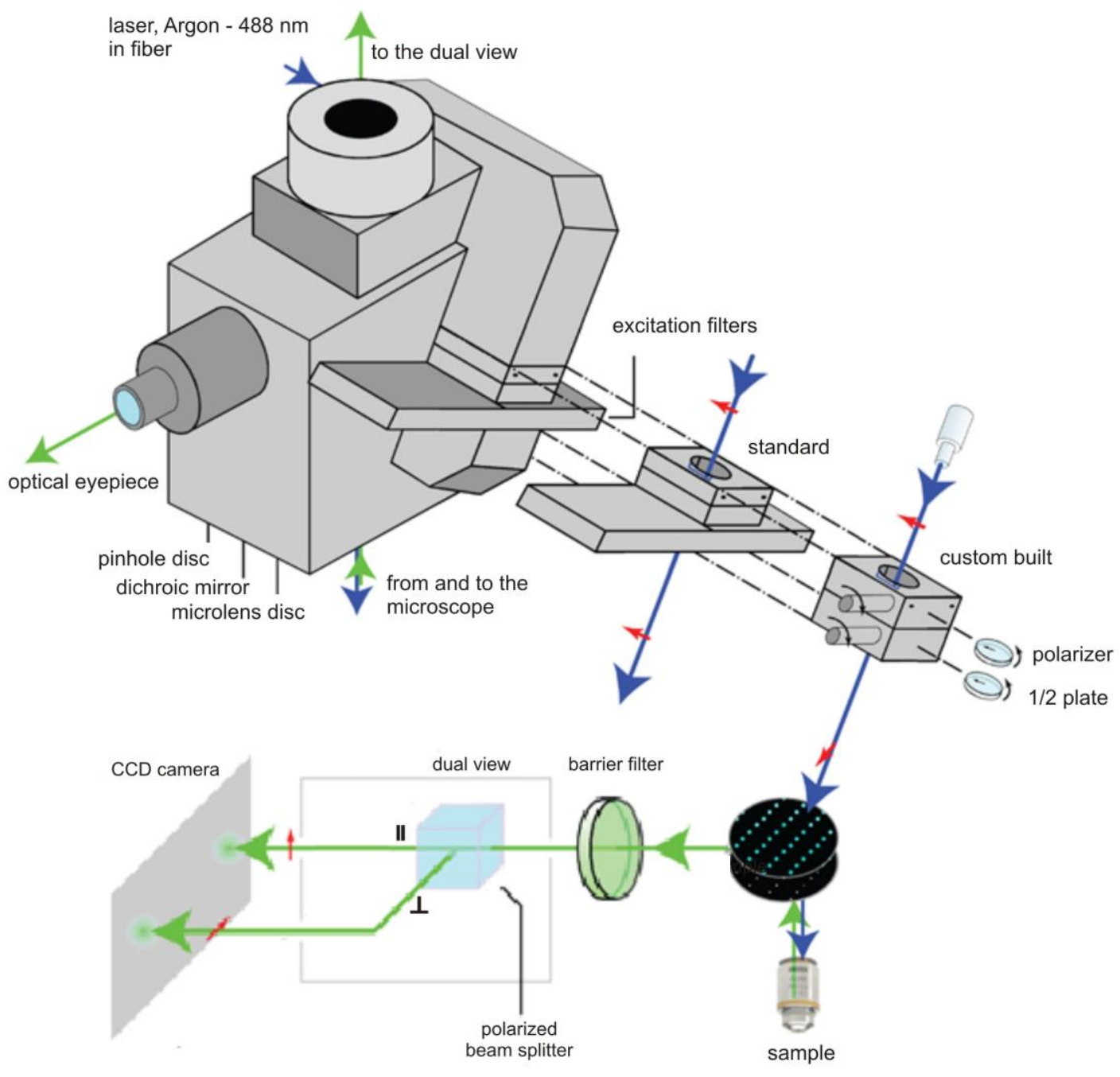

Fig. R13: Experimental setup, fluorescence anisotropy

Schematic view of the whole setting, capable to detect conformational states of proteins in C. elegans in vivo.

Pixel resolution was increased by resample the images to allow detection of for shifts smaller then a pixel. Second, cross-correlation between a number of image points was computed to estimate the relative position and rotation of the two images. The registration is usually aided by imaging test fluorescent beads followed by this automatic procedure and by eventual user-guided shift to compensate for possible software errors. Once the two images are successfully segmented and registered, fluorescence anisotropy images can be computed pixel-by-pixel by the following equation (Eq. 1).

$$
r=\frac{I_{/ /}-g I_{\perp}}{I_{/ /}+2 g I_{\perp}} \quad \text { eq. } 1
$$


where $g$ is a calibration parameter." (Henschel, Esposito et. al., in preparation)

For calculation of the anisotropy we used a Matlab toolbox written by my collaborator Alessandro Esposito that can be found in the appendix.

To calibrate the typical field of view a $100 \mu \mathrm{M}$ FITC solution is used (Fig. R14 A). A large area of each channel shows a bright consistent signal. Fluorescent beads, used to segment and register the two polarization-dependent images are clearly detectable (Fig. R14 B). Matlab calculates and presents the fluorescence images segmented (Fig. R14 C) and then ratioed to obtain anisotropy images (Fig. R14. D). All signals within the orange area presented in (Fig. R14 E) are used for calculation of the anisotropy. To ensure unobjectionable calculation of the ratio and therefore values of the anisotropy, calibration was repeated before every new experiment.

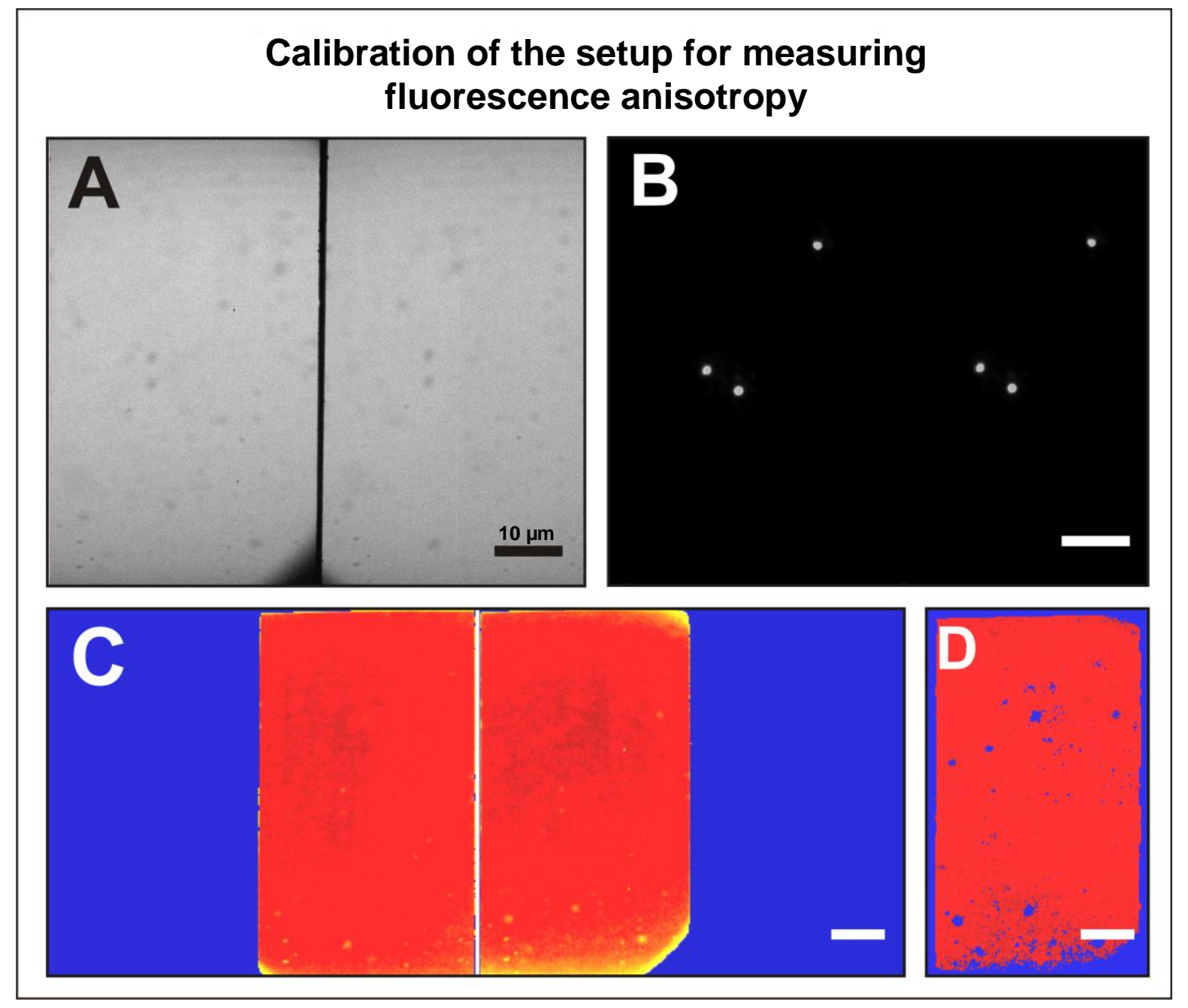

Fig. R14: Calibration of the setup for measuring fluorescence anisotropy

A) $100 \mu \mathrm{M}$ FITC solution, B) fluorescent beads of $1 \mu \mathrm{m}$ diameter, $\mathbf{C}$ ) the two separate channels and D) provided calibrated area in an overlay (calibrated area coloured in orange), defined by Matlab. All scalebars: $10 \mu \mathrm{m}$. 
Before addressing the UNC-104 question it is necessary to test the new setting "in vivo". Therefore GFP-fusion control proteins with distinct conformational status are expressed in C. elegans. A constitutive dimeric and a constitutive monomeric construct have been chosen. As a dimer construct heavy chain of kinesin-1 (known to be strictly dimeric in vivo, Vale, 2003) c-terminal fused with GFP is used. Structural analysis shows that C-termini of both chains are close together, ensuring a suitable distance for energy transport during fluorescence anisotropy (Lidke et al., 2003). As a constitutive monomer reference,

\section{Dynamic range of fluorescence anisotropy}
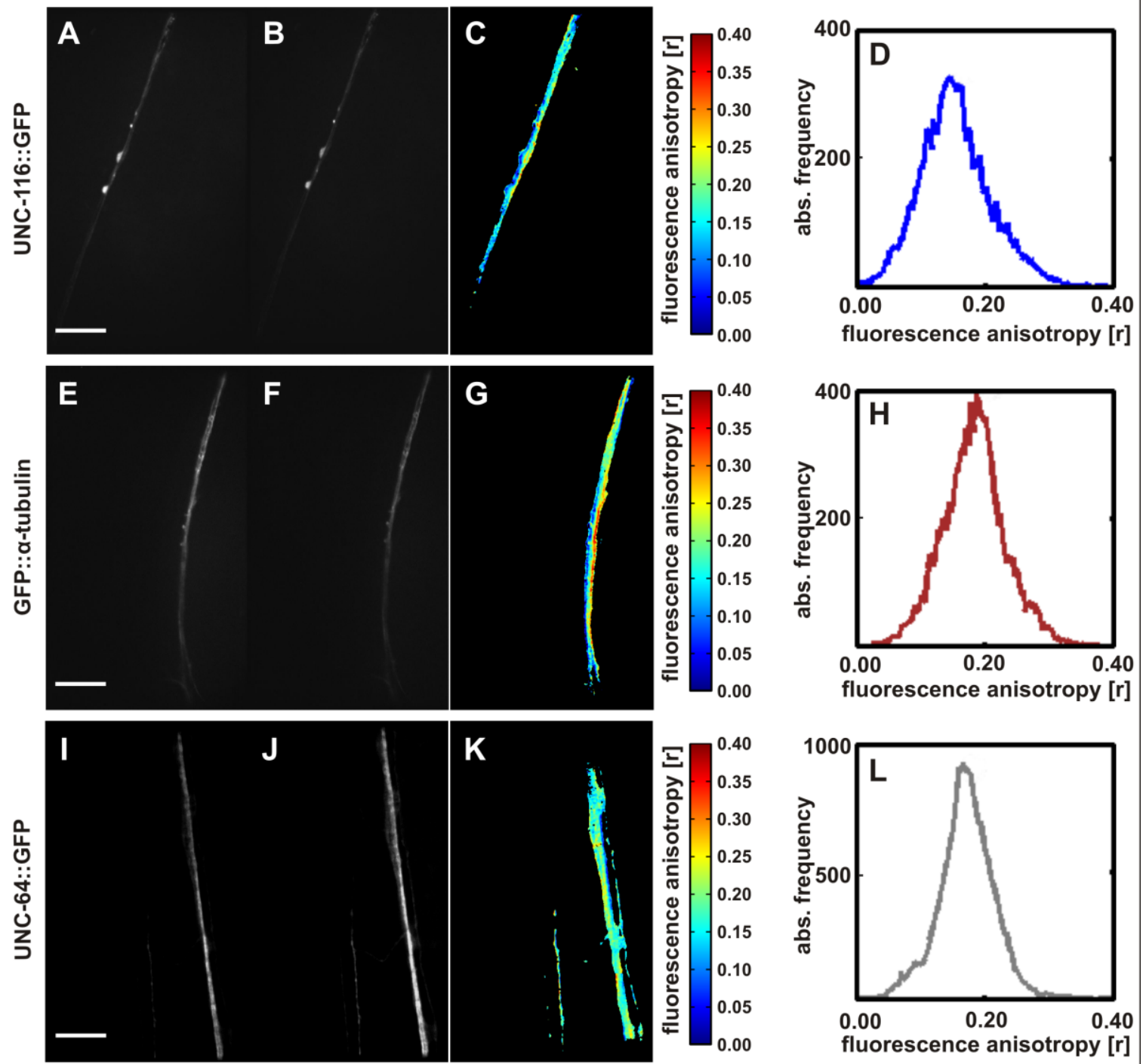

Fig. R15: Dynamic range of the developed system for measurements of fluorescence anisotropy Part of the ventral nerve cord of GFP fusion protein expressing worm strains using Dual View ${ }^{\circledR}$. Top: UNC-116::GFP, middle: GFP::a-tubulin, bottom: UNC-64::GFP. A),E) and F): parallel channels, B), F) and J): orthogonal channels, C), G) and K) fluorescence anisotropy ( $r$ ) calculated by Matlab. D), H) and L): histograms of the fluorescence anisotropy of the given picture. Pictures of the UNC-64::GFP are rotated by $180^{\circ}$. 
GFP::a-tubulin incorporated into microtubules is used. The expression level of tagged tubulin is kept at low stochiometry to endogenous tubulin to cause no instability of the microtubules (Ludin and Matus, 1998, Heidemann et al., 1999). The distance of two a-tubulin subunits is $8.3 \mathrm{~nm}$ (Howard et al., 1998). This would be close to the upper limit of FRET. $\alpha$-tubulin is a molecule that is modified post translationally. Several important modifications are performed n-terminally. Impaired modifications result in neuronal degradation (MacRae, 1996, Westermann and Weber, 2003). As the neurons in the $C$. elegans strain expressing the GFP:: $\alpha$-tubulin are phenotypically unaffected, we can consider a low expression rate resulting in a much larger distance between the GFP molecules to detect any energy transfer. As a third control UNC-64::GFP is used, a protein that can be in both a monomeric and a homodimeric state (Arien et al., 2003, van den Bogaart et al., 2011).

Absolute anisotropy values differ daily for biological reasons such as humidity, feeding status and therefore a thickened epidermis and a more viscous cytosol effect the anisotropy in vivo. This is the reason daily arithmetic means were used and compared on a daily basis. All daily experiments showed a significance $(p \leq 0.05)$ in coupled Bonferroni test.

Focusing on the ventral nerve cord of GFP fusion protein expressing worm strains, the fluorescent axons are clearly detectable. Apart from a slight reduction of intensity the parallel channels (Fig. R15 A, E and I) and orthogonal channels (Fig. R15 B, F and J) appear identical to their reference channels. Matlab calculates the anisotropy values of each pixel and visualizes them in a heat map (Fig. R15 C, G and K). In addition the histogram of each picture is documented (Fig. R15 D, H and L) showing all data points of the corresponding experiment. All histograms show almost gaussian distribution, the peaks of the three groups are separated and the peak of the UNC-64::GFP histogram is located between the peaks of the UNC-116::GFP and the GFP::tub-1

This result becomes more obvious in Fig. R16 A, showing a cumulative histogram of fluorescence anisotropy of all pictures of each group (UNC-116::GFP, GFP::tub-1 and UNC-64::GFP). The three peaks are separated. The blue line, representing the UNC$116::$ GFP strain is showing the lowest value with respect to fluorescence anisotropy, followed by the grey line representing the UNC-64::GFP worm strain. The red line representing the GFP::tub-1 worm strain shows the highest peak with respect to the fluorescence anisotropy values of the other two groups. The relative difference between the constitutive dimer UNC-116 and the constitutive monomer tub-1 in all daily experiments is aprox. 20\% (Fig. R16 B)

As the histograms are following nearly gaussian distribution (Fig. R15 D, H and L), it was decided to use the value of the highest frequency of each picture as its total value. 


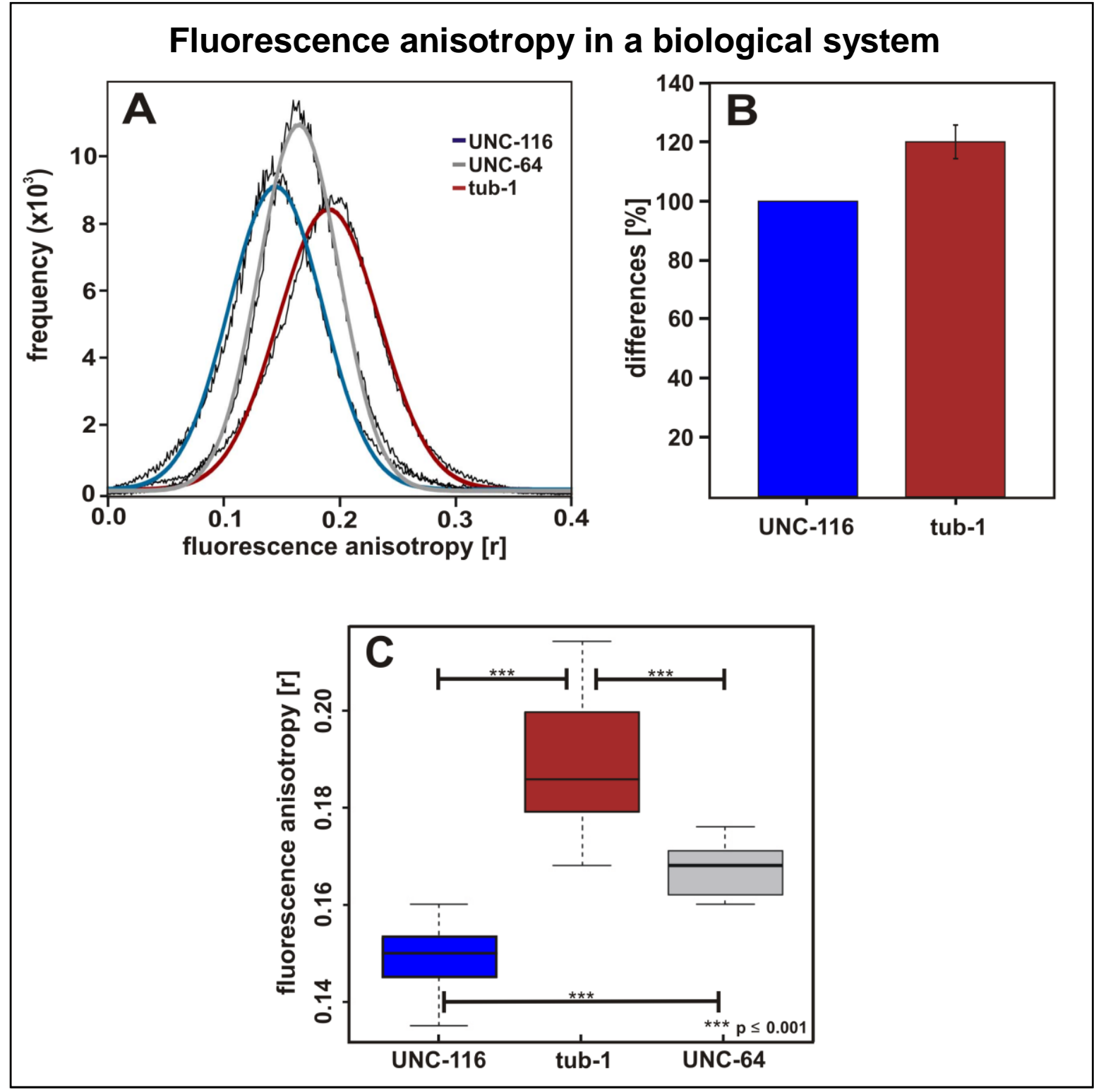

Fig. R16: Fluorescence anisotropy in a biological system

A) Histogram of cumulative distribution of fluorescence anisotropy of all pictures of each group. UNC-116::GFP, GFP::tub-1 and UNC-64::GFP. B) Differences of average anisotropy values of constitutive dimer UNC-116 and constitutive monomer tub-1 in \%. C) Boxplot of one whole experiment comparing the strictly monomeric, the strictly dimeric protein and the protein that can occur in both conformational states.

This set of data it visualized in a box plot (Fig. R16 C). The boxes are representing $50 \%$ of all data points of one group. The black line located in the box is the median value and the pointed line, ending in a bar is representing $95 \%$ of values of one group. The fluorescence anisotropy values of the UNC-116::GFP are separated from the others and lower with very high significance. This construct is representing the constitutive dimer. The box of the GFP::a-tub-1, representing the constitutive monomer, shows highest values with respect to the other groups and is strictly separated from them. The box of the UNC-64::GFP, representing a protein that can act as monomer and dimer in vivo, shows values in between the other groups and is significantly different from them. 
5.4.4.2 Conformational states of UNC-104 and UNC-104-mutants determined via fluorescence anisotropy.

The developed method is suitable for giving serious information about conformational states of proteins in living $C$. elegans. As fluorescence anisotropy is a comparative method and the aim is to get information about the conformational states of the UNC-104WT, all mutant strains are compared to this strain.

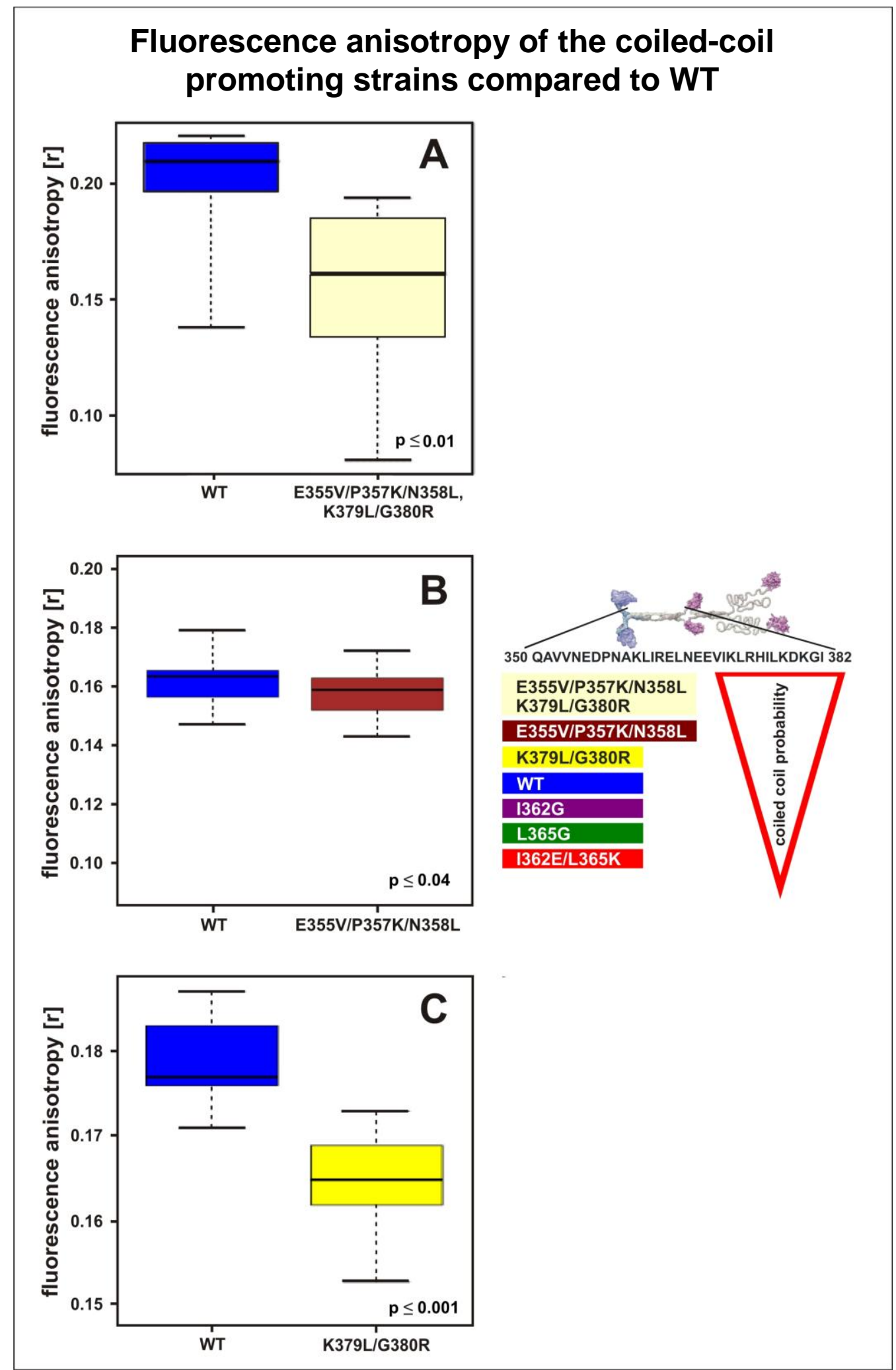


Fig. R17: Fluorescence anisotropy of the coiled-coil promoting strains compared to WT Boxplots of fluorescence anisotropy of the coiled-coil promoting strains compared to WT. Significances are determined by coupled Bonferroni test.

Values of the coiled-coil promoting mutant strain E355V/P357K/N358L/K379L/G380R are significantly reduced in fluorescence anisotropy compared to WT-UNC-104::GFP (Fig. R17 A). In this mutant proteins consist more in a homodimeric state than those in the WTUNC-104::GFP strain in vivo. Mutant strain E355V/P357K/N358L shows a low, but also significant reduction of fluorescence anisotropy compared to wild type (Fig. R17 B), also indicating that UNC-104::GFP proteins in this strain consist more in a homodimeric state than those in the WT-UNC-104::GFP strain in vivo. Analysis of the coiled-coil promoting strains indicates, that the hypothesis with reference to the dimer formation in vivo is true.

Mutant strain K379L/G380R also shows a reduction of fluorescence anisotropy (Fig. R17 C). The coiled-coil prediction of this mutant is estimating a higher coiled-coil probability and a more stable and elongated heptad motif area compared to wild type. The highly significant result of the fluorescence anisotropy shows, that this hypothesis is true and that the mutant shows more proteins in homodimeric state compared to WT in the living worm. As described above, absolute values of fluorescence anisotropy diversify daily due to for biological reasons. All repetitions of these experiments show a $p$-value of $\leq 0.05$ in coupled Bonferroni test.

Analysis of the coiled-coil impaired strains also verifies our hypothesis with reference to the dimer formation in vivo (Fig. R18). Mutant strain L365G shows an increase of fluorescence anisotropy compared to WT (Fig. R18 A) indicating a more monomeric conformation of UNC-104::GFP in this mutant strain in vivo. Mutant strain I362L/E365K also shows an increase of fluorescence anisotropy (Fig. R18 B) compared to WT. According to the hypothesis, data show that mutations decreasing the length of the coiledcoil area and a reduction of the coiled-coil-probability in the neck region is decreasing the probability of UNC-104 acting as a homodimer in vivo.

In both mutants the $50 \%$ boxes are significantly separated from the WT. As for the dimeric mutant strains it is imperative, that all repetitions of these experiments show a $p$ value of $\leq 0.05$ in coupled Bonferroni test. 


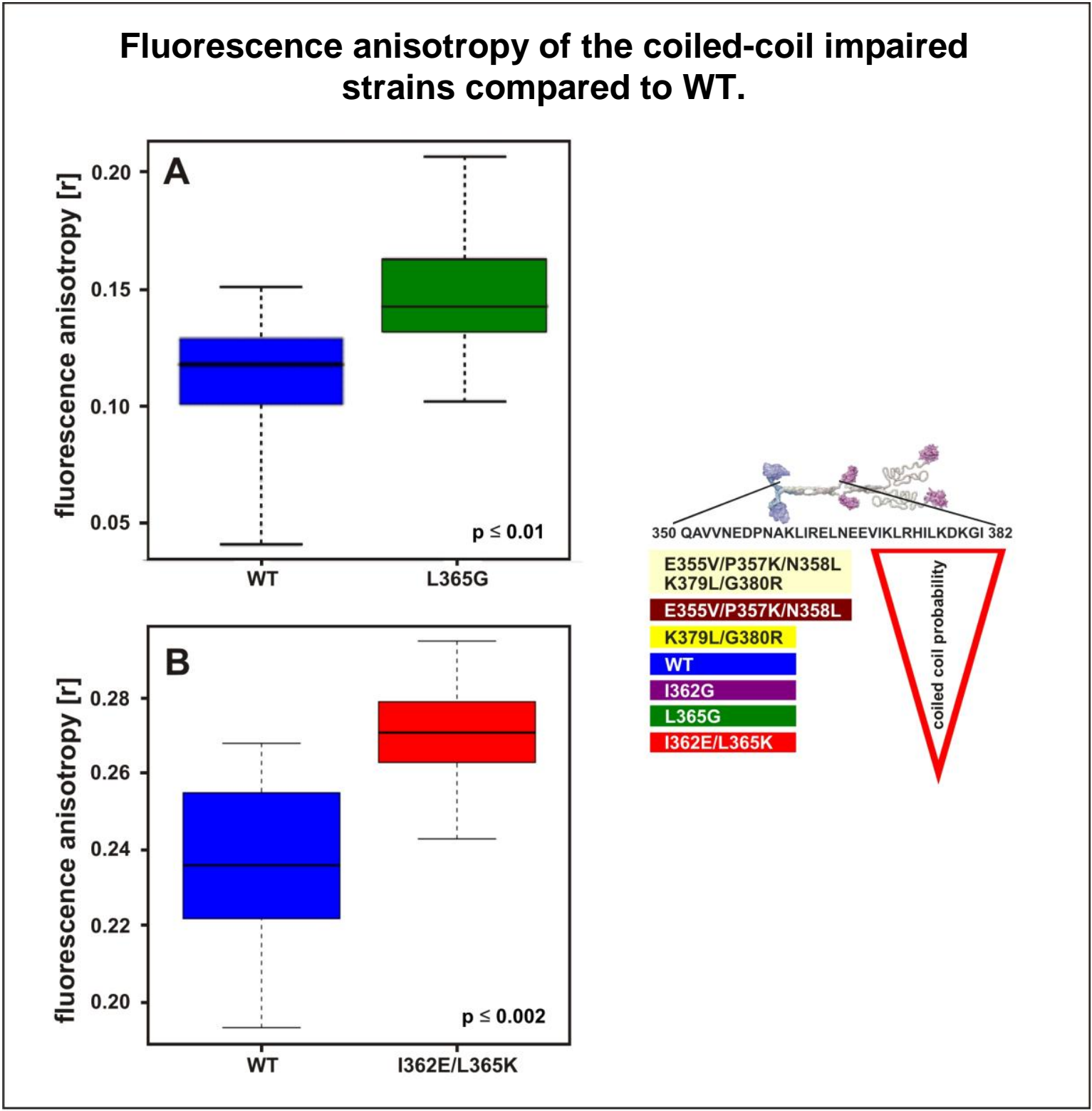

Fig. R18: Fluorescence anisotropy of the coiled-coil impaired strains compared to WT Box-plots of fluorescence anisotropy of the coiled-coil impaired strains compared to WT. Significances are determined by coupled Bonferroni test.

In total my in vivo data show a strong correlation between calculated and measured coiled-coil probability, dimer formation and vesicle velocities. In our experimental setting we can not exclude dimer formation due to aggregation e.g. caused by overexpression. To estimate the influence of aggregation effects we performed a comparison between a high and a low expressing strain of UNC-104::GFP controlled by the endogenous unc-104 promoter by fluorescence anisotropy and found no differences between both groups. Expression levels of the constructs can be seen in Fig. R20. Here we visualize the expression by Western blot vs. GFP. It therefore can be concluded that the chosen expression range does not lead to a detectable aggregation of the GFP constructs and no detectable change of fluorescence anisotropy (Fig. R19 A). 
Kinesin UNC-104 is a protein that binds to vesicles and is responsible for its anterograde transport. GFP is fused directly to the cargo binding domain (PH-domain) of the motor protein. We have to address the question if a binding to the vesicle approaches the GFP fluorophores of two motor proteins (that do not interact) to a distance where they can perform FRET. As these fluorophores are inhibited in rotation they could reduce the value of fluorescence anisotropy indicating a false positive dimer. For this reason we investigated UNC-104 that is deficient of the cargo binding domain (UNC-104 $\Delta \mathrm{PH}$ ) (Fig. R19 B) and compared this strain to WT-UNC-104. Data show that there is no significant difference compared to the WT suggesting that experiments do not show decreased fluorescence anisotropy and false positive dimers by cargo binding effects.

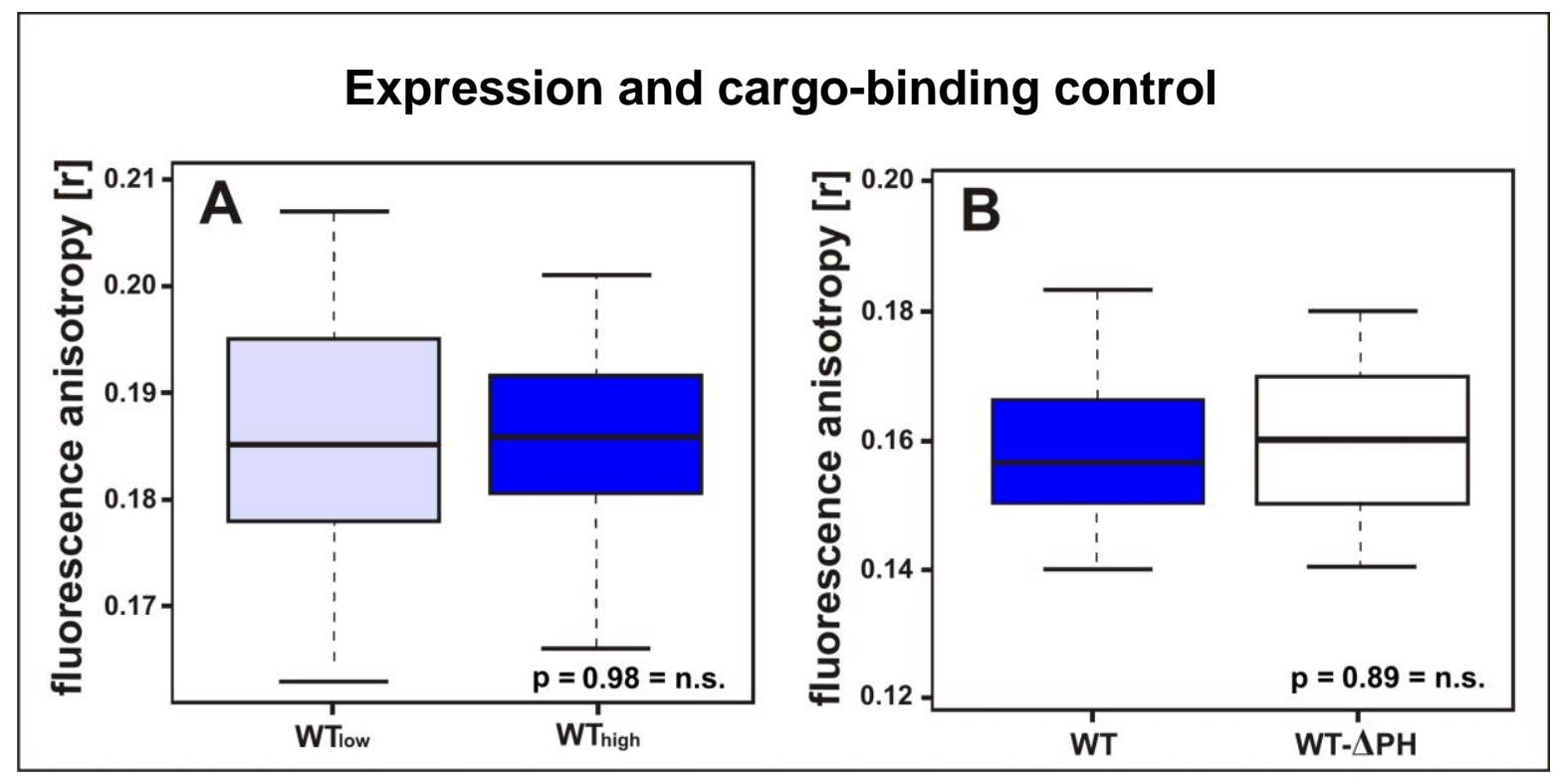

Fig. R19: Expression and cargo-binding control

A) Comparison of a low expressing and a high expressing strain of WT-UNC-104::GFP to exclude interfering aggregation effects influencing fluorescence anisotropy values. B) Comparison of a cargo binding domain (plekstrin homology domain, $\mathrm{PH}$ ) depleted mutant strain with WT UNC-104 in order to detect possible effects influencing fluorescence anisotropy due to cargo binding. Significances are determined by coupled bonferoni test.

Although it is already shown that the expression levels of the GFP-tagged proteins do not influence fluorescence anisotropy values expression levels of the injected constructs are analyzed by anti-GFP antibodies, whereas anti-a-tubulin antibodies are used for loading control. The house keeping protein $\alpha$-tubulin shows an equivalent amount of material used for SDS PAGE (Fig. R20 bottom). Expression levels of dimer/monomer control (UNC116::GFP and $\alpha$-tubulin::GFP) strains are within the same range, expression level of UNC-64::GFP is slightly enhanced compared to the controls (Fig. R20 top). As a control of the capability of the system, high and low expressing strains of UNC-104 are shown. The construct UNC-104 $\triangle \mathrm{PH}$ show the same expression level as the WT-UNC-104. 


\section{Expression levels of constructs for fluorescence anisotropy measurements}

A
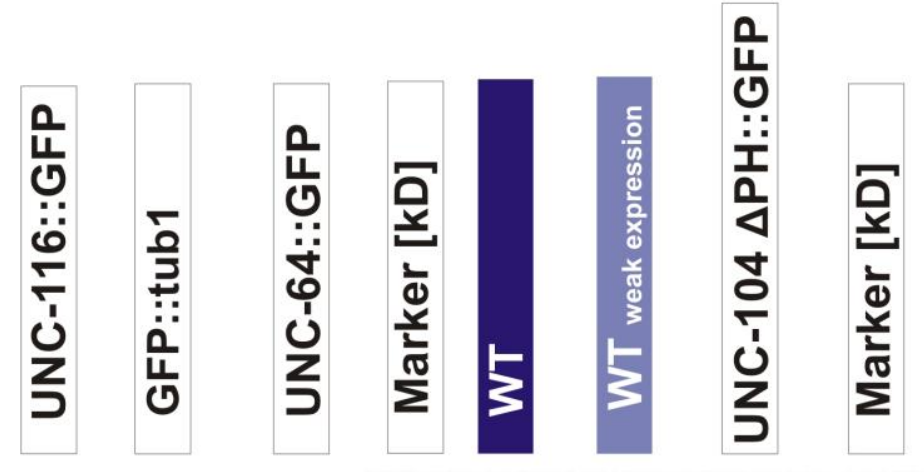

0

는

:
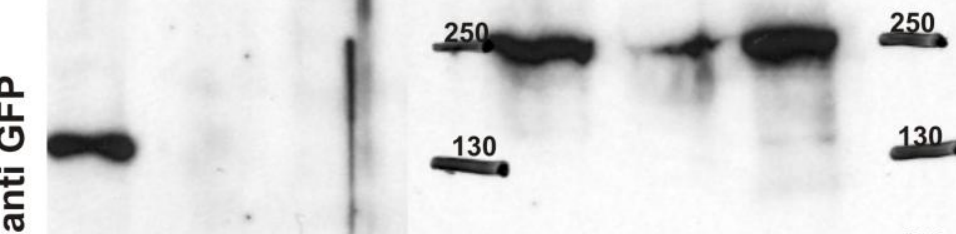

号
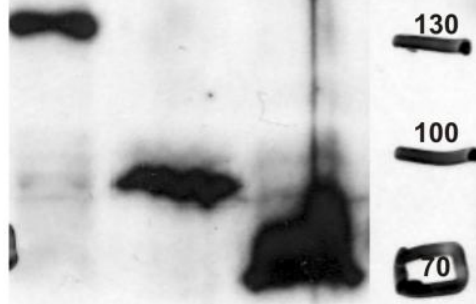

130
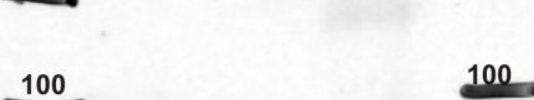

100

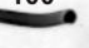

70

70

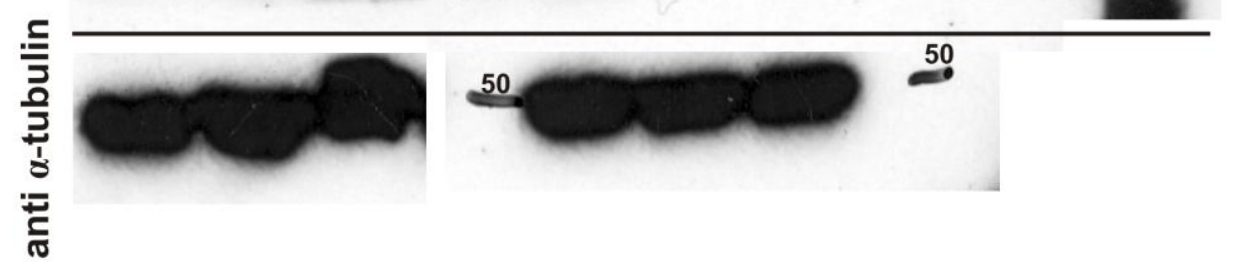

B

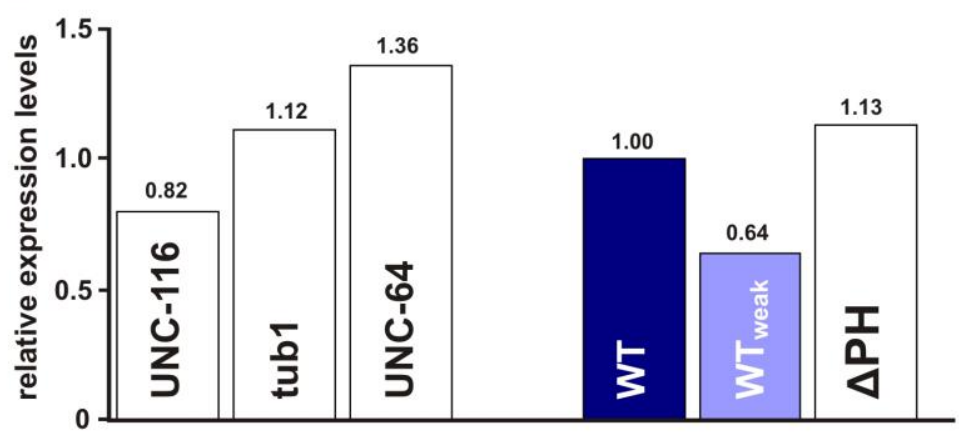

Fig. R20: Expression levels of constructs for fluorescence anisotropy measurements A) Expression levels of worm strains important for comparison in fluorescence anisotropy are detected by Western blot vs. GFP. For loading control the house keeping marker anti-a-tubulin is used. B) Relative expression levels normalized to the house-keeping gene. 


\subsection{In vitro experiments}

The in vivo data suggest a direct link between dimerization probability and transport velocities. To verify these results I also investigated the properties of the motor in several in vitro assays. Former studies reported that FL-UNC-104 can not be produced recombinantly in bacteria (personal communication, Vale lab). In all in vitro experiments performed in this thesis, a truncated form of UNC-104 is used which is recombinantly expressed and purified. It includes aa 1-446 fused with GFP for detection and $\mathrm{His}_{6}$ for purification (Fig. R4). The neck region of UNC-104 is ending at aa 389 so this construct is suitable for investigation of the neck region. The point mutations used in the in vivo assays have been cloned into this construct. This was preformed by site directed mutagenesis followed by a ligation of the mutated part into the pET17b expression vector. With a Multi Motor Gliding Assay I tested the activity of WT and mutated proteins in vitro. Using TIRF we investigated the speed of the motor, with gel filtration the probability of the proteins to build dimers and with biochemical cross linking we tested the direct interaction and formation of homodimers.

\subsubsection{Purification of truncated motors}

The purification is mainly performed by the technicians Kerstin von Rhoden and Charlotte Willms. The WT truncated motor is purified by Ni-NTA (batch procedure) followed by purification with ion exchange FPLC. The mutant forms of UNC-104 are purified only by FPLC. Motors used for microtubule affinity purification are purified by Ni-NTA in batch procedure. Both purification methods ensure an accumulation of the target protein but not a contamination-free solution (Fig. R21). That's why a double purification with Ni-NTA and FPLC was preferred.

On the left side of the SDS-PAGE the bacteria lysate is applied (L). Ni-NTA purification gives a very high yield of protein (protein band at $76 \mathrm{kD}$ ) but both larger and smaller proteins are contaminating the solution. Purification with FPLC gives a more pure sample, but the yield is much lower compared to Ni-NTA purification. 


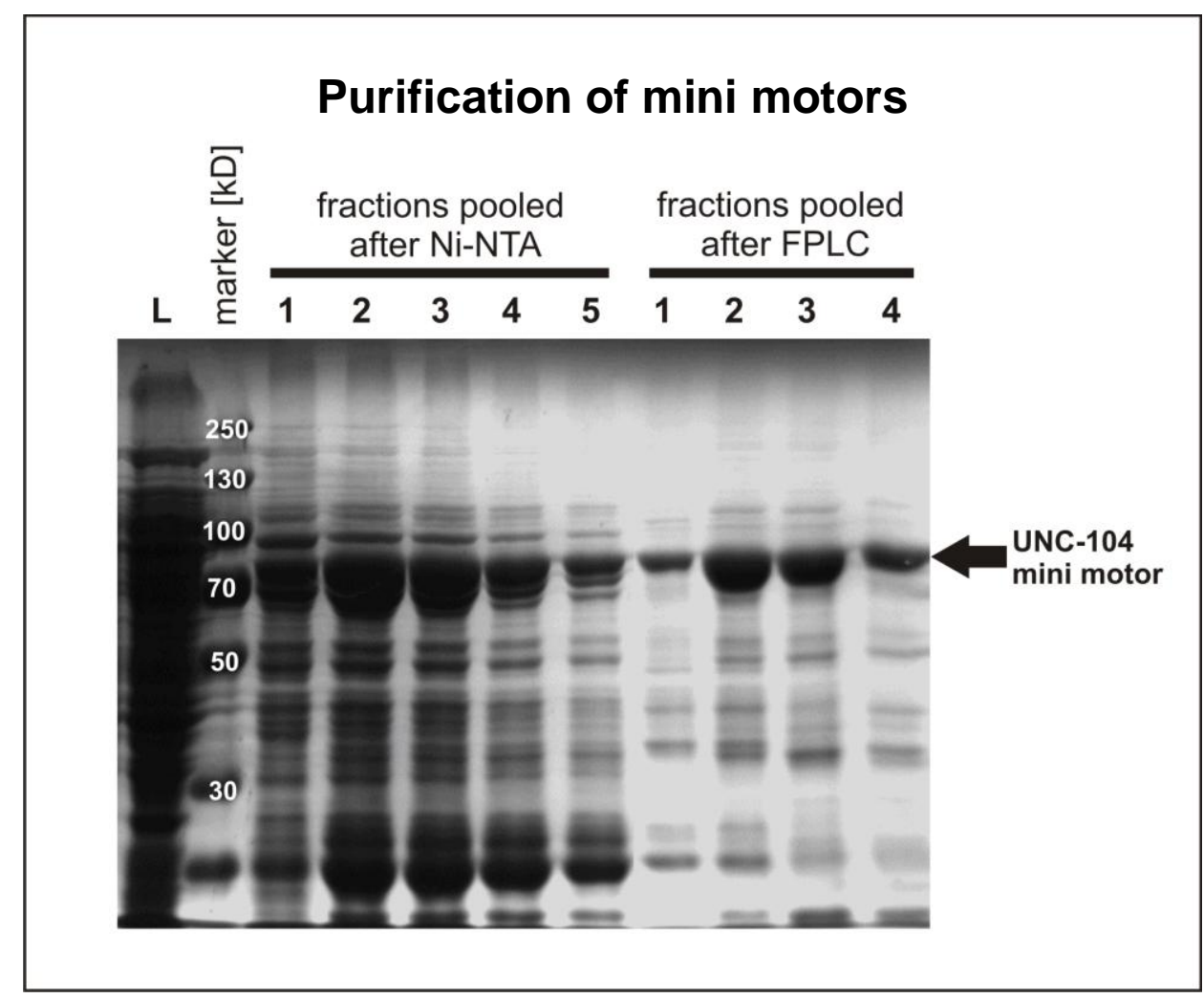

Fig. R21: Purification of mini motors

Purification of truncated motors. L: bacteria lysate. 1-5 left: fractions from Ni-NTA purification, 1-4 right: fractions from FPLC purification.

\subsubsection{Mutations in the neck coiled-coil do not affect activity and properties of the motor head.}

In vivo data suggest that mutations affecting the neck coiled-coil domain are influencing motor behaviour. I hypothesised that these effects are either due to their probability to build homodimeric structures or due to their ambition to stay monomeric. A reduction of velocities, as we showed for coiled-coil impaired mutants in vivo, can also occur through impaired motor activity. For this reason we tested the biophysical properties and the activity of the motor in a multi motor gliding assay. This assay has the advantage that its results are independent from any homo-dimerization processes. Kinetics of coiled-coil promoting mutant E355V/P357K/N358L/K379L/G380R and coiled-coil impaired mutant I362E/L365K are compared to WT (Fig. R22). The experiments have been performed by Diploma student Olaf Meissner. 


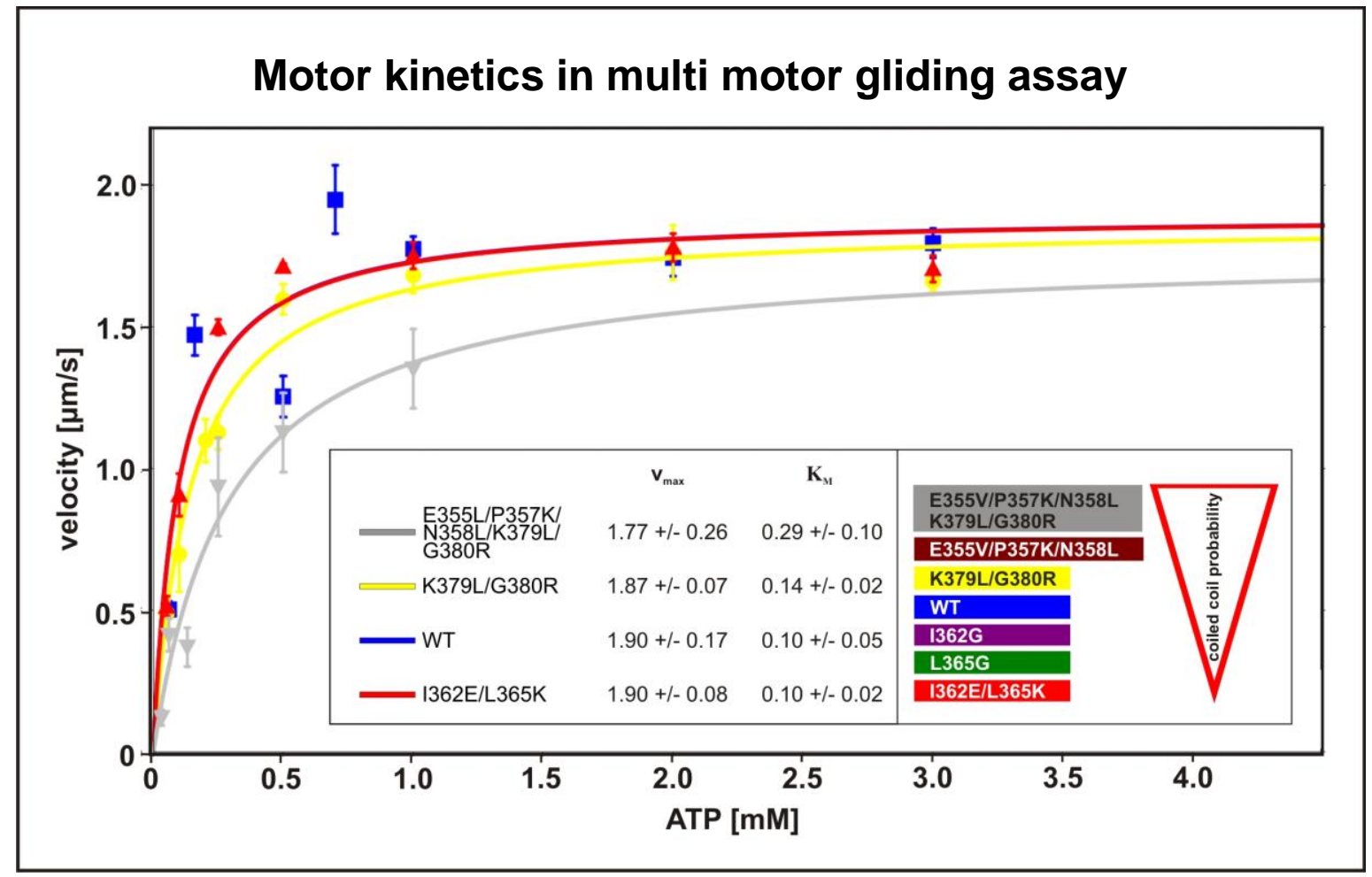

Fig. R22: Motor kinetics in multi motor gliding assay

Michaelis-Menten kinetics of coiled-coil promoting mutants E355V/P357K/N358L/K379L/G380R and K379L/G380R and coiled-coil impaired mutant I362E/L365K compared to WT.

WT-UNC-104, coiled-coil impaired mutant I362E/L365K and coiled-coil promoting mutant K379L/G380R are showing very similar kinetics and velocities (Fig. R22), comparable to published data for WT (Al-Bassam et al., 2003). This result shows that mutations neither influence ATP-hydrolysis nor impairs motor head function, nor taking influence on the neck-linker function. Coiled-coil promoting mutant E355V/P357K/N358L/K379L/G380R shows a much higher $\mathrm{K}_{\mathrm{M}}$. The reason for this phenomenon might be because of low effective concentration. During purification coiled-coil promoting mutant E355V/P357K/N358L/K379L/G380R tends to build aggregates that accumulate in enclusion bodies and builds insoluble aggregates in bacteria. Denaturated (urea) based purification gives huge amounts of monomers. Unfortunately it was not possible to renaturize those into an active form. Microtubule affinity purification (see below) shows that this mutant is either degrading quickly or it shows a very high percentage of inactive motors indicated by a very low yield after microtubule affinity purification process. This is also the reason why this mini motor was not used for cross linking. In multi motor gliding assay mini motor E355V/P357K/N358L/K379L/G380R shows an unattended behaviour. $41 \%$ of analyzed microtubules driven by the motor a slowing down of the microtubules or even a stop and go event occurred. The WT mini motor showed $14 \%$ of these events. This indicates a low amount of active motor or an inactivation of motors during the 
experiment. In case of inactivation, motors can not detach from the microtubule and have to be ripped of indicated by a slowing down or pause of the microtubule transport.

To conclude the results of the multi motor gliding assay, coiled-coil impaired mutant I362E/L365K and coiled-coil promoting mutant K379L/G380R are behaving like WT motor in reference to its motor activity. This confirms the hypothesis, that the impaired velocities in vivo are not caused by a reduced motor activity and strengthens the theory of the influence of dimer formation on velocity.

\subsubsection{Biophysical properties of UNC-104 and the coiled-coil mutants in single molecule measurements}

As the multi motor gliding assay shows results, irrespective of any homo dimerization a characterization of the motor on basis of a single molecule level in order to result motor's biophysical properties has to be performed. This is done by single molecule measurements in TIRF (total internal reflection fluorescence) microscopy. In combination with a microtubule assay we can characterize the movement of the mini motors along microtubules in vitro. The motion of motors along microtubules is monitored by time and the tracks are analyzed by kymography.

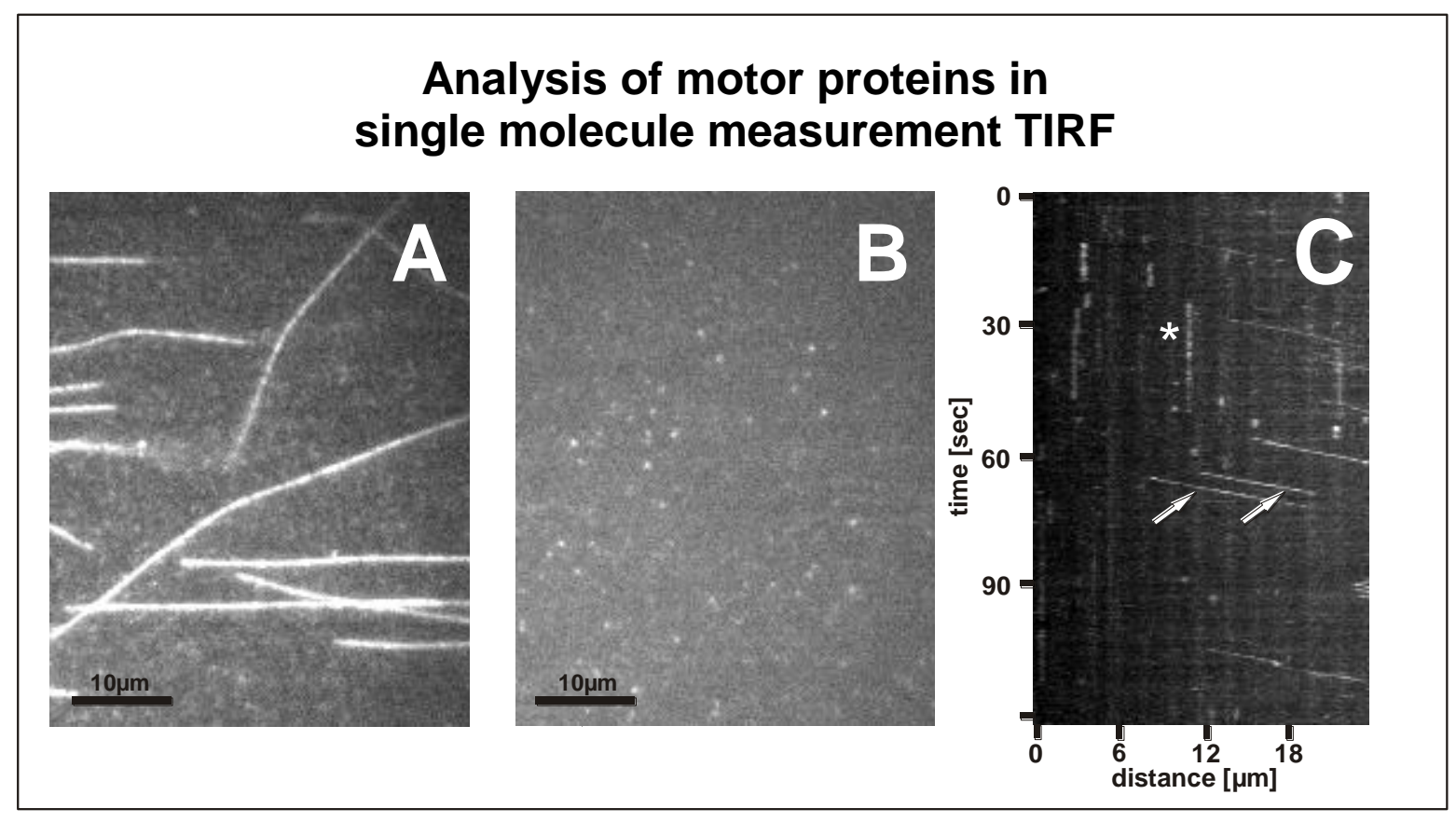

Fig. R23: Analysis of motor proteins in single molecule measurement TIRF

A) TMR-labelled microtubules B) GFP marking the tagged motos. C) Kymograph of motors moving along one microtubule, monitored by TIRF microscopy. 
Fig. R23 A shows polymerized tubulin (microtubules) with $25 \%$ tetramethylrhodamine labelled tubulin monomers. Upon excitation with $\lambda=473 \mathrm{~nm}$ using the emission filter $605 / 70 \mathrm{~nm}$ the filamentous structure of the microtubules are visible. R23 B) shows the GFP fusion molecules excited with $\lambda=473$ under the emission filter of $530 / 50 \mathrm{~nm}$. Figure $23 \mathrm{C}$ is similar to those for vesicle velocities with a few stational particles visible as horizontal lines (asterisk) and moving particles signing aslope tracks (arrows).

The purified mini motors in in vitro assays achieve higher velocities than those in living worms. This is a result of biological parameters like viscosity, ATP supply and blocked binding sites by other MT-binding proteins.

The average velocity of truncated WT motors in this assay is $1.69 \mu \mathrm{m} / \mathrm{s}$. The highest velocities are in the range of $2.8 \mu \mathrm{m} / \mathrm{s}$ to $3.6 \mu \mathrm{m} / \mathrm{s}$. Both coiled-coil promoting constructs E355V/P357K/N358L/K379L/G380R and K379L/G380R show average velocities in the same range $(1.45 \mu \mathrm{m} / \mathrm{s}$ and $1.65 \mu \mathrm{m} / \mathrm{s})$ and both show max. velocities in the range of $3.0 \mu \mathrm{m} / \mathrm{s}$ (Fig. R24). WT and coiled-coil promoting constructs show similar distributions with their peaks in the range of $1.2 \mu \mathrm{m} / \mathrm{s}$ to $2.0 \mu \mathrm{m} / \mathrm{s}$.

Coiled-coil impaired constructs $\mathrm{I362G}$ and I362E/L365K show a more than 50\% reduction of average velocities with 0.62 and $0.79 \mu \mathrm{m} / \mathrm{s}$ compared to WT (1,69 $\mu \mathrm{m} / \mathrm{s})$ (Fig. R25). The peaks in the distribution are between 0.4 and 1.4 compared to 1.2 to $2.0 \mu \mathrm{m} / \mathrm{s}$ in coiled-coil promoting constructs. Additionally the maximum velocity of the coiled-coil impaired constructs is reduced by more than $50 \%$ compared to WT (1.71 compared to $3.51 \mu \mathrm{m} / \mathrm{s}$ ). The number of events is drastically reduced in the coiled-coil impaired constructs, as lots of more videos have to be analyzed to get a suitable number for statistics. Mutant L365G, another coiled-coil impaired construct, could not show enough events to draw any conclusion, even as all events had been less than $1.05 \mu \mathrm{m} / \mathrm{s}$ (data not shown).

In total we can conclude that coiled-coil promoting constructs show velocities similar to WT constructs, regarding average velocities and velocity distributions. Coiled-coil impaired constructs show a more than $50 \%$ reduction in (total and average) velocities and the number of events is reduced. 


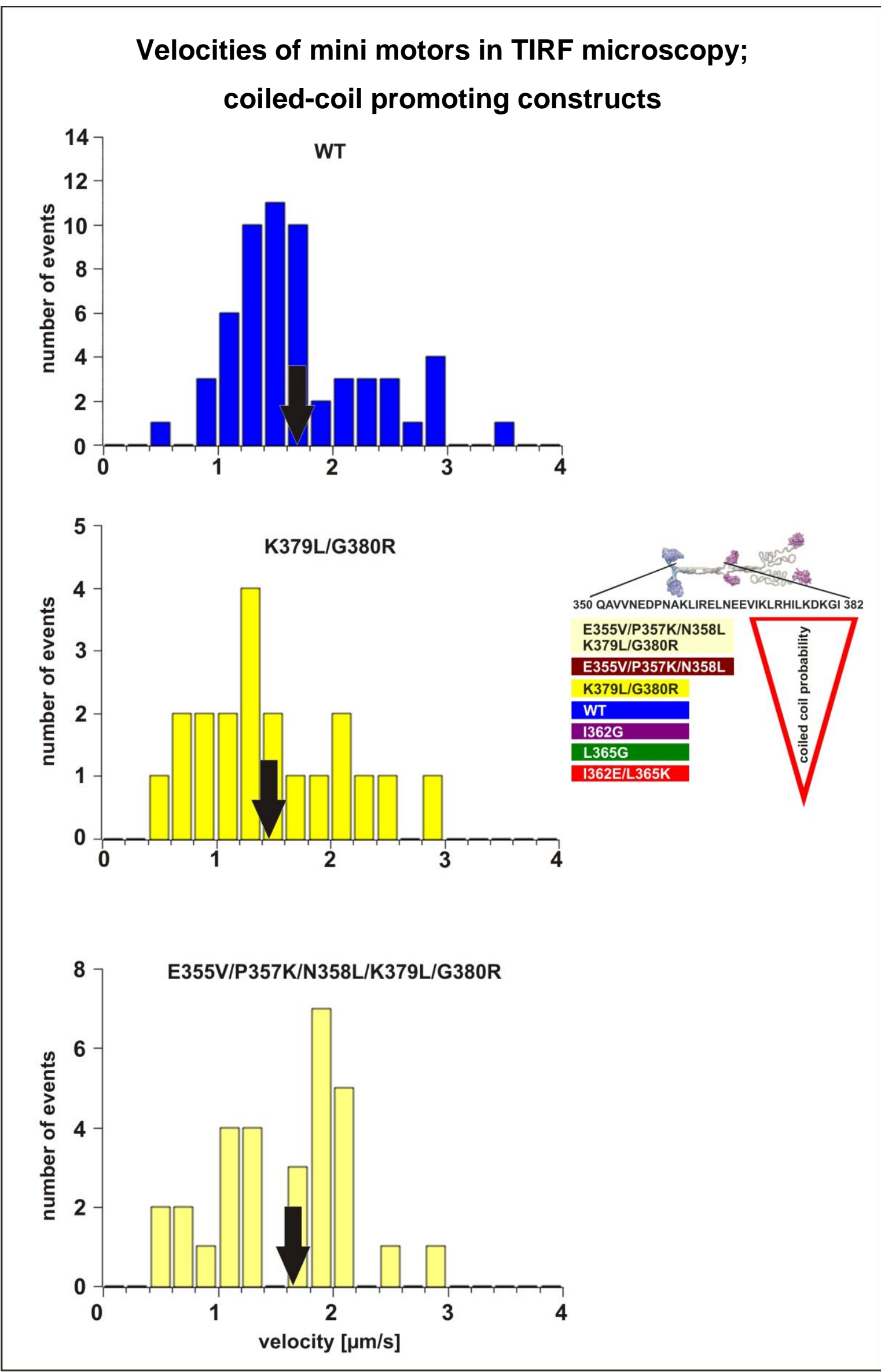

Fig. R24: Velocities of mini motors in TIRF microscopy; coiled-coil promoting constructs Histogram of velocities of mini motors in TIRF microscopy measurements of coiled-coil promoting constructs E355V/P357K/N358L/K379L/G380R and K379L/G380R compared to WT. 


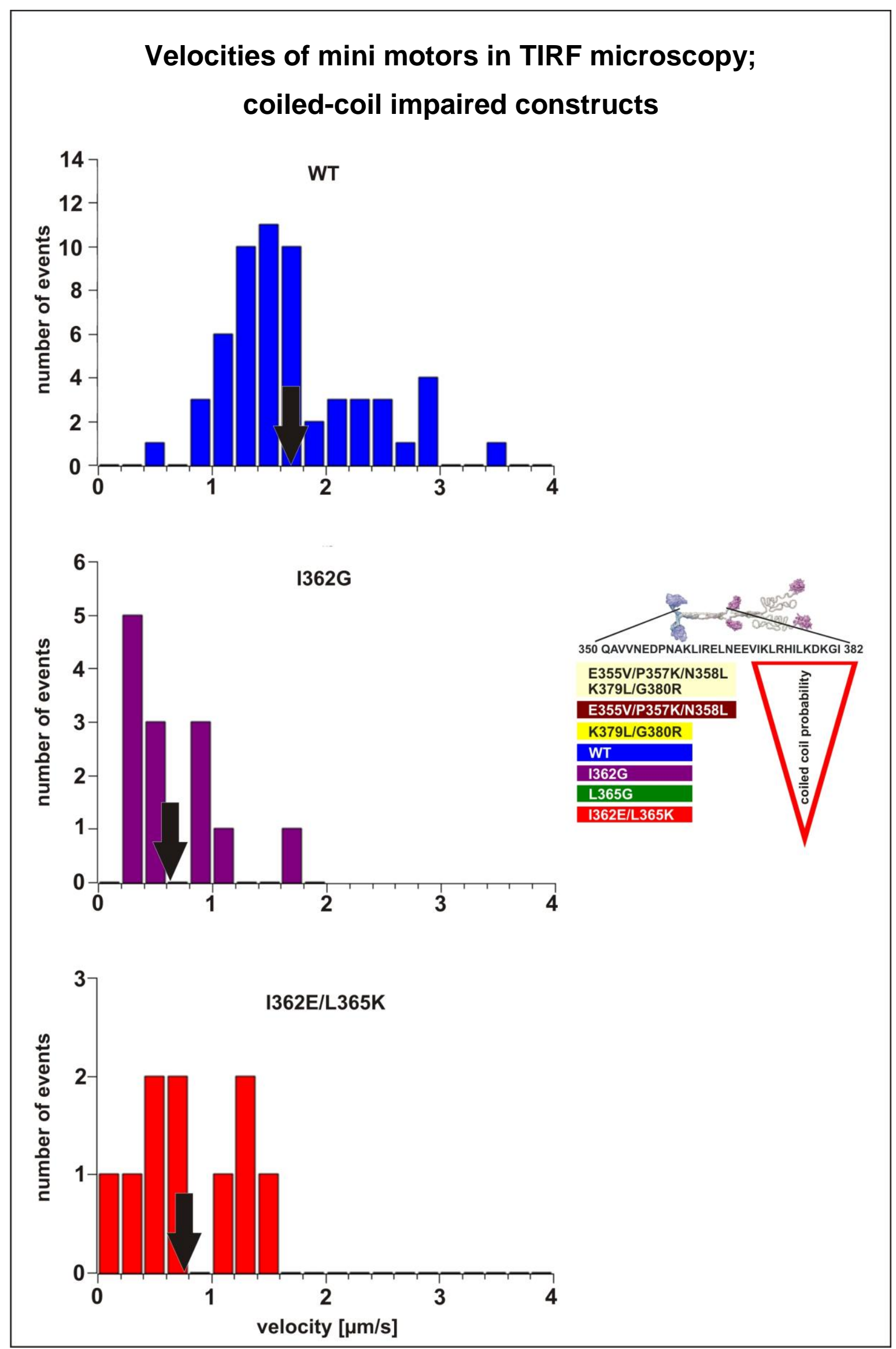

Fig. R25: Velocities of mini motors in TIRF microscopy; coiled-coil impaired constructs Histogram of TIRF measurements of coiled-coil impaired constructs I362G and I362E/L365K compared to WT. 
I conclude that only coiled-coil promoting constructs can form regular and active dimers reaching WT velocities. The events shown by the coiled-coil impaired constructs can not reach WT velocities. The results suggest that the lower movement of the coiled-coil impaired constructs result in rare aggregation of motors at the MTs by an unspecific or casual interaction.

\subsubsection{Ability of UNC-104 to form complexes in vitro}

Results of single molecule TIRF microscopy suggests a hint that only coiled-coil promoting mini motors are able to generate high velocities. A direct proof of the conformational state of these mini motors has to be adduced. One way to detect protein complexes is gel filtration to separate proteins and protein complexes by size. Using purified protein sample gel filtration is a suitable method to detect homo protein-protein interaction as dimers/multimers should be visible and can be separated in a native elution buffer. In this case monomeric UNC-104 mini motors should be detected at $72 \mathrm{kD}$ and dimeric mini motors should be detected at $145 \mathrm{kD}$.

Coiled-coiled promoting construct E355V/P357K/N358L/K379L/G380R shows one distinct peak at aprox. $100 \mu \mathrm{L}$ elution volume correlating nearly with the exclusion volume of the column at about $960 \mathrm{kD}$. As GFP was detected via dot blot (not shown), this peak is most likely representing large clusters of the motors forming at this motor concentration. Another very small peak is shown at low molecular weight. This is representing degradation products of the motor protein (and free GFP), as also here GFP was detected. The drop of absorption at $1.0 \mathrm{ml}$ and the sharp peak at $1.25 \mathrm{ml}$ plus the drop under 0.0 after the column volume is due to effects of ATP in the sample and in the buffer and can be neglected for motor protein analysis. These effects are also visible in the other constructs. The WT protein shows a less distinct peak in the same high molecular range as the coiled-coiled promoting construct, that may also represents aggregates. The main peak of the WT motor protein is its monomeric form, followed by the peak of the degradation products. The coiled-coil impaired construct I362E/L365K does not seem to be able to form aggregates, as there is no peak visible that is places at areas representing higher molecular weights as monomers. Apart from this the signal is identical to the signal of the WT.

Unfortunately the main material of the sample is sticking to the column, as a huge peak is visible at the washing steps with high salt concentration at the end of every run. The results of gel filtration suggest of the possibility of protein interaction of the three monitored constructs. Coiled-coil promoting strain E355V/P357K/N358L/K379L/G380R 
seems to have a strong ambition to interact. Using a concentration of $400 \mu \mathrm{g} / \mathrm{ml}$ almost all motor proteins seem to form a conglomerate resulting in a complex of high molecular weight. The coiled-coiled impaired construct I362E/L365K seems to be impaired in forming these complexes. Only monomeric motor proteins can be detected. The WT construct shows both signals, aggregates and monomers.

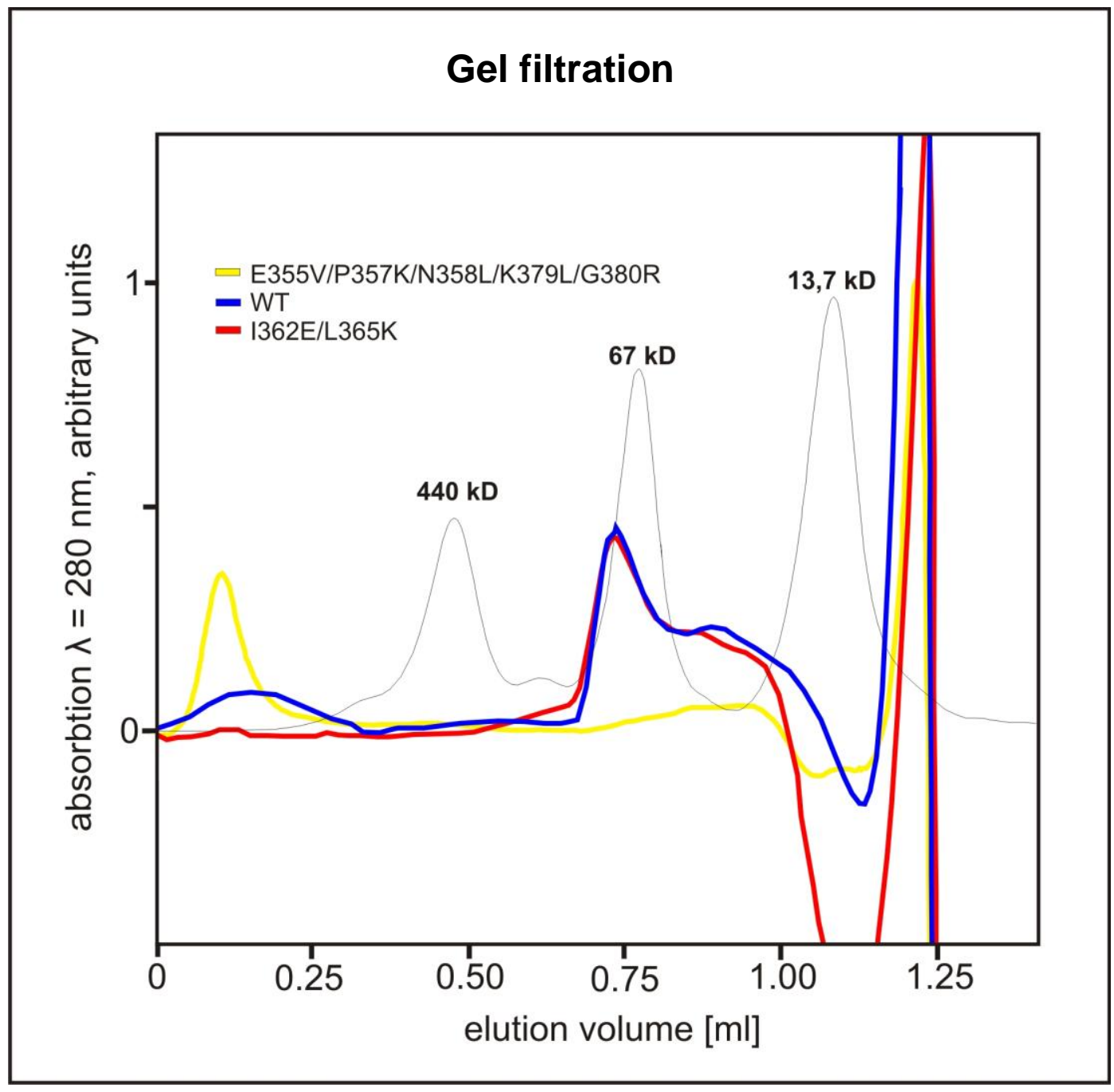

Fig. R26. Gel filtration

Gel filtration of WT-UNC-104, coiled-coil promoting mutant E355V/P357K/N358L/K379L/G380R and coiled-coil impaired mutant I362E/L365K. Reference elution profile is given in black. 


\subsubsection{Microtubule affinity purification}

The purification of motor proteins by microtubule affinity is necessary if all motors in the solution have to be active (and native) or if purification via His-tag or FPLC retains large amounts of side products which might negatively influence further experiments. For the chemical cross linking (see next chapter) native state of the motor and purity of the solution is necessary to ensure reliable results. Microtubule affinity purification is performed after pre-purification of motors at Ni-NTA (Fig. R21). The Ni-NTA purification binding the His-tag is an affinity purification using the C-terminal part of the truncated motor (Fig. R4). The target of the microtubule affinity purification is the n-terminal motor domain. This double affinity purification, using binding sites that are separated by a large distance result in highly pure target proteins.

Fig. R27 A shows a Western blot (vs. GFP) to detect the purification during the process. The line marked with HPM is representing the His-tag purified motor before microtubule affinity purification. To visualize side products that are detected by the GFP antibody, $8-20 \mu \mathrm{g}$ of protein is loaded. The further lines are representing probes from the purification process. Line $S_{1}$ shows the supernatant after the incubation step with the MTs. A dominant band of target protein is detectable, representing unbound or inactive (deficient in ATP/AMP-PNP-binding). The band transformed to a smile at $45 \mathrm{kD}$ is due to a massive tubulin content of the fraction. Detectable side products are as accumulated in this fraction as inactive motor protein unable to bind microtubules. Line $S_{s}$ shows the supernatant after the gradient centrifugation. Target protein and some smaller proteins are detectable. The band of target protein in this line is representing motors detaching from the MTs during the purification process. The smaller proteins seem to be degraded target proteins. $E_{1}$ and $E_{2}$ are fractions after elution Steps 1 and 2 . While elution step 1 provides a high purity and a low yield Elution step 2 shows a higher yield but a larger amount of degradation products showing that the protein is very sensitive to degradation. $E_{p}$ represents the pool of $E_{1}$ and $E_{2}$ and the material used for chemical cross linking.

To check any contaminations with proteins being not detectable with the GFP antibody a SDS-PAGE is performed (Fig. R27B) analysing pooled fraction $E_{p}$. Apart the band of the target protein two other bands are visible by closer look, representing tubulin $(55 \mathrm{kD})$ and the main degradation product $(40 \mathrm{kD})$ marked with the asterisk.

Apart from degradation products and a small amount of tubulin the purification of the truncated motor is successful and provides a suitable educt for the chemical crosslinking. 


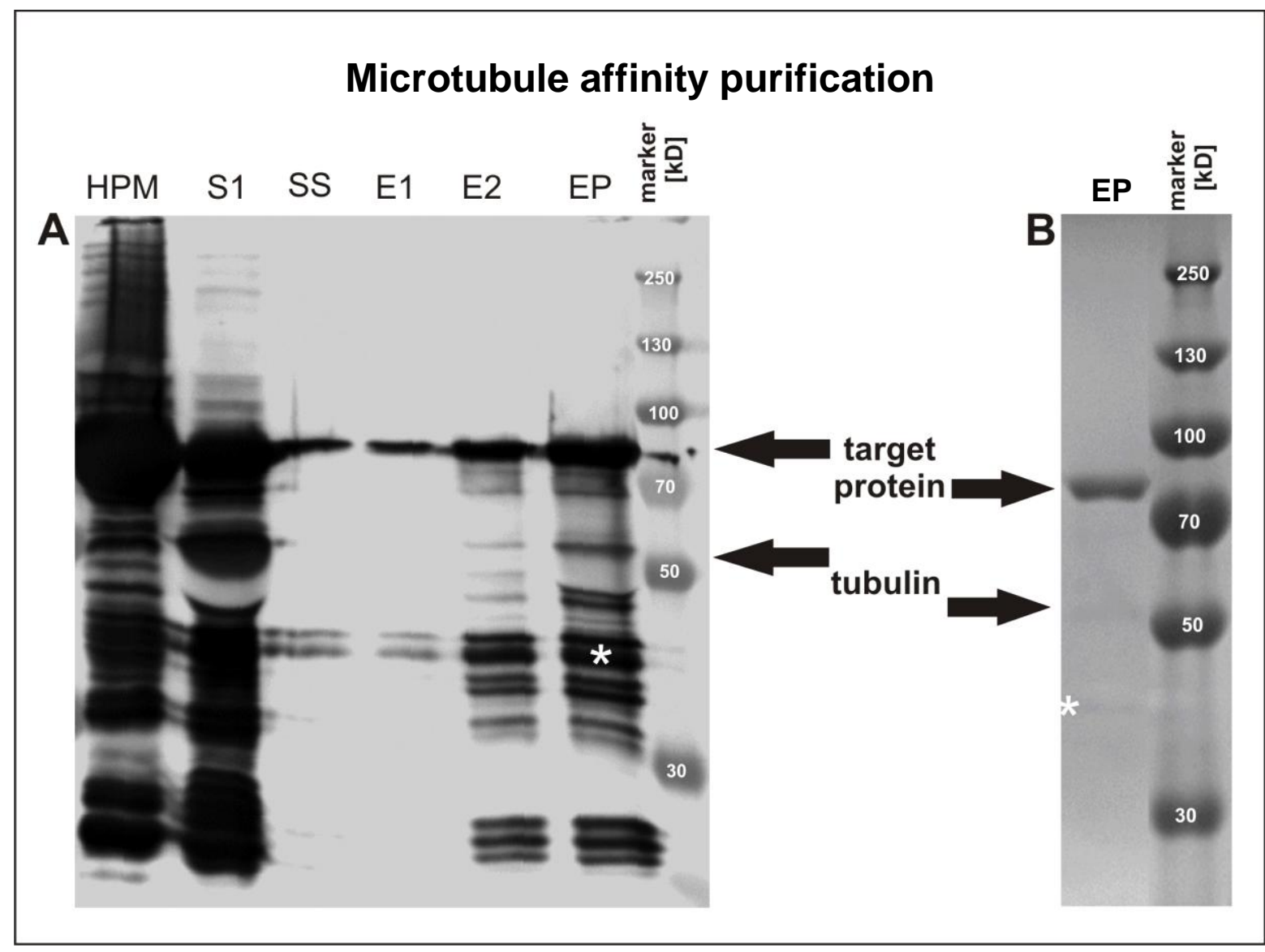

Fig. R27: Microtubule affinity purification

A) Western blot vs. GFP of the fractions during microtubule affinity purification. B) SDS-PAGE analytics to detect non GFP proteins in the purified protein solution.

\subsubsection{Direct interaction of UNC-104 visualized by chemical cross linking}

Chemical cross linking is a method to demonstrate protein-protein interaction in vitro. After the two affinity purification steps, the protein solutions are sufficient pure to proof in vitro protein-protein interaction of UNC-104 with each other, without interferences by other proteins. Cross linking studies with the WT, with a coiled-coil promoting and a coiled-coil impaired construct are performed. The detection of the truncated motors is performed by Western blot vs. GFP. The cross linking reaction is stopped at 10, 30, 60, 120, and 180 min, giving a time lapse resolution of the process. As a reference point for "untreated" motor, the quenched and inactive cross-linker solution is used.

"Untreated" coiled-coil impaired mutant I362E/L365K (Fig. R28A) shows a dominant protein band at height of the monomer and a small band of degradation product. During the cross link procedure some bands of unidentified side products with slightly 
increased size compared to the monomer are appearing. The signal is increasing till $120 \mathrm{~min}$ of incubation. The amount of monomers is decreasing significantly at $180 \mathrm{~min}$ indicating of over all degradation of the protein. The most important fact is, that in the coiled-coil impaired construct I362E/L365K no dimer of UNC-104 is detectable. The reference for "no treatment" $(0 \mathrm{~min})$ is displaced from another part of the identical blot for better comparison, using Adobe Photoshop. To strike out this modification, the contrast of this line is increased.

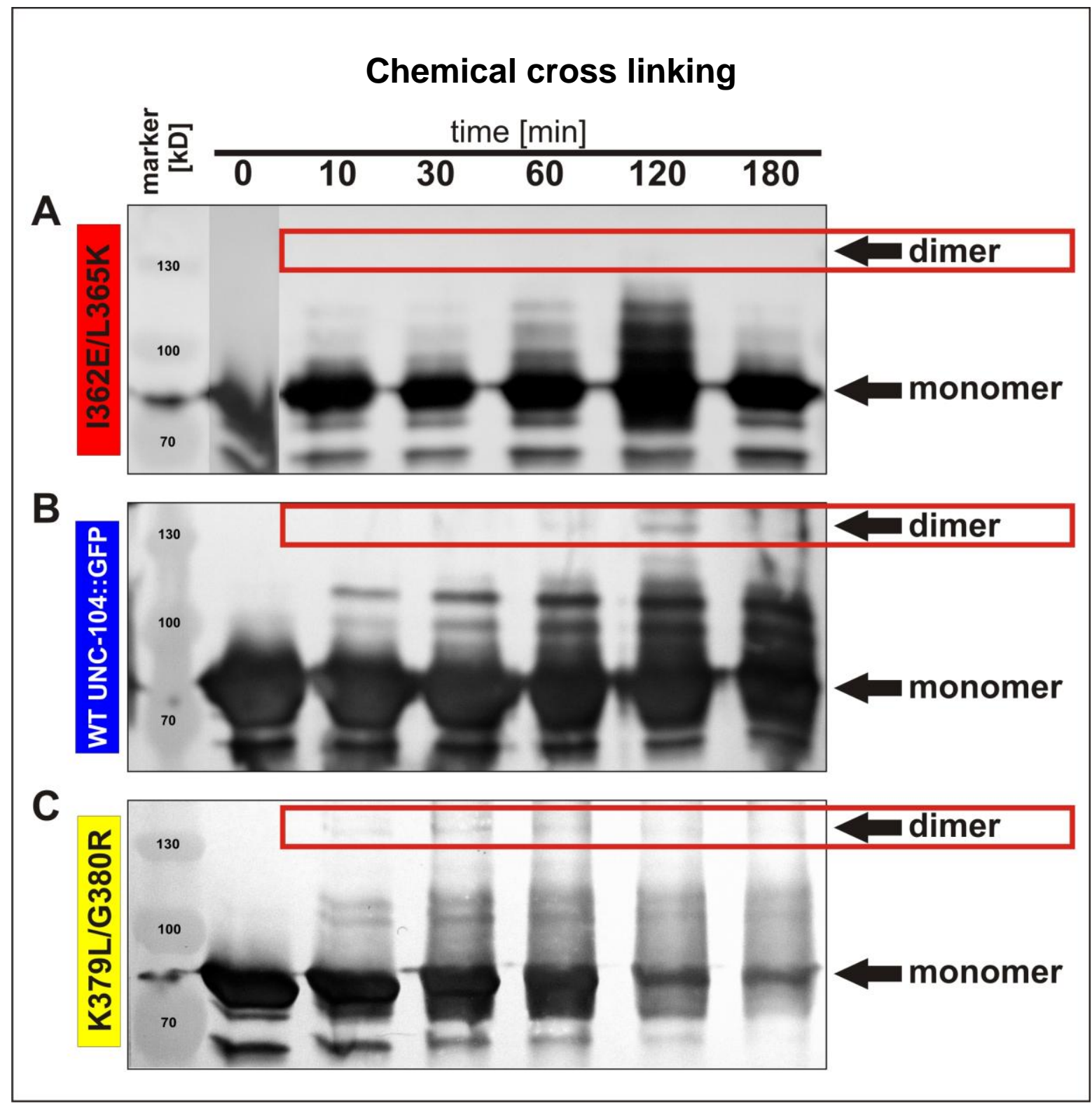

Fig. R28: Chemical cross linking

A) Time lapse of chemical cross linking of purified coiled-coil impaired truncated motor I362E/L365K in vitro, detected by Western blot using an antibody vs. GFP. B) Identical experiment for WT truncated motor and C) coiled-coil promoting construct K379L/G380R. 
The WT UNC-104 (Fig. R28 B) shows a dominant protein band at the monomer and also the side products are visible according to the coiled-coil impaired construct. The big difference is an appearance of a distinct protein band at the size of the dimer, increasing from 30 to 180 min incubation time.

The coiled-coil promoting construct K379L/G380R (Fig. R28 C) shows its dominant protein band at the monomer and the amount of side products is increasing from 10 to $60 \mathrm{~min}$. In this mutant, the defined protein band at the height of the dimer is appearing instantly and is constantly increasing in the same time scale. The whole amount of protein is decreasing after 120 min incubation time. This effect is due to general degradation of the protein similar to the other groups.

The results of microtubule affinity purification show an accumulation of tubulin in the motor protein sample. To proof that the cross-linking products at $140 \mathrm{kD}$ size do not occur due to any cross-link of tubulin with the motor, a Western blot vs. a-tubulin in parallel to the cross linking of WT construct was performed (Fig. 29). In both groups incubation time was $60 \mathrm{~min}$. Both left lanes show the result of incubation with cross linker, right pockets show incubation with an insufficient concentration of cross linker.

\section{Chemical cross linking; tubulin control}

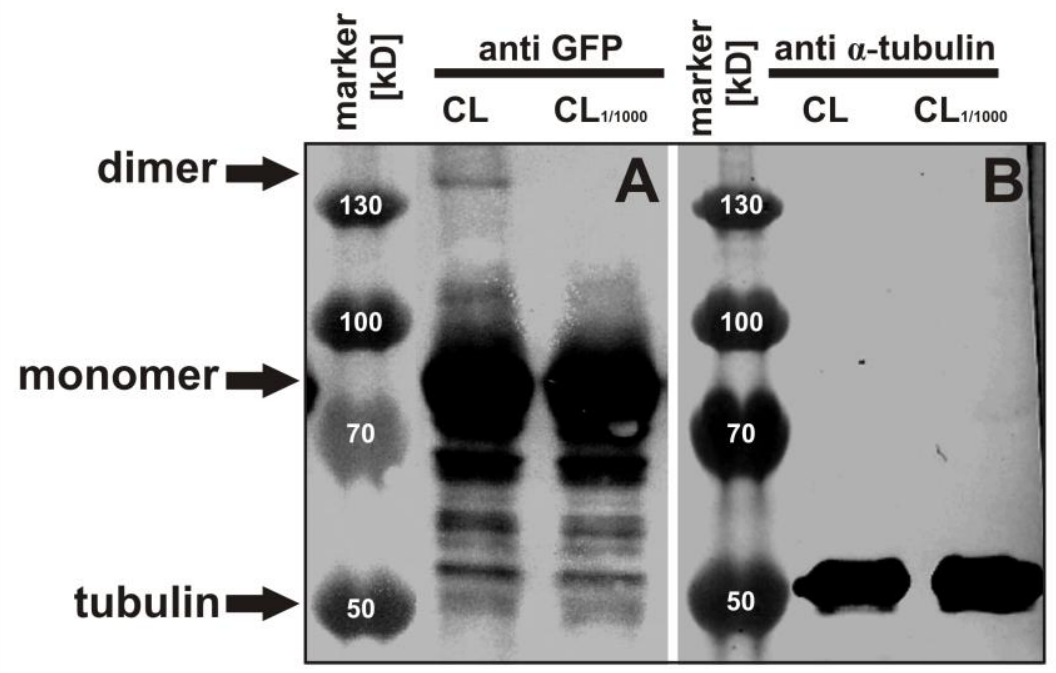

Fig. R29: Chemical cross linking; tubulin control

A) Western blot, performed with anti-GFP. B) shows the identical experiment stained with $\alpha$-tubulin $A B$. Lines marked with $C L$ are treated like described above, lines with $\mathrm{CL}_{1 / 1000}$ are treated with an insufficient amount of $\mathrm{CL}$ for any detectable effect. 
Notably the tubulin $A B$ does not stain any other protein bands apart from the $\alpha$-tubulin at $50 \mathrm{kD}$, showing that the protein band supposed to be the UNC-104 dimer can not be a motor-tubulin complex and suggesting a kinesin homodimer formation.

The cross linking experiments confirm the results shown of the in vivo experiments, that both WT and coiled-coil promoting construct K379L/G380R are able to physically interact in vitro and are able to act as a homodimer, whereas the co coiled-coil impaired construct I362E/L365K is not able to dimerize and shows less functional activity. 


\section{Discussion}

\subsection{UNC-104 is in dimeric conformation in living neurons in $C$. elegans}

In vivo and in vitro studies of this thesis lead to the conclusion that UNC-104 can act as a dimeric motor during transport processes in neurons of living organisms. In vitro studies suggest the neck coiled-coil region as the putative dimerization region (Tomishige et al., 2002, Klopfenstein et al., 2002) thus I mutated motors influencing the coiled-coil probability. Only motors with high probability for coiled-coil formation in the neck coiledcoil region are able to rescue the UNC phenotype and reach high transport velocities in vivo. Coiled-coil impairing mutations in this region can not rescue the UNC phenotype and do not achieve velocities necessary for fast axonal transport in vivo. Dimer formation itself is tested in vivo by a new developed system combining fluorescence anisotropy with spinning disc laser confocal microscopy, showing that coiled-coil promoting mutant motors are more likely to exist in a dimeric form than WT motors in vivo. On the other hand coiled-coil impaired mutant motors are more likely to be monomeric than WT motors in vivo. This implicates that coiled-coil formation is necessary for dimer formation and function. In vivo studies are supported by single molecule measurements in vitro, indicating the same correlation between coiled-coil formation and velocity as given in the in vivo experiments, although maximum transport velocities are indistinguishable in in vitro multi-motor gliding assays. Direct dimerization of the WT and the coiled-coil promoting strains in vitro is evidenced by cross linking.

\section{Rescue in a mutant background}

In order to test the rescue capability, unc-104 transgenes were introduced into the unc-104(e1265) mutant background. What are the reasons to choose the unc-104(e1265) hypomorph as suitable background for this study? As previously reported this mutant has a point mutation in the PH-domain (Hall and Hedgecock, 1991) with endogenous UNC104(e1265) still being expressed in the worm (Kumar et al., 2010). I assume that basal expression of UNC-104(e1265) does not interfere with the introduced transgenes. On the one hand there are hints that cargo binding is essential for activation of the protein (AlBassam et al., 2003, Hammond et al., 2009) so a potential heterodimerization between an endogenous and a mutant motor is not very likely. On the other hand, total amount of endogenous UNC-104 is reduced in unc-104(e1265) mutant compare to WT (Kumar et al., 2010). A putative heterodimer of an endogenous cargo binding-impaired motor and a 
dimerization-impaired motor then would be able to transport cargo processively. Even if there are a few heterodimeric proteins, in case of the dimer-impaired strains, our result shows: those hypothetical few ones are not able to rescue the phenotype. As such, a heterodimer has only one GFP fluorophore it would appear as a monomer in fluorescence anisotropy measurements. In case of another putative scenario, that a WT or coiled-coil promoting motor is able to dimerize with a cargo-binding impaired endogenous motor, creating a moving dimer, fluorescence anisotropy measurement will identify this motor as monomeric, because of the single fluorophore. In this case the fluorescence anisotropy signal will be moved towards the monomeric value range. This effect will not change the comparison in to WT group in fluorescence anisotropy, as then both, WT and coiled-coil promoting strain will be affected by this phenomenon, even a single cargo binding motor will be sufficient to activate another one. (Nevertheless, this could be an interesting effect for activation of inactive motors.) Thus, as all named effects will not affect the results, the unc-104(e1265) hypomorph is a suitable background.

\section{Expression and overexpression}

Another critical point could be the expression level of UNC-104::GFP in order to rescue the uncoordinated phenotype. Overexpression of the motor can cause an uncphenotype acting dominant-negatively and reducing the rescue frequency previously described by Zhou (Zhou et al., 2001). In contrast to their results we did not see a worm population with only partly rescued unc-phenotype but a full rescue. In this case we can consider the expression level in all used strains as physiological. This assumption is stressed by the comparative study of WT strains in fluorescence anisotropy. Expression levels of the two used WT strains differ by $36 \%$. Both strains fully rescue the uncphenotype and do not show any significant differences in conformation. Another important point is the comparability of the utilized strains. The strains are generated by microinjection, so a discrete expression level of the strains can never be set up. Since all constructs have the identical promoter, the expression level can only be influenced by the amount of DNA used for microinjection but is mainly influenced by the uptake of DNA into the developing cells. Even if the same amount of plasmids is injected into the gonad expression levels of the resulting transgenic strain can differ. For example, the mutant E355V/P357K/N358L/K379L/G380R injected with $20 \mathrm{ng}$ of DNA per $\mu$ shows a much higher expression on the protein level than I362G, that was injected with 70 ng of DNA per $\mu \mathrm{l}$ with identical volume of injected liquid. Do these differences in the expression level will influence the results? Phenotypically this is not the case, as can be seen comparing coiled-coil promoting strains K379L/G380R and E355V/P357K/N358L/K379L/G380R or coiled-coil impaired strains L365G and I362E/L365K. In both cases the groups show 
identical tendencies irrespective of their higher or lower expression level. Comparable results of independence of motor's expression level with respect of motor characteristics had been shown by Shubeita (Shubeita et al., 2008). Changes of motor copy numbers have no consequences to kinesin-1 intracellular transport processes. At least an expression level differering by a factor of two does not interfere with the conclusions drawn.

\section{Establishing a consistent expression and transport system}

As previously described the $C$. elegans system is suited to address questions of motor characteristics and conformational states. The basic question of the conformational state of kinesin-3/KIF1A was addressed by Hammond (Hammond et al., 2009). They used a heterologous expression system. The mouse orthologue KIF1A was expressed in COS and murine CAD cell line by driving the expression under one of the strongest available mammalian promoter (CMV, Tornøe et al., 2002). In this system they showed, that the motor is in an inactive state and able to dimerize. One of the methods they used to determine the dimeric state is FRET. FRET is dependent on distances between two fluorophores and independent of the conformational state. Clustering without directed interaction can increase the FRET efficiency. In a system of overexpression of a soluble, cytosolic target protein (even it is in an inactive state) the cell is distributing the protein in high concentrations. Therefore the chance of cluster formation is always present. Recent studies showed an accumulation process for proteins designated for degradation in COS cells (Drake et al., 2010) near the nucleus. In these areas the concentration of inactive proteins is even increased. As Hammond performed full cell FRET analysis, results are including these areas of accumulated GFP fusion proteins. Thus they can never exclude TIRF signals by cluster formation within the whole cell and especially in the areas described by Drake. In fact, a closer look on the given figures to this experiment is suggesting an accumulation near the nucleus. A possible control by a strictly monomeric protein expressed in the used system was not performed.

Hammond also described, that in his system the KIF1A is inactive. This phenomenon is explained by a self inhibitory mechanism by intermolecular interaction with the fork-head domain or the coiled-coil domain (although Hammond does not reveal what part of KIF1A interacts with this region). The direct evidence for dimerization was performed by chemical cross-linking of COS cell lysates (and further on, of lysates of primary neurons, without any dimer control group). The signal of the control group kinesin1 shows a clear band at dimer size. The signal of the cross linked dimer of KIF1A is smeared and shows no distinct, main band signal. While my in vitro cross linking results show a clear dimer band, it is unclear whether additional proteins in cross linking cell 
lysate are responsible for a high-molecular weight signal. Interestingly, Hammonds experiments show no monomeric signal visible after crosslinking. This would lead the conclusion of $100 \%$ motor dimerization, a surprising finding in a cell type where KIF1A is in a $100 \%$ inactive form. While it remains to be seen how appropriate control groups for monomeric behaviour behave in such a heterologous overexpression system, physiological conditions would help to clarify the significance of the results.

One big difference of this work to Hammonds work is the $C$. elegans system used in this thesis which has several intrinsic controls with respect of the correct expression level the activity and the native state of the protein. A possible overexpression is visualized by an unc-phenotype and therefore improper innervation of the body wall muscles. Only motor expression levels in a physiological range result in a phenotypic uncoordinated rescue and synaptic vesicular transport. As motor proteins movement can be visualized by time lapse confocal microscopy a direct evidence of the native and active state of the protein can be performed. So instead using in a non neuron expression factory as performed by Hammond, the $C$. elegans model visualizes native proteins.

The measured velocities in the $C$. elegans neurons are 3.5-fold lower, than those published in $2001(1.01+/-0.53 \mu \mathrm{m} / \mathrm{s}$ vs. $0.29+/-0.09 \mu \mathrm{m} / \mathrm{s})$. The reason for this phenomenon could partially lie in the relatively low end-of-fiber laser power due to the polarization setup. Probably only apparently large and therefore bright vesicles could be visualized. Indeed, early observations of axonal transport in giant squid axon report a size-dependent velocity profile (Allen, 1982). While it is less clear how the velocity of multiple cargo-attached motors mechanically relates to vesicle size, viscous drag and cargo load, there is ample evidence for an increase in stall force upon engaging multiple motors on a given cargo vesicle (Vershinin et al., 2007; Shubeita et al., 2008; Kunwar et al., 2008). It is likely that a stiff motor-cargo compliance would result in slowed transport, an effect that scales with the size of the cargo (Kunwar et al., 2008). Currently, such considerations are well formulated in elaborate models that remain to be tested by experimental data.

At least two effects can influence the transport by sterical interference. The first one is the traffic on the microtubules itself. Large particles suffer more from sterical effects on the microtubule surface and viscous drag (due to Stokes' radius). In axons, microtubules function as highways between cell soma and the synapses. Both anterograde and retrograde transport of essential proteins occur with high frequency and are crucial for the neurons survival and maintenance (Morris and Hollenbeck, 1993). A second effect is the concentration of motors on the membrane. Given an estimated length of a fully extended kinesin-3 (100 nm), motors bound anywhere on small vesicles $(50 \mathrm{~nm}$ diameter) would easily reach the microtubule surface. With increasing vesicle size, an 
efficient cargo-microtubule interaction becomes sterically hindered unless local motor concentration or clustering on the vesicle-microtubule interface is achieved (Erickson et al., 2011). In vitro, motor clustering can increase the frequency but not the speed of cargo movement (Klopfenstein et al., 2002). It is unclear whether in vivo small and large vesicle differ in their propensity to cluster motors.

As my measurements had been carefully performed on healthy, young adult worms, comparable results from different worm strains are expected with respect to their transport parameters. Nevertheless it has to be mentioned that the amount of total detected particles in the coiled-coil impaired worm strains in total had been reduced. Almost 10-20 times more movies had to be analysed for these strains compared to the coiled-coil promoting ones. But even with this amount, less events could be detected compared to coiled-coil promoting strains. This phenomenon is emphasizing my hypothesis of a dimeric state of the motor during vesicle transport.

\section{Measuring protein-protein interaction}

What are the technical and analytical possibilities to get information of proteinprotein interactions and conformational states in vivo in a non-invasive manner? A method suited to report a proximity-sensitive read-out such as fluorescence anisotropy, FLIM measurements would be one possibility. Another method is TIRF microscopy to distinguish monomer and dimer based on fluorescence intensity in $C$. elegans neuronal cell culture. This method was performed in collaboration with the group of Dr. Jürgen Klingauf at the Max Planck Institute of Biophysical Chemistry. The aim of this collaboration was to detect moving particles in the axons and define the amount of motors by recognition and counting of bleaching steps. Unfortunately the data analysis was challenging. The primary neurons were purified and developed normally in cell culture dishes in vitro, but the neurites showed to be not as thin as those visible in the organism and therefore the thickened neurite was filled with GFP-coupled particles. On that account a recognition of moving particles was not possible. A solution for this problem could have been a growth of primary neurons in a chamber leading to a channel that ends in a chamber filled with a chemoattractive reagent. A directional growth and therefore a thinner and longer neurite process could be generated. There had been commercially available chambers like these, but they had unfortunately not been suitable to perform TIRF microscopy, as the bottom of the chamber consists of a thick synthetic material and not of glass.

In the in vitro studies truncated forms of the protein have been used, as the full length protein can not be produced and purified from bacteria. The focus of interest is at the neck coiled-coil. Previous in vitro studies showed, that the truncated UNC-104 $1-446$ is a 
perfect candidate to answer the questions in this study, as it includes the whole neck coiled-coil but is long enough to keep the parameters of motility in single molecule assays and multi motor events (Al-Bassam et al., 2003). When purifying the proteins, a difference between the coiled-coil promoting and the coiled-coil impairing constructs became obvious. Whereas the coiled-coil impaired constructs easily could been purified an accumulation of coiled-coil promoting constructs in inclusion bodies could be detected resulting in a very low yield. As the effect can only be seen at coiled-coil promoting constructs it could be estimated, that there is a dimerization/multimerization effect at high concentrations. This could be verified by the results of the gel filtration showing only one a high molecular peak at the E355V/P357K/N358L/K379L/G380R construct, giving evidence this multimerization processes at high concentrations.

Identical to the results of the motor velocities in vivo, the amount of movies taken to get a comparable amount of moving particles of coiled-coil impaired motors had been ten fold higher compared to coiled-coil promoting motors. Mutant L365G, another coiledcoil impaired construct, could not show enough events for a conclusion. The result of the mini motors are very robust and kinetics and velocities are similar to former data (AlBassam et al., 2003, Klopfenstein et al., 2002). Also the cross-linking of the motor proteins show distinct results with respect to the possibility of dimer formation.

In addition to the cross linking, another method to visualize homodimerization was performed. In collaboration with Ingo Gregor in the group of Prof. Jörg Enderlein dualfocus fluorescence correlation spectroscopy was measured with the WT-mini motor, a coiled-coil promoting and a coiled-coil impaired construct. By evaluation of the distances between two fluorophores passing the field we wanted to draw conclusions about conformational state of the passing mini motors. If the distance is stable and close together, we can conclude a homodimer, if distances vary a solution of monomeric proteins will be the case. Unfortunately it rapidly became clear, that the necessary low concentration of $100 \mathrm{pM}$ is too low to draw any conclusions regarding the conformation.

Another possibility to check the conformational state of a protein is by a calorimetric way. As dimer formation shows measurable entropic effects a comparison of WT, coiled-coil promoting and coiled-coil impaired constructs would have been possible. This method requires high concentrations of affinity-purified mini motors. As mentioned before, the purification of the coiled-coil promoting mini motors is difficult and does not provide high yield of constructs. This is the reason, why calorimetry has not been performed in this thesis. 


\subsection{Fluorescence anisotropy is a suitable method to analyze conformational states of proteins}

Identification of protein-protein interactions became one of the most important topic in biochemistry and molecular medicine in recent decades. The main focus in this fields is actually pointing on methods being non invasive and non destructive, where these proteins can be characterized in vivo under physiological conditions.

Quantitative imaging techniques such as Foerster Resonance Energy Transfer (FRET) and Fluorescence Lifetime Imaging Microscopy (FLIM) has been the methods of choice, when there was the need to map biochemical reactions in the living cell. FRET occurs when two fluorophores are in close proximity $(<8 \mathrm{~nm})$ permitting excitation energy to transfer radiation less from one fluorophore (donor) to another (acceptor), and strongly depends on the intra-fluorophore distance. Therefore, FRET has been used to sense molecular proximity and possible molecular interactions and to map biochemical reactions. FRET facilitates the depletion of the donor excited state and thus can be quantified by a reduction of the fluorescence lifetime of the donor fluorophore. FLIM has become broadly used among the biomedical community but is still comparatively expensive and often too slow to offer fast imaging of biochemical reactions in a living cell or organism.

One aim of this thesis was to create a cost-effective instrumentation to measure protein-protein interactions in living organisms. One of the most common methods is (hetero-)FRET. Fluorescence anisotropy is also used to detect protein-protein interactions (receptor/ligand) but can also be used to measure homo-FRET between identical fluorophores (Weber, 1954) as the emitted fluorescence can exhibit a rotation in polarization upon radiation-free energy transfer (Lidke et al., 2003). Fluorescence anisotropy as well as FRET shows a spacial proximity implying direct interaction. There is one decisive difference between the homo-FRET in fluorescence anisotropy and heteroFRET. Hetero-FRET requires equi- or nearly equi-expressed amounts of the different fluorophores. This method can be suitable for heterologous expression in vitro for example in cell culture. For the expression in cells of living organisms this restriction is crucial. In vivo expression like performed in the $C$. elegans system can not assure equal expression as expression is dependent on uptake of the same amounts of both plasmids during oogenesis. A microinjection of a plasmid containing both fluorophore tagged proteins is not possible as the plasmid will be too large for efficient insertion in the oocytes as both proteins have to contain the last 8 introns for efficient expression in the cell. With the homo-FRET of fluorescence anisotropy the problem of equi-expression is avoided and the total expression of the protein can be kept lower. In case of UNC-104 this is an 
important point as described before. Even if a perfect balanced hetero-FRET system would possibly be more sensitive it is not suitable for the used $C$. elegans system. Another possible method could be FLIM. FLIM measurements are both cost intensive in acquisition and has imaging rates of over $1 \mathrm{~s}$ (Gerritsen et al., 2002). The developed system based on fluorescence anisotropy is much less money consuming and acquisition times can be kept lower.

As the developed system is cost effective, the setup is comparatively simple and an easy calculation of the data can be performed, fluorescence anisotropy was the method of choice for this project. The capability of the system was described in detail in the results chapter 5.4.4.1. Identification of pure monomeric and pure dimeric proteins in the living organism is possible. The comparison of their fluorescence anisotropy values show a high significance of $p \leq 0.05$ in linked Bonferroni test. Proteins enabled to be present in both monomeric as dimeric form such as sytaxin-1 show values in between both other groups.

Analysis of fluorescence anisotropy images allows a pixel-by-pixel calculation. The signal-to-noise ratio in fluorescence imaging is limited at least by the number of photons acquired in each pixel. As measurements are performed in a living worm the background noise is higher than in a pure protein solution. Therefore higher expression levels or longer acquisition times are necessary. As second restriction an increase of the kinesin-3 expression level can lead to impaired neuronal function, visualized by an unc-phenotype caused by improper innervation of body wall muscles, and therefore is no option (Zhou et al. 2001). An increase of the acquisition time can be the method of choice, if necessary, and does not affect the values of fluorescence anisotropy as the ratio between the two channels stays the same.

\subsection{The neck coiled-coil of UNC-104 is an essential part in the homodimerization process}

The results of this thesis do not only show the conformational state of kinesin-3 in vivo, they also give insight into the region responsible of the homo-dimerization. It could be shown directly, that an intact heptad motif and therefore a high coiled-coil probability adjacent the neck linker is essential for dimer formation. All constructs that can rescue worms WT-behaviour, show fast motor velocities and dimeric structure in fluorescence anisotropy have one parameter in common. They have an over $90 \%$ coiled coil probability from the beginning of the neck coiled coil region at aa 358 reaching at least to aa 379 . The coiled coil probability of the WT is $80 \%$ at this aa reaching also to aa 379 . My results 
show, that motors with a lower coiled-coil probability show less dimeric structure, than WT motors in fluorescence anisotropy. In fact the small area of at most 21 aa is playing a crucial role in the dimerization process of kinesin-3. Shorter constructs did not show motility in vitro (Tomishige et al., 2002, Klopfenstein et al., 2002) as constructs including aa 446, used in this thesis show all characteristics of a fast and processive motor. One of the putative dimerization site of kinesin-3 lies between the beginning of the neck coiledcoil at aa 358 and aa 446 whereas a high coiled-coil probability the area between aa 358 and 379 is crucial for dimer formation. This region is consistent with the postulated area from Rashid (Rashid et al., 2005) determined by in silico calculation and in vitro peptide analysis in UNC-104 and the homologous area of murine KIF1A (aa 365- 389) and studies from KIF5C/KIF1A chimeras (Hirokawa et al., 2009).

\subsection{Direct link between vesicle velocities and the potential to form a homodimer in vivo}

As UNC-104 is described as a monomeric motor there had been a long-lasting discussion how the motor can achieve these high velocities. With this thesis I provide evidence that the capability of dimer formation via the neck coiled-coil is essential for performance of high velocity transport in vivo. The first direct indication is the total rescue of the uncphenotype in the hypomorph background that is only performed by the coiled-coil promoting strains. This phenomenon is supported by the vesicle movement in the living worm. Only the coiled-coil promoting strains display high velocities in transport processes driven by UNC-104 motors. This evidence is highlighted by the in vitro experiments and velocities in single molecule measurements, where only the coiled-coil promoting constructs are able to reach high velocities.

\subsection{Consequences of an active dimeric kinesin-3 for the neuron}

The principle "activation through dimerization" is a common and well described phenomenon in cell biology. Homo/heterodimerization of receptors are initializing signalling cascades (Mellado et al., 2001), signal protein family SH-2 activates kinases by their homodimerization (Nishi et al., 2005). In the field of motor proteins this has not been shown yet. If UNC-104 is monomeric is solution and inactive in the absence of cargo, the homodimerization can be an activating step leading to a motor able to perform fast axonal 
transport opening an additional regulatory system for the cell. It is speculated that cargo binding is a first crucial step of regulation, as cargo binding can probably lead to a self regulatory activation (Hammond et al., 2009) and degradation upon loss of specific cargo binding (Kumar et al., 2010).

To tackle the question of motor regulation the mechanistic workings of UNC-104 have to be addressed. How can this activation be performed? What are the conformational states of an inactivated form of UNC-104? Is the molecule folded in an inactive state and which parts of the protein are still accessible for binding or interaction to other proteins? Al-Bassam does suggest an inhibited cargo binding (Al-Bassam et al., 2003). Hammond did show, that in an artificial system lacking proper cargo (Hammond et al., 2009) MT-binding is impaired. Both speculated an intermolecular interaction of the cargo binding domain within an area between the fork-head domain and the neck coiledcoil leading to inactivation. This hypothesis is supported by the results of Hirokawa who only detect folded or condensed KIF1A in low angle rotary shadowing electron microscopy (Hirokawa, 1998, see also Fig. 16 A). Lee showed an interaction of the isolated domains of fork-head with the hinge region by co-immunoprecipitation, an observation that requires functional verification (Lee et al., 2003).

One experimental approach can be conventional hetero-FRET in vitro. FRET donors (and corresponding acceptors) can be fused to the FL-UNC-104 at $\mathrm{N}$ - and C-terminal ends (motor domain or cargo-binding domain) or chemically crosslinked at selective areas like the hinge region, the fork-head domain or the coiled-coil regions. Measurements of FRET efficiency in solution allow to gain insight into the conformation. When a certain conformation is identified, these experiments can be extended by presenting either cargo or MTs to the FRET constructs. In this case does the FRET signal disappear due to cargo presentation and/or to MT-presentation.

In my work the fluorescence anisotropy comparison of the WT-UNC-104 and the cargo binding impaired motor $\Delta \mathrm{PH}$ did not show any differences. This suggests, that the dimerization state of UNC-104 is irrespective of cargo binding. The question remains: Is the dimer formation of full-length UNC-104 probably an activating factor for cargo binding or for microtubule binding? In case of a microtubule binding a combination of the previously described experiment with single molecule measurement TIRF will give information about a potential processivity and therefore an activation of the motor into a processive one, due to dimer formation.

Another crucial question is the effects of known or putative interaction partners of UNC-104. Actual there are several proteins interacting with UNC-104 with unknown function (Koshizuka et al., 2005, Wagner et al., 2009, Hsu et al., 2011). Those could be taking part in regulatory processes of UNC-104 activity and therefore the efficiency of 
anterograde axonal transport. Regulated axonal transport could be a result of a balanced motor/effector expression ratio: a low expression rate resulting in mostly monomeric UNC104 motors resulting in slow vesicle movement, or a high expression of UNC-104 and low expression of regulating proteins resulting in fast dimeric UNC-104 proteins and fast axonal transport and a third stage with additional high expression of the supporting proteins (probably stabilizing dimers, and additionally cargo binding) resulting in an increased flux rate. This stage could be necessary during neurite outgrowth or axonal regeneration. A micro array study to investigate the expression levels of UNC-104 and its interacting candidates in regenerating neurons (ligated sciatic nerve) or developing primary neurons could be a first step to investigate this theory. 


\section{References}

Aizawa H., Sekine Y., Takemura R., Zhang Z., Nangaku M., Hirokawa N., Kinesin family in murine central nervous system. J. Cell Biol. 119, 1287-1296, 1992.

Al-Bassam J., Cui Y., Klopfenstein D., Carragher B.O., Vale R.D., Milligan R.A., Distinct conformations of the kinesin Unc104 neck regulate a monomer to dimer motor transition., J Cell Biol, 163(4):743-53, 2003.

Alberts B., Johnson A., Lewis, J., Raff M., Roberts, K. Walter, P., Molecular biology of the cell (Fifth Edition), New York: Garland Science, 2008.

Allen R.D., Metuzals J., Tasaki I, Brady S., Gilbert S.P., Fast axonal transport in squid giant axon., Science. 218(4577):1127-9, 1982.

Andersson E.R., The role of endocytosis in activating and regulating signal transduction., Cell Mol Life Sci, Nov 24, 2011. [Epub ahead of print]

Arien H., Wiser O., Arkin I.T., Leonov H., Atlas D., Syntaxin 1 A modulates the voltage-gated L-type calcium channel (Ca(v)1.2) in a cooperative manner., J Biol Chem., 278(31),29231-9, 2003.

Axelrod D., Total Internal Reflection Fluorescence Microscopy., Methods in Cell Biology, 30, 245270, 1989.

Bananis, E., Murray, J. W., Stockert, R. J., Satir, P., Wolkoff, A. W., Microtubule and motordependent endocytic vesicle sorting in vitro., J. Cell Biol. 151, 179-186, 2000.

Bananis E., Nath S., Gordon K., Satir P., Stockert R.J., Murray J.W., Wolkoff A.W., Microtubuledependent movement of late endocytic vesicles in vitro: requirements for Dynein and Kinesin., Mol Biol Cell., 15(8):3688-97, 2004.

Barkus R.V., Klyachko O., Horiuchi D., Dickson B.J., Saxton W.M., Identification of an axonal kinesin-3 motor for fast anterograde vesicle transport that facilitates retrograde transport of neuropeptides., Mol Biol Cell, (1):274-83, 2008.

Baumann J., Fayer M.D., Excitation transfrer in disorderd two dimensional and anisotropic three dimensional systems: Effects of special geometry on time resolved observables., J. Chem. Phys., $85,5241-5348,1986$.

Bertani G., Studies on lysogenesis I. The mode of phage liberation by lysogenic Escherichia coli., Journal of Bacteriology, 62, 3, 293 - 399, 1915.

Bier M., Processive motor protein as an overdamped brownian stepper., Phys Rev Lett, 91(14), 2003.

Bindokas V.P., Lee C.C., Colmers W.F., Miller R.J., Changes in mitochondrial function resulting from synaptic activity in the rat hippocampal slice., J. Neurosci, 18, 4570-4587, 1998.

Blangy A., Lane H.A., d'Hérin P., Harper M., Kress M., Nigg EA., Phosphorylation by p34cdc2 regulates spindle association of human Eg5, a kinesin-related motor essential for bipolar spindle formation in vivo., Cell 83, 1159-1169, 1995.

Bloom K., Nuclear migration: cortical anchors for cytoplasmic dynein., Curr. Biol., 11, R326-329, 2001.

van den Bogaart G., Meyenberg K., Risselada H.J., Amin H., Willig K.I., Hubrich B.E., Dier M., Hell S.W., Grubmüller H., Diederichsen U., Jahn R., Membrane protein sequestering by ionic proteinlipid interactions., Nature, 479(7374),552-5, 2011. 
Brady S.T., A novel brain ATPase with properties expected for the fast axonal transport motor., Nature, 317, 73-75, 1985.

Brady S.T., Pfister K.K., Bloom G.S., A monoclonal antibody against kinesin inhibits both anterograde and retrograde fast axonal transport in squid axoplasm. Proc. Natl. Acad. Sci. U. S. A, 87, 1061-1065, 1990.

Brenner S., The genetics of Caenorhabditis elegans., Genetics, 77, (1), 71-94, 1974.

Brown A., Slow axonal transport: stop and go traffic in the axon., Nat Rev Mol Cell Biol, 1(2):153-6, 2000.

Brown C.L., Maier K.C., Stauber T., Ginkel L.M., Wordeman L., Vernos I., Schroer T.A., Kinesin-2 is a motor for late endosomes and lysosomes., Traffic, 6(12):1114-24, 2005.

Byrd D.T., Kawasaki M., Walcoff M., Hisamoto N., Matsumoto K., Jin Y., UNC-16, a JNK-signaling scaffold protein, regulates vesicle transport in C. elegans., Neuron, 32:787- 800, 2001.

Cai Q., Gerwin C., Sheng Z. H., Syntabulin mediated anterograde transport of mitochondria along neuronal processes., J. Cell Biol., 170, 959-969, 2005.

Campenot R.B., Eng H., Protein synthesis in axons and its possible functions., J. Neurocytol, 29, 793-798, 2000.

Campenot R.B., Maclnnis B.L., Retrograde transport of neurotrophins: fact and function. J. Neuriobiol, 58(2):217-29, 2004.

Caroni, P., Actin cytoskeleton regulation through modulation of $P I(4,5) P(2)$ rafts., EMBO J., 20 , 4332-4336, 2001.

Carter A.P., Cho C., Jin L., Vale R.D., Crystal structure of the dynein motor domain., Science, 331(6021):1159-65, 2011.

Chan F.T., Kaminski C.F., Kaminski Schierle G.S., HomoFRET fluorescence anisotropy imaging as a tool to study molecular self-assembly in live cells., Chemphyschem., 12(3):500-9, 2011.

Cho K.I., Cai Y., Yi H., Yeh A., Aslanukov A., Ferreira P.A. Association of the kinesin-binding domain of RanBP2 to KIF5B and KIF5C determines mitochondria localization and function., Traffic, 8, 1722-1735, 2007.

Cho C., Vale R.D., The mechanism of dynein motility: Insight from crystal structures of the motor domain., Biochim Biophys Acta. Oct 28. [Epub ahead of print] 2011.

Chu P.J., Rivera J.F., Arnold D.B., A role for Kif17 in transport of Kv4.2., J. Biol. Chem. 281, 365373, 2006.

Christiansen M., Estevez A., Yin X., Fox R., Morrison R., McDonnell M., Gleason C., Miller D.M., Strange K., A primary culture system for functional analysis of $\mathrm{C}$. elegans neurons and muscle cells, Neuron, 33, 503-514, 2002.

Cole D.G., Saxton W.M., Sheehan K.B., Scholey J.M., A "slow" homotetrameric kinesin-related motor protein purified from Drosophila embryos., J. Biol. Chem. 269, 22913-22916, 1994.

Corti, Osservazioni microscopiche sulla Tremella e sulla circolazione del fluido in una pianta acquajuola., Lucca, 1774.

Coy D.L., Hancock W.O., Wagenbach M., Howard J., Kinesin's tail domain is an inhibitory regulator of the motor domain., Nature Cell Biol 1, 288-292, 1999. 
Daire V., Giustiniani J., Leroy-Gori I., Quesnoit M., Drevensek S., Dimitrov A., Perez F., Poüs C., Kinesin-1 regulates microtubule dynamics via a $c$-Jun $N$-terminal kinase-dependent mechanism., $J$ Biol Chem, 284(46):31992-2001, 2009.

Davenport J.R., Watts A.J., Roper V.C., Croyle M.J., van Groen T., Wyss J.M., Nagy T.R., Kesterson R.A., Yoder B.K., Disruption of intraflagellar transport in adult mice leads to obesity and slow-onset cystic kidney disease., Curr Biol, 17(18):1586-94, 2007.

DeGiorgis J.A., Petukhova T.A., Evans T.A., Reese T.S., Kinesin-3 is an organelle motor in the squid giant axon., Traffic, (11):1867-77, 2008.

Dertinger T., Pacheco V., von der Hocht I., Hartmann R., Gregor I., Enderlein J., Two-focus fluorescence correlation spectroscopy: a new tool for accurate and absolute diffusion measurements., ChemPhysChem, 8, 433 - 443, 2007.

Diefenbach R.J., Mackay J.P., Armati P.J., Cunningham A.L., The C-terminal region of the stalk domain of ubiquitous human kinesin heavy chain contains the binding site for kinesin light chain., Biochemistry 37, 16663-16670, 1998.

Doherty G.J., McMahon H.T., Mechanisms of endocytosis., Annu Rev Biochem, 78:857-902, 2009.

Dorner C., Ullrich A., Häring H.U., Lammers R., The kinesin-like motor protein KIF1C occurs in intact cells as a dimer and associates with proteins of the 14-3-3 family., J Biol Chem, 274, 3365433660, 1999.

Drake K.R., Kang M., Kenworthy A.K., Nucleocytoplasmic distribution and dynamics of the autophagosome marker EGFP-LC3., PLoS One, 23;5(3), 2010.

Dupuy D., Li Q.R., Deplancke B., Boxem M., Hao T., Lamesch P., Sequerra R., Bosak S., Doucette-Stamm L., Hope I.A., Hill D.E., Walhout A.J., Vidal M., A first version of the Caenorhabditis elegans Promoterome. Genome Res, 14(10B):2169-75, 2004.

Durbin R., Studies on the development and organisation of the nervous system of Caenorhabditis elegans., PhD thesis, Kings College, Cambridge, UK, 1987.

Endow S.A., Waligora, K.W., Determinants of kinesin motor polarity., Science, 281, 1200-1202, 1998.

Erickson R.P., Jia Z., Gross S.P., Yu C.C., How molecular motors are arranged on a cargo is important for vesicular transport., PLoS Comput Biol, 7(5), 2011.

Fabricius C., Berthold C.H., Rydmark M., Axoplasmic organelles at nodes of Ranvier. II. Occurrence and distribution in large myelinated spinal cord axons of the adult cat., J. Neurocytol., 22, 941-954, 1993.

Falnikar A., Toleb S., and Baas P.W., Kinesin-5, a mitotic microtubule-associated motor protein, modulates neuronal migration., Mol Biol Cell, 22(9):1561-74, 2011.

Falzone TL, Stokin GB, Lillo C, Rodrigues EM, Westerman EL, Williams DS, Goldstein LS. Axonal stress kinase activation and tau misbehavior induced by kinesin-1 transport defects., J Neurosci, 6;29(18):5758-67. 2009.

Falzone TL, Gunawardena S, McCleary D, Reis GF, Goldstein LS., Kinesin-1 transport reductions enhance human tau hyperphosphorylation, aggregation and neurodegeneration in animal models of tauopathies., Hum Mol Genet, 15;19(22):4399-408, 2010.

Fasman G.D., Circular dichroism and the conformational analysis of biomolecules., Springer, 1996.

Fehr A.N., Asbury C.L., Block S.M., Kinesin steps do not alternate in size., Biophys J, 94(3):L20-2, 2008. 
Ferenz N.P., Gable A., Wadsworth P., Mitotic functions of kinesin-5., Semin Cell Dev Biol, 21(3):255-9, 2010.

Friedman D.S, Vale R.D., Single-molecule analysis of kinesin motility reveals regulation by the cargo-binding tail domain., Nature Cell Biol, 1, 293-297, 1999.

Fung B.K., Stryer L., Surface density determination in membranes by fluorescence energy transfer., Biochemistry, 17(24):5241-8, 1978.

Gibbons, I.R., Rove, A.J.,Dynein: a protein with adenosine triphosphate activity from cilia., Science, 149, 424-426, 1965.

Gidwani A., Holowka D., Baird B., Fluorescence anisotropy measurements of lipid order in plasma membranes and lipid rafts from RBL-2H3 mast cells., Biochemistry, 40(41):12422-9, 2001.

Gerritsen H.C., Asselbergs M.A., Agronskaia A.V., Van Sark W.G., Fluorescence lifetime imaging in scanning microscopes: acquisition speed, photon economy and lifetime resolution., J Microsc, 206(Pt 3):218-24, 2002.

Glater, E. E., Megeath, L. J., Stowers, R. S., Schwarz, T. L., Axonal transport of mitochondria requires milton to recruit kinesin heavy chain and is light chain independent., J Cell Biol, 173, 545557, 2006.

Goode B.L., Drubin G.D., Barnes G., Functional cooperation between the microtubule and actin Cytoskeletons., Curr Op in Cell Biol, 12:63-71, 2000.

Goud B., McCaffrey M., Small GTP-binding proteins and their role in transport., Curr Opin Cell Biol, 3(4):626-33, 1991.

Greenfield N.J., Using circular dichroism spectra to estimate protein secondary structure., Nature protocols, 1 (6), 2876-90, 2006.

Hall, D.H., Hedgecock, E.M., Kinesin-related gene unc-104 is required for axonal transport of synaptic vesicles in C. elegans., Cell 65, 837-847, 1991.

Hammond J.W., Cai D., Blasius T.L., Li Z., Jiang Y., Jih G.T., Meyhofer E., Verhey K.J., Mammalian Kinesin-3 motors are dimeric in vivo and move by processive motility upon release of autoinhibition., PLoS Biol., 7(3), 2009.

Hanahan D., Studies on transformation on Escherichia coli with plasmids., Journal of Molecular Biology, 166, 4, 557 - 580, 1993.

Hanlon D.W., Yang Z., Goldstein L.S., Characterization of KIFC2, a neuronal kinesin superfamily member in mouse., Neuron., 18(3):439-51, 1997.

Haycraft C.J., Zhang Q., Song B., Jackson W.S., Detloff P.J., Serra R., Yoder .K., Intraflagellar transport is essential for endochondral bone formation., Development, 134(2):307-16, 2007.

Heidemann S.R., Kaech S., Buxbaum R.E., Matus A., Direct observations of the mechanical behaviors of the cytoskeleton in living fibroblasts., J Cell Biol, 145(1):109-22, 1999.

Hemerly A.S., Ferreira P., de Almeida Engler J., Van Montagu M., Engler G., Inzé D., cdc2a expression in Arabidopsis is linked with competence for cell division., Plant Cell, 5, 1711-1723, 1993.

Henson J.H., Cole D.G., Roesener C.D., Capuano S., Mendola R.J, Scholey J.M., The heterotrimeric motor protein kinesin-Il localizes to the midpiece and flagellum of sea urchin and sand dollar sperm., Cell Motil. Cytoskeleton, 38, 29-37, 1997. 
Hirokawa N., Kinesin and dynein superfamily proteins and the mechanism of organelle transport., Science, 279(5350):519-26, 1998.

Hirokawa N., Pfister K.K., Yorifuji H., Wagner M.C., Brady S.T., Bloom G.S., Submolecular domains of bovine brain kinesin identified by electron microscopy and monoclonal antibodydecoration,. Cell 56, 867-878, 1989.

Hirokawa N., Nitta R., Okada Y., The mechanisms of kinesin motor motility: lessons from the monomeric motor KIF1A., Nat Rev Mol Cell Biol, 10(12):877-84, 2009.

Hochuli E., Bannwarth W., Döbeli H., Gentz R., Stüber D., Genetic Approach to Facilitate Purification of Recombinant Proteins with a Novel Metal Chelate Adsorbent., Bio/Technology, 1321-1325, 1988.

Hoepfner S., Severin F., Cabezas A., Habermann B., Runge A., Gillooly D., Stenmark H., Zerial M., Modulation of receptor recycling and degradation by the endosomal kinesin KIF16B., Cell, $121(3): 437-50,2005$.

Hollenbeck P.J., The distribution, abundance and subcellular localization of kinesin., J Cell Biol, 108(6):2335-2342, 1989.

Holzinger A. and Lutz-Meindl U., Kinesin-like proteins are involved in postmitotic nuclear migration of the unicellular green alga Micrasterias denticulata. Cell Biol Int, 26, 689-697, 2002.

Horiguchi K., Hanada T., Fukui Y., Chishti A.H., Transport of PIP3 by GAKIN, a kinesin-3 family protein, regulates neuronal cell polarity., J Cell Biol. 174(3):425-36, 2006.

Howard J., Hudspeth A.J., Vale R.D., Movement of microtubules by single kinesin molecules., Nature, 342(6246):154-8, 1989.

Hsu C.C., Moncaleano J.D., Wagner O.I., Sub-cellular distribution of UNC-104(KIF1A) upon binding to adaptors as UNC-16(JIP3), DNC-1(DCTN1/Glued) and SYD-2(Liprin- $\alpha)$ in C. elegans neurons., Neurosc., 176:39-52, 2011.

Hua W., Chung J., Gelles J., Distinguishing inchworm and hand-over-hand processive kinesin movement by neck rotation measurements., Science, 295(5556):844-8, 2002.

Hurd D.D., Saxton W.M., Kinesin mutations cause motor neuron disease phenotypes by disrupting fast axonal transport in Drosophila., Genetics, 144(3):1075-85, 1996.

Imamura T., Huang J., Usui I., Satoh H., Bever J., Olefsky J.M., Insulin-induced GLUT4 translocation involves protein kinase $C$ - $\lambda$-mediated functional coupling between Rab4 and the motor protein kinesin., Mol. Cell. Biol., 23, 4892-4900, 2003.

Jaulin F., Xue X., Rodriguez-Boulan E., Kreitzer, G., Polarization-dependent selective transport to the apical membrane by KIF5B in MDCK cells. Dev. Cell 13, 511-522., 2007.

Jo K., Derin, R., Li M., Bredt D.S., Characterization of MALS/Velis-1, -2, and -3: a family of mammalian LIN-7 homologs enriched at brain synapses in association with the postsynaptic density-95/NMDA receptor postsynaptic complex., J. Neurosci., 19, 4189-4199, 1999.

Kadkhodayan S., Elliott L.O., Mausisa G., Wallweber H.A., Deshayes K., Feng B., Fairbrother W.J., Evaluation of assay technologies for the identification of protein-Peptide interaction antagonists., Assay Drug Dev Technol, 5(4):501-13, 2007.

Kamal A., Stokin G.B., Yang Z., Xia C.H., Goldstein L.S., Axonal transport of amyloid precursor protein is mediated by direct binding to the kinesin light chain subunit of kinesin-I, Neuron. 28(2):449-59, 2000. 
Kamal A., Almenar-Queralt A., LeBlanc J.F., Roberts E.A., Goldstein L.S., Kinesin-mediated axonal transport of a membrane compartment containing beta-secretase and presenilin-1 requires APP., Nature, 2001.

Kanai, Y., Dohmae, N.,Hirokawa, N., Kinesin transports RNA: isolation and characterization of an RNA-transporting granule., Neuron, 43, 513-525, 2004.

Kapitein L.C., Hoogenraad C.C., Which way to go? Cytoskeletal organization and polarized transport in neurons., Mol Cell Neurosci. 46(1):9-20, 2011.

Kadkhodayan S., Elliott L.O., Mausisa G., Wallweber H.A., Deshayes K., Feng B., Fairbrother W.J., Evaluation of assay technologies for the identification of protein-Peptide interaction antagonists., Assay Drug Dev Technol, 5(4), 501-13, 2007.

Kayadjanian, N., Lee, H. S., Pina-Crespo, J., Heinemann, S. F., Localization of glutamate receptors to distal dendrites depends on subunit composition and the kinesin motor protein KIF17., Mol. Cell. Neurosci., 34, 219-230, 2007.

Kikkawa M., Sablin E.P., Okada Y., Yajima H., Fletterick R.J., Hirokawa N., Switch-based mechanism of kinesin motors., Nature, 411(6836):439-45, 2001.

Klopfenstein D.R., Tomishige, M., Stuurman N., Vale R.D., Role of phosphatidylinositol $(4,5)$ bisphosphate organization in membrane transport by the Unc104 kinesin motor., Cell, 109, 347358, 2002.

Klopfenstein D.R., Vale R.D., The lipid binding pleckstrin homology domain in UNC-104 kinesin is necessary for synaptic vesicle transport in Caenorhabditis elegans., Mol Biol Cel, 15(8):3729-39, 2004.

Klumperman J., Transport between ER and Golgi., Curr Opin Cell Biol, 12(4):445-9, 2000.

Koshizuka T., Kawaguchi Y., Nishiyama Y., Herpes simplex virus type 2 membrane protein UL56 associates with the kinesin motor protein KIF1A., J Gen Virol., 86(Pt 3):527-33, 2005.

Koyama E., Young B., Nagayama M., Shibukawa Y., Enomoto-Iwamoto M., Iwamoto M., Maeda Y., Lanske B., Song B., Serra R., Pacifici M., Conditional Kif3a ablation causes abnormal hedgehog signaling topography, growth plate dysfunction, and excessive bone and cartilage formation during mouse skeletogenesis., Development, 134(11):2159-69, 2007.

Kumar J., Choudhary B.C., Metpally R., Zheng Q., Nonet M.L., Ramanathan S., Klopfenstein D.R., Koushika S.P., The Caenorhabditis elegans Kinesin-3 motor UNC-104/KIF1A is degraded upon loss of specific binding to cargo., PLoS Genet. 6(11), 2010.

Kunwar A., Vershinin M., Xu J, Gross S.P., Stepping, strain gating, and an unexpected forcevelocity curve for multiple-motor-based transport., Curr Biol, 18(16):1173-83, 2008.

Kutys M.L., Fricks J., Hancock W.O., Monte Carlo analysis of neck linker extension in kinesin molecular motors., PLoS Comput Biol, 6(11) 2010.

Laemmli U.K., Cleavage of structural proteins during the assembly of the head of bacteriophage T4., Nature, 227, 680, 1970.

Laferrière N.B., MacRae T.H., Brown D.L., Tubulin synthesis and assembly in differentiating neurons., Biochem Cell Biol, 75(2):103-17, 1997.

Lakowitcz L.R., Principles of fluorescence spectroscopy., $2^{\text {nd }}$ edition, Kluwer Academic / Plenum Publishers, New York, 1999.

Lasek, R.J., Garner, J.A., Brady, S.T., Axonal transport of the cytoplasmic matrix., J. Cell Biol, 99, 212-S221, 1984. 
Lee, J.R., Shin H., Ko J., Choi J., Lee H., Kim E., Characterization of the movement of the kinesin motor KIF1A in living cultured neurons., J Biol. Chem, 278:2624-2629, 2002.

Lee J.R., Shin H., Choi J., Ko J., Kim S., Lee H.W., Kim K., Rho S.H., Lee J.H., Song H.E., Eom S.H., Kim E., An intramolecular interaction between the FHA domain and a coiled coil negatively regulates the kinesin motor KIF1A., EMBO J., 23(7):1506-15, 2004.

Li J., Cao Z.C., Tang Z., Wang K., Tan W., Molecular beacons for protein-DNA interaction studies., Methods Mol Biol, 429:209-24, 2008.

Lidke D.S., Nagy P., Barisas B.G., Heintzmann R., Post J.N., Lidke K.A., Clayton A.H., Arndt-Jovin D.J, Jovin T.M., Imaging molecular interactions in cells by dynamic and static fluorescence anisotropy (rFLIM and emFRET). Biochem Soc Trans, 31(Pt 5):1020-7, 2003.

Ludin B., Matus A., GFP illuminates the cytoskeleton., Trends Cell Biol, 8(2):72-7, 1998.

Lupas, A., Van Dyke, M., Stock, J., Predicting Coled Coils from Protein Sequences, Science, 252:1162-1164, 1991.

MacRae T.H., Tubulin post-translational modifications--enzymes and their mechanisms of action., Eur J Biochem, 244(2):265-78, 1997.

Manfredi G., Xu Z., Mitochondrial dysfunction and its role in motor neuron degeneration in ALS., Mitochondrion, 5, 77-87, 2005.

Marszalek J.R., Liu X., Roberts E.A., Chui D., Marth J.D., Williams D.S., Goldstein LS., Genetic evidence for selective transport of opsin and arrestin by kinesin-II in mammalian photoreceptors., Cell, 102(2):175-87, 2000.

Martin T.F., $P I(4,5) P(2)$ regulation of surface membrane traffic., Curr Opin Cell Biol., 13(4), 493-9, 2001.

Mattie F.J., Stackpole M.M., Stone M.C., Clippard J.R., Rudnick D.A., Qiu Y., Tao J., Allender D.L., Parmar M., Rolls M.M., Directed microtubule growth, + TIPs, and kinesin-2 are required for uniform microtubule polarity in dendrites., Curr Biol., 20(24):2169-77, 2010.

Maupas E., Modes et formes de reproduction des nématodes. Archives de Zoologie Experimentale et Generale, 8: 463-624, 1900.

Mellado M., Rodríguez-Frade J.M., Vila-Coro A.J., Fernández S., de Ana A.M., Jones D.R., Torán J.L., Martínez C., Chemokine receptor homo- or heterodimerization activates distinct signaling pathways., EMBO, 20, $2497-2507,2001$

Mello C.C., Kramer J.M., Stinchcomb D., Ambros V., Efficient gene transfer in C.elegans: extrachromosomal maintenance and integration of transforming sequences. EMBO J, 10(12):395970, 1991.

Miki, H., Setou, M., Kaneshiro, K. \& Hirokawa, N., All kinesin superfamily protein, KIF, genes in mouse and human., Proc. Natl Acad. Sci. USA, 98, 7004-7011, 2001.

Miki H., Okada Y., Hirokawa N., Analysis of the kinesin superfamily: insights into structure and function., Trends in Cell Biology Vol.15 No.9, 2005.

Morris R.L., Hollenbeck P.J., The regulation of bidirectional mitochondrial transport is coordinated with axonal outgrowth., J. Cell Sci. 104, 917-927, 1993.

Munier-Lehmann H., Mauxion F., Hoflack B., Function of the two mannose 6-phosphate receptors in lysosomal enzyme transport., Biochem Soc Trans 24:133-136, 1996. 
Nakagawa T., Setou M., Seog D., Ogasawara K., Dohmae N., Takio K., Hirokawa N., A novel motor, KIF13A, transports mannose-6-phosphate receptor to plasma membrane through direct interaction with AP-1 complex., 103(4):569-81, 2000.

Nakata, T., Hirokawa, N., Point mutation of adenosine triphosphate-binding motif generated rigor kinesin thatselectively blocks anterograde lysosome membrane transport., J. Cell Biol. 131, 10391053, 1995.

Nangaku M., Sato-Yoshitake R., Okada Y., Noda Y., Takemura R., Yamazaki H., Hirokawa N., KIF1B, a novel microtubule plus end-directed monomeric motor protein for transport of mitochondria., Cell, 79, 1209-1220, 1994.

Nishi M., Werner E.D., Oh B.C., Frantz J.D., Dhe-Paganon S., Hansen L., Lee J., Shoelson S.E., Kinase activation through dimerization by human SH2-B., Mol Cell Biol, 25(7), 2607-21, 2005.

Nitta R., Kikkawa M., Okada Y. Hirokawa N., KIF1A Alternately Uses Two Loops to Bind Microtubule., Science, 305, 5684, 678-683, 2004.

Niwa S., Tanaka Y., Hirokawa N., KIF1Bbold beta- and KIF1A-mediated axonal transport of presynaptic regulator Rab3 occurs in a GTP-dependent manner through DENN/MADD, Nature Cell Biology 10, 1269 - 1279, 2008.

Noda Y., Okada Y., Saito N., Setou M., Xu Y., Zhang Z., Hirokawa N., KIFC3, a microtubule minus end-directed motor for the apical transport of annexin XIIIb-associated Triton-insoluble membranes., J Cell Biol. 155(1):77-88, 2001.

Nomarski G., Microinterféromètre differentielle a ondes polarisées., J. Phys. Radium, 16, 9, 1955.

Novick P., Brennwald P., Friends and family: the role of the Rab GTPases in vesicular traffic., Cell., 75(4):597-601, 1993.

Okada Y., Yamazaki H., Sekine-Aizawa Y., Hirokawa N., The Neuron-Specific Kinesin Superfamily Protein KIFIA Is a Unique Monomeric Motor for Anterograde Axonal Transport of Synaptic Vesicle Precursors., Cell, 81, 769-780, 1995.

Okada Y., Hirokawa N., A processive single-headed motor: kinesin superfamily protein KIF1A., Science, 283(5405):1152-7, 1999.

Okada Y., Hirokawa N., Mechanism of the single-headed processivity: diffusional anchoring between the K-loop of kinesin and the $C$ terminus of tubulin., Proc Natl Acad Sci U S A, 97(2):640$5,2000$.

Palacios I.M., St Johnston D., Kinesin light chainindependent function of the Kinesin heavy chain in cytoplasmic streaming and posterior localisation in the Drosophila oocyte., Development 129, 5473-5485, 2002.

Paschal B.M., Schpetner H.S., Vallee R.B., MAP1C is a microtubule activated ATPase which translocatess microtubules in vitro and has dynein like properties., J. Cell Biol., 105, 1273-1282, 1987.

Patel N., Thierry-Mieg D., Mancillas J.R., Cloning by insertional mutagenesis of a cDNA encoding Caenorhabditis elegans kinesin heavy chain., Proc Natl Acad Sci U S A, 90(19):9181-5, 1993.

Peters N.T, Kropf D.L., Kinesin-5 motors are required for organization of spindle microtubules in Silvetia compressa zygotes., BMC Plant Biology, 6:19, 2006.

Rashid D.J., Bononi J., Tripet B.P, Hodges R.S., Pierce D.W., Monomeric and dimeric states exhibited by the kinesin-related motor protein KIF1A., J Pept Res., 65(6):538-49, 2005. 
Reck-Peterson S.L, Yildiz A., Carter A.P., Gennerich ., Zhang N., Vale R.D., Single-molecule analysis of dynein processivity and stepping behavior., Cell, 126(2):335-48, 2006.

Reid E., Kloos M., Ashley-Koch A., Hughes L., Bevan S., Svenson I.K., Graham F.L., Gaskell P.C., Dearlove A., Pericak-Vance M.A., Rubinsztein D.C., Marchuk D.A., A kinesin heavy chain (KIF5A) mutation in hereditary spastic paraplegia (SPG10)., Am J Hum Genet. Nov;71(5):1189-94, 2002.

Rice S., Lin A.W., Safer D., Hart C.L., Naber N., Carragher B.O., Cain S.M., Pechatnikova E., Wilson-Kubalek E.M., Whittaker M., Pate E., Cooke R., Taylor E.W., Milligan R.A., Vale R.D., A structural change in the kinesin motor protein that drives motility., Nature, 02(6763):778-84, 1999.

Riddle, C. elegans, $2^{\text {nd }}$ edition, Cold Spring Harbour Laboratory Press, Appendix 3, 1997.

Sack S., Müller J., Marx A., Thormählen M., Mandelkow E.M., Brady S.T., Mandelkow E., X-ray structure of motor and neck domains from rat brain kinesin., Biochemistry, 36(51):16155-65, 1997.

Santama, N., Er, C. P., Ong, L. L. \& Yu, H., Distribution and functions of kinectin isoforms., J. Cell Sci. 117, 4537-4549, 2004

Sawyer W.H., Winzor D.J., Theoretical aspects of the quantitative characterization of ligand binding., Curr Protoc Protein Sci, 2001.

Saxton W.M., Hicks J., Goldstein L.S., Raff E.C., Kinesin heavy chain is essential for viability and neuromuscular functions in Drosophila, but mutants show no defects in mitosis., Cell, 64(6):1093102, 1991.

Schonteich E., Wilson G.M., Burden J., Hopkins C.R., Anderson K., Goldenring J.R., Prekeris R., The Rip11/Rab11-FIP5 and kinesin II complex regulates endocytic protein recycling., J Cell Sci., 121:3824-33, 2008.

Setou, M., Nakagawa, T., Seog, D. H., Hirokawa, N., Kinesin superfamily motor protein KIF17 and mLin-10 in NMDA receptor-containing vesicle transport., Science, 288, 1796-1802, 2000.

Shastry, S., Hancock W.O., Neck linker length determines the degree of processivity in kinesin-1 and kinesin-2 motors., Curr Biol. 20(10), 939-43, 2010.

Shubeita G.T., Tran S.L., Xu J., Vershinin M., Cermelli S., Cotton S.L., Welte M.A., Gross S.P. Consequences of motor copy number on the intracellular transport of kinesin-1-driven lipid droplets., Cell, 135(6):1098-107, 2008.

Simons K., Ikonen E., Functional rafts in cell membranes., Nature, 387(6633), 569-72, 1997.

Smith D.S., Eremin S.A., Fluorescence polarization immunoassays and related methods for simple, high-throughput screening of small molecules., Anal Bioanal Chem, 391(5):1499-507, 2008.

Stauber, T., Simpson, J. C., Pepperkok, R. \& Vernos, I., A role for kinesin-2 in COPI-dependent recycling between the ER and the Golgi complex., Curr. Biol. 16,2245-2251, 2006.

Stokin G.B., Lillo C., Falzone T.L., Brusch R.G., Rockenstein E., Mount S.L., Raman R., Davies P., Masliah E., Williams D.S., Goldstein L.S., Axonopathy and transport deficits early in the pathogenesis of Alzheimer's disease., Science, 307, 1282-1288, 2005.

Sulston J.E., Horvitz H.R., Post-embryonic cell lineages of the nematode, Caenorhabditis elegans., Dev. Biol. 56 (1): 110-56, 1977.

Svoboda K., Schmidt C.F., Schnapp B.J., Block S.M., Direct observation of kinesin stepping by optical trapping interferometry., Nature, 365(6448):721-7, 1993.

Sweeney H.L., Houdusse A., Structural and functional insights into the Myosin motor mechanism., Annu Rev Biophys., 39:539-57, 2010. 
Tabb J.S., Molyneaux, B.J., Cohen, D.L., Kuznetsov, S.A., and Langford, G.M., Transport of ER vesicles on action filaments in neurons by myosin.V., J.Cell Sci., 111, 3221-3234, 1998.

Takeda S., Yonekawa Y., Tanaka Y., Okada Y., Nonaka S., Hirokawa N., Left-right asymmetry and kinesin superfamily protein KIF3A: new insights in determination of laterality and mesoderm induction by kif3A-/- mice analysis., J Cell Biol.,145(4):825-36, 1999.

Takeda S., Yamazaki H., Seog D.H., Kanai Y., Terada S., Hirokawa N., Kinesin superfamily protein 3 (KIF3) motor transports fodrin-associating vesicles important for neurite building., J. Cell Biol. 148, 1255-1265, 2000.

Tanaka Y., Kanai Y., Okada Y., Nonaka S., Takeda S., Harada A., Hirokawa N., Targeted disruption of mouse conventional kinesin heavy chain, kif5B, results in abnormal perinuclear clustering of mitochondria., Cell 93, 1147-1158, 1998.

Terada, S., Kinjo, M. \& Hirokawa, N., Oligomeric tubulin in large transporting complex is transported via kinesin in squid giant axons., Cell 103, 141-155, 2000.

Tien N.W., Wu G.H., Hsu C.C., Chang C.Y., Wagner O.I., Tau/PTL-1 associates with kinesin-3 KIF1A/UNC-104 and affects the motor's motility characteristics in C. elegans neurons., Neurobiol Dis, 43(2):495-506, 2011.

Tomishige M., Klopfenstein D.R., Vale R.D., Conversion of Unc104/KIF1A kinesin into a processive motor after dimerization., Science, 297(5590):2263-7, 2002.

Tomishige M., Stuurman N., Vale R.D., Single-molecule observations of neck linker conformational changes in the kinesin motor protein., Nat Struct Mol Biol., 13(10):887-94, 2006.

Tramier M., Coppey-Moisan M., Fluorescence anisotropy imaging microscopy for homo-FRET in living cells. Methods Cell Biol.85:395-414, 2008.

Tornøe J, Kusk P, Johansen TE, Jensen PR. Generation of a synthetic mammalian promoter library by modification of sequences spacing transcription factor binding sites., Gene, 297(1-2):2132, 2002.

Turner J., Anderson R., Guo J., Beraud C., Fletterick R., Sakowicz R., Crystal structure of the mitotic spindle kinesin Eg5 reveals a novel conformation of the neck-linker., J Biol Chem, 276(27):25496-502. 2001

Vale, R.D., Reese T.S., Sheetz M.P., Identification of a novel force generating protein, kinesin, involved in microtubule-based motility. Cell, 42(1):39-50, 1985.

Vale R.D., Milligan R.A., The way things move: looking under the hood of molecular motor proteins., Science, 288(5463):88-95, 2000.

Vale R.D., The molecular motor toolbox for intracellular transport., Cell., 112(4):467-80, 2003.

Vallee R.B., Tai C., Faulkner N.E., LIS1: celluar fuction o a disease causing gene., Trends Cell Biol., 11, 155-160, 2001.

Varela F.G., Maturana H.R., Uribe R., Autopoiesis: the organization of living systems, its characterization and a model, Curr Mod Biol., 5(4):187-96. 1974.

Verburg J., Hollenbeck P.J., Mitochondrial membrane potential in axons increases with local nerve growth factor or semaphorin signaling., J Neurosci., 28(33):8306-15, 2008.

Verhey K.J., Meyer D., Deehan R., Blenis J., Schnapp B.J., Rapoport T.A., Margolis B., Cargo of kinesin identified as JIP scaffolding proteins and associated signaling molecules., J. Cell Biol. 152, 959-970, 2001. 
Vershinin M., Carter B.C., Razafsky D.S., King S.J., Gross S.P., Multiple-motor based transport and its regulation by Tau., Proc Natl Acad Sci U S A,104(1):87-92, 2007.

Wagner O.I., Esposito A., Köhler B., Chen C.W., Shen C.P., Wu G.H., Butkevich E., Mandalapu S., Wenzel D., Wouters F.S., Klopfenstein D.R., Synaptic scaffolding protein SYD-2 clusters and activates kinesin-3 UNC-104 in C. elegans., Proc Natl Acad Sci U S A, 106(46):19605-10, 2009.

Weber G., Rotational Brownian motion and polarization of the fluorescence of solutions., Adv. Prot Chem, 8:415-459, 1954.

Westerholm-Parvinen A., Vernos I., Serrano L., Kinesin subfamily UNC104 contains a FHA domain: boundaries and physicochemical characterization., FEBS Lett, 486, 285-290. 2000.

Westermann S., Weber K., Post-translational modifications regulate microtubule function., Nat Rev Mol Cell Biol., 4(12):938-47, 2003.

Wood, W.B., The nematode Caenorhabditis elegans., Cold spring Harbour laboratory Press, 1988.

Wozniak M.J., Allan V.J., Cargo selection by specific kinesin light chain 1 isoforms., EMBO J, 25 , 5457-5468, 2006.

Wozniak M.J., Melzer M., Dorner C., Haring H.U., Lammers R., The novel protein KBP regulates mitochondria localization by interaction with a kinesin like protein. BMC., Cell Biol., 6, 352005.

Yildiz A., Forkey J.N., McKinney S.A., Ha T., Goldman Y.E., Selvin P.R., Myosin V walks handover-hand: single fluorophore imaging with 1.5-nm localization., Science, 300(5628):2061-5, 2003.

Yildiz A., Tomishige M., Vale R.D., Selvin P.R., Kinesin walks hand-over-hand., Science, 303(5658):676-8, 2004.

Yonekawa Y., Harada A., Okada Y., Funakoshi T., Kanai Y., Takei Y., Terada S., Noda T., and Hirokawa N., Defect in synaptic vesicle precursor transport and neuronal cell death in KIF1A motor protein-deficient mice., J Cell Biol, 141: 431-441, 1998.

Zhao C., Takita J., Tanaka Y., Setou M., Nakagawa T., Takeda S., Yang H.W., Terada S., Nakata T., Takei Y., Saito M., Tsuji S., Hayashi Y., Hirokawa N., Charcot-Marie-Tooth disease type $2 A$ caused by mutation in a microtubule motor KIF1Bbeta., Cell, 105(5):587-97, 2001.

Zhou H.M., Brust-Mascher I., Scholey J.M., Direct visualization of the movement of the monomeric axonal transport motor UNC-104 along neuronal processes in living Caenorhabditis elegans., J Neurosci., 21(11), 3749-55, 2001. 


\section{ACKNOWLEDGEMENTS}

The thesis would have been impossible or at least not as enjoyable without the support, engagement and contribution of many people. I would like to express my sincere gratitude to:

My supervisor Dr. Dieter Klopfenstein for giving me the opportunity and his trust to develop this project freely and his unlimited support and enthusiasm. He has the great gift to motivate in situations when it was necessary and slowing down, when my enthusiasm was too large. Many thanks for the opportunity to present my data in various international conferences.

The members of my thesis committee Prof. Nils Brose, Prof. Frauke Melchior and Prof. Andreas Wodarz for very intensive discussions, great suggestions and constructive criticism.

My collaborators Prof. Fred Wouters, Dr. Alessandro Esposito, Dr. Ingo Gregor and Dr. Matthias Gralle. All four are contributed in the development of the fluorescence anisotropy setting. Thanks for the fruitful discussions. In addition, thanks to Ingo for his measurements of dual focus FCS and the introduction in this technique.

My collaborators Dr. Jürgen Klingauf and Kerstin Wiederhold for their measurement of the circular dichroism of the synthesized peptides.

My collaborator Dr. Bernhard Schmid for the possibility to use his equipment performing the gel filtration.

Dr. Eugenia Butkevich for providing the worm strains being the control strains in fluorescence anisotropy.

My diploma Student Olaf Meissner for his evaluation of the motor behaviour in MMGA.

The technicians Kerstin von Rhoden, Charlotte Willms and Ulrike Schulz for their support, especially during purification of the mini-motors.

Prof. Christoph Schmidt and the lab members Dr. Florian Rehfeldt, Christopher Battle, Marcel ("Dr. Evil San") Bremerich, André Düselder, Florian Schlosser and Alok Weßel for deep and interesting discussions about motors, vesicle behaviour and viscosity.

Special thanks to Christina Thiele, who introduced me to the world of "her" TIRFmicroscope and Lennart Opitz, for his support in statistical questions.

Jenna Overhageböck who did always understand and respect if I had to cancel or postpone the training because of my experiments.

Nadine Herrmann and Alexander Grundt just because they always have been there, as friends.

My parents Heinrich and Bärbel Henschel, my sister Gabi and my brother Rainer for their unlimited support.

and my partner Stephanie Roloff not only for the discussions concerning biochemical questions but mainly because she was always there, when I needed her and for her fine intuition to know what I need, before I even know it by myself. Thanks Steffi! 


\section{APPENDIX}

9.1 Table of figures

9.2 Physical units and prefixes

9.3 Vector maps

9.4 List of primers

9.5 Table of kinesins and their binding partners for intracellular transport

9.6 Matlab parameters and functions for fluorescence anisotropy

9.7 Curriculum vitae 


\subsection{Table of figures}

Fig. 11:

Fig. 12.

Fig. 13:

Fig. 14:

Fig. 15:

Fig. 16:

Fig. 17

Fig. 18:

Fig. A1:

Fig. M1:

Fig. M2:

Fig. M3:

Fig. M4:

Fig. M5:

Fig. M6:

Fig. R1:

Fig. R2:

Fig. R3:

Fig. R4:

Fig. R5:

Fig. R6:

Fig. R7:

Fig. R8:

Fig. R9:

Fig. R10:

Fig. R11:

Fig. R12:

Fig. R13:

Fig. R14:

Fig. R15:

Fig. R16:

Fig. R17:

Fig. R18:

Fig. R19:

Fig. R20:

Fig. R21:

Fig. R22:

Fig. R23:

Fig. R24:

Fig. R25:

Fig. R26.

Fig. R27:

Fig. R28:

Fig. R29:
Cytoskeleton of a mammalian cell 3

Structure of Kinesin-1.

Kinesin-1 walking models

Vesicle traffic in eucaryotic cells $\quad 10$

Motor proteins involved in neuronal transport processes. 12

Structure of conventional kinesin and KIF1A/UNC-104 15

Anatomy of an adult hermaphrodite $\quad 20$

Nervous system of $C$. elegans 22

Working hyothesis $\quad 25$

Microinjection of DNA into gonads of $C$. elegans. 31

1-Ethyl-3-(3-dimethylaminopropyl)carbodiimid (EDC) 52

Principle of TIRF microscopy $\quad 57$

Experimental setting of the TIRF Microscope 58

TIRF reaction chamber $\quad 59$

Characteristic patterns of CD spectra 63

Sequence analysis of the neck coiled-coil an effects on helical formation $\quad 69$

Coiled-coil probability of the neck linker / neck coiled-coil region 70

Circular dichroism spectra of modified peptides of UNC-104 71

UNC-104 constructs

Expression levels of the UNC-104 constructs in C. elegans 74

C. elegans phenotypes $\quad 76$

C. elegans motility assay $\quad 78$

C. elegans egg-laying behaviour $\quad 79$

Expression in C. elegans nervous system and kymography 81

Motor movement of coiled-coil promoting construct 82

Motor movement of coiled-coil impaired constructs 83

Experimental setup, polarization $\quad 85$

Experimental setup, fluorescence anisotropy 86

Calibration of the setup for measuring fluorescence anisotropy 87

Dynamic range of fluorescence anisotropy 88

Fluorescence anisotropy in a biological system 90

Fluorescence anisotropy of the coiled-coil promoting strains compared to WT 91

Fluorescence anisotropy of the coiled-coil impaired strains compared to WT 93

Expression and cargo-binding control 94

Expression levels of constructs for fluorescence anisotropy measurements 95

Purification of mini motors $\quad 97$

Motor kinetics in multi motor gliding assay 98

Analysis of motor proteins in single molecule measurement TIRF 99

Velocities of mini motors in TIRF microscopy; coiled-coil promoting constructs 101

Velocities of mini motors in TIRF microscopy; coiled-coil impaired constructs 102

$\begin{array}{ll}\text { Gel filtration } & 104\end{array}$

Microtubule affinity purification $\quad 106$

$\begin{array}{ll}\text { Chemical cross linking } & 107\end{array}$

Chemical cross linking; tubulin control 108 


\subsection{Physical units and prefixes}

\section{Physical units}

\begin{tabular}{ll}
\hline $\mathrm{A}$ & ampere \\
$\AA$ & angstrom unit \\
${ }^{\circ} \mathrm{C}$ & degree celsius \\
$\mathrm{g}$ & gram \\
$\mathrm{Xg}$ & acceleration of gravity on earth \\
$\mathrm{h}$ & hour(s) \\
$\mathrm{I}$ & liter \\
$\mathrm{M}$ & molar $(\mathrm{mol} / \mathrm{l})$ \\
$\mathrm{min}$ & minute $(\mathrm{s})$ \\
$\mathrm{m}$ & meter \\
$\mathrm{OD}$ & optical density \\
$\mathrm{rpm}$ & rotations per minute \\
$\mathrm{S}$ & second(s) \\
$\mathrm{U}$ & unit \\
$\mathrm{V}$ & volt
\end{tabular}

\begin{tabular}{ll} 
Prefixes & \\
\hline $\mathrm{k}$ & kilo- $10^{3}$ \\
$\mathrm{C}$ & centi- $10^{-2}$ \\
$\mathrm{~m}$ & mili- $10^{-3}$ \\
$\mu$ & micro- $10^{-6}$ \\
$\mathrm{n}$ & nano- $10^{-9}$ \\
$\mathrm{p}$ & pico- $10^{-12}$
\end{tabular}




\subsection{Vector maps}

\subsection{1. pBluescript KS (+)}

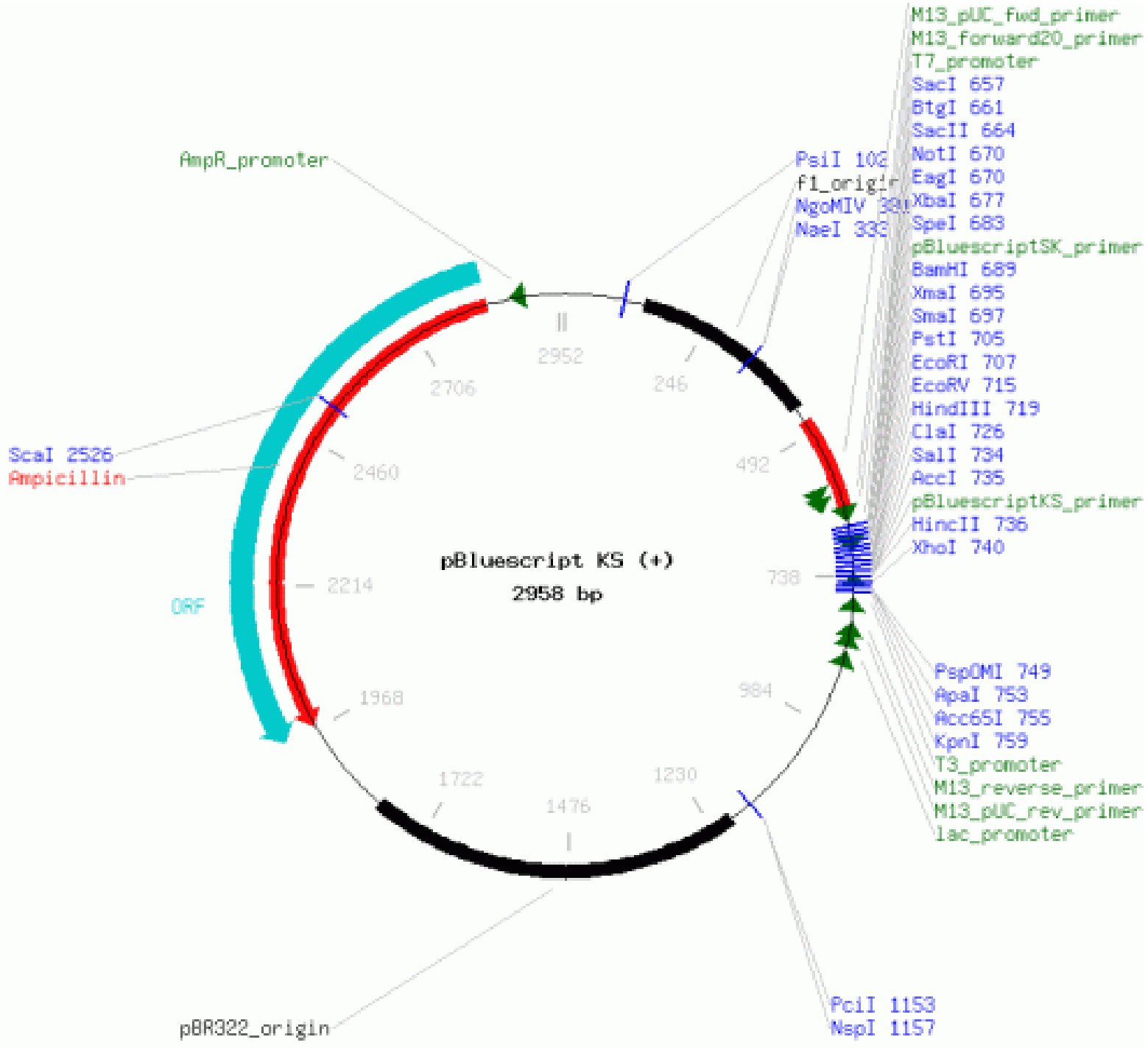




\subsection{2. $p E T-17 b$}

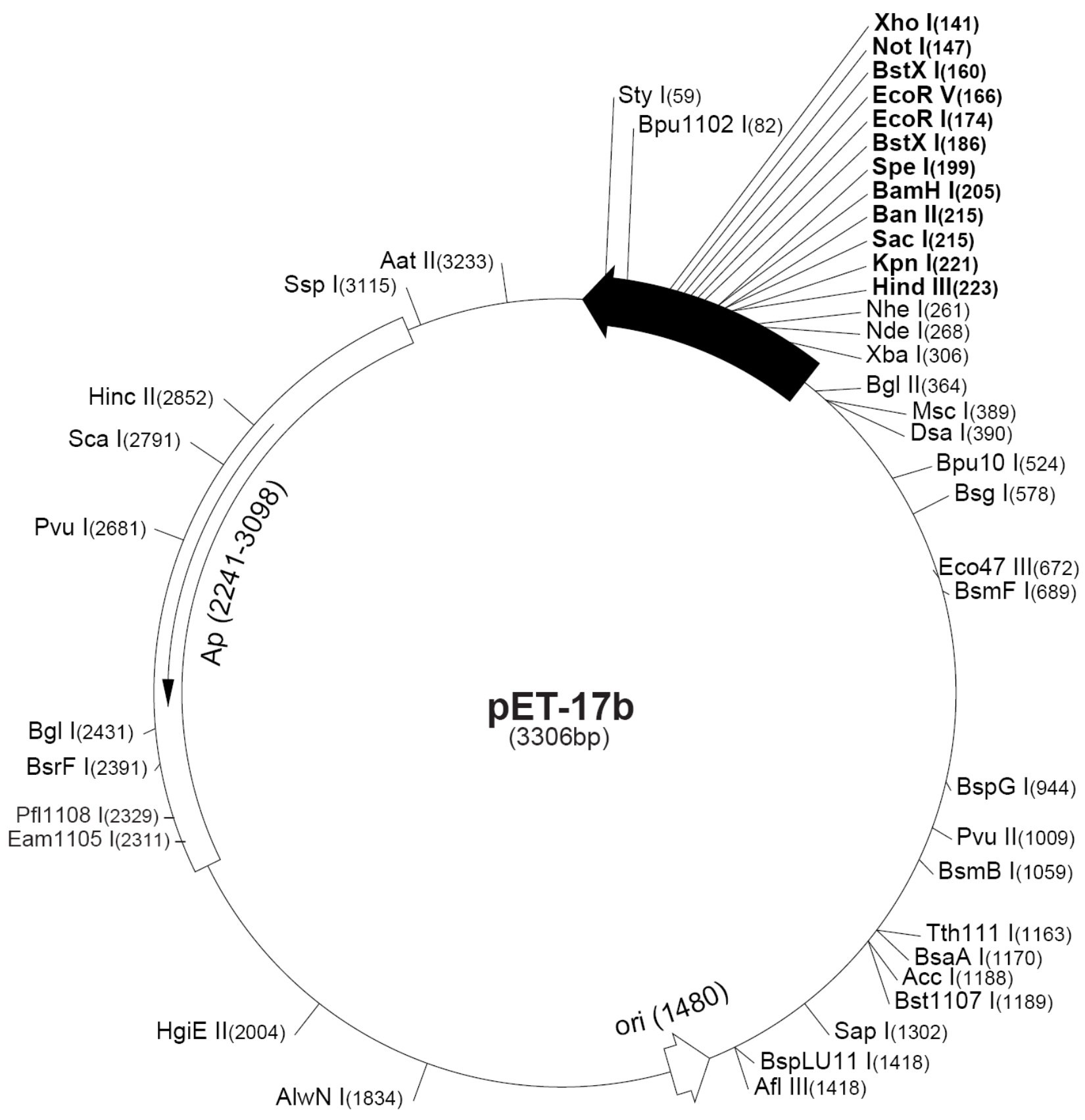




\subsection{3. pPD95.77 with UNC-104-FL}

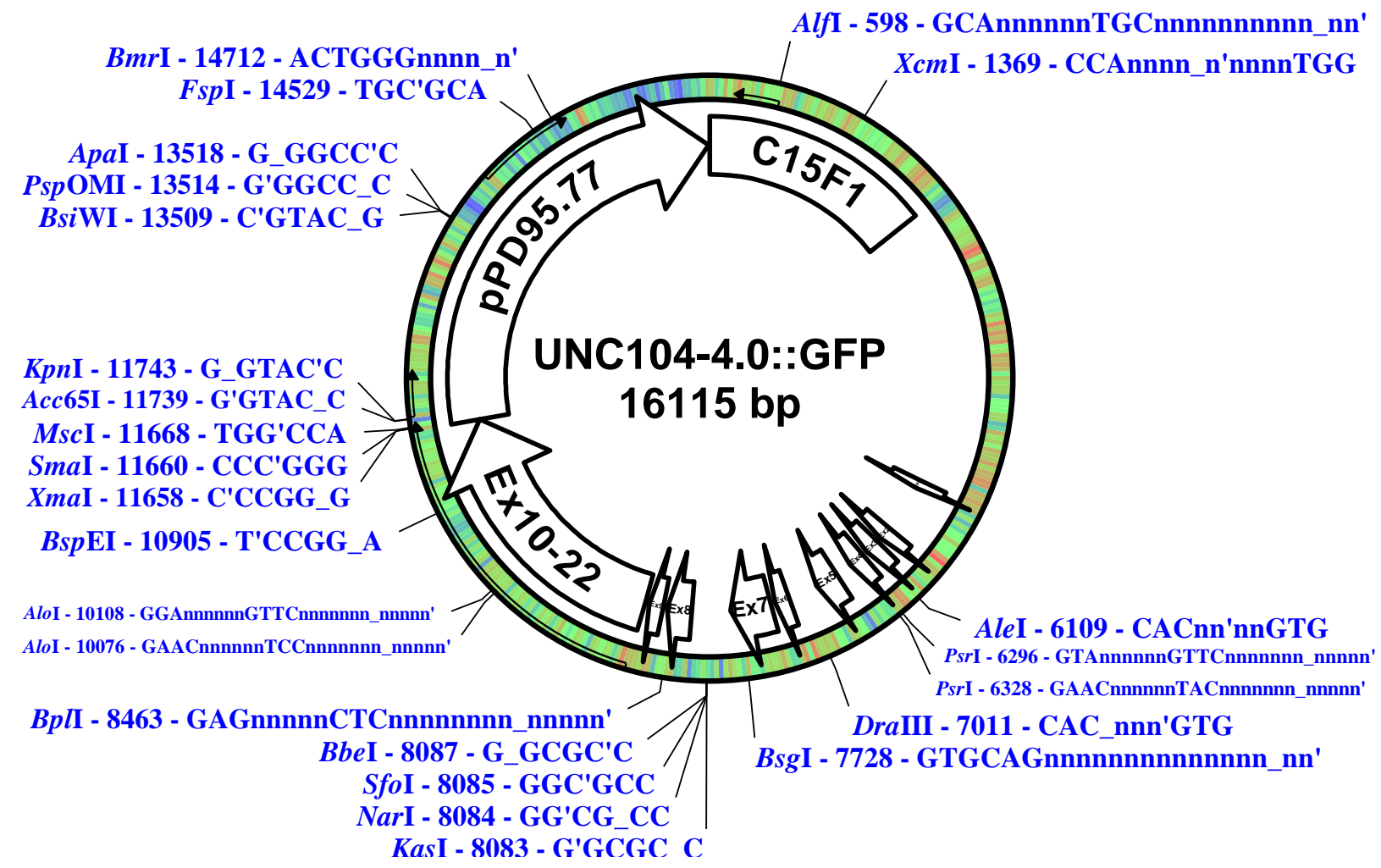




\subsection{Sequence FL-UNC-104::GFP in pPD 95.77}

1 AAGCTTGCAT GCCGCCTATT ATtTGGTGGT TGTACGAGGC AGGTAGGCAT 51 GTTAACGTTC ACGTGAAAGG TTTATTGGAA ATATTGCCGT TTAGATGTTT 101 CAgATTCAgA AAATATTTAA ATtTAgAgCG TTCGCATGGA GTGTAGAAAA 151 AAGAGATGA AAGAATCCAA ACAGGTTTTC ATATGTCATT TTTTGTTTTT

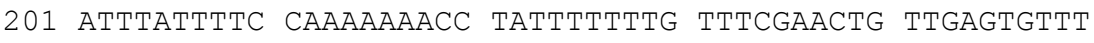
251 TGTCTTGGGA TTTTATTTTT GATTCTGTCA ATTCTGGTGG CTCTTCTATT 301 TTTTTCGGAA AAgTGTACTT GTAAAAGGGA ATTGGTGACA ATAGAAATCT 351 CAATACTATC TTCAAAATGC TCCGAATTTT CAGAGCATTT GCCTGGTCGA 401 TAAATGATAA AGATGAGTTG CACAGTGAAT ATGGATATAT TTCTGTGAAA 451 CCAAACACAA AAGAAGTCGC ACTGACAACT GTAATGAATA ATGGTTTTGT 501 GACAGTCGAA GAAGGTCCAG TCAATGgAAA TCAAATTAGA TTCCGGCTTA 551 AGGATATCGG AAGAATTAGT TTCAGCAGAG ATTTGCCTGT TCATGATGTA 601 AgTTTTTAGA ATAGTGTTTT TGTGTGTAGT CATAACAATG AAAACCAACA 651 ACAAAATTCA AAAACGCTCT AATTTCACAT AATTCAATCA AACTCAAAAT 701 TTAAAATATT CAGCTCGTCC GAGAATGGAC TCTTCTGGAT CGATCAACAC 751 TTCAAGCCCG TCTGAACATG GAGACATTAA CACATGGAAT GCAGGAGCAC 801 ACATTTATTC GTTACAACAA AATTGAGCCA TAAACTGAAG AAAAACGTGT 851 TTATCTCTTT CTATTCCACT TCTAGTCAAC TACTTCCCAC TCAATTGATT 901 CCCCCTTTCC CCTTAAAAAT AAAAACTCTT GCTGCTTTTT ATGAGTTTTC

951 CTAAAAGCTG CTAAATATGT ATATAGCACC ATCTCAAGAG TCACTGTATA 1001 ATAGAATAGT GAAAATAAAT GAGCTGTGAA ATGAGCCAAA ATGAAAAAGA 1051 AAAAGAAAGC AAATGAAGTG AGAAAATGGA TGCAAGAATT GACACTTTTA 1101 TtgGCAATTC ATGAgGATTC TAACGAtgAg tgAagAtgAa AgAgtAgACT 1151 AGCGGAGAAT AAGGTTTTAG AAGAAATTTC GATGGGAGTT GATGACATTT 1201 GTGATTTTTA AACTTAAATT TTAACTTATC GCTTAGTGAT CTTTAATCAT 1251 AACCGACTTT AGCAAGTTCA TGAAAAAAGA AACTTTCGAT CGGCATTCGA 1301 TCATAATTTT TAGACATATT ATAGAGCATT CTCGTGTCTC CCCATAGTTG 1351 TAAATATGCA ACCAGATGTC CGTTGGTGCA ATTTAGTTGC TCATCAAGTT 1401 CTCTATGTCC ATTTCTATTC TGTTCAACCA CTTCATTTCC CCTTTTGACA 1451 TTTTTCTATC TGTGAGAGCT TCATCTCCCA TCGTTTCCTC TTAACGTCTT 1501 CAGAAAGACA AATCGTTGCC AAATTCATCA TTTTCGAGTG CCAGGCATCC 1551 AATAACCGAA AGAATGGGA CAAAGAGTGC TTTTCAACGG AAATTAGAAC 1601 CATTTTTCTG AAAGAAGTCT GCGCGAGATA AGCAAAGTTT TAAATTTTCA 1651 TGAAAACCAC AAGCGCGTAT TTTGAGTTTT TCACAACTTT AGAAAAATTC 1701 AAAAAACGGA TGCCAACGTT ACAGGAAAAT GCCGAAAATT CGAGAAACAA 1751 TAATTTCCAT GAACATTTAA AAATAATTTT TTCACGACCC ATTTGTAATA 1801 GTGAATTAGT AAGGGTATTT AATCTGATAC ATTTCCAAAA AATAATGCAA 1851 TGTTTGCCGA AAACTTGACG ATTTGCCGTT CGCCTGAAAA TACTGTATGA 1901 TGACTGAAAA ATTTCCCGTT TGCGAAATCT GTGATTCCTA TAAAATTAGA 1951 CTTCTAAATA AATTGGCATT TAAAATCATG ATTAGAAGAA AACTAAACCA 2001 CAAAGAATAT GAAAACACAC TTCTATAATT AATTTTTACA ATTAGATATA 2051 TGATTTCATA AAGCTGCAGT GCTGTTATTT TGATCTCAAT CTATTTACAA 2101 AAATAACACT GAAAAGTACT TTATGCCTTG CAAGAAATGC TCAATTTCTG 2151 TGTATTCTAC GCTTAAGCAC CTTCTATTCA GCACCTACTC GGGAATTCTC 2201 CACCAAATCC ATTCTCATTT TCTTCTTTTC TCTCTCAACT CGTCTTCAAT 2251 CTCTTCACCT CGTCCACTAT TTCATCCCCG GAGACTTGTT CCCCAGACGT 2301 CGTGCCTCCA ATCGATCCAT TTGTGGAGCC CGCGTCGTCC ACAGAGCTTC 2351 TGCCGTTTCA TCTCTGCGTC TCGTTCACCC ATTAGACGTT GTGCTTCCTC 2401 CCTGCCTGAA AATAGCCCCA CACAACATAG ACTTGCTCTT CTTTCTTCTA 2451 CTTTTTTTCT CATTCTTTTT TCTCCAGATA CGCCTTTATT CAAATGACGT 2501 GTTTCTTTTT TTTGTCTGTT CAAAAACCAA CAACTCATGA TCATCAGATG 2551 ATGATGGTCA AAAATCCCTT CCGGTTTTCC TTTTCTTCCC AAATTTTGGC 2601 TTGGACTTTT TTTGAATTAT GACACCAAAA CATGCAACGA CGTATATATA 2651 TGCAAACGTA GAATATCGA TTTCAGAACC GAATCATTGT CGAGATTAAA 2701 AgGGAGGAAA TTGATATGTG ATGGAAATAg ATTGAgGGCT GAATTTTTGA 2751 GATTGAAAAA ACAATTGTAT AATGTAAGTA GATAAAACAA AGCTGTATTG 2801 AATTTATAAA TATCTAATAC ATTTTCTAAT ACAAAAATAA ATTTGATTTT 2851 GTACTTTTCT TAAAAAGTGA TCAGAATTTC CACTAGATGT TTTTGGCAAC 2901 AATCACCTGA TAATTGGATT AAAATTTGAC AAAACTGTTT AAGTACAAGC 2951 GAACTAGATG AGAATTTCTA CCTTTTTCTT TCAATTGAAT ATTTTCGTAT 3001 TCTATCCCTC CGTGCTTTCA TTTTCCATTG ACGTTTTATG GTTCAATATA 3051 TATCCTAAAA GTTTTCCTTA CCCTTTCTCC TACTAGTTTC ATCTCTTCTT 3101 CTAAATAATT AACATTTCTT TATTTAATTG ATTTCTTTCC ATTTCACGTC 3151 ATTTCTTCAT TTAGCACAAC ATTCTTCTTT TATTCCCATC CAATCGCCTT 3201 CTCCGTTCAT TCCGGCCCCT TTTTCAGCTT CAAATTGAAC AACAAAAACA 3251 CATTGCGTGA CGATAAAACT TCCAGTTCCC GTCTTCAAAA CGTCATTCCG 3301 AGAGACTATT CGCCTGGAAC CCTCGCCTTT TTTTCATTAT GTGCTCATCC 
3351 CTAAAAGAgC CAAGAGCTCT CAAAAACTGC TGgGGATCTT CGTGAAAAAA

3401 TGTTTGGTTG AAAATTGTTG AAGCATCTTG AATTACCATT TACTAAAgGA

3451 CCAAGTATAC ATTTTGAAAT AgGCTCCGAA AGATTGAAGC ATATTTTGAA

3501 CTAGATAATA TTAATTAAAT TCATTTTGTT GGTGTTAACT TTTATTTTAA

3551 GTTGCGAGCA TGTTACCGTA AGAACCTTTT TCATTTTTTA TTTTAAATAA

3601 AATTTTACAA TTTGTCTTGA GCAACTTGTT CTATAAGTGA TATCAACTTC

3651 AAATTAGTGA GCATATAAAA TTAAAATGAG AAAAAACAAT AGCGTGGATA

3701 GAAAAATCAC CATAGGCCAG GAAAATCTGT AAGAGATTTT CCCGTGTTAG

3751 CTAAACTTTT GAAATTGTTT ACATTTTTAA AGGTTATGTT TTACCATCTG

3801 ATTCTTTACA GATCGGTTTT TTTTAACATA TGACAATAGT TTTAACCTTT

3851 CGTTTTTGAA CCTTTAAATT TGAAAATCAA TAGTTTTCAT TAAATACTCA

3901 TTGATTACAG TAGCCATTGG AACTTTATGT CTCCTTTCGC TGACCTTAGG

3951 GAACATTGTG CCAAAATCAG TTTTGCTTCC AAAATCAGAT TCTATAATTT

4001 CTACACTGTG ACTCACAAAA ACCAACCAAA TTCAATCATT TTTCTGTATC

4051 CTGCCTTCTT CTTTTTTCGA ATGTTCTTTT TCTCCTTGTT TCTCTTTTTT

4101 CCATGTTTAT CATCGTCATC TGTTGCTTCT TCTCGGCTTC TCTAATTTCA

4151 GCCCAACCCC TTTTTTTTCC TCATCTAATT AAATTCGCCT CGAGGCTCCG

4201 TCCTCCTCCA TCTCTATCTT TTTCTCTTTT CTCTTCCATT CCGAACTTTT

4251 TCTTTCCCAA TCGACCATCT ATTCGAAGAT TCATTGCTGC CTTTTTTTCA

4301 GCACTCTTCT TCATTTTTTT TTTCGAATAC ACATTCAATA GAAAACTGGA

4351 GAAGAAGAGG AAAAGCATCG AGGAGACGAT AAGTGGGGCT CAACGCCATT

4401 GGATGATTGA CTCGAGCTGA GAAGAAGGAC TCAAGAGGTG AGCCAAAATT

4451 GCAAAATAGA AGAAGAAAAA ATAGAAAAAC AAGAGGAAAG GGAAACAAAT

4501 GTCTTGTTAT AGATGTTGAT GTGTGAAAAA AAACGATATA GAAAAATGAC

4551 ATGGCTGAAC GGAGTTATTA TCTTGACTTG AAAGGCGGTA TTCGAAAAAT

4601 TCAGATTTTA CGTTAAAAAT TCCCTTTTTA ACTCAAAGTA CCCAAAAATG

4651 GGCTAAAATT CAAAAATACC ACAATAGAAC ACTTAAAAGA TTCTGTAAGT

4701 TTGTAGGACT GCATTTTAAT CCTAAAAATA TGGTTTCAAA AAAATTAATT

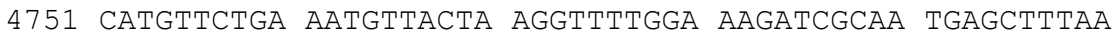

4801 CTTTTCAAGA TTTTTCTTCA AgAgTTGGTA AAATTTTTGA CATCAGTAAA

4851 CTTGTAGTTT TAAAAAACTT TTAAAACCCC TTTTCAATTT GTTTCAAAAT

4901 TTCAAAATGT TCAAATCTTA ATGCTTAAAA TTGAAATTCA ATGAAAATAG

4951 ATCACAATTC ACGTCATTTG GCATTTGCTT CTTTTCCCTG CCTGAGCCAA

5001 CATTTTCTAA TCGAATCAAC CATTAATCTG TTTTATTTCG TCAATTTCTT

5051 TTTTCCTTCT TTCCTTATTA GCATATATCG ATCTTACTTC AATTGTTTAA

5101 ATAAATCTCA ATAAACAAGT TCAAAATAAC ATGTGAATTC CAATTTCTAC

5151 GAACGAATTC TTGAATTAAT TAAAACAATT TCAGATGTCA TCGGTTAAAG

5201 TAGCTGTACG TGTTCGCCCA TTCAACCAAC GGGAAATCTC GAACACTTCA

5251 AAATGTGTCC TTCAAGTAAA TGGAAATACG ACGAGTAAGT GCCCCAAGGG

5301 ATTTAGAAAT GGCGGGTGAC ATTTGAGACT GAGTTAACCC CTTTCTACGA

5351 AAtATTTTCC GAGAAAAAAg GATAgGCTGC CGTCCCAAAA TGATGCGAAA

5401 AACGTTGgtG ACGTCCAAGA GTCTTTGGgA ATAATTGAAA AgAtgAgAgA

5451 GAAGCAATGC ATAAAAAAGA ACAGACGGGG TCTTGAAATG AATAAGAGGA

5501 ATTAAAAGAT ATTCTGGAGG TATGGGATTC AATATTGGGA TCTACCATTG

5551 AgCAATACCA CCACATGTTT CGTTCCGTGT TTCTAACACA GAGTTTTTGA

5601 AgCATAGATA GGTGTTCATA TTTGCGTTGg AgAgTAGTGA TCTCCAAGAT

5651 ATATTTTTAT ACACAGTCTT TAAATGTTTT ATTTTTAAAT TTTAATTTTA

5701 AAGAATGGTT GTAAAATATG CTCAATTCAA AGCTCCCTGA TAACAATACA

5751 TGATACTGTA GTAGCATACT GTATGAACTG TTTCAAATTA AAATATTCCA

5801 ATTTTCAGCA ATAAATGGTC ATTCAATTAA CAAGGAGAAC TTCAGTTTCA

5851 ATtTTGATCA TTCATATTGg TCGTTtgCGA GGAATGACCC ACATTTTATC

5901 ACCCAAAAAC AAGTATATGA AGAGCTCGGA GTTGAAATGT TGGAACACGC

5951 ATTTGAAGGG TTCGTTTGAT GTACATAGAT TAATAGTTTA AATAATTGAC

6001 TTCTAGGTAT AATGTCTGCA TTTTTGCATA CGGTCAAACA GGATCAGGAA

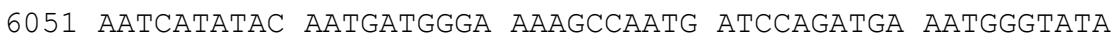

6101 ATTCCACGTT TGTGCAATGA TTTATTTGCA CGAATTGATA ATAACAATGA

6151 TAAAGATGTT CAATATTCTG TAGAgGTAAT TATTTTTGAT ACATTAATTC

6201 ATgGAAACTA ACAATATTAT tACAgGtATC GTAtATgGAA ATTtATtGTG

6251 AACGAGTAAA AGATCTTCTG AATCCTAACT CTGGAGGTAA CCTAAGGGTT

6301 CGTGAACATC CTTTACTTGG ACCTTACGTC GATGACCTTA CCAAAATGGC 6351 AGTTTGTTCT TACCACGACA TTTGCAATCT GATGGACGAA GGAAATAAAG 6401 CGAGGTGAgA GAGTGAGAgA CGgAgAACAT TAGAGAAAAT CAACGGAAGT 6451 ATCATGGCAA ACTAAACCAA GTTTAATGAC CGGGGGTATA CACAGGTAAC 6501 CCGCGACAAG CGAGCGATGA CTTGCATGCG AGAAGTCTGG GGTTCGATTC 6551 CCCATACCTC CAGTAAAGTT TTGCTCTTTT TCAGAACTGT TGCTGCAACA 6601 AATATGAATT CGACATCATC AAGATCCCAT GCGGTATTCA CAATAGTACT 6651 CACTCAAAAA AGACATTGTG CTGATTCTAA TTTGGATACT GAGAAGCATT 6701 CAAAAATTTC TTTGGTTGAT TTGGCAGGAT CCGAAAGAGC CAATTCTACA 6751 GGAGCGGAAG GTCAACGACT AAAAGAAGGA GCAAATATCA ACAAGAGCTT 6801 GACAACGTTG GGTCTTGTAA TCAGTAAACT TGCAGAAGAA GTTAGTTTAA

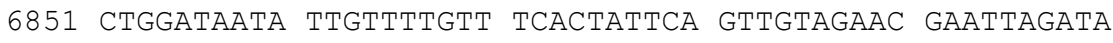


6901 AAgAtgCAgt AAgtTAgAgt GtgAggAtTA tTAATTtTAC AtCACGTtTt 6951 TTCAACCGTA ACACAGTTTT ATGAGTGTAT TGTGACTTGA ATGTGATCTA 7001 TTTAACACGT TGTGCAAACA AAATCACTAA GTTGGTTTAT TCTAAATTTC

7051 AATTAGTTTT GAAATAAATT GTGATAAACA GCTTTGCACA TGAGCTTACC 7101 GAGTGGAAAC CAACTTAATT TACAATCCAC AGATTCATAA AATTTAACAA 7151 AgTTTAATTT ATTTATAgTC AACAAAgAAg AAAAAgTCCA ACAAAGGTGT 7201 GATTCCTTAT CGTGATTCTG TGCTGACGTG GCTTCTGAGA GAAAATCTGG 7251 GAGGAAATTC GAAAACTGCG ATGCTCGCGG CATTATCTCC AGCTGATATT 7301 AACTTTGATG AAACACTGA TACTTTGAGg TAATCAAAAC ATGGAAATTA 7351 TCAATTAAAA ATACCAAAAT CTTTTAGATA TGCCGATAGA GCGAAACAAA 7401 TTGTTTGTCA AGCAGTTGTT AATGAGGATC CAAATGCAAA ACTTATTCGT 7451 GAACTCAATG AAGAAGTTAT CAAACTTCGT CACATTTTGA AAGATAAGGG 7501 AATTGATGTC ACAGACGTAC AGGAGACACC CGGAAAACAC AAAAAAGGAC 7551 CGAAATTGCC AGCTCATGTA CATGAGCAAC TTGAGAAGCT TCAAGAATCT 7601 GAGAAATTGA TGGCTGAAAT TGGAAAGACT TGGGAGCAGA AATTAATTCA 7651 TACAGAAGAA ATTAGAAAAC AACGAGAGGA AGAACTTCGT GATATGGGTC 7701 TTGCGTGTGC AGAAGATGGA ACAACATTAG GCGTATTTAG TCCAAAGAAG 7751 TTACCCCATT TAGTTAACTT GAATGAAGAT CCATTGATGT CAGAGTGTCT 7801 CATATATTAT CTTAAAGAAg GAGTAACTAG GTATGACTTT GTATAAAAAT 7851 ATATCTTGGA GGTATGGGGA ATTGAACCCC AGCCCTCTCC CATGCTAAGG 7901 GAGCGCTCTA CCACTGAGCT ATACCCCCGC ATGATGAAGC TTGTTTTAAT 7951 TCTTTTGAAG TTGCCGACGA CTGTGAAACG TTTTCCCTTC GCTAAGAAGC 8001 TAGAAACCTG ATTGTTTGCC TTCCGCGCGG AATGATTTTC TTATTATACA 8051 CACTCTCTAC TCTCCAACCC AAATATGAAC GCGGCGCCTA TCTATGCTTC 8101 AAAAAGTCTT CGTTAGAAAG ACTGAATAAA ACATGCGGGG GTATAGCTCA 8151 GTGGTAGAGC GCTCCCTTAG TATGGGAGAg GGCTGGGGTT CAATTCCCCA 8201 TACCTCCAGA ATAATTTTTG CAAGTGGAAC ATTATTTTGA AATAAGTTAT 8251 GTTTCAGCGT CGGCCGCCCT GTAGCTGAAC ATCGTCCAGA CATTCTCTTA 8301 TCGGGAGAAG CGATTCTCGA ATTACATTGT GAATTTATAA ACGAAGATGG 8351 AAATGTGACA TTGACAATGA AACCGAATGC ATCTTGCTAT ATAAATGGAA 8401 AACAAGTGAC AACTCCTACT GTATTACACA CAGGATCTAG AGTTATTCTC 8451 GGTGAACATC ACGTTTTCCG ATATAATGAT CCACAGGAAG CAAGGCAAAG 8501 CAGGCATAAC TTGGCAGCAA TAGCTGGTTA GTTCAGAAAA ATCATTTTAA 8551 TCAAAGGTTT AAAATAATTG TAGAACAACC AATTGATTGG AAATATGCTC 8601 AACAAGAACT TCTAGACAAA CAAGGAATTG ATCTAAAAGC AGATATGGAG 8651 AAGAAAATGT TAGAAATGGA ATCTCAATAC AGAAGAGAAA AAGTAGAATT 8701 GGAACAAAAA ATGTATCATC AGACAAGGGT AAACCTACAT TCATTTGTAA 8751 ATATTTAAAA AAATAAATTT CTTAGGAATA TGAATCAATG ATTGAAAATC 8801 TTCAAAAACA AGTGGATTTG GCACAATCTT ATATATCTGG TGGTGGTTCT 8851 ATTTGGGAAG GAGAACGAAT GTTGACGTCA TCTTTACTTG AATTCCCGGA 8901 AgAGTTAAAA TGGACATCAG ATCAAAAACG AGTTGTACTA AAAGCTGCAA 8951 TCAAATGGA ATATCATCAA TTCACATCTG TTCGAGATGA TCTTTGgGgA 9001 AATGCTATTT TTGTGAAGGA AgCGAATGCG ATTTCAGTTG AACTCAAGAA 9051 AAAAGTTCAA TTCCAATTTG CTCTGCTAAC CGATACAATG TACAGCCCAC 9101 TGCCACCTGA TCTATTGCCA CCAGGAGAAG ACTTAACCCT TCGTCCATAT 9151 CCAAAAACTG TTGTCGCTAT TCAAGTTCAA GATCTAAAAA ATGGAGCAAC 9201 TCATTACTGG AGCATTGAAA AATTAAAACA ACGATTGGAA GCAATGCGTG 9251 ATATGTATGA AACTGATGCA GAAATGTCGC CAgCTGATGg AgAtCCAATG 9301 ATGGATGCTT TAATGGGAAC TGATCCATTT TATGATCGAT TCCCATGGTT 9351 TCGAATGGTT GGAAGAGCAT TCGTTTATTT GAATAACTTA TTGCATAATG 9401 TTCCTCTCAT TCATAAAGTA GCAGTTGTCA ATGAAAAAgG AGAAGTGAAG 9451 GgtTATCTGA AAgTTGCCAT CGAACCGgTT CAAAAAgATg AAgTGATCAA 9501 TCAAAAGAAA GGTGTTCGAC AAACAGCAAA GCTTCATTTC AGAAAAGAGG 9551 ATTTCCTGAA ATCACATAAA AATGGAGAAA CTTCTGATTC TGATGCTCTC 9601 GCATTTCCTG AACACATGCA AGAGGAAGTA GAATTCTGTT TCCGTGTAGT 9651 CGTTCTACAA GCCATTGACG TGGCAGACAC ATATTCTGAT GTTTTCTGTC 9701 AATTCAATTT CTTGCACCGC CATGATGAAG CCTTCTCAAC GGAGCCAATG 9751 AAAAACTCAA AATCTCCATT AACATTCGAA CACACCCAAA ATCTTCACAT 9801 CAAAATGAGC AAGACATTCC TTCATTATCT CCATCATTTC CCAATCATTT 9851 TCGAGGTATT TGGACATTTC CAACCAAAAA GTGAACAGTT CAATTTCGAA 9901 AGACAAAATA GTGCTCTTGG CAGACGACTG AGCACAAAAT TGACATTCCA 9951 ACAGCCGAGT TTGGTTATTT CAACTCCTGT CAAGAGCAAA AAAGCAAATG 10001 CACCAATTCA GAACAATAAC GCATCTGTTA AATCAAAACA TGATCTTCTT 10051 GTGTGGTTCG AAATTTGTGA ATTGGCAAAT AATGGAGAAT ATGTTCCAAC 10101 AATAGTTGAT CATGCTCAAG GACTTCCAAC TCATGGAATA TTTTTACTTC 10151 ATCAAGGAAT TCAACGTAGA ATTAAAATCA CAATATGCCA TGAAAAAGGA 10201 GAATTGAAAT GGAAAGATTG TCAAGAACTA GTTGTTGGAC GTATTCGAGC 10251 TGGACCTGAA TGGGCTGGCG GAGATGATGT TGATGTTTTA TCACTTGGTC 10301 TATTCCCTGG AACATTTATG GAATTCTCAA TGGATGACAG AACATTCTTC 10351 CAATTTGAAG CTGCCTGGGA TTCTTCTCTT CATAACTCTC CACTTTTGAA 10401 TCGAGTTTCG AATTACGGTG ATCAAATTTA CATGACACTT TCCGCTTATA 
10451 TGGAACTCGA TGGATGTGCT CAACCAGCTG TTGTTACTAA AgAtCTTTGT 10501 CTATTGATCT ATGCAAGAGA CTCGAAGATC TCAGCTGCCA GTCGTTTCTG 10551 TCGATCATTG GTCGGAGGAA TTTCAAAATC TCCAGAAATG AACCGTGTCC 10601 CAGGAGTGTA TCAACTGTGC CTGAAGGATG GATCCGACTC AGGTAGTCCA 10651 GGTGCAATTC GTCGACAACG TCGTGTACTT GACACCTCAT CAGCCTATGT 10701 TCGAGGAGAA GAGAATCTCG GACAATGGA ACCACGTGGA GATTCTCTTA 10751 TCTTTGAGCA TCAGTGGGAA TTGGAAAAAC TGACACGATT ACAACAAGTC 10801 GAAAGAGTTC GATTATTCCT GAGACTTCGT GATCGACTGA AAGGAAAGAA 10851 GAATAAGGGA GAAGCGAGAA CACCAGTTAG TCCATGTGAT CCAGTTTGTG 10901 CAATTCCGGA AAgTATCAAG TTAGACGAgA AAgAtAAAgG AATTGTTGgT 10951 AAAGTGCTTG GATTAATCAG AAGAAAGATT CCAATGAACA AGGATCCACC 11001 AACTGGAAAC AAAGCTCAAG AATTGAGTGA TGAAAGTGGA TCAAATAGTA 11051 TAACATCTCC AGTGTCTGAT AGATCCTTGA TCAAATCCTC TCGATCTTCG 11101 GATCTCCTGT GCCGACAGAA ATCAAAATCC GATCAGAACC TTGCATCAAA 11151 TGATGATATA GTTGATAATT TAgGAgGAAT GAAACGAAGT TTGAGTGGAT 11201 CACGAATTCT TCAACTCAAT ATTTTAGTGC CAGAAGTACT TGAAGAAAGA 11251 GTTGGAGTTG TTGTTTCAAA GAAAGGATAT ATGAATTTCT TGGAAGAAAA 11301 GACTCAAGGA TGGACTCGTC GATGGGTTAT TGTTCGTCGT CCATATATTC 11351 TTTTATTCCG TGATGATCGA GATTTGGTTA TTCGAGGAAT CATTAATCTG 11401 GCAAATGCTA GAATTGAACA TTCGGAAGAT CAACAAGCAA TGGTGAAAGT 11451 ACCAAATACT TTCAGTGTTT GCACTAATCA ACGTGGATTC CTTATGCAAA 11501 TGATGCCGGG CGATGAgATg TATGATTGGC TGTACGCAAT CAATCCATTG 11551 ATGGCTGGAC AAATGAAATT ACATGGAAAT CAAAATGGAA CAACATTGAA 11601 ATCTCCAACA TCATCATCTT CAATTGCTGC TTCACTGCAG GTCGACTCTA 11651 GAGGATCCCC GGGATTGGCC AAAgGACCCA AAgGTATGTT TCGAATGATA 11701 CTAACATAAC ATAGAACATT TTCAGGAGGA CCCTTGAGGG TACCGGTAGA 11751 AAAAATGAGT AAAGGAGAAG AACTTTTCAC TGGAGTTGTC CCAATTCTTG 11801 TTGAATTAGA TGGTGATGTT AATGGGCACA AATTTTCTGT CAGTGGAGA 11851 GGTGAAGGTG ATGCAACATA CGGAAAACTT ACCCTTAAAT TTATTTGCAC 11901 TACTGGAAAA CTACCTGTTC CATGgGTAAg TTTAAACATA TATATACTAA 11951 CTAACCCTGA TTATTTAAAT TTTCAGCCAA CACTTGTCAC TACTTTCTGT 12001 TATGGTGTTC AATGCTTCTC GAgAtACCCA GATCATATGA AACGGCATGA 12051 CTTTTTCAAG AGTGCCATGC CCGAAGGTTA TGTACAGGAA AGAACTATAT 12101 TTTTCAAAGA TGACGGGAAC TACAAGACAC GTAAGTTTAA ACAGTTCGGT 12151 ACTAACTAAC CATACATATT TAAATTTTCA GGTGCTGAAG TCAAGTTTGA 12201 AGGTGATACC CTTGTTAATA GAATCGAGTT AAAAGGTATT GATTTTAAAG 12251 AAgATGGAAA CATTCTTGGA CACAAATTGG AATACAACTA TAACTCACAC 12301 AATGTATACA TCATGGCAGA CAAACAAAAg AATGGAATCA AAGTTGTAAG 12351 TTTAAACATG ATTTTACTAA CTAACTAATC TGATTTAAAT TTTCAGAACT 12401 TCAAAATTAG ACACAACATT GAAGATGGAA GCGTTCAACT AGCAGACCAT 12451 TATCAACAAA ATACTCCAAT TGGCGATGGC CCTGTCCTTT TACCAGACAA 12501 CCATTACCTG TCCACACAAT CTGCCCTTTC GAAAGATCCC AACGAAAAGA 12551 GAGACCACAT GGTCCTTCTT GAGTTTGTAA CAGCTGCTGG GATTACACAT 12601 GGCATGGATG AACTATACAA ATAGCATTCG TAGAATTCCA ACTGAGCGCC 12651 GGTCGCTACC ATTACCAACT TGTCTGGTGT CAAAAATAAT AGgGGCCGCT 12701 GTCATCAGA TAAGTTTAAA CTGAGTTCTA CTAACTAACG AGTAATATTT 12751 AAATTTTCAG CATCTCGCGC CCGTGCCTCT GACTTCTAAG TCCAATTACT 12801 CTTCAACATC CCTACATGCT CTTTCTCCCT GTGCTCCCAC CCCCTATTTT 12851 TGTTATTATC AAAAAAACTT CTTCTTAATT TCTTTGTTTT TTAGCTTCTT 12901 TTAAGTCACC TCTAACAATG AAATTGTGTA GATTCAAAAA TAGAATTAAT 12951 TCGTAATAAA AAGTCGAAAA AAATTGTGCT CCCTCCCCCC ATTAATAATA 13001 ATTCTATCCC AAAATCTACA CAATGTTCTG TGTACACTTC TTATGTTTTT 13051 TTTACTTCTG ATAAATTTTT TTTGAAACAT CATAGAAAAA ACCGCACACA 13101 AAATACCTTA TCATATGTTA CGTTTCAGTT TATGACCGCA ATTTTTATTT 13151 CTTCGCACGT CTGGGCCTCT CATGACGTCA AATCATGCTC ATCGTGAAAA 13201 AGTTTTGGAG TATTTTTGGA ATTTTTCAAT CAAGTGAAAg TTTATGAAAT 13251 TAATTTTCCT GCTTTTGCTT TTTGGGGGTT TCCCCTATTG TTTGTCAAGA 13301 GTTTCGAGGA CGGCGTTTTT CTTGCTAAAA TCACAAGTAT TGATGAGCAC 13351 GATGCAAGAA AgATCGgAAg AAgGTTTGgG TTTGAgGCTC AgtgGAAgGT 13401 GAGTAGAAGT TGATAATTTG AAAGTGGAGT AGTGTCTATG GGGTTTTTGC 13451 CTTAAATGAC AGAATACATT CCCAATATAC CAAACATAAC TGTTTCCTAC 13501 TAGTCGGCCG TACGGGCCCT TTCGTCTCGC GCGTTTCGGT GATGACGGTG 13551 AAAACCTCTG ACACATGCAG CTCCCGGAGA CGGTCACAGC TTGTCTGTAA 13601 GCGGATGCCG GGAGCAGACA AGCCCGTCAG GGCGCGTCAG CGGGTGTTGG 13651 CGGGTGTCGG GGCTGGCTTA ACTATGCGGC ATCAGAGCAG ATTGTACTGA 13701 GAGTGCACCA TATGCGGTGT GAAATACCGC ACAGATGCGT AAGGAGAAAA 13751 TACCGCATCA GGCGGCCTTA AGGGCCTCGT GATACGCCTA TTTTTATAGG 13801 TTAATGTCAT GATAATAATG GTTTCTTAGA CGTCAGGTGG CACTTTTCGg 13851 GGAAATGTGC GCGGAACCCC TATTTGTTTA TTTTTCTAAA TACATTCAAA 13901 TATGTATCCG CTCATGAGAC AATAACCCTG ATAAATGCTT CAATAATATT 13951 GAAAAAGGAA GAGTATGAGT ATTCAACATT TCCGTGTCGC CCTTATTCCC 
14001 TTtTTTGCGg CATTTTGCCT TCCTGTTtTt GCTCACCCAG AAACGCTGGT 14051 GAAAGTAAAA GATGCTGAAG ATCAGTTGGG TGCACGAGTG GGTTACATCG 14101 AACTGGATCT CAACAGCGGT AAGATCCTTG AGAGTTTTCG CCCCGAAGAA 14151 CGTTTTCCAA TGATGAGCAC TTTTAAAGTT CTGCTATGTG GCGCGGTATT 14201 ATCCCGTATT GACGCCGGGC AAGAGCAACT CGGTCGCCGC ATACACTATT 14251 CTCAGAATGA CTTGGTTGA TACTCACCAG TCACAGAAAA GCATCTTACG 14301 GATGGCATGA CAGTAAGAGA ATTATGCAGT GCTGCCATAA CCATGAGTGA 14351 TAACACTGCG GCCAACTTAC TTCTGACAAC GATCGGAGGA CCGAAGGAGC 14401 TAACCGCTTT TTTGCACAAC ATGGGGGATC ATGTAACTCG CCTTGATCGT 14451 TGGGAACCGG AGCTGAATGA AGCCATACCA AACGACGAGC GTGACACCAC 14501 GAtgCCTGTA GCAATGGCAA CAACGTTGCG CAAACTATTA ACTGGCGAAC 14551 TACTTACTCT AGCTTCCCGG CAACAATTAA TAGACTGGAT GGAGGCGGAT 14601 AAAGTTGCAG GACCACTTCT GCGCTCGGCC CTTCCGGCTG GCTGGTTTAT 14651 TGCTGATAAA TCTGGAGCCG GTGAGCGTGG GTCTCGCGGT ATCATTGCAG 14701 CACTGGGGCC AGATGGTAAG CCCTCCCGTA TCGTAGTTAT CTACACGACG 14751 GGGAGTCAGG CAACTATGGA TGAACGAAAT AGACAGATCG CTGAgATAGG 14801 TGCCTCACTG ATTAAGCATT GGTAACTGTC AGACCAAGTT TACTCATATA 14851 TACTTTAGAT TGATTTAAAA CTTCATTTTT AATTTAAAAG GATCTAGGTG 14901 AAGATCCTTT TTGATAATCT CATGACCAAA ATCCCTTAAC GTGAGTTTTC 14951 GTTCCACTGA GCGTCAGACC CCGTAGAAAA GATCAAAGGA TCTTCTTGAG 15001 ATCCTTTTTT TCTGCGCGTA ATCTGCTGCT TGCAAACAAA AAAACCACCG 15051 CTACCAGCGG TGGTTTGTTT GCCGGATCAA GAGCTACCAA CTCTTTTTCC 15101 GAAGGTAACT GGCTTCAGCA GAGCGCAGAT ACCAAATACT GTCCTTCTAG 15151 TGTAGCCGTA GTTAGGCCAC CACTTCAAGA ACTCTGTAGC ACCGCCTACA 15201 TACCTCGCTC TGCTAATCCT GTTACCAGTG GCTGCTGCCA GTGGCGATAA 15251 GTCGTGTCTT ACCGGGTTGG ACTCAAGACG ATAGTTACCG GATAAGGCGC 15301 AGCGGTCGGG CTGAACGGGG GGTTCGTGCA CACAGCCCAG CTTGGAGCGA 15351 ACGACCTACA CCGAACTGAG ATACCTACAG CGTGAGCATT GAGAAAGCGC 15401 CACGCTTCCC GAAGGGAGAA AGGCGGACAg GTATCCGGTA AGCGGCAGGG 15451 TCGGAACAgG AgAgCGCACG AgGgAgCTTC CAgGgGgAAA CGCCTGgtAT 15501 CTTTATAGTC CTGTCGGGTT TCGCCACCTC TGACTTGAGC GTCGATTTTT 15551 GTGATGCTCG TCAGGGGGGC GGAGCCTATG GAAAAACGCC AGCAACGCGG 15601 CCTTTTTACG GTTCCTGGCC TTTTGCTGGC CTTTTGCTCA CATGTTCTTT 15651 CCTGCGTTAT CCCCTGATTC TGTGGATAAC CGTATTACCG CCTTTGAGTG 15701 AGCTGATACC GCTCGCCGCA GCCGAACGAC CGAGCGCAGC GAGTCAGTGA 15751 GCGAGGAAGC GGAAGAGCGC CCAATACGCA AACCGCCTCT CCCCGCGCGT 15801 TGGCCGATTC ATTAATGCAG CTGGCACGAC AGGTTTCCCG ACTGGAAAGC 15851 GGGCAGTGA CGCAACGCAA TTAATGTGAG TTAGCTCACT CATTAGGCAC 15901 CCCAGGCTTT ACACTTTATG CTTCCGGCTC GTATGTTGTG TGGAATTGTG 15951 AGCGGATAAC AATTTCACAC AGGAAACAGC TATGACCATG ATTACGCCAA 16001 GCTGTAAGTT TAAACATGAT CTTACTAACT AACTATTCTC ATTTAAATTT 16051 TCAGAGCTTA AAAATGGCTG AAATCACTCA CAACGATGGA TACGCTAACA 16101 ACTTGGAAAT GAAAT 


\subsection{List of primers}

\subsection{1 pPD 95.77}

\begin{tabular}{|c|c|c|}
\hline construct & & sequence \\
\hline \multirow[t]{2}{*}{ unc-104::unc-104 I362G/L365G::GFP } & fw & GAGGATCCAAATGCAAAACTTGGTCGTGAAGGCAATGAAGAAG \\
\hline & rev & CTTCTTCATTGCCTTCACGACCAAGTTTTGCATTTGGATCCTC \\
\hline \multirow[t]{2}{*}{ unc-104::unc-104 I362G::GFP } & fw & GGATCCAAATCGAAAACGTGGTCGTGAACTCAATGAAG \\
\hline & rev & CTTCATTGAGTTCACGACAAGTTTTGCATTTGGATCC \\
\hline \multirow[t]{2}{*}{ unc-104::unc-104 I362E/L365K::GFP } & fw & GGATCCAAATGCAAAACTTGAGCGTGAAAACAATGAAGAAGTTATCAAACTTCGTCAC \\
\hline & rev & GTGACGAAGTTTGATAATCTCTTCATTGTTTTCACGCTCAAGTTTTGCATTTGGATCC \\
\hline \multirow[t]{2}{*}{ unc-104::unc-104 L376G::GFP } & fw & ATCAAACTTCGTCACATTGGGAAAGATAAGGGAATTGAT \\
\hline & rev & ATCAATTCCCTTATCTTTCCCAATGTGACGAAGTTTGAT \\
\hline \multirow[t]{2}{*}{ unc-104::unc-104 L365G::GFP } & fw & GCAAAACTTATTCGTGAAGGCAATGAAGAAGTTATCAAACTTCG \\
\hline & rev & CGAAGTTTGATAACTTCTTCATTGCCTTACCGAATAAGTTTTGC \\
\hline \multirow[t]{2}{*}{ unc-104::unc-104 K379L::GFP } & fw & CTTCGTCACATTTTGAAAGATTTGGGAATTGATGTCACAGACGTACAGG \\
\hline & rev & CCTGTACGTCTGTGACATCAATTCCCAAATCTTTCAAAATGTGACGAAG \\
\hline \multirow[t]{2}{*}{ unc-104::unc-104 E355V::GFP } & fw & GTCAAGCAGTTGTTAATGTGGATCCAAATGCAAAAC \\
\hline & rev & GTTTTGCATTTGGATCCACATTAACAACTGCTTGAC \\
\hline \multirow[t]{2}{*}{ unc-104::unc-104 N358L/P357K::GFP } & fw & GCAGTTGTTAATGAGGATAAACTTGCAAAACTTATTCGTGAACTC \\
\hline & rev & GAGTTCACGAATAAGTTTTGCAAGTTTATCCTCATTAACAACTGC \\
\hline \multirow[t]{2}{*}{ unc-104::unc-104 K379L/G380R::GFP } & fw & CTTCGTCACATTTTGAAAGATTTGCGTATTGATGTCACAGACGTACAGG \\
\hline & rev & CCTGTACGTCTGTGACATCAATACGCAAATCTTTCAAAATGTGACGAAG \\
\hline \multirow{2}{*}{$\begin{array}{l}\text { unc-104::unc-104 } \\
\text { N358L/P357K/K379L::GFP }\end{array}$} & fw & CGTCACATTTTGAAAGATTTGGGAATTGATGTCACAGACG \\
\hline & rev & CGTCTGTGACATCAATTCCCAAATCTTTCAAAATGTGACG \\
\hline \multirow{2}{*}{$\begin{array}{l}\text { unc-104::unc-104 } \\
\text { E355V/P357K/N358L::GFP }\end{array}$} & fw & GTCAAGCAGTTGTTAATGTGGATAAACTTGCAAAACTTATTCGTGAACTCAATG \\
\hline & rev & CATTGAGTTCACGAATAAGTTTTGCAAGTTTATCCACATTAACAACTGCTTGAC \\
\hline \multirow{4}{*}{$\begin{array}{l}\text { unc-104::unc-104 } \\
\text { E355V/P357K/N358L/K379L/G380R::GFP }\end{array}$} & fw & CTTCGTCACATTTTGAAAGATTTGCGTATTGATGTCACAGACGTACAGG \\
\hline & rev & CCTGTACGTCTGTGACATCAATACGCAAATCTTTCAAAATGTGACGAAG \\
\hline & fw & GTCAAGCAGTTGTTAATGTGGATAAACTTGCAAAACTTATTCGTGAACTCAATG \\
\hline & rev & CATTGAGTTCACGAATAAGTTTTGCAAGTTTATCCACATTAACAACTGCTTGAC \\
\hline Sequencing primer & fw & TGTTCTTACCCACGACATTTGC \\
\hline
\end{tabular}

\subsubsection{PET 17b}

\begin{tabular}{|c|c|c|}
\hline construct & & sequence \\
\hline \multirow[t]{2}{*}{ 1-446unc-104 I362G/L365G::GFP } & $\mathrm{fw}$ & GAGGATCCAAATGCAAAACTTGGTCGTGAAGGCAATGAAGAAG \\
\hline & rev & CTTCTTCATTGCCTTCACGACCAAGTTTTGCATTTGGATCCTC \\
\hline \multirow[t]{2}{*}{ 1-446unc-104 I362G::GFP } & $\mathrm{fw}$ & GGATCCAAATCGAAAACGTGGTCGTGAACTCAATGAAG \\
\hline & rev & CTTCATTGAGTTCACGACAAGTTTTGCATTTGGATCC \\
\hline \multirow[t]{2}{*}{ 1-446unc-104 I362E/L365K::GFP } & fw & GGATCCAAATGCAAAACTTGAGCGTGAAAACAATGAAGAAGTTATCAAACTTCGTCAC \\
\hline & rev & GTGACGAAGTTTGATAATCTCTTCATTGTTTTCACGCTCAAGTTTTGCATTTGGATCC \\
\hline \multirow[t]{2}{*}{ 1-446unc-104 L376G::GFP } & fw & ATCAAACTTCGTCACATTGGGAAAGATAAGGGAATTGAT \\
\hline & rev & ATCAATTCCCTTATCTTTCCCAATGTGACGAAGTTTGAT \\
\hline \multirow[t]{2}{*}{ 1-446unc-104 L365G::GFP } & fw & GCAAAACTTATTCGTGAAGGCAATGAAGAAGTTATCAAACTTCG \\
\hline & rev & CGAAGTTTGATAACTTCTTCATTGCCTTACCGAATAAGTTTTGC \\
\hline \multirow[t]{2}{*}{ 1-446unc-104 K379L::GFP } & fw & CTTCGTCACATTTTGAAAGATTTGGGAATTGATGTCACAGACGTACAGG \\
\hline & rev & CCTGTACGTCTGTGACATCAATTCCCAAATCTTTCAAAATGTGACGAAG \\
\hline \multirow[t]{2}{*}{ 1-446unc-104 E355V::GFP } & $\mathrm{fw}$ & GTCAAGCAGTTGTTAATGTGGATCCAAATGCAAAAC \\
\hline & rev & GTTTTGCATTTGGATCCACATTAACAACTGCTTGAC \\
\hline \multirow[t]{2}{*}{ 1-446unc-104 N358L/P357K::GFP } & fw & GCAGTTGTTAATGAGGATAAACTTGCAAAACTTATTCGTGAACTC \\
\hline & rev & GAGTTCACGAATAAGTTTTGCAAGTTTATCCTCATTAACAACTGC \\
\hline \multirow[t]{2}{*}{ 1-446unc-104 K379L/G380R::GFP } & fw & CTTCGTCACATTTTGAAAGATTTGCGTATTGATGTCACAGACGTACAGG \\
\hline & rev & CCTGTACGTCTGTGACATCAATACGCAAATCTTTCAAAATGTGACGAAG \\
\hline \multirow[t]{2}{*}{ 1-446unc-104 N358L/P357K/K379L::GFP } & $\mathrm{fw}$ & CGTCACATTTTGAAAGATTTGGGAATTGATGTCACAGACG \\
\hline & rev & CGTCTGTGACATCAATTCCCAAATCTTTCAAAATGTGACG \\
\hline \multirow[t]{2}{*}{ 1-446unc-104 E355V/P357K/N358L::GFP } & fw & GTCAAGCAGTTGTTAATGTGGATAAACTTGCAAAACTTATTCGTGAACTCAATG \\
\hline & rev & CATTGAGTTCACGAATAAGTTTTGCAAGTTTATCCACATTAACAACTGCTTGAC \\
\hline \multirow{4}{*}{$\begin{array}{l}\text { 1-446unc-104 } \\
\text { E355V/P357K/N358L/K379L/G380R::GFP }\end{array}$} & fw & CTTCGTCACATTTTGAAAGATTTGCGTATTGATGTCACAGACGTACAGG \\
\hline & rev & CCTGTACGTCTGTGACATCAATACGCAAATCTTTCAAAATGTGACGAAG \\
\hline & fw & GTCAAGCAGTTGTTAATGTGGATAAACTTGCAAAACTTATTCGTGAACTCAATG \\
\hline & rev & CATTGAGTTCACGAATAAGTTTTGCAAGTTTATCCACATTAACAACTGCTTGAC \\
\hline \multirow[t]{2}{*}{ 1-446unc-104 N145K } & fw & CGGTCAAACAGGATCAGGAAAAGCATATACAATGATGGGAAAAGCC \\
\hline & rev & GGCTTTTCCCATCATTGTATATGCTTTTCCTGATCCTGTTTGACCG \\
\hline \multirow[t]{2}{*}{ Sequencing primers } & fw & CGTTGGGTCTTGTAATCAG \\
\hline & fw & GAGAAATTGATGGCTGAAATTGG \\
\hline
\end{tabular}




\subsection{Table of kinesins and their binding partners for intracellular transport}

\begin{tabular}{|c|c|c|c|}
\hline \multicolumn{4}{|l|}{ Axonal transport } \\
\hline Motor & Cargo type & Adaptor/scaffold protein & Cargo molecules \\
\hline KIF1A od KIF1B $\beta$ & $\begin{array}{l}\text { Synaptic vesicle } \\
\text { precursors } \\
\text { Vesicles } \\
\end{array}$ & DENN/MADD & $\begin{array}{l}\text { Synaptophysin, synaptotagmin } \\
\text { and RAB3a } \\
\text { Ptdlns }(4,5) \mathrm{P}_{2}\end{array}$ \\
\hline KIF1Ba & Mitochondria & KBP & Mitochondrial proteins \\
\hline \multirow[t]{8}{*}{ KIF5 } & Mitochondria & \begin{tabular}{|l|} 
Milton, Miro, \\
Syntabulin, RanBP2 \\
\end{tabular} & Mitochondrial proteins \\
\hline & Lysosomes & unknown & LAMP2 \\
\hline & $\begin{array}{l}\text { Synaptic vesicle } \\
\text { precursors }\end{array}$ & UNC-76 & UNC-51 and synaptotagmin \\
\hline & $\begin{array}{l}\text { Synaptic membrane } \\
\text { precursors }\end{array}$ & Syntabulin & Syntaxin1 \\
\hline & $\begin{array}{l}\text { Synaptic membrane } \\
\text { precursors }\end{array}$ & none & SNAP25 \\
\hline & Vesicles & JIPS & APOER2 \\
\hline & Vesicles & JIP1 & Phosporylated APP \\
\hline & Tubulin dimer & CRMP & Tubulin \\
\hline KIF5A & Neurofilament proteins & unknown & NF-H, NF-M and NF-L \\
\hline \multirow[t]{3}{*}{ KIF3A, KIF3B } & Vesicles & Fodrin & unknown \\
\hline & Vesicles & unknown & APC and PAR3 \\
\hline & Vesicles & unknown & $\mathrm{N}$-cadherin and $\beta$-catenin \\
\hline KIF13B (GAKIN) & Vesicles & Centaurin- $\alpha 1$ & Ptdlns $(3,4,5) \mathrm{P}_{3}$ \\
\hline
\end{tabular}

\begin{tabular}{|c|c|c|c|}
\hline \multicolumn{4}{|c|}{ Dendritic transport } \\
\hline Motor & Cargo type & Adaptor/scaffold protein & Cargo molecules \\
\hline \multirow[t]{3}{*}{ OSM-3 } & Vesicles & LIN10, LIN2, LIN7 & NR2B \\
\hline & Vesicles & unknown & GluR5 \\
\hline & \begin{tabular}{|l|} 
Vesicles \\
\end{tabular} & unknown & Kv4.2 \\
\hline \multirow[t]{3}{*}{ KIF5 } & Vesicles & GRIP1 & GluR2 \\
\hline & mRNP complex & unknown & hnRNP-U, Pur- $\alpha$, Pur- $\beta$ \\
\hline & mRNP complex & FMRP & unknown \\
\hline KIFC2 & Multivesicular organelles & unknown & unknown \\
\hline \multicolumn{4}{|c|}{ Conventional transport } \\
\hline Motor & Cargo type & Adaptor/scaffold protein & Cargo molecules \\
\hline \multirow[t]{4}{*}{ KIF5 } & ER & unknown & Kinectin \\
\hline & Golgi-ER vesicles & unknown & $\mathrm{p} 115$ \\
\hline & $\begin{array}{l}\text { TGN-Plasma membrane } \\
\text { vesicles }\end{array}$ & unknown & RAB4 \\
\hline & Endosomes & unknown & p75 \\
\hline \multirow[t]{3}{*}{ KIF3A or KIF3B } & Golgi-ER vesicles & unknown & KDEL receptor \\
\hline & Early and late endosomes & unknown & RAB4 and RAB7 \\
\hline & Recycling endosomes & RIP11 & RAB11 \\
\hline KIF20A & Golgi aparatus & unknown & RAB6 \\
\hline \multirow[t]{2}{*}{ KIFC3 } & Golgi aparatus & unknown & unknown \\
\hline & $\begin{array}{l}\text { TGN-Plasma membrane } \\
\text { vesicles }\end{array}$ & unknown & Annexin XIIIb \\
\hline KIF13A & $\begin{array}{l}\text { TGN-Plasma membrane } \\
\text { vesicles }\end{array}$ & AP-1 complex & M6PR \\
\hline KIFC2 & Early endosomes & unknown & RAB4 \\
\hline KIF16B & Early endosomes & unknown & $\begin{array}{l}\text { Ptdlns }(3,4,5) \mathrm{P}_{3}, \mathrm{EGF} \text {, } \\
\text { EGF receptor, RAB5 }\end{array}$ \\
\hline KIF4 & Vesicles & unknown & $\mathrm{L} 1$ \\
\hline
\end{tabular}




\subsection{Matlab parameters and functions for fluorescence anisotropy}

\section{Eachaniso}

function distrib=eachaniso(tifname, cal, ENH, x)

warning off all

Img=imread (tifname);

warning on all

- calibration data

o contains ROI, im G (g factors), im M (mask),

ㄴ $\operatorname{cotat}$ (angle bētween channels), $\bar{t}$ shift (distance between channels), thr

Img=anisotropy_enhance (Img, ENH); 을 wer / other filters

o display(['Optimal threshold from raw image: ', num2str(opthr(Img))]);

thr $=\operatorname{mean} 2(\mathrm{Img})$;

oimagesc (Img);

display(['Threshold used for subtracted image: ', num2str(thr)]);

[A DC AB DCB]=anisotropy_compute(Img, cal.G_cal, cal.im_M, cal.ROI, Cal.t_shift, cal.t rotat,

thr);

$\therefore=$ uncorrected anisotropy

$D C=$ uncorrected total value

$\therefore A B=$ anisotropy after background correction

$D C B=$ total value after background correction

ㄴ $w r=$ wrong anisotropy after background correction as used before

$\therefore 13 / 03 / 07$

$\div$ Mask $=D C B>(12 *$ mean2 $(D C B))$;

Mask $=(\mathrm{DCB}>(2 \star \operatorname{mean} 2(\mathrm{DCB}(\mathrm{DCB}>1))))$;

․ Mask $=D C B>500 ; \therefore D C B>\max (D C B(:)) / 30$;

imshow (Mask);

odisplay (['Wrong ' num2str(mode(nonzeros(wr. *Mask),2)) '; mean ' num2str(mean(nonzeros (wr.

${ }^{*}$ Mask))) '; stdev ' num2str(std(nonzeros(wr. *Mask)))]);

odisplay 'Wrong: ', mean (nonzeros (wr. *Mask))

$\mathrm{w}=\mathrm{size}(\mathrm{DCB}, 2)$;

$\mathrm{h}=\mathrm{size}(\mathrm{DCB}, 1)$

f=figure ('units', 'Pixels','Position', [50 $50 \mathrm{w}+440 \mathrm{~h} / 2+50]$ );

ojetud=flipud (colormap (jet (255)));

jetnew=colormap (jet (255));

jetnew $(1,:)=\left[\begin{array}{lll}0 & 0 & 0\end{array}\right]$;

ojetud $(206: 255,:)=[] ;$ ocale end in orange

ojetud $(e n d,:)=\left[\begin{array}{lll}0 & 0 & 0\end{array}\right]$;

colormap (jetnew);

ax1 = subplot $(1,4,1)$;

ax2 = subplot $(1,4,2)$;

ax4 = subplot $(1,4,4)$;

axes $(\operatorname{ax} 1)$;

set(ax1,' 'units', 'pixels', 'position', [0 $30 \mathrm{w} / 2 \mathrm{~h} / 2$ ]);

imagesc ( $\mathrm{DCB} .{ }^{\star}$ Mask)

axis image

axis off

응 imagesc (DCB. *Mask)

ax2=subplot $(1,4,2)$;

axes $(\operatorname{ax} 2)$;

set (ax2,' 'units', 'pixels', 'position', [(w/2+20) $30 \mathrm{w} / 2+100 \mathrm{~h} / 2])$;

imagesc $\left(\mathrm{AB} .{ }^{\star}\right.$ Mask)

axis image

axis off

set (ax2, 'CLim', [ [ 0.4$])$;

caxis manual

colorbar('units', 'pixels', 'position', [(w+60) $3020 \mathrm{~h} / 2]$ );

axes $(\operatorname{ax} 4)$;

set (ax4,' 'units', 'pixels', 'position', [(w+210) (h/4-50) 150 150]);

axis square

display(['BCK mean ' num2str(mean(nonzeros (AB.*Mask))) '; mode ' num2str(mode (nonzeros (AB.

${ }^{*}$ Mask), 2)) '; stdev ' num2str (std(nonzeros (AB.*Mask)))])

odisplay (['NOB mode ' num2str(mode(nonzeros (A. *Mask),2)) '; mean ' num2str(mean (nonzeros(A.

*Mask))) '; stdev ' num2str(std(nonzeros (A. *Mask)))]) ;

D: \Messungen Volker \eachaniso.m $2 / 2$

oset (gca, 'xlim', [min(nonzeros (AB. *Mask)) max(nonzeros(AB.*Mask))])

set (gca, 'xlim', [ [ 0.4$]$ )

[pathstr, name, ext, versn] = fileparts (tifname);

saveas (f, [name 'result.fig']);

saveas (f, [name '-result.tif'],'tiffn'); ouncompressed TIFF

\% $x$ should be implemented before

$\therefore x=0: 0.001: 0.5$

distrib=hist (nonzeros $\left(\mathrm{AB} .{ }^{\star}\right.$ Mask $\left.), \mathrm{x}\right)$. / length (nonzeros $\left(\mathrm{AB} .{ }^{\star}\right.$ Mask $\left.)\right)$;

tmp $=\left[\mathrm{x}^{\prime}\right.$ hist (nonzeros $\left(\mathrm{AB} .{ }^{*}\right.$ Mask $\left.\left.), \mathrm{x}\right){ }^{\prime}\right]$;

save([name ' values.dat'], 'tmp', '-ASCII');

odisplay (['Mean' num2str(sum(n(1:401). $\left.\left.\left.{ }^{\star} x(1: 401)\right) / \operatorname{sum}(n(1: 401))\right]\right)$; 


\section{$\underline{\text { Mode }}$}

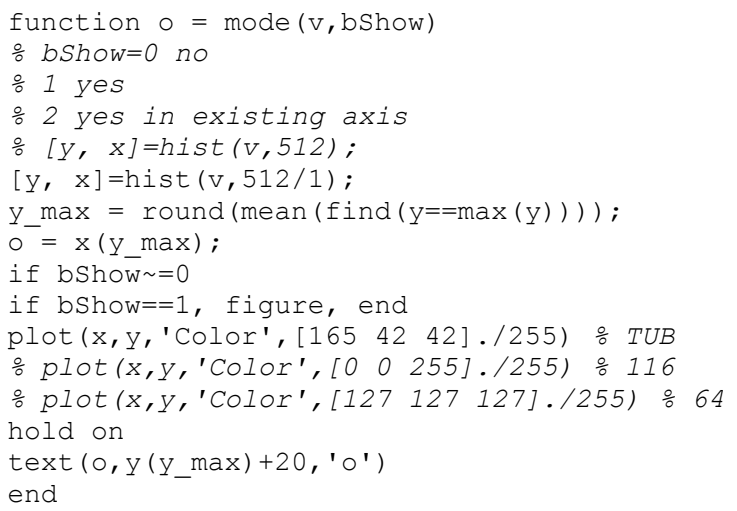

\section{OPTHR}

$\because$ FUNCTION T=OPTHR (I)

AUTHOR: Felix Toran Marti.

DATE: $8 / 5 / 00$

OMATLAB VERSION: $5 . x$

oTo contact author use:

○E-MAIL: ftoran@aimme.es

$\circ \mathrm{PHONE}:+34 \quad 654082088$

oThis function finds the optimal threshold corresponding to the intensity image I.

oThe function is intended to be a enhancement of the images toolbox for thresholding

opurposes. It can be a quick way to automate the process of manually selecting a

othreshold after seeing the histogram of an image. Also, the function helps user

ofinding a reasonable good threshold value when the selection is not evident. $\circ$

\%The following example code reads a TIFF image, finds its optimal threshold, and converts oit to a binary image:

$\div[\mathrm{x}, \operatorname{map}]=$ tiffread $(\mathrm{c}: \backslash$ myimage.tiff' $) ;$

$\circ \mathrm{I}=$ ind2gray $(\mathrm{x}, \mathrm{map})$;

othreshold=opthr(I);

$\circ \mathrm{B}=\mathrm{im} 2 \mathrm{bw}(\mathrm{I}$, threshold)

imshow $(B)$

If the histogram of image I is purely bimodal, the threshold will take a value

\%in the middle of the valley between the 2 modes (the logical election).

oIn other difficult cases, when the modes are overlapped, the threshold will minimize

othe error of interpreting background pixels as objects pixels, and vice versa.

oThis algorithm is a small version of a more complex statistical method,

offering good results and normally using a reduced number of iterations.

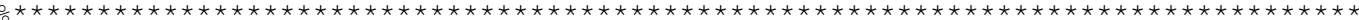

olmage size

[rows, cols] =size (I)

oInitial consideration: each corner of the image has background pixels.

oThis provides an initial threshold (T), calculated as the mean of the gray levels contained

oin the corners. The width and height of each corner is a tenth of the image's width

\%and height, respectively.

col_chloor (cols/10);

rows $\mathrm{C}=\mathrm{floor}$ (rows $/ 10)$

cornēers=[I (1:rows_c, 1:col_c); I (1:rows_c, (end-col_c+1) :end); . .

I ( (end-rows $c+1): \bar{e}$ d, $1: \mathrm{co} \bar{l} c) ; I(($ end-rows $c+1): e n \bar{d},(e n d-c o l c+1): e n d)]$;

$\mathrm{T}=$ mean (mean (corners)) ;

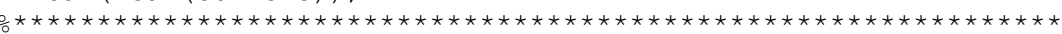

O ITERATIVE PROCESS

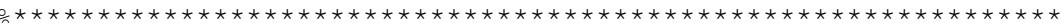

while numel (find ( $>$ T) ) $>0$

-1. The mean of gray levels corresponding to objects in the image is calculated.

oThe actual threshold $(T)$ is used to determine the boundary between objects and

○background.

mean obj=sum (sum $\left.\left((I>T) .{ }^{*} I\right)\right) / \operatorname{numel}($ find $(I>T))$

D: \Messungen \Volker $\backslash$ opthr.m $2 / 2$

-2. The same is done for the background pixels.

mean_backgnd=sum (sum $\left.\left((\mathrm{I}<=\mathrm{T}) \cdot{ }^{\star} \mathrm{I}\right)\right) / \operatorname{numel}(\mathrm{find}(\mathrm{I}<=\mathrm{T}))$;

⒊ $\overline{\mathrm{A}}$ new threshold is calculated as the mean of the last results:

new $T=$ (mean obj+mean backgnd) $/ 2$;

\%4. A new iteration starts only if the threshold has changed. 
if $(\mathrm{abs}($ new $T-T) / T<0.005)$

break;

else

$\mathrm{T}=$ new $\mathrm{T}$;

end

end

-At this stage, the optimal threshold value is contained in $T$.

\section{Refine location}

function $0=$ refine_location (c1, c2, im, r)

zoom $=5$;

$\mathrm{C} 1=$ zoom $* \mathrm{C} 1$;

$\mathrm{c} 2=$ zoom $* \mathrm{c} 2$;

im $=$ imresize (im, zoom);

$r=$ zoom $\star r$;

err $=[]$

h=figure; $\frac{\circ}{0}$ debug

for $i=1: 100$

$\mathrm{x} 11=\operatorname{round}(\mathrm{c} 1(1)-r)$;

$\mathrm{x} 12=\operatorname{round}(\mathrm{c} 1(1)+r)$;

$\mathrm{y} 11=\operatorname{round}(\mathrm{c} 1(2)-r)$;

$\mathrm{y} 12=\operatorname{round}(\mathrm{c} 1(2)+\mathrm{r})$

$\mathrm{x} 21=\operatorname{round}(\mathrm{c} 2(1)-r)$.

$\mathrm{x} 22=\operatorname{round}(\mathrm{c} 2(1)+r)$;

y21 $=\operatorname{round}(\mathrm{c} 2(2)-r)$

y22 = round $(\mathrm{c} 2(2)+\mathrm{r})$;

e $x 11=\operatorname{size}(i m, 2) *(x 11 / \operatorname{size}(i m, 2)-1) ;$ e $x 11=e x x 11 *\left(e \_x 11>0\right)$;

e $x 12=\operatorname{size}(i m, 2) *(x 12 / \operatorname{size}(i m, 2)-1) ; e x 12=e x 12 *(e x 12>0) ;$

$e^{-}$y11 $=\operatorname{size}(i m, 1) *(y 11 / \operatorname{size}(i m, 1)-1) ;$ e_y11 = e_y11* (e_y11>0) ;

$\mathrm{e}^{-\mathrm{y} 12}=\operatorname{size}(\mathrm{im}, 1) *(\mathrm{y} 12 / \operatorname{size}(\mathrm{im}, 1)-1) ; \mathrm{e}^{-\mathrm{y} 12}=\mathrm{e}^{-\mathrm{y} 12 *}\left(\mathrm{e}^{-\mathrm{y} 12>0)}\right.$;

e $x 21=\operatorname{size}(i m, 2) *(x 21 / \operatorname{size}(i m, 2)-1) ;$ e $x 21=e x 21 *(e x 21>0)$;

$e^{-} \times 22=\operatorname{size}(i m, 2) *(x 22 / \operatorname{size}(i m, 2)-1) ; e^{-} \times 22=e^{-} \times 22 *\left(e^{-} \times 22>0\right)$;

e y21 = size $(i m, 1) *(y 21 / \operatorname{size}(i m, 1)-1) ;$ e y21 = e y21* (e y21>0);

e_y22 = $\operatorname{size}(i m, 1) *(y 22 / \operatorname{size}(i m, 1)-1) ; e^{-}$y22 $=e^{-}$y22* $\left(e^{-}\right.$y22>0 $)$;

그HIS SECTION MUST BE COMPELTED

e $\mathrm{x}=\max ([\mathrm{e} \mathrm{x} 12, \mathrm{e} \times 22])$;

$e^{-} y=\max \left(\left[e^{-} y 12, e^{-} y 22\right]\right)$;

ctr $1=\operatorname{im}(y \overline{1} 1:(y 12-\bar{e} y), x 11:(x 12-e x))$;

ctr 2 = im (y21: (y22-e_y), x21: (x22-e_x));

$\mathrm{b}=\operatorname{zeros}\left(\mathrm{size}\left(\mathrm{ctr}{ }_{-}\right)\right)^{-}$;

if $i==1$;

$\operatorname{err}(1)=\operatorname{mean} 2\left((\operatorname{ctr} 1-\operatorname{ctr} 2) \cdot{ }^{\wedge} 2\right)$

display(['Refining posit̄ion... \#' num2str(i) ', error = ' num2str(err(1)) ' ']); end

$\mathrm{C}=\left(\operatorname{abs}\left(\right.\right.$ normxcorr2 $\left.\left.\left(\operatorname{ctr}_{-} 1, \mathrm{ctr} 2\right)\right)\right)$;

[yy $\mathrm{xx}]=\mathrm{find}(\mathrm{c}==\max (\mathrm{c}(:)))$;

$y=y y-\operatorname{size}(\operatorname{ctr} 1,1)$;

$\mathrm{xx}=\mathrm{xx}-\operatorname{size}\left(\operatorname{ctr}^{-} 1,2\right)$;

odisplay $\left(\left[\begin{array}{lll}x x & y \bar{y}\end{array}\right]\right)$;

$\mathrm{c} 2(1)=\mathrm{c} 2(1)+\mathrm{xx}$;

$c 2(2)=c 2(2)+y y ;$

$\mathrm{b}=(i * b+c t r 2) / 2$

$\mathrm{a}=\operatorname{cat}\left(3, \operatorname{cat}\left(\overline{3}, \mathrm{~b}, \mathrm{ctr}{ }_{1}\right), \mathrm{ctr} 2\right) ; \quad$ debug

imshow $(\mathrm{a} . /(\max (\mathrm{a}(\mathrm{:}))))$;

drawnow

othis section should be completed

$\mathrm{x} 1=\max ([\operatorname{round}(\mathrm{c} 2(1)-r) 1])$;

$\mathrm{x} 2=\min ([\operatorname{round}(\mathrm{c} 2(1)+\mathrm{r})-\mathrm{e} \mathrm{x} \operatorname{size}(\mathrm{im}, 2)])$

$\mathrm{y} 1=\max ([\operatorname{round}(\mathrm{c} 2(2)-r) 1 \overline{1}]) ;$

y2 $=\min ([\operatorname{round}(\mathrm{c} 2(2)+r)-e \mathrm{y} \operatorname{size}(i m, 1)])$;

$\operatorname{err}(i+1)=\operatorname{mean} 2\left(\operatorname{abs}\left(\operatorname{ctr} \_1(1: \overline{:} 1+y 2-y 1,1: 1+x 2-x 1)-i m(y 1: y 2, x 1: x 2)\right)\right)$

o conditional exit

if err(i+1)>=err(i), break; end

display(['Refining position... \#' num2str(i+1) ', error = ' num2str(err(i+1)) ' ' ]); end $\frac{\circ}{0}$ refine reference positions

close (h) odebug

$\mathrm{o}=\mathrm{c} 2 / \mathrm{zoom}$; 


\section{Split transform}

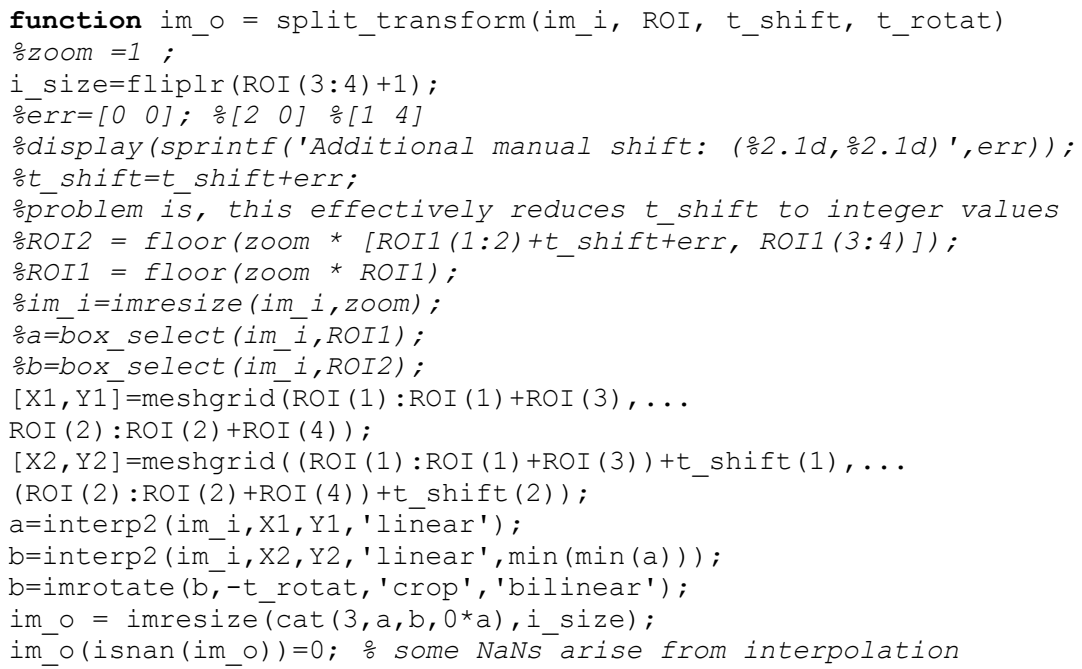

\section{Anisotropy splithreshold}

function [s1, s2, box, v_thr]=anisotropy_splithreshold_opthr(im_i) \% sl should be the parallel (more intense) channel regardless of its o position v_thr=opthr (im_i); 


\section{Imfluo threshold bwarea}

afunction bw2 = imfluo_treshold_bwarea(bw, arthr) conn = conndef (ndims (bw), 'maximal');

$\mathrm{L}=\mathrm{bwlabeln}(\mathrm{bw}, \mathrm{conn})$;

$\mathrm{s}=$ regionprops ( $\mathrm{L}$, 'area');

area $=$ [s.Area $]$

idx $=$ find (area $>=\operatorname{arthr}(1)$ \& area $<=\operatorname{arthr}(2))$;

bw2 = ismember ( L, idx);

bw2 = bwlabel $(\mathrm{bw} 2>0)$;

return

a =regionprops ( $1 \mathrm{~b})$;

l=length ( [a.Area $])$;

ind $=(1: 1)$;

ind=ind ([a.Area]<area (1) | [a.Area]>area (2)) i

for $i=1$ : length (ind)

lb $(1 \mathrm{~b}==$ ind $(i))=0$;

end

$1 \mathrm{~b} 2=\mathrm{bwlabel}(1 \mathrm{~b}>0)$;

return

\section{Allanisos}

clear

$\mathrm{x}=-.2: 0.001: 0.6$;

format compact;

ENH=struct ( 'bWiener', $\{0\}$, 'WienerKernel', $\left\{\left[\begin{array}{ll}3 & 3\end{array}\right]\right\}, \ldots$

'bFilter', \{1\},'FilterKernel', \{fspecial('gaussian', [5 5], 2) \},...

'bBlockFilter', $\{0\}$, 'BlockFunction', $\{$ ' ' $\}$, 'BlockKernel', $\{$ '' $\}, \ldots$

'TresholdType', \{'none' $\},$ 'Treshold', $\{$ ' ' $\}, \ldots$

'BackgroundType', \{'none'\}):

load cal

cal.G_cal=im_G;

cal.im $M=i m \bar{M}$;

cal.t_shift=t_shift:

cal.t rotat $=t^{-}$rotat

$\mathrm{CaI} \cdot \mathrm{ROI}=\mathrm{ROI}$

olddir=cd;

cd(uigetdir('.','Please open base directory'));

allfiles=dir ('*.tif'); 으의olders with separate images

hists=zeros (length (allfiles), length (x));

for $i=1$ :length (allfiles)

hists (i,:) = eachaniso(allfiles(i).name, cal, ENH, x) ;

close;

end

save('hists', 'hists');

resume=fopen ('stats.txt','a');

fprintf(resume, 'File name $\backslash t \backslash t \backslash$ tMean anisotropy $\backslash n$ ')

for $i=1$ :length (allfiles)

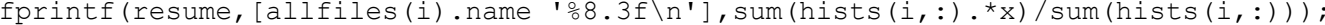
end

fclose (resume);

cd (olddir);

\section{Anisotropy centroid}

function [out ImgSeg]=anisotropy centroid (im i)

im $i=$ filter2 (fspecial ('gaussian', 7, 3), im i);

oim_i $=i m \_i-i m o p e n\left(i m \_i, \operatorname{strel}\left(\operatorname{disk}^{\prime}, \operatorname{fix}\left(\overline{s i z e}\left(i m \_i, 1\right) / 10\right)\right)\right)$;

$\operatorname{trh}^{-}=\operatorname{opth} \bar{r}(i m i) ;$

ImgMask = imfīll( (im_i trh), 'holes')

음 Imalley $=\max \left(\max \left(i m \_i(:)\right)\right)-i m i$;

\% ImgWat $=$ watershed (ImgValley. ${ }^{\star}$ ImgMask);

응 Imeg = ImgWat. * ImgMask;

tmp $=\operatorname{sum}(\operatorname{sum}($ ImgMask.*im i) ). / sum (sum(ImgMask));

ImgSeg $=i m i>(t m p+2 *$ sqrt $($ tmp-trh $))$;

ImgSeg = imfiluo_treshold_bwarea (ImgSeg, [10 1000]);

$\mathrm{s}=$ regionprops (ImgSeg, 'Centroid', 'MajorAxisLength');

out = reshape ([s.Centroid], [2 length(s) ]) ';

oMaxDiameter $=\max ([\mathrm{s}$. MajorAxisLength $])$;

\% figure, imagesc(ImgSeg) \% debug 


\section{Anisotropy compute}

function $\left[a n\right.$ dc an_bk dc_bk] = anisotropy_compute(im_dc, im_G, im_M, ROI, $t \_s h i f t$, t_rotat, thr)

$a=$ split transform (im dc, ROI, t shift, t rotat);

$\frac{\circ}{b} \mathrm{~b}=\mathrm{im} \mathrm{M}^{-} .^{*}\left(\mathrm{a}(:,:, 1)>0.01 .{ }^{*} \mathrm{a}(:,:, 2)>\overline{0} .01\right) .^{\star}(\mathrm{a}(:,:, 2) . /(\mathrm{a}(:,:, 1)+1 \mathrm{E}-23))$;

$\mathrm{dc}=\left(\mathrm{a}(:,:, 1)+2 * i m \mathrm{G} \cdot{ }^{*} \mathrm{a}(:,:, 2)\right) ; \%$ uncorrected value

$\mathrm{mk}=\left(\mathrm{dc}>\operatorname{mean}\left(\right.\right.$ nonzeros $\left(\mathrm{dc} \cdot{ }^{*}\right.$ im_M) $\left.)\right)$

$\mathrm{bk}=\sim$ imdilate $(\mathrm{mk}$, strel ('disk', 10)) .* im_M; \% make sure only background included

$\mathrm{b} 1=\operatorname{mean}\left(\right.$ nonzeros $\left.\left(\mathrm{a}(:,:, 1) .{ }^{\star} \mathrm{bk}\right)\right) ;$ o background parallel channel

$\mathrm{b} 2=\operatorname{mean}\left(\right.$ nonzeros $\left.\left(\mathrm{a}(:,:, 2) .{ }^{*} \mathrm{bk}\right)\right) ; \%$ background perp. channel

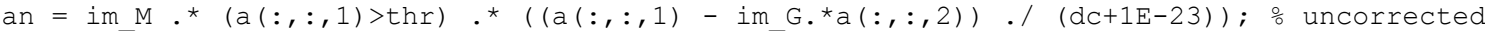

o arbitrary threshold

$\mathrm{dc} \_\mathrm{bk}=\left(\mathrm{a}(:,:, 1)-\mathrm{b} 1+2 * i \mathrm{~m}_{-} \mathrm{G}^{*}(\mathrm{a}(:,:, 2)-\mathrm{b} 2)\right)$

$\mathrm{an} \mathrm{bk}=\mathrm{im} \mathrm{M.*}(\mathrm{a}(:,:, 1)>\operatorname{th} r) . *\left(\left(\mathrm{a}(:,:, 1)-\mathrm{b} 1-i m \mathrm{G}^{*}(\mathrm{a}(:,:, 2)-\mathrm{b} 2)\right) . /(\mathrm{dc} b \mathrm{~b}+1 \mathrm{E}-23)\right)$;

o $\bar{a}$ rbitrary threshold

\% figure, imagesc (an bk)

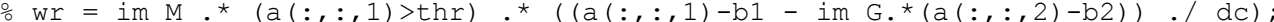

o figure, $\overline{i m a g e s c}\left((\mathrm{a}(:,:, 1)>\operatorname{thr})+\left(\mathrm{a}(:,:, 2)>\left(\operatorname{thr} .{ }^{\circ} 0.85\right)\right)\right)$, axis image

ofigure, imagesc $\left(\mathrm{dc} .{ }^{\star} \mathrm{bk}\right)$, axis image

\section{Anisotropy enhance}

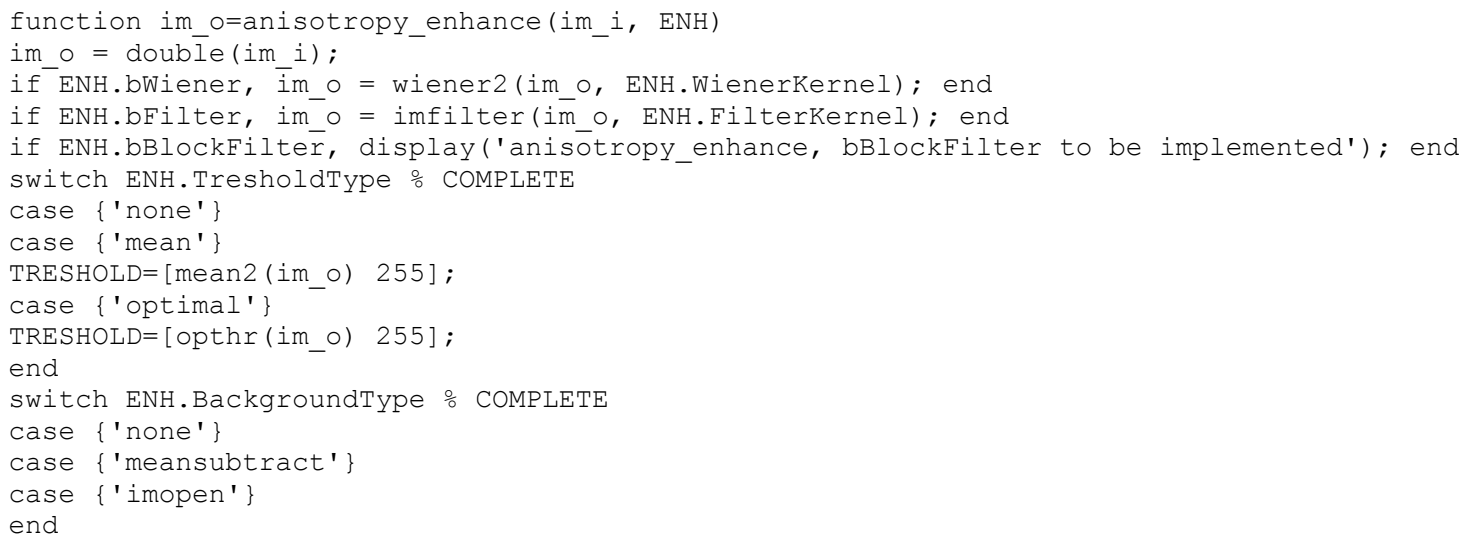




\subsection{Curriculum vitae}

\section{Personal information}

name

home address

work address

e-mail

date of birth

place of birth

marital status

nationality

Education

1996

$1997-2003$

$2002-2003$

Sept. 2003

$2004-2006$

$2007-2012$
Volker Christoph Henschel

Mittelstrasse $3 g$

37077Göttingen

Georg -August Universität Göttingen

Drittes Physikalisches Institut, Biophysik

Friedrich-Hund-Platz 1

37077 Göttingen

vhensch@gwdg.de

31.12.1976

Munich

unmaried

german university-entrance diploma at the Gymnasium Starnberg

Studies in biochemistry, University of Bielefeld, Germany

Diploma thesis

„Analysis of the molybdenum storage-protein azotobacter vinelandii regarding the mechanism of assembly and release of molybdenum"

graduated as Dipl. Biochem.

Working in the department of experimental neurology at the Universitäy of Ulm; main research: axonal regeneration.

Member of the PhD programm Gauss at the Georg-August University Göttingen.

Topic: "Conformational states of monomeric kinesin

UNC-104 during synaptic vesicle transport" under supervision of Dr. Dieter Klopfenstein Center for Molecular Physiology of the Brain (CMPB) from march 2010: Drittes Physikalisches Institut, department of Biophysics. 


\section{Teaching and supervision}

Supervision of Olaf Meissner, diploma student at the Georg -August Universität Göttingen, 2010-2012.

Instructor of the practical course "Biochemistry for medical students" 2007-2010.

Instructor in the seminar "Cytoskelleton" for students of the degree program "molecular medicine" at the GGNB of the Georg -August Universität Göttingen, 2008/2009.

Supervision of Nora Hipp, bachelor student at the University of Ulm, 2005/2006.

Instructor of the practical course "Bioanorganische Chemie" for students of biochemistry 2002-2003.

\section{Publications:}

Fenske D., Gnida M., Schneider K., Meyer-Klaucke W., Schemberg J., Henschel V., Meyer A.K., Knochel A., Müller A.,

A new type of metalloprotein: The Mo storage protein from azotobacter vinelandii contains a polynuclear molybdenum-oxide cluster., Chembiochem., Feb;6(2):405-13, 2005.

\section{Publications in preparation:}

Volker C. Henschel, Alessandro Esposito, Matthias Gralle, Eugenia Butekevich, Christoph F. Schmidt, Fred Wouters and Dieter R. Klopfenstein, Detection of conformational states of proteins in C.elegans in vivo by confocal fluorescence anisotropy.

journal not yet determined

Volker C. Henschel, Eugenia Butekevich, Christoph F. Schmidt and Dieter R. Klopfenstein, Kinesin-3 (UNC-104) can act as a dimeric motor during axonal transport C. elegans neurons in vivo.

journal not yet determined

\section{Poster presentations at scientific conferences:}

Volker C. Henschel, Alessandro Esposito, Eugenia Butekevich, Christoph F. Schmidt, Fred Wouters and Dieter R. Klopfenstein, Detection of conformational states of proteins in C.elegans in vivo by confocal fluorescence anisotropy,

International Bunsen Discussion Meeting - FRET in Life Sciences, Göttingen, Germany, March 2011.

Volker C. Henschel, Alessandro Esposito, Eugenia Butekevich, Christoph F. Schmidt, Fred Wouters and Dieter R. Klopfenstein, Kinesin-3 (UNC-104) can act as a dimeric motor during axonal transport $\mathrm{C}$. elegans neurons in vivo.

DPG Frühjahrstagung 2011, Dresden, Germany, March 2011.

Volker C. Henschel, Alessandro Esposito, Eugenia Butekevich, Christoph F. Schmidt, Fred Wouters and Dieter R. Klopfenstein, Detection of conformational states of proteins in C.elegans in vivo by confocal fluorescence anisotropy,

DPG Frühjahrstagung 2011, Dresden, Germany, March 2011. 
Volker C. Henschel, Alessandro Esposito, Eugenia Butekevich, Christoph F. Schmidt, Fred S. Wouters and Dieter R. Klopfenstein, Confocal fluorescence anisotropy for the detection of conformational states of proteins in $\mathrm{C}$. elegans in vivo.

$50^{\text {th }}$ annual meeting of the American Society for Cell Biology (ASCB), Philadelphia, PA, USA, December 2010.

Volker Henschel, Matthias Gralle, Fred S. Wouters and Dieter R. Klopfenstein, Mutations in Kinesin-3's putative dimerization region effect motor velocities and muscle contraction in $C$. elegans neurons in vivo.

Horizons in Molecular Biology 2009, Göttingen, Germany, September 2009.

Volker Henschel, Matthias Gralle, Fred S. Wouters and Dieter R. Klopfenstein, Mutations in Kinesin-3 (UNC-104) neck region effect motor velocities and muscle contraction in $\mathrm{C}$. elegans neurons in vivo.,

Gordon Research Conference, Motile \& Contractile Systems, Mechanical Basis Of Cellular Function, Colby-Sawyer College, New London, NH, USA, July 2009.

Volker Henschel, Matthias Gralle, K. Wiederhold, Dirk Fasshauer, Fred S. Wouters and Dieter R. Klopfenstein., C. elegans Kinesin-3 dimerization mutants are affected in synaptic vesicle transport.

SFB523 Symposium: Intracellular Transport \& Trafficking, Max-Planck Institute for Biophysical Chemistry, Göttingen, Germany, April 2008.

Volker Henschel, Matthias Gralle, K. Wiederhold, Dirk Fasshauer, Fred S. Wouters and Dieter R. Klopfenstein, Mutations in Kinesin-3 neck linker domain effect motor velocities in vivo.

European C. Elegans Meeting 2008 (EWM2008), Carmona (Seville), Spain, March 2008.

V. Henschel, K. Wiederhold and D. R. Klopfenstein, Kinesin UNC-104 dimerization mutants are impaired in axonal transport.

SFB 523 Retreat, Protein and Membrane Transport between Cellular Compartments, Castle Ringberg/Tegernsee, Germany, Oktober 2007.

\section{Talks at scientific conferences:}

Volker C. Henschel

"Kinesin-3 (UNC-104) can act as a dimeric motor during axonal transport C. elegans neurons in vivo"

DPG Frühjahrstagung 2011, Dresden Germany, March 2011.

Volker C. Henschel

"Conformational states of kinesin UNC-104 in action"

invited talk, DPG summer school, Northeim, Germany, October 2009.

Volker Henschel

Kinesin UNC-104 dimerization mutants are impaired in axonal transport.

SFB 523 Retreat, Protein and Membrane Transport between Cellular Compartments,

Castle Ringberg / Tegernsee, Oktober 2007. 